Paula Herrero-Diz

Anahi Cárcamo

$\checkmark$ anessa R. Breijo

Rosaba Mancinas

(Editoras)

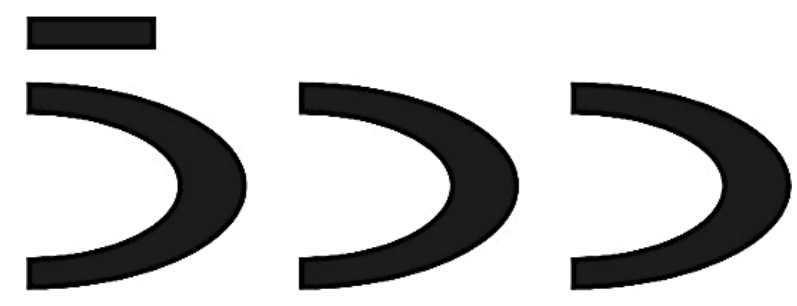

V/CENTERNARIO

$1^{a}$ VUEITIA AI

MUNDO

Cuadernos Artesanos de Comunicación / 161 


\section{Cuadernos Artesanos de Comunicación \\ Coordinador editorial: José Manuel de Pablos - jpablos@ull.edu.es \\ Comité Científico \\ Presidencia: José Luis Piñuel Raigada (UCM) \\ Secretaría: Milena Trenta}

- Francisco Campos Freire (Universidad de Santiago de Compostela)

- José Cisneros (Benemérita Universidad Autónoma de Puebla, BUAP)

- Bernardo Díaz Nosty (Universidad de Málaga, UMA)

- Carlos Elías (Universidad Carlos III de Madrid, UC3M)

- Paulina B. Emanuelli (Universidad Nacional de Córdoba, UNC)

- José Luis González Esteban (Universitas Miguel Hernández de Elche, UMH)

- Marisa Humanes (Universidad Rey Juan Carlos, URJC)

- Juan José Igartua (Universidad de Salamanca, USAL)

- Xosé López (Universidad de Santiago de Compostela)

- Maricela López-Ornelas (Universidad Autónoma de Baja California, UABC)

- Octavio Islas (Universidad de los Hemisferios, Ecuador)

- Javier Marzal (Universidad Jaume I, UJI)

- José Antonio Meyer (Benemérita Universidad Autónoma de Puebla, BUAP)

- Ramón Reig (Universidad de Sevilla, US)

- Miquel Rodrigo Alsina (Universidad Pompeu Fabra, UPF)

- Xosé Soengas (Universidad de Santiago de Compostela)

- José Luis Terrón (Universidad Autónoma de Barcelona, UAB)

- José Miguel Túñez (Universidad de Santiago, USC)

- Victoria Tur (Universidad de Alicante, UA)

- Miguel Vicente (Universidad de Valladolid, UVA)

- Ramón Zallo (Universidad del País Vasco, UPV-EHU)

- Núria Almiron (Universidad Pompeu Fabra, UPF)

\footnotetext{
* Queda expresamente autorizada la reproducción total o parcial de los textos publicados en este libro, en cualquier formato o soporte imaginables, salvo por explícita voluntad en contra del autor o autora o en caso de ediciones con ánimo de lucro. Las publicaciones donde se incluyan textos de esta publicación serán ediciones no comerciales y han de estar igualmente acogidas a Creative Commons. Harán constar esta licencia y el carácter no venal de la publicación.
}

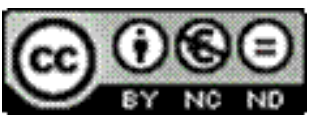

Este libro y cada uno de los capítulos que contiene (en su caso), así como las imágenes incluidas, si no se indica lo contrario, se encuentran bajo una Licencia Creative Commons Atribución-No Comercial-Sin Derivadas 3.0 Unported. Puede ver una copia de esta licencia en http://creativecommons.org/licenses/by-nc-nd/3.0/ Esto significa que Ud. es libre de reproducir y distribuir esta obra, siempre que cite la autoría, que no se use con fines comerciales o lucrativos y que no haga ninguna obra derivada. Si quiere hacer alguna de las cosas que aparecen como no permitidas, contacte con los coordinadores del libro o con el autor del capítulo correspondiente.

* La responsabilidad de cada texto es de su autor o autora. 


\section{Paula Herrero-Diz, Anahí Cárcamo, Vanessa Rodríguez Breijo y Rosalba Mancinas (Editoras)}
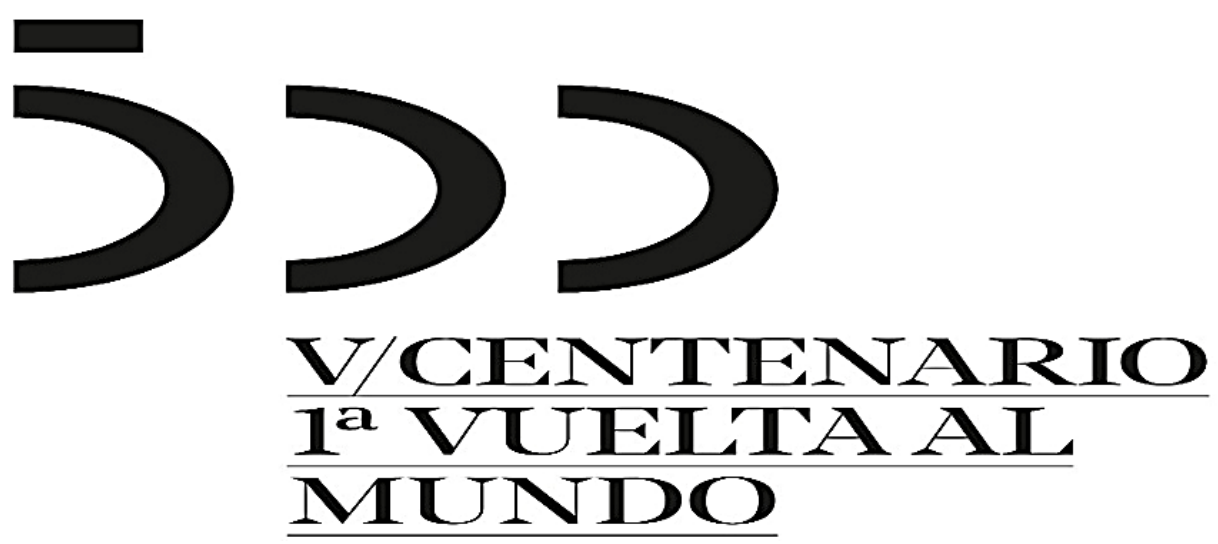

José Manuel Ledesma Alonso, Ángeles Martínez-García, Antonio Gómez-Aguilar, Enrique Martínez Jiménez, Alejandro Tapia Frade, Francisco Montes Tubío, Francisco-Javier García Herrero, María-

Cruz Alvarado, David Varona Aramburu, Marta Pérez-Escolar, Eduardo Gallegos Krause, Jaime Otazo Hermosilla, Irene Rodríguez Cachón, Beatriz Valverde, José Antonio Muñiz-Velázquez, Javier Lozano Delmar.

Forma de citar este libro

P Herrero-Diz/A Cárcamo/V Rodríguez Breijo/R Mancinas (Eds.). (2019). Poner aquí el título del capítulo, en $V$ Centenario $/ 1^{a}$ Vuelta al Mundo. Cuadernos Artesanos de Comunicación, cac161. La Laguna (Tenerife): Latina.

DOI: $10.4185 / \operatorname{cac} 161$

Cuadernos Artesanos de Comunicación / 161 
CAC $161^{\circ}-V$ Centenario / $1^{a} V$ uelta al Mundo

Paula Herrero-Diz, Anahí Cárcamo, Vanessa Rodríguez Breijo y Rosalba Mancinas (Editoras)

| Precio social: 8,95€ | Precio en librería. 11,65€ |

Editores: Samuel Toledano y Milena Trenta

Diseño: F. Drago

Ilustración de portada: Fragmento del cuadro conmemorativo de

Salaverría

Imprime y distribuye: F. Drago. Andocopias S. L.

c/ La Hornera, 41. La Laguna. Tenerife.

Teléfono: 922250554 | fotocopiasdrago@,telefonica.net

Edita: Sociedad Latina de Comunicación Social - edición no venal - La Laguna (Tenerife), 2019 - Creative Commons

http://www.revistalatinacs.org/14SLCS/portada2014.html

Descargar en pdf:

http://www.cuadernosartesanos.org/\#161

ISBN - 13: 978-84-17314-18-7

DL: TF-550-2019

DOI: $10.4185 / \operatorname{cac} 161$ 


\section{Centenario / $1^{a}$ Vuelta al Mundo}

\section{Resumen}

Un grupo de académicos de diferentes procedencias analizan diversos aspectos dela primera circunnavegación, que se inició en Sevilla y Sanlúcar de Barrameda donde el río Guadalquivir se entrega al mar Atlántico, a las órdenes del marino portugués Magallanes y acabó comandada por el marino Vasco Juan Sebastián Elcano tras la muerte violenta del comandante de la expedición en una isla filipina. El libro quiere ser una oportunidad académica para analizar varios aspectos de aquella hazaña, realizada hace ahora 500 años y que dejó patente la redondez el planeta. Y abrió vías para el comercio con Asia, tras dar el nombre al paso por el sur de América hacia el lejano continente asiático, al que entonces solo se podía llegar o regresar tras una larga travesía por tierra.

Palabras clave

Magallanes, Elcano, Vuelta al mundo.

Forma de citar este libro:

Nombre del autor del capítulo, título del capítulo, en "Título del libro" (Coord. P Herrero-Diz, A Cárcamo, V Rodríguez Breijo y R Mancinas (Eds.). (2019). V Centenario / $1^{a}$ V uelta al Mundo. Cuadernos Artesanos de Comunicación, cac161. La Laguna (Tenerife).

DOI: $10.4185 /$ cac161 


\section{INDICE}

\section{Introducción}

Rosalba Mancinas-Chaves, et al

1. Tenerife, primerar etapa

José Manuel Ledesma Alonso

2. Magallanes: construyendo el héroe

Ángeles Martínez-García, et al.

3. Cartografía, geometría y comunicación: cómo narrar la forma del mundo a partir del viaje de Magallanes y Elcano

Enrique Martínez Jiménez, et al

4. Juan Sebastián Elcano en la notafilia española: dos visiones, una epopeya

Francisco-Javier García Herrero, et al...............................................71

5. Teoría del framing y protoperiodismo. Estudio de los atributos asociados a la figura de Magallanes en los diarios de Pigafetta y Francisco Albo

David Varona Aramburu, et al....

6. Los relatos de viajes y la conformación de los medios de comunicación modernos en torno las categorías de información y espectáculo

Eduardo Gallegos Krause, et al.

7. Dos travesías, dos formas de relatar la vuelta al mundo: Antonio Pigafetta, Richard Hakluyt y The World Encompassed

Irene Rodríguez Cachón, et al. 145 
8. La falsa primera vuelta al mundo. E1 caso de la supuesta circunnavegación china de 1421 desde el paradigma de la posverdad

José Antonio Muñiz-Velázquez, et al ..........................................175

Autores

El contenido de este libro ha sido sometido a un proceso de revisión de doble ciego por pares, semejante al sistema de revisión de un artículo científico para un journal. 



\section{章 \\ Introducción}

C OMO es bien sabido, en 2019 empezaron los actos de $\checkmark$ conmemoración por el V Centenario de la primera vuelta al mundo que llevaron a cabo -entre 1519 y 1522- una flota comandada por Magallanes al principio y Juan Sebastián Elcano al final. El objetivo era buscar una ruta comercial para las Islas Molucas, el resultado fue un acto simbólico de gran trascendencia para la era de globalización que hemos alcanzado quinientos años después, en el siglo XXI.

En esta obra se reúnen una serie de trabajos que analizan las implicaciones comunicativas del evento. Nuestro punto de partida es la indisoluble relación entre desarrollo y comunicación. La narración del acontecimiento se convierte en algo tan importante como el acontecimiento en sí y la forma en que esta narración se lleva a cabo, muestra antecedentes de protoperiodismo y propaganda. Con esta serie de trabajos que giran en torno al aspecto comunicativo de la circunnavegación, nos unimos a los actos conmemorativos con un análisis académico desde el ámbito de la comunicación.

En "Magallanes: construyendo el héroe" Ángeles Martínez-García y Antonio Gómez-Aguilar analizan la figura de Magallanes a través de un método cualitativo que toma como punto de partida "el viaje del héroe" como modelo establecido. Con una revisión y fundamentación teórica muy sólida diseñan una herramienta específica basada en El héroe de las mil caras de Joseph Campell (2013) y El viaje del escritor, de Christopher Vogler (2001), considerando algunos elementos de Jung y Bauzá. Aplican esta herramienta a Relación del primer viaje alrededor del mundo, de Antonio Pigafetta y Magallanes: el hombre y su gesta, de Stefan Sweig. Con este análisis demuestran la construcción del héroe desde distintos puntos de vista, concluyen que "ambas obras contienen en su interior elementos 
suficientes para enaltecer a la persona de Magallanes..." sin detenerse en el lado personal.

Los mapas son, definitivamente, un elemento de representación visual muy importante para la época. Casi tan importante como los descubrimientos llega a ser la comunicación de los mismos. En ese sentido, los mapas "no solo registran los espacios descubiertos, sino que los crean a través de su representación". En "Cartografía y exploración: comunicar el trazo del mundo a partir del primer viaje de circunnavegación”, Enrique Martínez-Jiménez, Alejandro Tapia-Frade y Francisco Montes-Tubío analizan ocho mapas surgidos o relacionados con la Casa de la Contratación de Sevilla, el lugar donde se encuentran los mapas más precisos de la época y que fue donde Magallanes acudió para documentarse en cartografía. El objetivo inicial es considerar la diferencia entre los mapas anteriores y posteriores al viaje de la vuelta al mundo. Para ello seleccionan los más representativos y aplican la técnica del análisis de contenido. En el artículo presentan los resultados de un análisis pormenorizado de los mapas seleccionados.

Con relación al otro protagonista de la gesta heroica de la circunnavegación, Francisco Javier García-Herrero y María Cruz Alvarado-López analizan la figura de Juan Sebastián Elcano en la notafilia española, con la hipótesis de partida que se enuncia en el título del trabajo "dos visiones, una epopeya". La originalidad del trabajo reside en el planteamiento que hacen los autores de una investigación numismática a partir de la teoría de la comunicación, cuando normalmente se aborda desde otras ciencias sociales. La figura del navegante vasco aparece en el billete de 500 pesetas de 1931 y en el de 5 pesetas de 1948. El objetivo de la investigación es buscar pormenores en dos momentos históricos muy diferentes que deciden usar como representación de héroe nacional a Juan Sebastián Elcano, símbolo del inicio de una nueva era. Se trata de dos Españas muy diferentes, durante la Segunda República y en la primera parte de la dictadura, unos pocos años después de la guerra civil. Llama la atención que la figura de Elcano aparece en estos dos momentos históricos tan distintos, lo que lo sitúa al nivel de personajes universales como Miguel de Cervantes, Diego Velázquez o Francisco de Goya.

En el cuarto estudio que se presenta en este monográfico, David VaronaAramburu, Marta Pérez-Escolar y Gema Sánchez-Muñoz abordan la figura de Magallanes desde la teoría del framing y el protoperiodismo. En 
este trabajo se destaca la figura del narrador como una parte importante del acontecimiento, que construye a través del relato el imaginario que habrá de divulgarse. Tenemos a Antonio Pigafetta que --como se demostraba en el primero de los estudios-- enaltece y construye la figura del héroe y a Francisco Albo, cuya narración contiene datos precisos y minuciosos con una descripción detallada de tiempo y espacio del viaje, sin dar lugar a la narrativa. A partir de tres encuadres (funciones, héroeantihéroe y el viaje) se hace un análisis detallado de estas dos narraciones, demostrando que "el hecho de utilizar o destacar una serie de atributos en cada encuadre genera que la opinión pública se forje una idea u otra sobre Magallanes: dependiendo del diario que se lea, se creará en su mente una imagen positiva o negativa de Magallanes". Con sus diferencias, más preciso el de Albo, más emotivo el de Pigafetta, estos textos representan la idea de protoperiodismo en aquellos momentos por la finalidad de informar, de registrar los acontecimientos para darlos a conocer.

Los investigadores chilenos Eduardo Gallegos Krause y Jaime Otazo Hermosilla indagan en la comparación entre la narración de la vuelta al mundo de Pigafetta (S. XVI) y los textos de la revista Le Tour du Monde (S. XIX-XX), la comparación se justifica porque ambos textos se desarrollan en un contexto colonial como formas prematuras de medios de comunicación e industria cultural. La información y el espectáculo se confunden en el exotismo con el que se describe la tierra desconocida y sus habitantes desde la perspectiva europea, igualmente la verdad y la mentira aparecen como una frontera difusa entre lo verosímil. Un análisis profundo que complementa las visiones anteriores del viaje de circunnavegación.

Cincuenta y ocho años después de la primera vuelta al mundo liderada por Magallanes-Elcano, Francis Drake circunnavegó el globo entre 1577 y 1580. En el texto "Dos travesías, dos formas de relatar la vuelta al mundo: Antonio Pigafetta, Richard Hakluyt y The World Encompassed", Irene Rodríguez-Cachón y Beatriz Valverde establecen una comparación entre las narraciones que surgen a partir de estos viajes. Del viaje impulsado por la corona española y la narración de Pigafetta destacan la capacidad narrativa en forma de crónica en al que algunas veces el autor asume el protagonismo y narra las vivencias con la carga emotiva del que lo ha presenciado. Del viaje de Francis Drake surgieron dos textos principalmente: "Sir Francis Drake's famous Voyage Round the World" 
incluido en el libro The Principall Navigations, Voiages, and Discoveries of the English Nation de Richard Hakluyt y The World Encompassed basado en las notas de Francis Fletcher, revisado y publicado bajo la supervisión del sobrino homónimo de Francis Drake. En ambas narraciones se percibe gran carga propagandística antiespañola sin perder de vista el objetivo principal que es manifestar la gloria nacional con más entusiasmo por el protagonista como héroe en el segundo de los trabajos estudiados. Los trabajos analizados muestran la relación histórica de rivalidad que han mantenido España y el Reino Unido en materia de exploración del mundo. Finalmente, aunque se sabe que los tres relatos se configuran con intereses distintos, los autores concluyen que existe similitud en los argumentos persuasivos en la forma de informar a la corona y al público en general de los respectivos viajes.

Para cerrar el monográfico, desde el paradigma de la posverdad, José Antonio Muñiz-Velázquez y Javier Lozano-Delmar analizan la falsa primera vuelta al mundo, el caso de la supuesta circunnavegación china de 1421. El autor británico Gavin Menzies publica en 2002 el libro 1421: the Year China Discovered the World, en el que sostiene la hipótesis de que una flota china dio la vuelta al planeta un siglo antes que Magallanes, antes de que Cristóbal Colón llegara a América. Los autores parten de la convicción de que la historia siempre ha sido terreno fértil para las alteraciones, considerando que hay intereses políticos, económicos y comerciales, además de culturales, en la pugna historiográfica. Después de analizar los distintos elementos a considerar para clasificar esta obra en el paradigma de la posverdad, comprueban cómo es clasificada en bibliotecas de gran prestigio como la biblioteca del Congreso de los Estados Unidos, dentro de la categoría vinculada a Historia, no de pseudohistoria. Aunque se trata de una obra que no ha tenido gran trascendencia, es conveniente advertir de los riesgos del revisionismo acientífico que se está dando en las más diversas disciplinas.

Rosalba Mancinas-Chaves Universidad de Sevilla 


\section{î 1 \\ Tenerife, primerar etapa

\author{
José Manuel Ledesma Alonso \\ Cronista Oficial de la Ciudad de Santa Cruz de Tenerife
}

Cómo citar: J M Ledesma Alonso (2019): “Tenerife, primera etapa”, en P Herrero-Diz/A Cárcamo/V Rodríguez Breijo/R Mancinas (Eds.) V Centenario / $1^{a}$ Vuelta al Mundo. Cuadernos Artesanos de Comunicación, cac161, pp 13-18. La Laguna (Tenerife): Latina. DOI: 10.4185/cac161

S ANTA CRUZ de Tenerife y Granadilla de Abona forman parte de la Red Mundial de Ciudades Magallánicas, constituida en Sevilla el 1 de febrero de 2013 con el fin de dar a conocer a los ciudadanos la Primera Vuelta al Mundo, iniciada por Fernando de Magallanes en 1519 y finalizada por Juan Sebastián Elcano en 1522.

La expedición permaneció fondeada en la bahía de Santa Cruz del 26 al 29 de septiembre, pues la Corona le había designado como Puerto Real de la Isla de Tenerife en 1506, lo que implicaba la arribada forzosa de las flotas que iban a la colonización de América con el fin de avituallarse y como contrapartida sustentar la economía de la Isla.

La Villa y Puerto de Santa Cruz había sido fundada por los castellanos 25 años antes (1494), contaba con una población de 200 habitantes, la mayoría pescadores, artesanos y pequeños comerciantes, cuyo alcalde era Marcos Pérez. Poseía un muelle de mampostería y madera, situado al N. de la playa de la Carnicería, en la caleta de Fernando Castro -no debe confundirse con la caleta de Blas Díaz- por donde se llevaba a cabo el tráfico de personas y mercancías. 


\section{El viaje}

Fernando de Magallanes, experto marino portugués, le propuso a su Rey, Manuel I, llegar a las Indias Orientales atravesando el Océano Atlántico, hasta encontrar las islas de la Especiería -Las Molucas en las Filipinas- (actual Indonesia), pues hasta entonces las Especias eran transportadas en grandes caravanas de camellos a través del continente asiático.

Ante su negativa, le presentó el proyecto al rey Carlos I de España, quién el 22 de marzo de 1518 firmó en Valladolid las capitulaciones y aportaba el $75 \%$ del presupuesto, mientras que un grupo de comerciantes contribuía con el otro $25 \%$.

Las Especias tenían gran demanda en Europa pues, además de ser una importante fuente de ingresos, mejoraban la calidad de vida de la sociedad al utilizarse para condimentar y conservar los alimentos: canela, clavo, pimienta, nuez moscada y jengibre; en la elaboración de perfumes: almizcle y ámbar; en la medicina: alcanfor, quina y opio; en las iglesias: incienso, etc.

Tras dos años de preparativos, el 10 de agosto de 1519, zarparon del puerto de Sevilla cinco navíos de la Corona, con 239 tripulantes: Trinidad, capitaneada por Magallanes; San Antonio, al mando del Juan de Cartagena; Concepción, comandada por Gaspar de Quesada y como maestre Juan Sebastián Elcano; Victoria, dirigida por Luís de Mendoza; y la carabela Santiago, por Juan Serrano.

Después de permanecer 39 días en Sanlúcar de Barrameda (Cádiz), reparando las naves que se encontraban en mal estado, el 20 de septiembre de 1519 tomaron rumbo a Tenerife, navegando en demanda de la punta de Anaga y, después de recorrer 700 millas náuticas, el 26 de septiembre llegaron a Santa Cruz, único puerto donde podían aprovisionarse las expediciones de la Corona para las Indias, las Islas Canarias, y el África Atlántica, consignadas por la Casa de Contratación de Sevilla

Por ello, en cumplimiento de una comisión Real, el viaje era considerado como secreto y estaba obligado a presentar sus respetos al Adelantado, que residía en La Laguna, aunque en esas fechas estaba en Barcelona. 
Para adquirir y preparar el avituallamiento necesario para esta expedición, sobre todo el agua tinerfeña por su extraordinaria calidad, previamente había llegado a la Isla un emisario del financiero burgalés Cristóbal de Haro, en la carabela de Juan Quintero.

En la Relación del primer viaje alrededor del Mundo, del cronista de la expedición Antonio Pigafetta, uno de los 31 que sobrevivió al viaje, revela que:...."El martes 20 de septiembre de 1519 partimos de San Lucar enfilando al sudoeste y el día 26 llegamos a una de isla Canaria llamada Tenerife, situada a los $28^{\circ}$ latitud, para surtirnos de carne, agua y madera. Anclamos allí tres días y medio, como lugar donde se aprovisionan las escuadras de dichas cosas. Después nos acercamos a otro puerto de la misma isla que denominan Monte Rosso, donde pasamos dos días pescando y tomamos bastimentos de carne salada, agua, leña, quesos y otros refrescos necesarios para la travesía”.

En la Narración corta y restringida de Vasco Gómez Gallego, compañero de Duarte Barbosa en la nao Trinidad, encontrada por el investigador tinerfeño Carlos Palles, expresa que “... En el nombre de Dios y a buen salvamento, el 10 de agosto del año 1519 partimos de Sevilla con cinco naves para ir a descubrir las Islas Molucas. Desde Sanlúcar navegamos al Sudoeste 960 millas, hasta llegar a las Islas Canarias, donde encontramos la isla de Tenerife, en la cual está el puerto de Santa Cruz, en $28^{\circ}$ de latitud Norte. Después de permanecer tres días en Santa Cruz navegamos hasta el tenedero de montaña Roja, en Granadilla, donde permanecimos fondeados dos días más para completar la carga de pez de los hornos allí existentes".

En Granadilla, Andrés Blanco, Blas Afonso, Hernán López, y Pedro de Indarchi, -Pedro de Tenerife-, maestros pegueros de los hornos de brea que el Duque de Medina Sidonia poseía en la Data de tierras que le fueron entregadas por Alonso Fernández de Lugo en compensación a la ayuda recibida durante la Conquista de la Isla de Tenerife, llevaron un barquichuelo cargado de pez desde el puerto de Abona a montaña Roja y, como allí no habían habitantes, ayudaron a tumbar la nao en la playa para calafatearla, por lo que creemos que fueron obligados a subir a bordo; Pedro en la nao capitana y los otros tres en la carabela Santiago. Para que cupiesen tuvo que bajar a tierra el sobresaliente Lázaro de Torres. 
La medianoche del lunes 2 de octubre de 1519, cuando los alisios comenzaron a soplar, los cinco barcos tomaron rumbo sudoeste y luego sur, para acercarse a la costa africana y aprovechar el viento alisio que les conduciría rumbo a América.

Después de haber explorado durante meses las costas de Sudamérica, donde el 3 de mayo de 1520 la carabela Santiago naufragó en el estuario del río Santa Cruz, en la Patagonia argentina, y la nao San Antonio retornó a Sevilla, el 6 de mayo de 1521, al haberse sublevado su tripulación, el 21 de noviembre de 1520 lograrían encontrar el paso que comunicaba el Océano Atlántico con el Pacífico, al que bautizaron como de Todos los Santos -Estrecho de Magallanes-.

A las islas Filipinas llegaron el 27 de abril de 1521, después de haber quemado la nao Concepción frente a la isla de Bohol, por falta de tripulación para continuar navegando. Aquí moriría Magallanes, en la batalla de Mactán.

Por tanto, a las islas Molucas, objetivo del viaje, sólo llegaron la nao Victoria, al mando de Juan Sebastián de Elcano y la Trinidad a cargo de Gonzalo Gómez de Espinosa, el 7 de noviembre de 1521.

El tornaviaje hacia España lo comenzaron el 21 de diciembre, con las bodegas repletas de especias. La Trinidad, con 17 supervivientes, regresó por el Pacífico Norte, pero un tifón la desarboló y diezmó su tripulación; sin embargo, la nao Victorianavegó hacia el Oeste y, aprovechando la corriente ecuatorial del Índico Sur, doblaría el cabo de Buena Esperanza, en el sur deÁfrica, y beneficiándose de los alisios de ambos hemisferios, navegaría por el Atlántico hasta llegar a la isla de Santiago, en Cabo Verde, el 9 de Julio de 1522, donde tuvo que fondear debido a las enfermedades que padecía la tripulación y la falta de alimentos.

Para ello, Elcano tuvo que fingir que formaba parte de una flota española que regresaba de América y había sufrido una tempestad que les había roto el mastelero y la verga del trinquete; argucia utilizada porque según el Tratado de Tordesillas (1494) acuerdo firmado por los reyes de Castilla y de Aragón, Isabel y Fernando, y el rey Juan II de Portugal, el dominio ultramarino se lo repartieron en virtud de una 
línea imaginaria de demarcación que, de norte a sur, discurría a 370 leguas al oeste de las islas de Cabo Verde.

Obtenido el permiso del Gobernador, 12 marineros bajaron a tierra con el fin de transbordar agua y provisiones, operación que repetirían varias veces hasta que fueron descubiertos al intentar comprar esclavos con especias, siendo retenidos en la isla, motivo por el que la Nao tuvo que zarpar con premura, dejándolos en tierra.

El sábado 6 de septiembre de 1522, la Victoria entraba en la bahía de Sanlúcar, con 18 supervivientes, extenuados y sin fuerzas, pero con 750 quintales de especias en la bodega, lo que haría el viaje muy rentable al cubrir con creces los gastos de la expedición.

Cuando Juan Sebastián de Elcano fue llamado por Emperador a Valladolid, le llevó muestras de las distintas especias, para que las conociera y disfrutara. Después de pedirle que le diera la cuarta y la veintena parte de los efectos que traían consigo, le suplicó que hablara con el Rey de Portugal para lograr la libertad de los 12 hombres que habían quedado presos en Cabo Verde, los cuales llegarían a Sevilla semanas más tarde, lo que hacía un total de 35 supervivientes. Entre ellos estaba Maestre Pedro de Tenerife.

Carlos I, obsequió a Juan Sebastián Elcano con un escudo en forma de globo terráqueo, con la leyenda "Primus Circumdedisti Me"-Fuiste el Primero en Circunnavegarme.

\section{Consecuencias}

La primera circunnavegación de la Tierra cambiaría para siempre su concepción, pues todos los mapas quedaron obsoletos ante la gran cantidad de nuevos datos y accidentes geográficos que habían descubierto, a la vez que demostraba su esfericidad, además de su redondez. También tendría una repercusión inmediata en el comercio, comunicaciones, botánica, zoológica, etc. 


\section{Reconocimientos a Magallanes y Elcano en Santa Cruz de Tenerife.}

En el Paseo de Visitantes Ilustre que se encuentra en el puerto tinerfeño, inaugurado en 2016, se levantan hitos en honor de Magallanes y Elcano, iniciativa llevada a cabo por la Tertulia Amigos del 25 de Julio, con la colaboración de la Autoridad Portuaria y el Ayuntamiento de Santa Cruz de Tenerife.

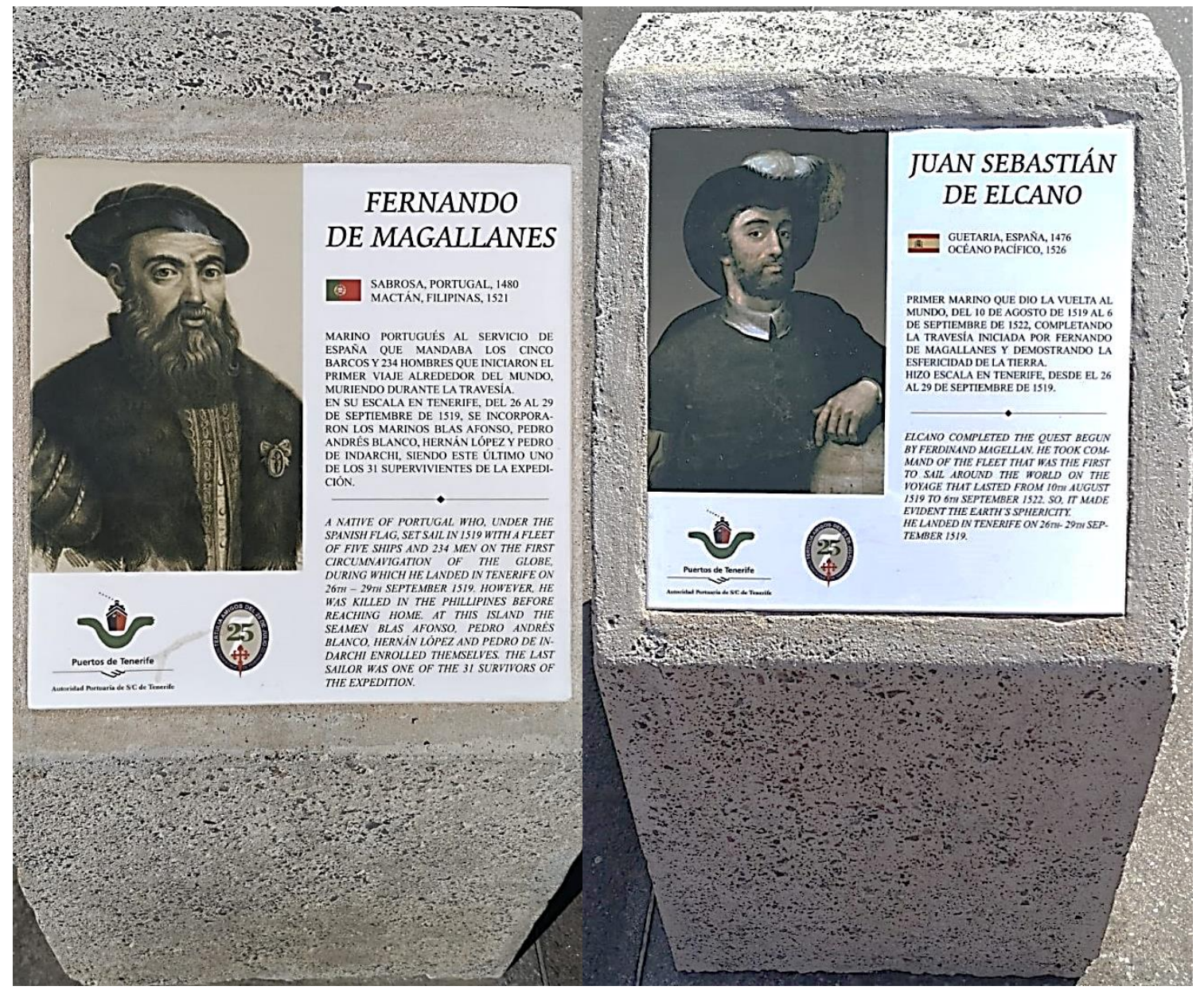

Y, desde el pasado jueves, 26 de septiembre, la estancia de la expedición en Santa Cruz se recuerda con una placa colocada al inicio del muelle Sur, justo en el lugar donde fondearon las cinco naos. 


\title{
Magallanes: construyendo el héroe
}

\author{
Ángeles Martínez-García \\ Universidad de Sevilla, US, España \\ Antonio Gómez-Aguilar \\ Universidad de Sevilla, US, España
}

Cómo citar: A Martínez-García, A Gómez-Aguilar (2019): "Magallanes: construyendo el héroe". Revista Latina de Comunicación Social, En P HerreroDiz/A Cárcamo/V Rodríguez Breijo/R Mancinas (Eds.) V Centenario / $1^{a}$ Vuelta al Mundo. Cuadernos Artesanos de Comunicación, cac161, pp 19-48. La Laguna (Tenerife): Latina. DOI: 10.4185/ cac161

\begin{abstract}
s
Introducción. El mundo de ayer, como el de hoy, necesita referencias. La creación de héroes, figuras elevadas a la categoría de seres extraordinarios, responde a esa necesidad humana de saber que hay otros que lo hicieron antes. Metodología. Este artículo usará un método cualitativo basado en un modelo establecido, el del viaje del héroe; se diseñará una herramienta ad hoc y se añadirán las variables complementarias que tienen que ver con los elementos morfológicos y funcionales de la figura del héroe. Resultados. En este artículo se revisarán dos obras literarias para detectar los principales mecanismos utilizados para la creación del héroe en torno a la historia de la primera circunnavegación. Discusión y conclusiones. Magallanes se convirtió en héroe desde el mismo momento en que emprendió su aventura. El cronista que lo acompañaba, A. Pigafetta, se encargó de construir al héroe en su escrito por la admiración que le profesaba y sentó las bases para otros que vinieron posteriormente.
\end{abstract}




\section{Keywords}

Héroe; mito; Magallanes; vuelta al mundo.

\section{Contents}

1. Introducción. 2 Método. 2.1.1. Estrategias metodológicas. 2.1.2. Población y muestra. 2.1.3. Instrumentos de recogida de información. 2.1.4. Procedimiento. 3. Resultados. 4. Discusión. 5. Conclusiones. 6. Referencias bibliográficas.

\section{Introducción}

T A FIGURA de Magallanes ha sido siempre el héroe magnífico de la primera circunnavegación. Los escritos de Pigafetta, cronista de la gesta en la travesía de Magallanes y Elcano entre 1519 y 1522 y superviviente de la misma, elevaron a la categoría de semidiós a un personaje que, paradójicamente y, ante todo, era humano. De la escasa bibliografía de la época se ha ido destilando toda una leyenda hasta nuestros días en torno al viajero en una travesía que modificó "la idea del mundo occidental acerca de la geografía y la cosmología, es decir, del estudio del universo y del lugar que ocupamos en él" (Bergreen, 2006, p. 18). En definitiva, esta gesta demostró que la Tierra era un solo mundo al fin y al cabo y que Magallanes, como lo llama Núñez de la Fuente (2017) fue un "hacedor de lo imposible" (p. 26). Este autor compara a Magallanes con los héroes griegos e incluso lo pone por encima de ellos:

Acaso puedes intuir siquiera qué odas y cantos habrían compuesto poetas tan insignes como Homero y Hesiodo exaltando a Tebas, Troya e Ítaca, si hubiesen sido cualesquiera de ellas el escenario elegido, en lugar de Sevilla, para convertirse en el alfa y el omega de tan extraordinaria proeza (Núñez de la Fuente, 2017, p. 29).

Escritos como los de Zweig (1931), Núñez de la Fuente (2017), Castillo Ceballos (2013) o el propio Pigafetta (2012), entre otros muchos, encumbran a Magallanes como héroe de una de las odiseas más importantes de la historia de la humanidad. 
Este artículo revisará materiales literarios para detectar los principales mecanismos utilizados para la creación del héroe en torno a la historia de la primera circunnavegación desde el punto de vista de los escritos de Campbell (2013), Vogler (2002), Bauzá (2009), Durand (2005), Kerenyi (2009) y Jung (2002), uniendo al esquema del viaje del héroe clásico las características psicológicas, éticas e intelectuales, así como los arquetipos que acaban de completar la figura.

El objetivo principal de este artículo es comprobar si se han usado de manera eficaz los distintos mecanismos para la creación de un héroe en torno a la figura de Magallanes. Para ello se partirá del monomito o viaje del héroe, modelo establecido por Campbell para comprobar si en los escritos seleccionados se ha seguido este esquema. Se comprobará si existe sinergia entre el personaje real y las aventuras de los héroes mitológicos o si, por el contrario, el patrón de base no ha sido tomado en cuenta. De igual forma, se comprobará si Magallanes es depositario en estos escritos de los valores de las figuras míticas de la Antigüedad.

Kerényi (2004) dice en sus escritos:

la mitología: es la suma de elementos antiguos transmitidos por la tradición (...), que tratan de los dioses y los seres divinos, combates de héroes y descensos a los infiernos, elementos contenidos en relatos conocidos y que, sin embargo, no excluyen la continuación de otra creación más avanzada (p. 17).

Los avances científicos hicieron que el mito quedase relegado a una mera fantasía durante el siglo XIX (Eliade, 1999); sin embargo, el siglo XX le devolvió su lugar: el cientificismo no era omnipotente frente a todos los dilemas del universo. Los estudiosos del siglo XX comenzaron a integrar aspectos cualitativos además de cuantitativos en los planteamientos científicos (Lévi-Strauss, 1987).

Las funciones y características del mito lo hacen idóneo para el momento vital que vive el individuo contemporáneo. Perdida su confianza en la razón y asumida su incapacidad para aprehenderlo todo a su alrededor, el ser humano busca referencias a las que asirse para 
responder a sus preguntas y llenar su vacío existencial. Para ello, crea figuras clave en el seno de las distintas esferas sociales, como el cine, la literatura, las artes, en definitiva, y también otros ámbitos, como el deporte o los videojuegos teniendo como base esencial el relato (Segal, 2004, p. 4)

Entendida como "una realidad cultural compleja, abordable e interpretable desde perspectivas múltiples" (Eliade, 1983, p. 12), el mito tiene en su interior muchas "voces" (Durand, 1993), esto es, se trata de un producto colectivo (Cencillo, 1998). Hunde sus raíces no ya en la lógica y el razonamiento, sino en lo irracional, en la parte intuitiva del ser humano. Cumple funciones esenciales y surge por unas necesidades fundamentales:

- Aprehensión del entorno. El mito es la primera forma de relación del ser humano con lo que le rodea (Huici, 1998).

- Búsqueda de sentido. Es un discurso dinámico que resuelve lo indecible de un dilema (Durand, 1993). Traza las constantes existenciales de la humanidad, sus signos de identidad o su sistema de referencia último (Kolakowski, 1990).

- Modelo de conducta humana. Funciona como "sistema de referentes orientativos de la praxis humana" (Cencillo, 1998, p. 23). Protagonizado por seres de naturaleza sobrenatural -dioses y héroes emparentados con ellos- fija una serie de modelos ejemplares de acciones humanas significativas (Rosales, 1996).

El ser humano ha tenido al mito como una guía que le acompañaba para dar sentido a lo que pasaba a su alrededor desde tiempos ancestrales. En los tiempos primigenios se consideraba que los seres que protagonizaban los relatos míticos no eran otra cosa que una ejemplificación de sus aspiraciones. De características casi sobrenaturales, estas figuras provocan la admiración del pueblo. Las civilizaciones más destacadas de la historia glorificaban a héroes y reyes; a través de leyendas y otros relatos poéticos impregnaron el origen de estos seres humanos de elementos fantásticos (Rank, 1981, p.9). Por ello existe la creencia de que los héroes podrían haber sido personas de carne y hueso transformadas de alguna forma en seres sobrenaturales y, posteriormente, en ejemplos paradigmáticos. 


\subsection{Características del héroe}

El Diccionario de la Real Academia en su acepción héroe/ína dice lo siguiente:

Del lat. heros, -ōis, y este del gr. ๆ̋ew hếrōs; la forma f.,

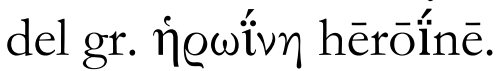

1. m. y

f. Persona que realiza una acción muy abnegada en beneficio de una causa noble.

2. m. y f. Persona ilustre y famosa por sus hazañas o virtudes.

3. m. $\mathrm{y}$

f. En un poema o relato, personaje destacado que actúa de una manera valerosa y arriesgada.

4. m. y f. Protagonista de una obra de ficción.

5. m. y

f. Persona a la que alguien convierte en objeto de su especial admiración.

6. m. En la mitología antigua, hombre nacido de un dios o una di osa y de un ser humano, por lo cual

era considerado más que hombre y menos que dios; $p$.

ej., Hércules, Aquiles, Eneas, etc.

Los héroes son un sistema de referencia para comprender una cultura concreta (Bauzá, 1998, p. 3). "Desde el momento en que el mito se desenvuelve en un tiempo histórico, sin dejar de ser mito, conlleva también en su discurso elementos que pertenecen a la sociedad y a la historia" (Bauzá, 1998, p. 109). Es por ello que el mito es una potente herramienta de estudio social.

No se puede encontrar una explicación acerca del origen y la naturaleza de los héroes. Siempre están "entre lo divino y lo humano, el orden y el desorden, lo civilizado y lo salvaje" (Bauzá, 1998, p. 37). A partir de un momento determinado, hacia el final del Renacimiento, existe un cambio en la figura del héroe, que deja de estar centrado en lo sobrenatural y pasa a fijarse más en lo cotidiano. A pesar de los cambios, hay elementos comunes en la figura del héroe, ya que están compuestos por la suma del conjunto de variantes que existen sobre él 
(Lévi-Strauss, 1977). Además, existe una necesidad inherente al ser humano de crear ídolos a los que "rendir culto"; esto explica la pervivencia de los héroes antiguos y el continuo nacimiento de héroes contemporáneos.

Se han detectado cuatro elementos básicos comunes a las figuras heroicas: transgresión, ética, muerte prematura y trágica y acción ejemplarizante.

La transgresión es tal vez uno de los elementos más definitorios del héroe. Se trata de esa tendencia a lo prohibido, a ir más allá de lo conocido y de los límites impuestos. Esto coincide con la postura anarquista del héroe, que puede considerarse "rebelde, renovador y revolucionario" (Rank, 1981, p. 113). Todas sus acciones van encaminadas a la búsqueda de la libertad, a la ruptura del orden establecido y a la instauración de nuevos valores (Bauzá, 1998, p. 149). "El héroe inicia su aventura desde el mundo de todos los días hacia una región de prodigios sobrenaturales, se enfrenta con fuerzas fabulosas y gana una victoria decisiva" (Campbell, 2013, p. 25).

Ahora bien, esa transgresión siempre se pone al servicio de los demás por lo que la defensa de los valores éticos se considera también imprescindible en la constitución de los héroes. Campbell (1991) dice que "un héroe es alguien que ha dado su vida por algo más grande que él mismo" (p. 179). En este sentido, no nos interesa tanto el héroe de lo trascendente, sino el héroe de un aquí y un ahora, esto es, de una determinada circunstancia histórica. Ese móvil ético también era muy valorado en el mundo antiguo.

La transgresión a niveles elevados llevará al héroe a una muerte prematura y, en muchas ocasiones, trágica. En parte se debe a que estos seres no alcanzan a medir las consecuencias de sus acciones (Bauzá, 1998 , p. 5). Es una muerte involuntaria, fruto de un error que han cometido; no obstante, "la grandeza del héroe radica en que al combatir arriesga su vida" (Bauzá, 1998, p. 31) y tras ella le aguarda la vida de la fama que lo trasciende. Los héroes suelen morir violentamente: despedazados, quemados, en suicidio, en combate. Este final trágico está muy unido al sufrimiento, algo distintivo de los héroes que los hace 
cercanos a los seres humanos y los conmueve; de hecho, "el dolor, la duda, el exilio existencial son las notas más humanas del héroe clásico" (Bauzá, 1998, p. 130). Ese dolor sirve como tránsito a la purificación de la figura heroica, que afronta el desenlace con decisión y valentía.

Las acciones de los héroes los convierten en modelo de excelencia para el resto de los mortales. Son ejemplo a seguir. A veces, como apunta Bauzá (1998), ayudan a despertar el heroísmo latente en las personas y de ellos se extraen enseñanzas que ayudan a afrontar cualquier circunstancia vital. Desde una lectura psicoanalítica, el camino del héroe es un símil de la vida misma, aquella marcada por obstáculos permanentes y que finalmente queda interrumpida por la muerte. El honroso acto que implica su entrega es un referente ético superior para el resto de los mortales. "El complicado héroe del monomito es un personaje de cualidades extraordinarias. Frecuentemente es honrado por la sociedad a la que pertenece, también con frecuencia es desconocido o despreciado" (Campbell, 2013, p. 29).

La figura del héroe, como la de cualquier mito, entraña una verdad de carácter simbólico, más allá de su arraigo histórico social, en tanto que responde a los grandes interrogantes de la humanidad: ¿De dónde venimos? ¿Hacia dónde vamos? ¿Por qué estamos aquí? En este sentido se encuadran las aportaciones de Kerenyi (2009), Cassirer (1993) o Durand (1979), más centradas en poner de relieve el valor cognoscitivo y simbólico de los mitos. Así se puede entender la creación constante de mitos y la resemantización de mitos antiguos de acuerdo a nuevas formas de vida y pensamiento (Bauzá, 1998).

\subsection{La travesía del héroe}

El segundo pilar en la construcción del héroe es el propio camino donde despliega todas las características anteriores. La fuente más reconocida que da cuenta de las diversas etapas del mito del héroe es la obra de Campbell El héroe de las mil caras (2013), publicado por primera vez en 1949. Siguiendo los estudios de Propp (2001) sobre las diversas funciones presentes en los cuentos, publicados por primera vez en 1928; y las aportaciones de Jung (2002) acerca del inconsciente colectivo y cómo este se manifiesta en patrones de comportamiento a 
los que él llamó arquetipos, Campbell desarrolló una serie de estándares de las distintas etapas de la travesía del arquetipo del héroe para constituirse como tal.

Tras Campbell, Vogler publicó en 1992 El viaje del escritor, una profundización sobre el libro de El héroe de las mil caras dirigido a contadores de historias $\mathrm{y}$, fundamentalmente, guionistas de cine, campo en el que él es un experto y donde desarrolla su carrera profesional.

A continuación, se expone la travesía del héroe atendiendo a las distintas fuentes enunciadas.

\subsubsection{El mundo ordinario: La partida}

Esta primera etapa se desarrolla en el mundo en el que el héroe se desenvuelve habitualmente. El héroe se da cuenta de que algo está cambiando, "Una ligereza -aparentemente accidental- revela un mundo insospechado y el individuo queda expuesto a una relación con poderes que no se entienden correctamente" (Campbell, 2013, p. 36). En esta etapa pueden considerarse a su vez cinco sub-etapas que se desarrollan a continuación.

En primer lugar, el héroe recibirá o sentirá la llamada a la aventura (Campbell, 2013, p. 36; Vogler, 2001, p. 131). Le será encomendada algún tipo de tarea o verá que su intervención es necesaria para resolver una situación. Campbell (2013) señala que suele ser un heraldo o mensajero quien transmite esta llamada, y que es común que esta figura tenga un componente oscuro, malvado. Sin embargo, también puede ser un "azoramiento del héroe" (Vogler, 2001, p. 132). Este primer estadio significa "que el destino ha llamado al héroe y ha transferido su centro de gravedad espiritual del seno de su sociedad a una zona desconocida" (Campbell, 2013, p. 40).

Campbell establece una segunda subetapa de negativa al llamado, el rechazo de la llamada para Vogler (2001, p. 140), en la que el héroe da la espalda a la misión. Campbell (2013) habla de ese momento como algo temporal puesto que la aventura empieza de una u otra manera. 
Sin embargo, Vogler (2001) considera también la figura del héroe resuelto o deseoso, como aquel que acepta o incluso busca la aventura.

El encuentro con el mentor es ese momento decisivo en que el héroe localiza una figura protectora que le proporciona los elementos necesarios para llevar a cabo su aventura. Como comenta Campbell (2013), "no es raro que el ayudante sobrenatural tenga forma masculina" (p. 48). Normalmente los héroes localizan alguna fuente de sabiduría antes de comenzar la aventura (Vogler, 2001).

El siguiente paso es crucial en tanto que es el paso a lo desconocido, más allá de los límites habituales del héroe. Es el cruce del primer umbral (Campbell, 2013) o travesía del primer umbral (Vogler, 2001, p. 160). Es una frontera, literal o metafórica, que separa el mundo cotidiano en el que vive el héroe de lo desconocido. Tras el umbral, al héroe le espera una nueva esfera.

El vientre de la ballena es la última subetapa de la partida. Con esta metáfora designa Campbell (2013) el paso a una "esfera de renacimiento" (p. 56). El héroe es "tragado" por lo desconocido. Vogler obvia esta etapa por considerarla redundante.

\subsubsection{El mundo extraordinario: La iniciación}

En esta etapa el héroe será puesto a prueba. En ella está concentrada gran parte de la acción y será motivo de la transformación profunda del héroe. Contiene seis subetapas.

La primera es el camino de las pruebas que, como dice Campbell (2013), es "la fase favorita de la aventura mítica" (p. 61). Vogler (2001, p. 167) la llama las pruebas, los aliados, los enemigos porque considera que es aquí donde encuentra elementos de ayuda, pero también adversarios.

La segunda subetapa es el acercamiento a la cueva profunda (Vogler, 2001, p. 176), una etapa en la que el héroe va avanzando con éxito, adquiriendo nuevos conocimientos y se prepara para la batalla más importante: aquella que le enfrentará a la derrota o incluso la muerte. 
Campbell no incluye esta etapa tal cual, sino que en su lugar habla del encuentro con la diosa (2013), que define metafóricamente como un "matrimonio místico del alma triunfante del héroe con la Reina Diosa del Mundo" (p. 68), una vez que todos los obstáculos han sido superados.

Durante el viaje del héroe, este se topa con multitud de obstáculos, algunos de los cuales pretenden que se aleje de su camino para que no consiga su objetivo. Es la etapa que Campbell denomina la mujer como tentación.

La siguiente subetapa es la reconciliación con el padre (Campbell, 2013, pp. 76-88). Tras enfrentarse con el padre, ambos se reconcilian, este lo reconoce como a un igual y el héroe puede continuar con su aventura.

La penúltima etapa de la iniciación es la apoteosis, donde vuelven a confluir los dos autores. Vogler la llama (2001, p. 190) la odisea o el calvario. Se trata, como dice Campbell (2013), de una "liberación potencial que está dentro de cada uno de nosotros, y que cualquiera puede obtener a través del heroísmo" (p. 89). Es una especie de estado divino al que el héroe llega después de atravesar el camino. Para Vogler (2001) este es el momento más trascendental de la travesía del héroe y lo define muy claramente: "Los héroes deben morir para poder renacer después" (p. 191).

El último episodio de la iniciación es aquel en que el héroe debe conseguir el objetivo impuesto al comienzo de su andadura y por el cual ha acumulado tanto sufrimiento. Campbell lo denomina la gracia última y Vogler lo llama la recompensa y es aquel momento en que el héroe debe enfrentarse a fuerzas superiores antes de volver a su mundo. Entonces se le otorga el elixir de la inmortalidad.

\subsubsection{El camino de regreso}

En esta etapa se cierra el viaje del héroe. Vogler llama a este tramo el camino de regreso (Vogler, 2001, p. 224) y cierra el ciclo de transformación. Es tarea del héroe traer los misterios de la sabiduría a su pueblo. Campbell divide el camino de regreso en diversas subetapas; 
la primera es la negativa al regreso (p. 114), donde el héroe rechaza la responsabilidad de difundir sus logros para mejorar a la comunidad de la que procede y a la que regresa renovado. La incredulidad o la imposibilidad de adaptación al entorno pueden ser algunas de las causas de este comportamiento.

Tras este momento, comienza una subetapa de huida mágica a la que Campbell supone dos estadios posibles. Si el trofeo ha sido conseguido con el apoyo de los dioses, esta última etapa será más tranquila y con el apoyo de sus patronos. Sin embargo, si el trofeo se ha conseguido oponiéndose a los guardianes, esta etapa será una "persecución agitada y a menudo cómica" (2013, p. 115), que puede complicarse con obstáculos increíbles. Se trata, en definitiva, de un último intento de impedir que el héroe no consiga su objetivo final.

Puede que en este estadio el héroe necesite "ser asistido por el mundo exterior al regreso de su aventura sobrenatural. En otras palabras, pudiera darse el caso de que el mundo tuviera que venir y rescatarlo" (Campbell, 2013, p. 120). Es la subetapa denominada rescate del mundo exterior, en la que el héroe siente que no quiere volver del mundo extraordinario en el que ha estado.

Aquí el héroe se encuentra en la frontera que separa el mundo sobrenatural del punto de partida. Ese es el cruce del umbral de regreso. Es un momento delicado en tanto que el héroe debe sobrevivir al "impacto del mundo", esto es, no será fácil mezclar los dos mundos -ordinario y extraordinario- y explicar sus hazañas a su vuelta.

“Cómo enseñar de nuevo, sin embargo, lo que ha sido enseñado correctamente y aprendido incorrectamente mil y mil veces a través de varios milenios de tontería prudente en la especie humana? Ésa es la última y difícil labor del héroe. ¿Cómo dar en el lenguaje del mundo de la luz, los mensajes que vienen de las profundidades y que desafían la palabra?" (Campbell, 2013, p. 127).

Campbell (2013) denomina a la siguiente subetapa la posesión de los dos mundos (p. 132), en tanto que el héroe posee la libertad para pasar 
de un lado a otro, de mundo a mundo. Es este talento del maestro el que hará que goce de un nuevo estatus cuando retorne a la cotidianeidad. Vogler (2001) define este momento como uno de los más "engañosos y desafiantes" (p. 233) y lo llama la resurrección, puesto que puede ocurrir que algunos héroes hayan perdido la vida con anterioridad a este momento. No obstante, todos alcanzan la resurrección "puesto que perviven tal y como existieron en la memoria de los supervivientes, aquellos por los que fehacientemente dieron su vida. Así pues, el público sobrevive y rememora la lección que un héroe trágico quiso transmitirnos" (Vogler, 2001, p. 237).

Gráficamente el camino del héroe quedaría de la siguiente forma:

\section{Gráfico 1. Las etapas del viaje del héroe}

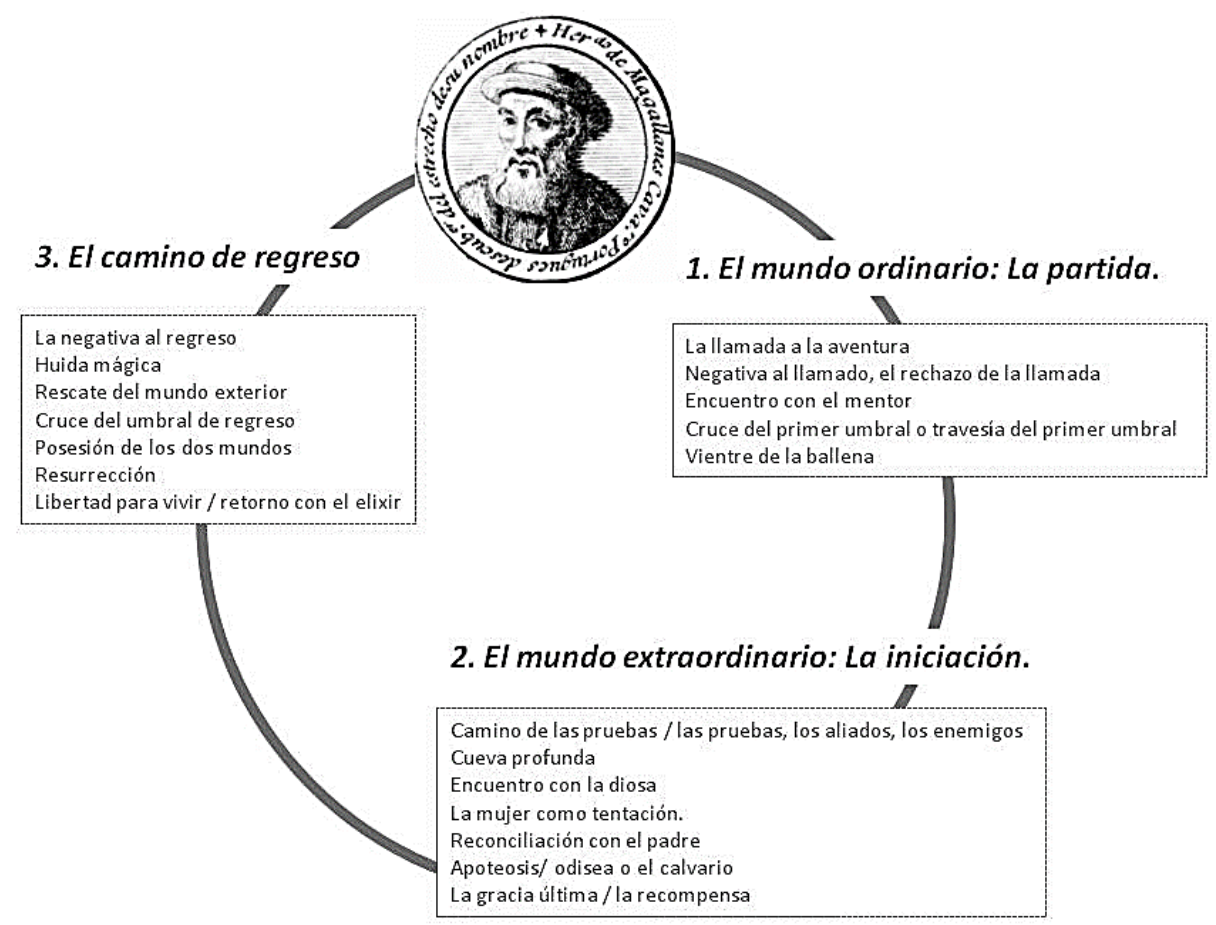

Fuente: Elaboración propia a partir de los escritos de Campbell (2013) y Vogler (2001).

El héroe ha cumplido ya su cometido, por lo que se ha ganado la libertad para vivir, según Campbell o el retorno con el elixir, como lo llama Vogler (2001, p. 252). "El héroe es el vehículo consciente de la Ley terrible y maravillosa" (Campbell, 2013, p. 137) y en ese sentido está preparado para cualquier cosa que se proponga: puede tomarse un 
descanso o bien ser requerido de nuevo para repetir una odisea similar. Si el viajero no porta algo que compartir no se convertirá en héroe, es decir, debe poder demostrar a una comunidad que ha estado en un lugar determinado y por ello se convierte en modelo para otros y demuestra que es posible vencer a la muerte. Así toma su puesto de liderazgo y servicio y esto lo sacará de su aislamiento para siempre.

Campbell (2013) resume todas las etapas de la siguiente forma:

El héroe mitológico abandona su choza o castillo, es atraído, llevado, o avanza voluntariamente hacia el umbral de la aventura. Allí encuentra la presencia de una sombra que cuida el paso. El héroe puede derrotar o conciliar esta fuerza y entrar vivo al reino de la oscuridad (batalla con el hermano, batalla con el dragón; ofertorio, encantamiento), o puede ser muerto por el oponente y descender a la muerte (desmembramiento, crucifixión). Detrás del umbral, después, el héroe avanza a través de un mundo de fuerzas poco familiares y sin embargo extrañamente íntimas, algunas de las cuales lo amenazan peligrosamente (pruebas), otras le dan ayuda mágica (auxiliares). Cuando llega al nadir del periplo mitológico, pasa por una prueba suprema y recibe su recompensa. El triunfo puede ser representado como la unión sexual del héroe con la diosa madre del mundo (matrimonio sagrado), el reconocimiento del padre-creador (concordia con el padre), su propia divinización (apoteosis) o también, si las fuerzas le han permanecido hostiles, el robo del don que ha venido a ganar (robo de su desposada, robo del juego); intrínsecamente es la expansión de la conciencia y por ende del ser (iluminación, transfiguración, libertad). El trabajo final es el del regreso. Si las fuerzas han bendecido al héroe, ahora éste se mueve bajo su protección (emisario); si no, huye y es perseguido (huida con transformación, huida con obstáculos). En el umbral del retorno, las fuerzas trascendentales deben permanecer atrás; el héroe vuelve a emerger del reino de la congoja (retorno; resurrección). El bien que trae restaura al mundo (elixir) (p. 140).

Algunas historias pueden aislar o engrandecer uno o varios elementos como el motivo de la prueba o la huida. Otras pueden unir un grupo 
de ciclos independientes en uno solo. Incluso pueden unirse caracteres distintos o un único elemento puede multiplicarse.

\section{Metodología}

\subsection{Estrategias metodológicas}

Se ha elegido un método cualitativo basado en un modelo establecido del que se encuentran infinitas copias: el viaje del héroe. Este patrón que describe con extraordinaria precisión el proceso de realización de un viaje, es a su vez un modelo para el buen funcionamiento de una historia. Originariamente descrito por Campbell y posteriormente ampliado por Vogler, para esta investigación se ha diseñado una herramienta ad hoc que contemple los principales hitos de ese viaje basada en las aportaciones de estos dos autores. Para obtener un mayor rigor científico y alcanzar el propósito de desentrañar los elementos que participan en la construcción del héroe, se han añadido una serie de variables que, partiendo de las aportaciones de Jung (2002), Bauzá (2009) y Kerenyi (2009) fundamentalmente, completan las características morfológicas y funcionales. De esta forma, la figura del héroe podrá estudiarse de una forma más completa y compleja.

\subsection{Población y muestra}

Se elegirán dos fuentes literarias: Relación del primer viaje alrededor del mundo (Pigafetta, 2012), Magallanes. El hombre y su gesta (Zweig, 2015).

El 10 de agosto de 1519 salía del muelle de las Mulas de Sevilla la expedición compuesta por las naos Trinidad, la capitana al mando de Magallanes - un nobel navegante portugués con una patente para explorar partes del mundo desconocidas y reivindicarlas para la corona española (Bergreen, 2006); Concepción, San Antonio, Victoria y Santiago (Mollá, 2017). Un mes y diez días después, tras obtener provisiones, la expedición salía desde Sanlúcar de Barrameda compuesta por 234 hombres. En enero de 1520 alcanzó el estuario del río de la Plata y constató que no estaba allí el paso al Pacífico. Dos meses les tuvo el mal tiempo varados en la bahía de San Julián, que finalmente fueron otros cinco más. Los motines empezaron a sucederse en abril de 1520 y, a pesar de que Magallanes consiguió 
sofocarlos, hubo un alto número de condenas a muerte, como las de dos capitanes de navíos, Luis de Mendoza y Gaspar de Quesada. Poco después se perdió una nao en viaje de exploración, otra capitaneada por Estévao Gomes desertó y regresó a España y en noviembre de 1520 por fin cruzaron el más tarde llamado Estrecho de Magallanes. Los meses que llevaron a abril de 1521 estuvieron repletos de penalidades, incluidas el hambre y el escorbuto y ese mes terminó con la trágica muerte de Magallanes en la isla de Mactán (Mollá, 2017). A continuación, se perdió otra nao por falta de tripulación y otra en mal estado quedó reparándose en Tidore, de tal forma que la nao Victoria, al mando de Juan Sebastián Elcano, fue la única que partió de Tidore el 21 de diciembre de 1521 y navegó cinco meses por el océano Índico. No fue hasta mayo de 1522 cuando, ya muy debilitados por el escorbuto y el cansancio, consiguieron cruzar el cabo de Buena Esperanza. Finalmente, tras tres años de tortuosa navegación, la nao Victoria consiguió regresar a Sanlúcar de Barrameda con solo 18 hombres a bordo. Se convirtió así en la primera expedición que consiguió dar la vuelta al mundo, hacer algo que nadie había hecho antes (Bergreen, 2006) y demostrar a la humanidad que la Tierra es redonda: hizo realidad un sueño tan antiguo como la propia imaginación humana. "Una odisea que cambió el rumbo de la historia y nuestro modo de ver el mundo" (Bergreen, 2006, p. 19). Se convirtió en el viaje marítimo más importante de todos los tiempos.

De esta gesta hubo un testigo de excepción: Pigafetta, un joven erudito de origen veneciano que acompañó a Magallanes desde el primer momento y lo sobrevivió hasta su vuelta a Sanlúcar de Barrameda. Bergreen (2006) define la crónica que escribió Pigafetta como "uno de los documentos más importantes de la Era de los Descubrimientos" (p. 444). Sin embargo, Pigafetta es parcial en sus escritos y deja de lado las drásticas medidas que Magallanes tomó para sofocar los frecuentes motines que se sucedieron en fechas próximas a su muerte. El volumen escrito por Pigafetta será el primer objeto de estudio, titulado Primer viaje alrededor del mundo, publicado por primera vez en 1536, de carácter póstumo, en lengua italiana y cuyo título original era Relazioni in torno al primo viaggio di circumnavigazione. Notizia del Mondo Novo con le figure dei paesi scoperti. Pigafetta fue un viajero italiano nacido en torno a 1490 que murió en 1534 en su ciudad natal, Vicenza. Hacia 1519 vino a España 
y sirvió a Carlos V para dar impulso a la empresa iniciada por los Reyes Católicos en el Atlántico. Poco después inició una relación de amistad con Magallanes que le llevó a acompañarlo en su viaje alrededor del mundo.

Fue él el encargado de dar cuenta por escrito de la gesta de Magallanes y su legado se convirtió en la fuente más importante sobre la primera circunnavegación. A pesar de que tomó notas de lo acaecido a diario, incluye en su escrito numerosos detalles fantasiosos. Pueden encontrarse en su libro datos de etnografía muy valiosos y elementos reseñables de la propia navegación.

Registrado como Antonio Lombardo y destinado a la nao Trinidad, capitaneada por Magallanes, consiguió ganarse la simpatía de este y servirle de traductor. El texto fue entregado por Pigafetta al rey Carlos I en una entrevista que mantuvieron en Valladolid a la vuelta del viaje. Según su propio relato, la última copia la entregó al gran maestre Philippe Villiers de l'Isle-Adam y posteriormente se retiró a Italia. El original no se conserva en la actualidad. Se trata de un diario personal posteriormente transformado en libro de viajes propio del Renacimiento, cuando este género estaba muy influenciado por obras como las de Marco Polo o Américo Vespucio. Es reflejo de su tiempo, con una plasmación evidente de los valores de la fe cristiana, uno de los pilares fundamentales de la Era de los Descubrimientos.

El segundo volumen a estudiar es Magallanes. El hombre y su gesta, de Zweig, publicado por primera vez en 1938. Este autor nace en Viena en 1881. Del 8 de agosto al 6 de octubre de 1936, Zweig realiza un crucero en el RMS Alcántara desde Southampton a Brasil y Argentina con escalas en Vigo y Lisboa, y vuelta en el RMS Almanzora con llegada a Southampton el 6 de octubre. Tal y como se puede leer en la introducción del propio volumen, durante ese viaje Zweig pasó de disfrutar con el mar tranquilo, las comodidades del transatlántico y al margen las ataduras de lo cotidiano en la primera semana del viaje a un estado de impaciencia por llegar a su destino que le hizo el viaje insufrible. En ese intervalo reflexionó sobre las extraordinarias condiciones de su viaje -comodidades, alimentación, clima, comunicaciones con tierra, entre otras- y las comparó con las 
condiciones de viajes similares en otros tiempos, sobre todo con las de aquellos primeros trayectos en los que algunos navegantes temerarios descubrieron nuevos mares. Reviviendo en su interior esos primeros viajes de los conquistadores del mar, se sintió enormemente avergonzado por su impaciencia, sentimiento que no le abandonó en el resto del viaje. Comenzó entonces su interés por conocer más sobre esos héroes anónimos. Su búsqueda empezó en la biblioteca del propio barco, donde consultó diversas historias sobre los primeros viajes y rutas por los océanos inexplorados. "De entre todas las figuras y todas las rutas, mi admiración se asió a los hechos del hombre que, en mi sentir, llegó a lo más extraordinario en la historia de los descubrimientos geográficos: Fernando de Magallanes, el que salió de Sevilla con cinco barcas de pescador para dar la vuelta a toda la tierra" (Zweig, 1957, p. 7).

A su vuelta del viaje, leyó e investigó y se asombró del poco crédito que entonces tenía aquella gesta heroica. Como en otras ocasiones, encontró la mejor forma de arrojar luz sobre ese hecho dándole forma literaria, ya que Zweig fue un asiduo escritor de biografías. En 1938 publicó su obra sobre Magallanes titulada originalmente Magellan - Der Mann Und Seine Tat, más tarde se publicó en inglés como Conqueror of the Seas: The Story of Magellan (1940) y finalmente fue publicada en España en 1957.

En este libro Zweig realiza un retrato de un hombre tenaz e intrépido, un aventurero y un navegante. Pero también ofrece la imagen de una época y de cómo se contemplaba en aquel momento el mundo desde Europa.

\subsection{Instrumento de recogida de información}

El instrumento de recogida de información parte de la división en distintas etapas de Campbell en El héroe de las mil caras (2013) y Vogler (2002) en El viaje del escritor, aderezado por los escritos de Jung (2002) y Bauzá (2009) que completan las características morfológicas y funcionales. 


\section{Resultados}

Se incluye a continuación la tabla con los resultados comparativos de ambas obras que servirán de base a la discusión posterior.

\section{HERRAMIENTA DE ANÁLISIS: LA CONSTRUCCIÓN DEL HÉROE}

\section{CARACTERÍSTICAS DEL HÉROE}

\begin{tabular}{|c|c|c|c|c|}
\hline & \multicolumn{2}{|c|}{ Pigafetta } & \multicolumn{2}{|c|}{ Zweig } \\
\hline & $\begin{array}{l}\text { SÍ } \\
/ \\
\mathrm{N} \\
\mathrm{O}\end{array}$ & $(\mathrm{pp})^{*}$ & $\begin{array}{l}\text { SÍ } \\
/ \\
\mathrm{N} \\
\mathrm{O}\end{array}$ & (pp) \\
\hline $\begin{array}{l}\text { 1.- TRANSGRESIÓN: Ruptura con el orden } \\
\text { establecido para instaurar nuevos valores. }\end{array}$ & $\sqrt{ }$ & 44 & $\sqrt{ }$ & 53 \\
\hline $\begin{array}{l}\text { 2.- VALORES ÉTICOS: Sus acciones tienen una causa } \\
\text { mayor que él mismo. }\end{array}$ & $\sqrt{ }$ & $\begin{array}{c}10,1114 \\
20,23 \\
28,30\end{array}$ & $\sqrt{ }$ & $\begin{array}{l}96,108 \\
160\end{array}$ \\
\hline 3.- MUERTE PREMATURA Y TRÁGICA & $\sqrt{ }$ & 31 & $\sqrt{ }$ & 172 \\
\hline $\begin{array}{l}\text { 4.- PARADIGMA: Modelo de excelencia para el resto de } \\
\text { los mortales. }\end{array}$ & $\sqrt{ }$ & 31 & $\sqrt{ }$ & 172 \\
\hline \multicolumn{5}{|l|}{ LA TRAVESÍA DEL HÉROE } \\
\hline \multicolumn{5}{|l|}{ 1.- MUNDO ORDINARIO - PARTIDA } \\
\hline 1.a.- Llamada a la aventura. & $\sqrt{ }$ & 43 & $\sqrt{ }$ & $41-42$ \\
\hline 1.b.- Rechazo de la llamada & $\sqrt{ }$ & 43 & $\sqrt{ }$ & $\begin{array}{c}50,63 \\
64\end{array}$ \\
\hline 1.c.- Encuentro con el mentor. & $\sqrt{ }$ & 43 & $\sqrt{ }$ & $\begin{array}{c}64,70 \\
71\end{array}$ \\
\hline 1.d.- Cruce del umbral. & $\sqrt{ }$ & 3 & $\sqrt{ }$ & 98 \\
\hline \multicolumn{5}{|l|}{ 2.- MUNDO EXTRAORDINARIO - INICIACIÓN } \\
\hline 2.a.- Camino de las pruebas: aliados, enemigos. & $\sqrt{ }$ & 3- 11 & $\sqrt{ }$ & $99-132$ \\
\hline 2.b.- Los desvíos del camino: La cueva más profunda. & $\sqrt{ }$ & 11 & $\sqrt{ }$ & $\begin{array}{l}136 \\
142\end{array}$ \\
\hline 2.c.- La apoteosis: Prueba difícil o traumática. & $\sqrt{ }$ & 12 & $\sqrt{ }$ & $\begin{array}{l}143 \\
144\end{array}$ \\
\hline 2.d.- La gracia última: Recompensa. & $\mathrm{X}$ & - & $\sqrt{ }$ & 202 \\
\hline \multicolumn{5}{|l|}{ 3.- EL REGRESO } \\
\hline 3.a.- La negativa al regreso & $\mathrm{X}$ & - & $\sqrt{ }$ & $\begin{array}{l}145, \\
146, \\
148\end{array}$ \\
\hline 3.b.- La huida mágica & $\sqrt{ }$ & 31 & $\sqrt{ }$ & $\begin{array}{l}172 \\
184\end{array}$ \\
\hline
\end{tabular}




\begin{tabular}{|c|c|c|c|c|}
\hline 3.c.- El cruce del umbral & $\sqrt{ }$ & 60 & $\sqrt{ }$ & $\begin{array}{l}191, \\
192\end{array}$ \\
\hline 3.d.- La resurrección & $\sqrt{ }$ & 32 & $\sqrt{ }$ & $\begin{array}{l}193, \\
197, \\
199\end{array}$ \\
\hline 3.e.- El retorno con el elixir & $\sqrt{ }$ & 60 & $\sqrt{ }$ & 194 \\
\hline
\end{tabular}

\section{Discusión}

La primera parte de la construcción del héroe es la que tiene que ver con elementos morfológicos y funcionales. La principal característica que debe tener el héroe se refiere a la transgresión, es decir, buscar la ruptura con el mundo ordinario. Magallanes busca ir más allá de los límites de lo conocido y para ello existe un personaje fundamental, Faleiro, que estudia los proyectos de Magallanes y, como indica Zweig (p. 53) ${ }^{1}$

... les da estructura científica, y sus cálculos reafirman con datos precisos lo que Magallanes conocía por pura intuición. (...) Comprométense bajo palabra de honor a guardar el secreto de su propósito hasta que llegue el momento decisivo de la realización, $y$, si es preciso, llevar a cabo sin el apoyo de su patria, y hasta en contra de ella, un hecho que no ha de pertenecer a un país único, sino a toda la Humanidad.

A pesar de que el rey de Portugal, su patria, le abandona, Magallanes, se siente siempre fuerte (Zweig, p. 51): "La patria le ha abandonado y ha roto los vínculos que le unían al cargo y al deber. ¡Mejor! Ahora es libre. Como tantas otras veces, el puño que intentaba apartar a un hombre, lo que logra en realidad es hacerlo entrar en sí mismo". Y es que, como el propio Zweig apunta (p. 142): "A Magallanes no le importa la vida mortal ante el inmortal hecho. Quien piensa en héroe, tiene que obrar necesariamente contra la razón”.

En lo referente a los valores éticos, Magallanes se presenta desde el comienzo, sobre todo en el libro de Zweig, como un hombre oscuro y de carácter reservado. Son numerosas las obras posteriores que han 
destacado la difícil personalidad del navegante, que le valió la animadversión de todos sus capitanes. Pigafetta, no obstante, suaviza de manera notable esta forma de ser en su escrito en pro de un relato mucho más dulcificado en torno a la figura de Magallanes, donde se da importancia a características como la valentía o la determinación para seguir adelante con su gesta aun en las situaciones más complicadas, o la misericordia que muestra en momentos como el de la tradición de los cuatro capitanes de los otros navíos (p. 10). Un reflejo de sus valores éticos es la redacción de su testamento; donde hablan "primero, el cristiano; luego, el hidalgo; y sólo [sic] al final, el marido y el padre" (Zweig, p. 96). Es destacable su fe en los valores cristianos y su devoción al rey de España, algo que le lleva a demostrar un afán evangelizador por todas las tierras que atraviesa (Pigafetta, pp. 11, 20, 23, 28, 30) (Zweig, pp. 108, 160).

En cuanto a la muerte prematura y trágica, no hay duda en Magallanes. El 27 de abril de 1521, cuando ya había encontrado el paso anhelado y poco antes de regresar a España, Magallanes es abatido por un grupo de indígenas en la batalla de Mactán. Pigafetta (p. 31) hace hincapié en que "A no haber sido por ese pobre capitán, ninguno de nosotros se habría salvado en las lanchas; porque, gracias a su ardor en el combate, fue como las pudimos alcanzar". Zweig (p. 172) relata también una batalla desigual que acabó con la vida de Magallanes. Sin embargo, llama la atención que ninguno ahonda en el comportamiento de él en la batalla, como sí hacen otros autores muy posteriores, como Mollá (2017), que describe en su obra novelizada el momento de la muerte de Magallanes y le atribuye valores notables. Por ejemplo, cuando se siente ya preso de la muerte, llama a Santander y le ordena volver a los botes para que salven sus vidas.

hincó la rodilla en tierra, se apoyó en su espada y con el agua a la altura de la herida en el muslo pareció ponerse en paz con Dios, aunque aún tuvo tiempo de levantar la cabeza con energía para volver a dirigirse a Juan.

--Id con Dios, Santander. Regresad a España y contad que morí defendiendo a mi rey. Os habéis portado como un buen soldado (p. 232). 
Zweig relata cómo el final de Magallanes se da en el "momento más alto y magnífico de sus realizaciones" (p. 172), dando a entender así que se trata de un momento prematuro para el capitán general. "Pero tan torpe desdicha sólo [sic] puede quitarle la vida, no la victoria; porque, estando ya coronada su empresa, después de un logro tan por encima de los demás, su destino individual es casi indiferente" (Zweig, p.172).

La última variable de este bloque es la de que los héroes son personajes paradigmáticos, esto es, sirven de ejemplo a la comunidad. Cuando muere Magallanes Zweig lo describe como: "Y así quitaron la vida al que era nuestro espejo, nuestro consolador y fiel caudillo" (p.172). Igualmente, Pigafetta (p. 31) utiliza el símil del espejo para indicar que Magallanes era un ejemplo para todos: "nuestro espejo, nuestra luz, nuestro reconforto y nuestro guía inimitable". En ambos casos se destaca el papel de guía que ejercía Magallanes respecto al grupo.

En cuanto a la travesía del héroe, la tabla arroja también datos bastante contundentes, aunque en ciertos momentos desigual en ambos volúmenes. En cuanto al mundo ordinario, aquel en el que se desarrolla la partida, la subetapa de la llamada a la aventura se ve reflejada más ampliamente en el libro de Zweig, donde se vincula la idea de Magallanes de circunvalar el mundo con una relación epistolar que este mantiene con el capital portugués Francisco Serrano, que desertó en una isla perdida de las Molucas (pp. 41-42)

el epicúreo renunciamiento de aquel capitán sin lustre ejerció la más decisiva influencia en la forma de vida de Magallanes y, de rechazo, en el curso histórico del descubrimiento del mundo (...) Después de la muerte de Serrao, se encontró entre sus papeles una carta de Magallanes en la que éste [sic] promete confidencialmente al amigo que irá pronto a Ternate, $<$ si no desde Portugal, por otro derrotero $>$. Y la idea que alimentó Magallanes toda su vida fue precisamente concretar este otro camino.

El libro de Pigafetta comienza contando el autor de forma autobiográfica lo que le lleva a embarcarse con Magallanes, pero no da 
cuenta de la motivación de su capitán general para dar la vuelta al mundo. Sin embargo, casi al final del volumen, en la página 43, se dice literalmente "Serrano fue un gran amigo y pariente de nuestro inolvidable capitán general, y verdadera causa de que se decidiera éste [sic] a su empresa".

En cuanto al rechazo de la llamada, ambos volúmenes recogen esta negativa de una forma externa al propio Magallanes, más acorde con la definición de Vogler que lo considera un obstáculo ajeno al héroe. Así lo expone Zweig (p.50) "En el momento de salir como un mendigo rechazado del palacio de su rey, está convencido de que no es hora de esperar ni de vacilar", en relación a la negativa del rey de Portugal de apoyar su empresa. Se suceden otras negativas como la de la Casa de Contratación (p. 63) en Sevilla o La Casa de Indias (p. 64).

Igualmente, Pigafetta recoge en su libro estos hechos mucho después incluso de que Magallanes hubiese muerto (p. 43): "Don Manuel, rey de Portugal a la sazón, negose a argumentar, como proponía nuestro capitán general para sus beneméritos”.

En referencia al encuentro con el mentor, Pigafetta consigna apenas una frase para referirse al apoyo del rey de España, mucho más receptivo que el de Portugal (p. 43): “... por lo que hubo de pasar a España éste [sic] obteniendo de la Sacra Majestad todo cuando supo pedir". Por su parte, Zweig entra en más detalles, añadiendo al rey de España, Juan de Aranda (p.64) y Cristóbal de Haro (p.70). Del rey de España se dice (p.71) 'Y el 22 de marzo de 1518, Carlos V (...) firma de su puño y letra la <Capitulación>, o sea el compromiso con Magallanes y Ruy Faleiro".

La última etapa de este periodo es la del cruce del umbral, aquella que se ha identificado con el inicio del viaje, es decir, el paso del mundo ordinario a ese mundo desconocido. En ambos casos coinciden en el tiempo: ese día en el que finalmente consiguen zarpar las cinco naves que había compuesto Magallanes para la gesta. Los dos hablan de Sevilla como inicio de la travesía que desciende hacia Sanlúcar. 
Finalmente, ambos hablan de una fecha concreta para definitivamente salir a la mar. En el caso de Pigafetta (p. 3) dice que por fin "El martes 20 de septiembre del mismo año partimos de ese lugar llamado San Lúcar, enfilando hacia el Sudoeste, y, antes de terminar el mes, el 26, arribamos a una isla de la Gran Canaria”. Y Zweig apunta que (p.98)

A la luz del amanecer -es un martes, 20 de septiembre de 1519, fecha memorable en la Historia del mundo- retiñen las áncoras, trepidan las velas y retruenan los cañones, mientras la tierra se va perdiendo de vista: el más extenso viaje de descubrimiento, la aventura más atrevida en la Historia de la Humanidad, ha empezado.

En cuanto al mundo extraordinario, el de la iniciación, es el de la aventura misma y tal vez al que más líneas le dedican ambos autores. En cuanto al camino de las pruebas, para Pigafetta se centra en un periodo no demasiado extenso antes de la apoteosis. Se enmarca, por tanto, entre las páginas 3 y 11 de su volumen y en ella se describen animales y tribus exóticas. Se habla de tiburones (p. 4), de tribus con jóvenes que se clavan clavos en la boca (p. 7), caníbales (p. 7), lobos marinos (p. 7), gigantes que son retenidos por Magallanes y su tripulación (p. 9), la posible traición de los cuatro capitanes de los otros navíos (p. 10) o la necesidad de evangelización (p. 11).

Para Zweig va de la página 99 a la 127 y narra toda la suerte de problemas con los que se va encontrando Magallanes hasta que consigue su objetivo. Por ejemplo, en la página 99 su suegro le advierte por carta de una posible conjura contra él: "Barbosa previene a su yerno de que tiene informes seguros de un plan secreto de los capitanes españoles que lleva a bordo, los cuales intentan negar la obediencia a Magallanes durante la travesía” (p.105), como así sucede. Es frecuente encontrar en estos volúmenes y en otros consultados referencia a la animadversión hacia Magallanes por parte del resto de la tripulación, que podría haber ocasionado los diversos levantamientos como cuando se relata en la página 121 la caída del San Antonio y posteriormente el juicio a los rebeldes (p. 126-127): “A fin de manifestar su autoridad con un enérgico escarmiento, Magallanes se decide a sacrificar a uno sólo [sic], y elige al único que se había puesto a la cabeza del motín con el 
acero desnudo: el capitán Gaspar Quesada". También se habla de Juan de Cartagena y un sacerdote que también fueron hallados culpables (p. 127) y que fueron dejados en la playa de San Julián con víveres para algún tiempo.

Tras el juicio a los rebeldes en el Puerto de San Julián la flota pasa cinco meses sitiada por el invierno. Allí conocen a indígenas de pies grandes (patagao) y llaman a su tierra Patagonia (p.130) y sufren todo tipo de desgracias (p.131).

Igualmente, hay referencias en el libro de Zweig a cabos que no son el buscado en la ruta a las Molucas, como sucede en la página 109-110 donde se comenta que el supuesto cabo es en realidad la desembocadura del Río de la Plata. "Ninguno de los capitanes, nadie de la tripulación, ha de darse cuenta del golpe mortal que sufre con esta desilusión su íntimo convencimiento [Magallanes]" y continúa:

¡Engañosas las informaciones sobre las cuales él había asentado su plan de la vuelta al mundo, erróneos todos los cálculos de Faleiro, falsas sus propias opiniones, falso lo que había prometido al rey de España y a sus consejeros! Si el paso existe -y por primera vez el hasta entonces archiconvencido hace esta reserva- ha de estar más hacia el Sur.

Posteriormente, en la exploración de la bahía el Santiago se estrella contra la costa en una tormenta. Cuando finalmente abandonan la bahía de San Julián, el balance es desastroso: un barco menos, baja de tres capitanes y un año de travesía perdido sin alcanzar su objetivo "Aquellos días debieron ser en la vida de Magallanes los más sombríos, tal vez los únicos en que el hombre de fe inquebrantable se desesperó, sin darlo a entender" (p. 132).

En referencia a los desvíos del camino, esa etapa justo antes de alcanzar la apoteosis, la relata Pigafetta en la página 11, en los episodios en los que se centra en el Cabo de las Once Mil Vírgenes y en la dificultad de navegar aquel estrecho, destacando la valentía del capitán general. Igualmente hay un momento de reencuentro con dos naves que parecen perdidas y el odio de Estebao Gomes hacia Magallanes, que se 
acrecienta en este momento. Para Zweig los hechos son los mismos: el mismo cabo, donde se divide la flota para explorar la zona en octubre de 1520. Tras agónicos días de espera vuelven ambos barcos con la noticia de que el canal tenía salida a aguas amplias y saladas que no podían ser un río (p.136). En este punto, Magallanes reúne por primera vez a sus capitanes para oír sus opiniones y es Estevao Gomes el único que propone regresar a España. No obstante, Magallanes da la orden de seguir ocultando a las tripulaciones la falta de víveres y continuar con la travesía (p.142).

En cuanto a la apoteosis, el momento crucial en el que el héroe consigue su anhelo, se relata con bastantes elementos comunes en ambos volúmenes. La nao San Antonio y la Concepción son enviadas a explorar el Canal del Sur y un bote es enviado a explorar el resto del canal hacia el oeste. Tras tres días, se descubre la salida al "desconocido gran Mar del Sur" (Zweig, p.143).

En el caso de Pigafetta (p. 12) comenta que "El capitán general lloró de alegría, designando a aquél [sic] "Cabo Deseado", porque lo deseamos todos tanto tiempo". En el caso de Zweig también está presente el llanto (p. 143, 144): "Este minuto es el momento cumbre de la vida de Magallanes (...) Todo se ha cumplido (...) Justificada y digna de la inmortalidad es su vida desde este momento (...) "Una corriente de lágrimas cálidas, abrasadoras, cae de sus ojos y se esconde en el oscuro matorral de sus barbas. La primera y la única vez en su vida que el hombre de acero derrama lágrimas de felicidad".

Tras ese momento crucial surge la última etapa del mundo extraordinario: la gracia última o recompensa. No se ven indicios en la obra de Pigafetta de dicha recompensa final de Magallanes; sin embargo, Zweig en las últimas páginas de su volumen reflexiona sobre el carácter heroico de la gesta:

En la Historia, nunca la utilidad práctica determina el valor moral de una conquista. Solo enriquece a la Humanidad quien acrecienta el saber en lo que le rodea y eleva su capacidad creadora. En este sentido, la hazaña de Magallanes supera a todas las de su tiempo y significa para nosotros una gloria 
singular en medio de sus glorias: la de no haber inmolado, como ocurre la mayor parte de las veces, la vida de miles y centenares de miles por una idea, sino solamente la propia vida (...) Por la gracia de tal heroísmo perdurará la proeza magnífica de esos cinco endebles y solitarios barcos que salieron para la guerra santa de la Humanidad contra lo ignoto; e inolvidable será también el nombre del primero que defendió la idea osada de la vuelta al mundo hasta la última de sus naves (p.202).

Comienza ahora la última parte del viaje: el regreso. La negativa al regreso es la primera subetapa, de la cual Pigafetta no da cuenta. Sin embargo, en Zweig sí se presenta este dilema para el héroe tras perder dos naves, recuperar una de ellas y creer que la otra ha desertado (p.145). Magallanes tiene entonces que afrontar una decisión urgente: "El avance hacia el ignoto Mar del Sur, que hace ocho días, bajo mejores auspicios, era ya una temeridad, ahora, desde la huida del San Antonio, es casi un suicidio" (p.146). Decide seguir adelante; Zweig relata este episodio de forma bastante literaria: "el 28 de noviembre, levar anclas e izar banderas: y los tres barcos humildes, solos, saludan, respetuosos, con descargas de artillería al mar desconocido, como se hace, caballerescamente, con un adversario de talla a quien se ha retado a un combate a vida o muerte" (p.148).

La huida mágica es esa etapa compleja del regreso que constituye una barrera de obstáculos que pretenden que el héroe no regrese. Magallanes encontrará aquí el final de sus días. Pigafetta (p. 31) recoge de qué manera el 27 de abril de 1521 en la batalla de Mactán del archipiélago de San Lázaro, Magallanes encuentra la muerte a manos de unos indígenas que no quisieron reconocer la autoridad del rey de España: "Llovieron sobre él, al punto, las lanzas de hierro y de caña, los terciarazos también". Zweig recalca la manera en que este hecho no resta ni un ápice de valor a la gesta de Magallanes: "De este modo insensato acaba, en el momento más alto y magnífico de sus realizaciones, el navegante más grande de la Historia, en una miserable escaramuza contra una horda de isleños desnudos" (p. 172).

A partir de este momento, se dividen las dos naves, el Trinidad, la nave capitana en muy malas condiciones, que habría de volver a España y 
“atravesar de regreso el Océano Pacífico para alcanzar por Panamá la España ultramarina, mientras el Victoria, a favor de los vientos favorables, hace rumbo de regreso por Occidente, a través del Océano Índico" (Zweig, p.184).

El cruce del umbral se produce cuando la nao Trinidad, capitaneada por Juan Sebastián Elcano, que curiosamente no se nombra en el volumen de Pigafetta, vuelve a Sanlúcar tres años después de su partida. "En este 6 de septiembre del año 1522 fue coronado el hecho más grande de la navegación", comenta S. Zweig (p.191). Y sigue Pigafetta (p. 60): "no éramos ya más que dieciocho, la mayor parte enfermos. El resto que partimos de Maluco... quien murió de hambre, quién evadiose de la isla de Timor, quiénes fueron ejecutados por sus delitos". "A la mañana siguiente, un remolcador arrastra al vencedor, al Victoria, Guadalquivir arriba, hacia Sevilla” (Zweig, p.192).

La resurrección en el caso de Magallanes es un proceso algo complejo puesto que a la vuelta de la expedición no parecía haber mucho empeño en hacer perdurar su liderazgo. Zweig (p.197) dice que "Ya el fiel Pigafetta parecía desconcertarse al ver que Magallanes era relegado sistemáticamente a último término" a pesar de que "Con alas de fuego rueda, entre tanto, la noticia de su feliz arribo, y despierta en toda Europa, primero, la atención de todos, y luego la admiración sin límites" (p. 193). Y es que el carácter de Magallanes, un hombre oscuro, definido por Zweig (p. 47) como "aquel hombre tostado, pequeño, borroso y reservado no poseyó ni un gramo siquiera del don de gentes (...) No sabía sonreír ni ser amable ni complaciente, como tampoco dar cuerpo a sus ideas en la conversación. Nada afable ni comunicativo, siempre envuelto en una nube misteriosa, el solitario eterno debía crear a su alrededor una atmósfera glacial, de incomodidad y de recelo, pues pocos llegaron a tratarle y ninguno conoció su íntimo sentir".

Sin embargo, la gloria de Magallanes llegó y "Esto es lo único que le fue concedido a Magallanes, el hecho, mas no su áurea sombra: el triunfo y la gloria temporal" (Zweig, p. 199). De hecho, fue una de las labores de Pigafetta, que decía "Y se verá la verdad de esto abiertamente, ya que ninguno se ingenió ni se atrevió hasta conseguir dar una vuelta a ese mundo según él ya casi la había dado”. 
El retorno con el elixir, ese punto en el que el héroe comparte su hallazgo con la comunidad y sale por fin de su aislamiento definitivo para quedar fijado en la memoria colectiva, es algo impulsado por los seguidores de Magallanes, el primero de los cuales es Pigafetta (p. 60): "Partiendo de Sevilla, pasé a Valladolid, donde presenté a la sacra Majestad de Don Carlos no oro ni plata, sino cosas para obtener mucho aprecio de tamaño señor. Entre las otras, le di un libro, escrito por mi mano, con todas las cosas pasadas, día a día, en nuestro viaje". Convierte de esta forma Pigafetta su escrito en el punto de partida de la construcción del héroe de Magallanes al dar cuenta de su gesta puntualmente. Zweig enaltece también su figura (p. 194) diciendo "Por fin, la cosmografía de griegos y romanos ha sido superada, y vencida la oposición de la Iglesia, y la fábula ingenua de los antípodas que andan cabeza abajo. Ha quedado fijada para todos los tiempos la medida de la órbita de la Tierra (...) La Tierra tiene puestos sus lindes y la Humanidad disfruta de su conquista (...) Bajo el pabellón español empezó Colón el descubrimiento del mundo, y bajo el mismo pabellón lo ha completado Magallanes".

\section{Conclusiones}

La figura de Magallanes sigue siendo hoy en día una figura rodeada de polémica. Algunos autores lo consideran un tirano, otros un traidor, otros un visionario, pero muchos más un héroe (Bergreen, 2006). A través de este estudio se ha comprobado cómo se ha llevado a cabo de forma eficaz la construcción del héroe tanto desde el punto de vista de los elementos morfológicos y funcionales como aquellos que tienen que ver con la propia travesía. Ambas obras contienen en su interior elementos suficientes para enaltecer a la persona de Magallanes dejando de lado su oscuro lado personal, del que poco o nada se comenta - hasta el punto de convertirlo en el héroe mundial que es hoy en día.

Pigafetta da con su obra el pistoletazo de salida a la construcción de un héroe propio del Renacimiento: la persona anónima que, gracias a su acción transgresora por una causa para el progreso de la humanidad, da su vida por algo más grande que él y se convierte en paradigma. Es 
un héroe del aquí y el ahora que pasa a formar parte del imaginario colectivo del mismo modo que los héroes ancestrales.

Ambas obras son, a su vez, testimonio de su tiempo, tan dispares entre ellas. Pigafetta da testimonio de primera mano y, sin embargo, su obra está más cerca de los mitos ancestrales, que hacen hincapié en las acciones y su valor simbólico. Zweig escribe su obra a partir de fuentes secundarias y redacta un texto documentado y profundo, propio del siglo XX, donde el lenguaje y su idea sobre Magallanes enaltecen la gesta que, sin duda, bien lo merece porque supone un cambio radical en la forma de ver el mundo.

\section{Referencias bibliográficas}

R Barthes (1990). La aventura semiológica. Barcelona, Paidós

R Barthes (1999). Mitologias. Madrid, Siglo veintiuno.

HF Bauzá (2007). El mito del héroe. Morfología y semántica de la figura heroica. México, Fondo de Cultura Económica.

L Bergreen (2006). Magallanes: hasta los confines de la tierra. Madrid, Planeta.

JC Bermejo Barrera (1989). Zeus, Hera y el matrimonio sagrado. Quaderni di storia, 30, 133-156.

JC Bermejo Barrera (1988). Grecia. El mito griego y sus interpretaciones. Madrid, Akal.

J Campbell (2013). El héroe de las mil caras. Madrid, Fondo de Cultura Económica.

J Campbell (1991). Elpoder del mito. Barcelona, Emecé.

G Castillo Ceballos (2013). La forja del héroe. Madrid, Rialp.

E Cassirer (1979). Filosofía de las formas simbólicas. México, FCE.

L Cencillo (1998). Los mitos. Sus mundos y su verdad. Madrid, Biblioteca de autores cristianos.

L Duch (1998). Mito, interpretación y cultura. Barcelona, Herder.

G Durand (1993). De la mitocrítica al mitoanálisis. Barcelona: Anthropos. M Eliade (1999). Mito y realidad. Barcelona, Kairós.

A Huici (1998). El mito clásico en la obra de Jorge Luis Borges. El Laberinto. Sevilla: Alfar.

CG Jung (2002). Los arquetipos y el inconsciente colectivo. Madrid, Trotta. K Kerenyi (2009). Los héroes griegos. Girona, Atalanta. 
L Kolakowski (1990). La presencia del mito. Madrid: Cátedra.

C Lévi-Strauss (1987). Antropología estructural. Buenos Aires, Eudeba.

C Lévi-Strauss (1987). Mito y significado. Madrid: Alianza.

M Martínez (2006). Mito, cine, literatura. Laberinto y caos en El tercer hombre. Sevilla, Alfar.

L Mollá (2017). La flota de las especies. Córdoba, Almuzara.

JM Núñez de la Fuente (2017). Diario de Magallanes: el hombre que lo vio y lo anduvo todo. Madrid, Doce Calles.

A Pigafetta (2012). Relación del primer viaje alrededor del mundo. Barcelona, Ed. Juventud.

V Propp (2001). Morfología del cuento. Madrid, Akal.

O Rank (1981). El mito del nacimiento del héroe. Barcelona, Paidós.

E Rosales (1996). El mito. Sevilla: Cuadernos Arbolays.

RA Segal (2004). Myth. A very short introduction. Estados Unidos:

Oxford University Press.

C Vogler (2001). El viaje del escritor. Las estructuras míticas para escritores, guionistas, dramaturgos y novelistas. Madrid, Ma Non Troppo.

S Zweig (2015). Magallanes. El hombre y su gesta. Barcelona, Debate. 


\title{
Cartografía, geometría y comunicación: cómo narrar la forma del mundo a partir del viaje de Magallanes y Elcano
}

Enrique Martínez Jiménez Universidad Loyola Andalucía, ULA emartinez@uloyola.es

Alejandro Tapia Frade Universidad Loyola Andalucía, ULA ajtapia@uloyola.es

Francisco Montes Tubío Universidad de Córdoba, UCO ir1motuf@,uco.es

Cómo citar: E Martínez Jiménez, A Tapia Frade, F Montes Tubío (2019): "Cartografía, geometría y comunicación: cómo narrar la forma del mundo a partir del viaje de Magallanes y ElCano". Revista Latina de Comunicación Social, En P Herrero-Diz/A Cárcamo/V Rodríguez Breijo/R Mancinas (Eds.) V Centenario / $1^{a}$ Vuelta al Mundo. Cuadernos Artesanos de Comunicación, cac161, pp 49-70. La Laguna (Tenerife): Latina. DOI: $10.4185 / \operatorname{cac} 161$

\begin{abstract}
s
Introducción: El análisis de los mapas en torno a la primera travesía alrededor del mundo es, sin duda, fundamental para explicar el conocimiento de la nueva tierra descubierta. Dicho mapa supone de hecho una de las grandes manifestaciones de comunicación visual de la época. Metodología: Con tal motivo, esta investigación trata de realizar un análisis de los mapamundis del siglo XVI relacionados con el viaje de circunnavegación de Magallanes y Elcano y producidos por los cartógrafos de la Casa de Contratación de Sevilla, prestando especial atención a la diferencia entre mapas previos y posteriores a dicho viaje.
\end{abstract}


Se usa como técnica el análisis de contenido. Resultados y conclusiones: Las diferencias entre mapas afloran en otros elementos relacionados con el contexto como la presencia de títulos y fechas de producción insertos en los mapas, y en los semióticos de tipo ordinal. No obstante, ha de advertirse que este análisis no contempla ni el trazo de los mapas ni lo fidedigno de su representación.

\title{
Keywords
}

Cartografía; vuelta al mundo; comunicación; geografía; semiótica.

\section{Contents}

1. Introducción. 2 Método. 2.1. Estrategias metodológicas. 2.2. Población y muestra. 2.3. Instrumentos de recogida de información. 2.4 Procedimiento. 3. Resultados. 4. Discusión y conclusiones. 5. Referencias bibliográficas.

\section{Introducción}

"Los padres sensatos dan a sus hijos raices y alas; $y$ también un mapa". Proverbio chino a partir de Miranda Bonilla, López Lara \& Canto Ruiz (2010).

\begin{abstract}
A FINALES del siglo XV, la imagen del mundo conocido sufre 1 una transformación radical bajo iniciativa exclusiva de los reinos ibéricos. En apenas treinta años tienen lugar el descubrimiento de América en el primer viaje de Colón (1492), la llegada de Vasco da Gama a la India (1497-1499) y el primer viaje de circunnavegación terrestre de Magallanes y Elcano (1519-1522).

La travesía alrededor del mundo devolverá, después de tres años de viaje, a solo 18 marineros en una nave de los 250 hombres y cinco barcos que inician la travesía, dejando en el camino a su propio promotor, Fernando de Magallanes, muerto en batalla en la isla de Mactán, en Filipinas. Entre los supervivientes se encuentra Antonio Pigafetta, que consciente de la importancia de la empresa redactó el diario oficial del viaje "Relación del primer viaje alrededor del Mundo"
\end{abstract}


(Pigafetta, 1800) al que acompañó de algunos mapas representando, entre otros espacios, el estrecho de Magallanes y las islas Molucas.

El objetivo inicial de encontrar una nueva ruta a las Islas Molucas para el comercio de las especias evitando el monopolio portugués será ampliamente superado por logros científicos resultado de la propia travesía, como la confirmación de la dimensión terrestre y de la conectividad de todos los océanos, o como el descubrimiento de nuevas constelaciones, recursos, etnias y territorios. El viaje de Magallanes y Elcano representa la consolidación de la navegación científica y es considerado una de las empresas de exploración más relevantes de la historia (Olmedo Granados, 2015; Sánchez Sorondo, 2006; Zweig, 2015).

La gesta de la circunnavegación terrestre solo sería posible con el apoyo de la cartografía como guía de viaje hasta los límites de la tierra conocida; a partir de esos límites la toma de datos astronómicos y topográficos y la creación sistemática de nuevos mapas, siguiendo un método científico, asegurarán que el nuevo conocimiento logrado fuera provechoso para los reinos promotores y para todos los navegantes posteriores.

La representación del mundo durante los siglos XIV y XV se materializa principalmente en los instrumentos básicos de la navegación, las llamadas cartas náuticas o portulanos, ya nacidas en el siglo XIII. Se trata de mapas de proyección plana orientados al norte magnético que representan, en su mayoría, las costas del Mediterráneo y en el que se sitúan los principales puertos existentes para irradiar desde ellos multitud de líneas siguiendo las direcciones de la rosa de los vientos representada en la misma carta (Sellés, 2007). Su principal característica es que se trata de representaciones topográficas, es decir basadas en una plasmación de datos de la realidad al papel considerando la Tierra como plana. La revolución que supone el descubrimiento de Cristóbal Colón, con el impulso de la llamada 'navegación de altura', provocará la necesidad de abordar el reto geométrico de proyectar la esfera terrestre sobre un plano.

Asimismo, es destacable el redescubrimiento, a mediados del siglo XV, de la obra geográfica de Claudio Ptolomeo (siglo II), que gracias al apoyo de la imprenta alcanzará una amplia difusión revolucionando el 
interés por la representación y el conocimiento de la Tierra. Como resultado, se realizan a partir de ese siglo los primeros atlas mundiales basados en sistemas de coordenadas de latitud y longitud que recogerán datos cada vez más abundantes gracias al progreso de las exploraciones marítimas y terrestres.

El desarrollo de la exploración del "Nuevo Mundo" obligará a superar la visión ptolemaica aceptando la existencia de un nuevo continente cuya representación se irá afinando progresivamente. El primer intento de representación de los territorios descubiertos es obra de Juan de la Cosa, cartógrafo que acompaña a las expediciones de Colón. Pronto se empezará a especular con la posibilidad de que las tierras descubiertas representan un nuevo continente. Será en 1507 cuando el editor alemán Martin Waldseemüller lo nombra en su mapamundi con el nombre de Américo Vespucio, cuyas obras estaba traduciendo, según la costumbre latinizado y con género femenino. Finalmente será Gerardus Mercator, el cartógrafo que desarrolla un innovador sistema de proyección para corregir las deficiencias de los portulanos y que dará paso a las llamadas cartas esféricas, quién tomará esa referencia inicial como norma popularizando el término de "América" en perjuicio de la figura de Cristóbal Colón.

Es evidente que en este contexto los avances científicos en campos como la astronomía, topografía, navegación y cartografía aportan una ventaja estratégica a los reinos que los dominen. Los mismos Reyes Católicos prevén la importancia del registro y visualización de los nuevos territorios en mapas como fuentes de información que mejoren la toma de decisiones políticas (Gómez Martín, 2015; Martín-Merás, 2000). Por esta razón, dotan desde su inicio a la Casa de Contratación de Sevilla, fundada en 1503, con la competencia de formación de cosmógrafos, cartógrafos y pilotos bajo la dirección del Piloto Mayor. El cartógrafo Américo Vespucio será el primero de ellos y recibirá la misión de confeccionar el denominado Padrón Real, un modelo de carta de navegación que quedaría en Sevilla para ser actualizado con la información resultante de cada exploración marítima una vez fuera contrastada. Esta institución sevillana dará a luz en las épocas posteriores de Carlos I y Felipe II a grandes cosmógrafos como Juan Vespucio, Diego de Ribero o Alonso de Santa Cruz, que dejarán obras notables para la historia de la cartografía universal. 
La cartografía es una ciencia que va más allá de su uso instrumental, los mapas no son solo un contenedor de información para su mejor visualización, sino también auténticos medios de comunicación y de difusión de ideas. Kolicny (1969) planteó de forma pionera que la información contenida y el uso del mapa deben tratarse como un todo desde su construcción, ya que los mapas no son solo un soporte de datos sino un medio de comunicación de los mismos. La cartografía, como ciencia, representa y describe fenómenos espaciales de manera simbólica con lo que acaba modelando la propia realidad descrita.

Aplicado a la época de los descubrimientos, los mapas no solo registran los espacios descubiertos sino que los crean a través de su representación (Bryan, 2009; Crampton, 2010), siendo esta característica la que dará lugar a la estrecha relación que se fraguará entre cartografía y colonialismo. Harley (1990) señala como ejemplo la labor de toma de posesión de las tierras descubiertas y la conversión al catolicismo de sus habitantes que Cristóbal Colón realiza en nombre de los reyes Isabel y Fernando. Colón renombra las islas y los lugares que poseen denominación indígena con nombres cristianos como "San Salvador", "Santa María de la Concepción" o "Trinidad". Su trabajo plasmado en mapas, como el mapamundi de Juan de la Cosa, es tan exitoso que son escasísimos los elementos geográficos americanos que han llegado hasta nuestros días con sus nombres indígenas originales. La cartografía confeccionada sirve como documento para el conocimiento y registro de información, pero también como herramienta de poder del imperio español sobre los nuevos territorios. De manera similar puede considerarse el caso, comentado anteriormente, del bautismo y nacimiento del continente americano gracias a las obras cartográficas de Waldseemüller y Mercator.

De hecho, se ha considerado a la cartografía de la época como elemento nuclear para describir y explicar la preeminencia económica, política y científica de España y Portugal en la época (Sánchez Martínez, 2009). Y específicamente de la semiótica de la cartografía para la comprensión de territorios (Nates Cruz y Raymond, 2006) y para la comunicabilidad del producto, modelo o imagen cartográfica (Azocar Fernández, 2017:71-72), aunque también se ha advertido de la inaccesibilidad al lector medio de la semiótica cartográfica actual (Lois, 2000). 
La empresa de Magallanes toma como fuentes los mapas más precisos de su época elaborados en la Casa de la Contratación de Sevilla para el Padrón Real. En el inventario de instrumentación científica relatado por Pigafetta en su diario (1800) se señalan " 23 cartas de marear hechas por Nuño García". Nuño García de Toreno fue Piloto Mayor de la Casa de Contratación en el periodo 1519- 1527 compartiendo su cargo con Juan Vespucio por lo que es normal que fuera su trabajo la documentación oficial de la que se surtiera la expedición.

Interesa en este artículo no solo el estudio de los mapas previos al viaje de circunnavegación terrestre y que sirvieron de fuente de información para el mismo, sino también el de la cartografía confeccionada posteriormente por la propia Casa de Contratación de Sevilla con las actualizaciones de los hallazgos realizados durante su travesía. La selección realizada se ha realizado atendiendo a los siguientes criterios: Obras confeccionadas por la Casa de Contratación de Sevilla o por los cosmógrafos formados en la misma. Obras que sean mapamundis, o representaciones completas de la Tierra. Obras que sirvieran para la preparación de la expedición magallánica o que plasmaran directamente informaciones recabadas en la misma.

El primer mapamundi seleccionado es el primer mapa del Nuevo Mundo realizado por Juan de la Cosa, cartógrafo de varias expediciones colombinas. Su mapa, datado en torno al 1500, es realizado para dar cuenta a los Reyes Católicos de los hallazgos de Colón y se convierte en el prototipo inicial de toda la producción de la Casa de la Contratación (Martín-Merás, 2000). De la Cosa, representa en su mapa los nuevos nombres ideados por Colón para los enclaves e islas descubiertos. Asimismo, incluye numerosos elementos de carácter semiótico que tiene un papel destacado en el objetivo comunicativo del mapa: la figura de San Cristóbal, portador de Cristo niño en sus brazos, situado en el eje de simetría del mapa; las banderas nacionales españolas e inglesas, aliados en ese momento; la representación en paralelo de otros descubrimientos portugueses y españoles, etc. Tras su pérdida y un periplo internacional azaroso la carta fue recuperada por el Ministerio de Marina encontrándose actualmente en el Museo Naval de Madrid.

Magallanes preparó su partida en Sevilla con sus compatriotas Pedro Reinel y su hijo Jorge y con Diego Ribero, encargados de la confección 
del Padrón Real en la Casa de Contratación; por tanto, contaba con los datos más recientes y fiables para la realización de su empresa (Olmedo Granados, 2015). Estos cosmógrafos son los autores de los siguientes mapas seleccionados:

El mapa de Jorge Reinel de 1519, fue probablemente realizado en Sevilla. Representa el recién descubierto por Núñez de Balboa Mar del Sur y un ficticio paso hacia el mismo que parece coincidir con el Río de la Plata. A poca distancia en ese mar aparecen las islas de las especias, las Molucas, error de distancia que constituyo una de las grandes penalidades de la expedición magallánica. Esta carta se encuentra en la actualidad en la Biblioteca Nacional de Francia, en París.

El mapamundi del Atlas Miller (1519) es una obra iluminada de cuidada realización destinada al monarca Manuel I de Portugal. Se identifica como autor al cartógrafo Lopo Homem, si bien se cree que también intervinieron en su realización Pedro y Jorge Reinel. Representa una gran proporción de masa terrestre frente a la de los océanos. El Nuevo Mundo se conecta con las Indias orientales si bien muestra un canal o posible paso al sur de Brasil. También se encuentra en posesión de la Biblioteca Nacional de Francia.

Hasta aquí los mapas que fueron fuente de información para la expedición de Magallanes. En los siguientes destacarán su precisión y carácter científico, posible gracias a la recogida de nuevos datos a lo largo de todo el globo terrestre tras su viaje.

El siguiente mapa seleccionado es el Planisferio de Castiglioni, realizado en Sevilla en 1525 por Diego Ribero, cosmógrafo de origen portugués y al servicio de la Casa de Contratación (Vigneras, 1962). Contiene de manera precisa los primeros hallazgos registrados a raíz de la primera vuelta al mundo. El espacio marítimo entre América y las Molucas se prolonga alcanzando sus dimensiones reales y se dibuja el estrecho de Magallanes. Se nombran tres océanos, correspondientes al Atlántico, Índico y Pacífico y se adorna con instrumentos astronómicos y de navegación que permitieron la gesta de Magallanes y Elcano como el quadrante, el astrolabio o el círculo solar. Este mapa se alberga en la Biblioteca Universitaria Estense de Módena.

El "Mapa del mundo conocido" es un mapa portulano de Juan Vespucio, hijo de Américo, realizado en 1526. Se trata de una copia 
decorada del Padrón Real en la que destaca el escudo de armas del imperio germánico de Carlos $\mathrm{V}$ coronando América y banderas de Castilla y León y banderas portuguesas marcando los territorios de cada reino en base al meridiano de Tordesillas. Posee dos rosas de los vientos y diversas naves, edificaciones y animales decorando la tierra y los océanos. Incorpora los descubrimientos del estrecho de Magallanes (1520), la ciudad de México-Tenochtitlán (1521) y la expedición de Ayllón hasta la Carolina del Sur (1521). El documento original se encuentra en poder de la Hispanic Society de Nueva York (Instituto Geográfico Nacional - Servicio de Documentación, n.d.).

Como indica su título, la "Carta universal en que se contiene todo lo que del mundo se ha descubierto fasta agora. Hizola Diego Ribero cosmographo de su magestad, ano de 1529, e[n] Sevilla" contiene toda la información recogida por la crónica de Pigafetta. Al igual que la anterior de 1525, destacan las banderas de Castilla y León y de Portugal y decoraciones con rosas de los vientos, naves y fauna y edificaciones. Destaca especialmente la línea de división del mundo derivada del Tratado de Tordesillas. Una copia original regalada por el emperador Carlos V al Papa se encuentra en el Museo del Palacio de Propaganda Fide en Roma.

El mapamundi de proyección ovalada incluido en el atlas portulano de Battista Agnese es un encargo para conmemorar el viaje de MagallanesElcano realizado en Venecia en torno al 1544. En el mapa se detalla la ruta seguida por la exploración desde Sanlúcar de Barrameda hasta el estrecho de Magallanes, el Pacífico y las islas Molucas, y el viaje de retorno por el Índico y el Atlántico Sur. En torno al mapa, doce angelotes o cabezas de viento representan los doce puntos cardinales. Se custodia actualmente en la Biblioteca Real de Turín.

Finalmente, una obra principal del cosmógrafo sevillano Alonso de Santa Cruz realizada para la Casa de la Contratación, probablemente entre 1539 y 1560, el "Islario general de todas las islas del mundo". Se trata de un atlas iniciado en época de Carlos $\mathrm{V}$ y finalizado y dedicado finalmente a su hijo Felipe II, que contiene una descripción precisa de todo el mundo conocido hasta mediados del siglo XVI. Los mapas poseen escalas de leguas marítimas y latitud y longitud en grados, además de orientaciones con rosas de los vientos. Santa Cruz concluye su Islario con capítulos especiales de su parte cuarta, dedicada a 
América, a la descripción y representación del estrecho de Magallanes y de la ciudad de Tenochtitlán. Dos copias originales de la obra residen en la Biblioteca Nacional Española, otros manuscritos parciales se encuentran en la Biblioteca municipal de Besançon y en la Biblioteca Nacional de Viena (Cuesta Domingo, 2016).

Investigaciones recientes sobre los mapas de la época suelen concentrarse en los ensayos, los aciertos y los errores que los cartógrafos hicieron para diseñar las tierras nuevas, particularmente el continente americano (Lois, 2007). En tal sentido, la praxis cartográfica formó parte del proceso de construcción intelectual que hicieron los europeos para imaginarse el nuevo mundo, para darle "tangibilidad textual" (Craib, 2000).

No obstante, hemos de destacar la investigación realizada por Lois (2007) sobre la representación del océano atlántico en tales mapas, y donde destaca que la clausura del Atlántico es "una señal de la captura de la finitud del mundo experimentada en el siglo XVI".

También la de Padrón (2015) sobre la cartografía de Filipinas y las indias orientales en los mapas realizados hasta la primera mitad del siglo XVIII, que destaca, ante todo, el olvido consciente de tales territorios en la producción cartográfica de la época.

En relativa coincidencia con lo anterior, el objetivo fundamental de este trabajo pasa por realizar un análisis del valor comunicativo de los mapamundis del siglo XVI relacionados con el viaje de circunnavegación de Magallanes y Elcano y producidos por los cartógrafos de la Casa de Contratación de Sevilla, prestando especial atención a la diferencia entre mapas previos y posteriores a dicho viaje. El análisis se ofrece desde una doble perspectiva: la formal, que incluye elementos que deberían encontrarse en todos los mapas, elementos esenciales referentes a contexto, y finalmente, elementos que se usan selectivamente para ayudar a comunicar con mayor eficiencia. De otro, la semiótica cartográfica, que incluye el análisis de signos nominales, ordinales y de otro tipo que cargan de valor significante a los mapas. Por ello, se presentan las siguientes hipótesis de trabajo:

H1: Existen diferencias notables entre mapas anteriores y posteriores al viaje de la vuelta al mundo en lo relativo a 
elementos formales de los mapas, esenciales y accesorios que ayudan a comunicar con mayor eficacia.

H2: Existen diferencias notables entre mapas anteriores y posteriores al viaje de la vuelta al mundo en lo relativo a los elementos nominales y ordinales de la semiótica cartográfica.

\section{Método}

\subsection{Estrategias metodológicas}

Con objeto de analizar los mapas, ahondando particularmente en la diferencia de datar el mapa antes o después del viaje, se realizó una plantilla de análisis basada en las aportaciones de Bertín (1983), Board y Taylor (1985) y Cleveland y McGill (1985) respecto del diseño, percepción y semiología de mapas. El método de análisis de los mapas es el llamado análisis de contenido.

\subsection{Población y muestra}

La muestra consta de ocho mapas surgidos o relacionados con la Casa de Contratación sevillana, siendo el de Juan de la Cosa el más antiguo (aproximadamente de 1500), y que, junto al de Jorge Reinel y el llamado "Mapamundi de Lopo Homem", en el que participaron Pedro y Jorge Reinel y que datan de 1519, forman la muestra de mapas pre-viaje.

Se completa la muestra con varios mapas inmediatamente posteriores al viaje, en concreto el Planisferio de Castiglioni, una carta universal de Diego Ribero confeccionada en Sevilla en 1525, el Mapamundi de Sevilla Biblioteca Apostólica Vaticana, del mismo autor, pero realizado en 1529, y el aportado por Juan Vespucio, sobrino del célebre Américo que dio nombre al nuevo mundo, datado en 1526.

Finalmente, se analizan el mapamundi de un atlas portulano, trazado en Venecia por Battista Agnese hacia 1544, y el Islario general del cosmógrafo Alonso de Santa Cruz (1539-1560), que no es stricto sensu un mapa, sino una enciclopedia o colección de mapas explicados. Se han excluido de este análisis las ilustraciones que Pigafetta realizó durante el viaje, de las islas Molucas y del estrecho de Magallanes, entre otros, ya que se trata de cartografías parciales, no mapamundis, y 
además están realizadas casi en exclusiva con el propósito de registro de datos para su posterior traspaso a otros documentos.

En resumen, se analizan ocho mapas relacionados con la primera vuelta al mundo, de los que tres son anteriores y los cinco restantes posteriores al viaje de Magallanes-Elcano.

\subsection{Instrumentos de recogida de información}

La plantilla de análisis está compuesta de diferentes partes. Así, las primeras cuestiones de la plantilla tratan elementos que se deberían encontrar en todos los mapas, tales como escalas u orientación. Tras estos, se analizan elementos esenciales referentes al contexto, elementos que se usan selectivamente para ayudar a comunicar más eficientemente y finalmente diferentes elementos semióticos de la cartografía (nominales, ordinales, etc.). En total, la plantilla cuenta con 24 elementos de análisis.

\subsection{Procedimiento}

El análisis se realizó durante el mes de septiembre de 2018 con los mapas impresos en alta resolución, apoyados por imágenes de los mismos digitalizadas. Posteriormente, los datos se incluyeron en el programa de análisis estadístico IBM SPSS (2012), donde se realizó el análisis de los datos obtenidos y se generaron las tablas correspondientes.

\section{Resultados}

La estructura de los resultados que a continuación se expone subraya el mismo orden de la plantilla antes mencionada. Así, en primer lugar, destacamos los resultados relacionados con los elementos que se deberían encontrar en todos los mapas. El primero de ellos, la presencia de una escala explícita, resulta fundamental a la hora de establecer relaciones de distancia y proporción entre los elementos de los mapas.

En este caso no se puede hablar de una situación variable considerando la condición de mapa pre-viaje o post-viaje. Así, en el caso de los mapas pre-viaje el mapa de Juan de la Cosa (1500) no posee una escala 
explícita de proporción, así como tampoco la tiene el mapa de Agnese (1544), aunque en este caso sí pueden apreciarse relaciones de proporción entre los elementos, y también tiene delimitados las líneas de los paralelos y meridianos.

Tabla 1. Elementos que deben estar presentes en todos los mapas.

\begin{tabular}{|c|c|c|c|c|}
\hline \multicolumn{2}{|c|}{ Recuento.- $N^{o}$ Mapas } & Previaje & Postviaje & Total \\
\hline \multirow{2}{*}{$\begin{array}{l}\text { ¿Tiene el mapa señalada } \\
\text { algún tipo de escala } \\
\text { explícitamente? }\end{array}$} & Sí & 2 & 4 & 6 \\
\hline & No & 1 & 1 & 2 \\
\hline \multicolumn{2}{|l|}{ Total } & 3 & 5 & 7 \\
\hline \multirow{3}{*}{$\begin{array}{l}\text { ¿Hay una rosa de los vientos } \\
\text { o indicador de puntos } \\
\text { cardinales? }\end{array}$} & $\begin{array}{l}\text { Sí, en posición } \\
\text { preeminente }\end{array}$ & 1 & 1 & 2 \\
\hline & $\begin{array}{l}\text { Sí, en pequeño en } \\
\text { cuadrante Inf. Izq }\end{array}$ & 2 & 3 & 5 \\
\hline & No & 0 & 1 & 1 \\
\hline \multicolumn{2}{|l|}{ Total } & 3 & 5 & 8 \\
\hline \multirow{2}{*}{$\begin{array}{l}\text { ¿Hay una leyenda que } \\
\text { indique el significado de los } \\
\text { símbolos? }\end{array}$} & $\begin{array}{l}\text { Sí, en pequeño en } \\
\text { cuadrante Inf. Izq }\end{array}$ & 0 & 1 & 1 \\
\hline & No & 3 & 4 & 7 \\
\hline Total & & 3 & 5 & 8 \\
\hline
\end{tabular}

Fuente: elaboración propia

La misma situación se aprecia en la presencia de una rosa de los vientos señalando posiciones cardinales en los mapas, ya que todos los mapas poseen dicho elemento salvo el de Agnese de 1544.

Finalmente, respecto del último elemento de que según Bertín (1983), Board y Taylor (1985) y Cleveland y McGill (1985) debiera estar presente en todos los mapas, una leyenda que explique el significado de los símbolos, es de destacar su ausencia general, tanto en los mapas pre-viaje como los post-viaje, salvo en el caso del islario general de Alonso (1539-1560), que explica con gran profusión todos los elementos de los mapas que componen el islario.

Continuando con la cuestión, se analiza ahora los elementos esenciales referentes al contexto, tales como la presencia de título en el mapa, el número de palabras de éste, y la fecha de producción del mismo.

A este respecto, y de acuerdo con los datos presentados en la tabla posterior, destaca la primera diferencia entre los mapas pre- y postviaje: mientras los mapas pre-viaje no tienen título, este se observa con 
claridad en tres de ellos posteriores al viaje, el de Ribera de 1525, el de Vespucio de 1526 y el Islario de Alonso de 1539-60. En los mapas destaca un título largo, de entre 12 y 15 palabras, teniendo por tanto un carácter más descriptivo que estrictamente enunciativo, con la excepción del de Juan Vespucio, que tiene 7 palabras, y sí se destaca su carácter enunciativo.

De igual forma, la fecha de producción del mapa no se observa en los mapas anteriores al viaje, pero si en el mapa de Ribera (1525) y el de Vespucio (1526), y aunque no explícitamente, pero con continuas referencias temporales en el islario de Alonso (1539-60).

No obstante, ni en el planisferio de Castiglioni (1525) ni en el mapa de Agnese (1544) se observa ninguno de elementos mencionados, por lo que no puede hablarse de una preocupación generalizada por los elementos referentes a contexto en los mapas posteriores al viaje.

Tabla 2. Elementos esenciales referentes a contexto.

\begin{tabular}{|l|l|r|r|r|}
\cline { 3 - 5 } \multicolumn{2}{l|}{ Recuento .- $\boldsymbol{N}^{\boldsymbol{o}}$ Mapas } & Previaje & Postviaje & Total \\
\hline \multirow{2}{*}{ ¿Tiene título el mapa? } & Sí, arriba centrado & 0 & 2 & 2 \\
\cline { 2 - 6 } & Ś, debajo centrado & 0 & 1 & 1 \\
\cline { 2 - 6 } & No & 3 & 2 & 5 \\
\hline \multirow{2}{*}{ Total } & & 3 & 5 & 8 \\
\hline \multirow{2}{*}{$\begin{array}{l}\text { ¿Consta la fecha de } \\
\text { producción del mapa? }\end{array}$} & Sí, pero sólo el año & 0 & 2 & 2 \\
\cline { 2 - 6 } Total & No & 3 & 3 & 6 \\
\hline
\end{tabular}

Fuente: elaboración propia

Respecto del tercer grupo de elementos analizados, los elementos que se usan selectivamente para comunicar más eficientemente, se analiza la presencia o ausencia de recuadros que enmarcan los mapas, la presencia de mapas de situación (locatormaps), mapas de detalle (insetmaps) y elementos bibliográficos o de producción de los mapas. Así, y de acuerdo con la tabla posterior, puede apreciarse el uso frecuente de recuadros para enmarcar el mapa. Dado que cuando aparece sólo hay uno, cabe destacar en este caso un recurso de carácter más estilístico que comunicativo.

Además, es destacable en el caso de los mapas anteriores al viaje una falta de uso general del resto de elementos, el mapa de situación y el mapa de detalle. Elementos bibliográficos o de producción de los 
mapas se pueden observar en el mapa de Reinel (1519), pero no en el resto.

En el caso de los mapas posteriores al viaje la situación presenta mayor variabilidad. Así, si bien mapas de situación y de detalle sólo se aprecian en el islario general de Alonso (1539-60), y elementos bibliográficos y de producción en éste y en el mapa de Ribera de 1525 y el de Vespucio de 1526. El planisferio de Castiglioni y el mapa de Agnese presentan la misma situación que los mapas anteriores al viaje, una ausencia absoluta de elementos que ayudan a comunicar más efectivamente salvo el mencionado recuadro que enmarca el mapa.

Tabla 3. Elementos que se usan selectivamente para comunicar más eficientemente.

\begin{tabular}{|c|c|c|c|c|}
\hline \multicolumn{2}{|l|}{$\begin{array}{l}\text { Recuento.- } N^{o} \\
\text { Mapas }\end{array}$} & \multirow{2}{*}{ Previaje } & \multirow{2}{*}{$\begin{array}{r}\text { Postviaje } \\
5\end{array}$} & \multirow{2}{*}{ Total } \\
\hline ¿Tiene el mapa & Sí, 1 & & & \\
\hline $\begin{array}{l}\text { recuadros que } \\
\text { enmarcan el mapa? }\end{array}$ & No & 1 & 0 & 1 \\
\hline \multicolumn{2}{|l|}{ Total } & 3 & 5 & 8 \\
\hline \multirow[t]{2}{*}{$\begin{array}{l}\text { ¿Tiene el mapa un } \\
\text { mapa de situación? }\end{array}$} & $\begin{array}{l}\text { Sí, en lugar } \\
\text { preeminente }\end{array}$ & 0 & 1 & 1 \\
\hline & No & 3 & 4 & 7 \\
\hline \multicolumn{2}{|l|}{ Total } & 3 & 5 & 8 \\
\hline \multirow[t]{2}{*}{$\begin{array}{l}¿ \text { ¿Tiene el mapa un } \\
\text { mapa de detalle? }\end{array}$} & $\begin{array}{l}\text { Sí, en lugar } \\
\text { preeminente }\end{array}$ & 0 & 1 & 1 \\
\hline & No & 3 & 4 & 7 \\
\hline \multicolumn{2}{|l|}{ Total } & 3 & 5 & 8 \\
\hline \multirow{2}{*}{$\begin{array}{l}\text { ¿Tiene el mapa } \\
\text { elementos } \\
\text { bibliográficos o de } \\
\text { producción? }\end{array}$} & $\begin{array}{l}\text { Sí, en lugar } \\
\text { preeminente }\end{array}$ & 1 & 3 & 4 \\
\hline & $\mathrm{No}$ & 2 & 2 & 4 \\
\hline \multicolumn{2}{|l|}{ Total } & 3 & 5 & 8 \\
\hline
\end{tabular}

Fuente: elaboración propia

Continuando con el análisis de los mapas mencionados, se destaca ahora el estudio de la semiótica de la cartografía. En dicho estudio se contempló el análisis de datos nominales, ordinales y finalmente de otro conjunto de datos.

Respecto del primero de ellos, los datos de tipo nominal, es destacable que todos los mapas, tanto los anteriores como los posteriores al viaje 
tienen puntos, áreas y líneas de simbología nominal. Por tanto, cabe destacar en general un uso simbólico generalizado en los mapas, usando todos los recursos disponibles en su momento.

Los elementos de tipo ordinal, a diferencia de los anteriores, presentan un panorama bien distinto. En concreto, se analizó si hay criterios de ordenación en los puntos de los mapas, si hay colores o patrones que indiquen criterios de tamaño en el mapa y finalmente si en las líneas hay elementos que también expresen criterios de ordenación.

Así, y de acuerdo con los datos presentados en la tabla 4, bien sean los colores de intensidad o colores gradados, no son usados en los mapas analizados, ya sean anteriores o posteriores al viaje.

No obstante, y a diferencia del ítem anterior, el tamaño del punto como recurso de ordenación en los mapas posteriores al viaje es un recurso que se usó en todos los casos, salvo en el de Agnese (1544). En el caso de los mapas anteriores al viaje, a diferencia de lo anteriormente señalado, es un recurso no utilizado.

Tabla 4. Semiótica de la cartografía. Datos ordinales.

\begin{tabular}{|c|c|c|c|c|}
\hline \multicolumn{2}{|l|}{ Recuento.- $N^{o}$ Mapas } & Previaje & Postviaje & Total \\
\hline \multirow[t]{2}{*}{$\begin{array}{l}\text { ¿Hay criterios de ordenación } \\
\text { en los puntos de los mapas? }\end{array}$} & $\begin{array}{l}\text { Sí, relacionado con } \\
\text { el tamaño del punto }\end{array}$ & 0 & 4 & 4 \\
\hline & No & 3 & 1 & 4 \\
\hline \multicolumn{2}{|l|}{ Total } & 3 & 5 & 8 \\
\hline $\begin{array}{l}\text { ¿Hay colores que indiquen } \\
\text { criterios de tamaño en el } \\
\text { mapa? }\end{array}$ & No & 3 & 5 & 8 \\
\hline \multirow[t]{2}{*}{$\begin{array}{l}\text { ¿Hay elementos en las líneas } \\
\text { que indiquen criterios de } \\
\text { tamaño? }\end{array}$} & $\begin{array}{l}\text { Sí, el grosor de la } \\
\text { línea indica } \\
\text { tamaños distintos }\end{array}$ & 2 & 3 & 5 \\
\hline & No & 1 & 2 & 3 \\
\hline \multicolumn{2}{|l|}{ Total } & 3 & 5 & 8 \\
\hline
\end{tabular}

Fuente: elaboración propia

Finalmente, el grosor de la línea como criterio ordinal es un recurso relativamente usado, tanto en los mapas anteriores como posteriores al viaje. Así, en el caso de los mapas anteriores al viaje se da en los mapas de Lopo Homen y Reinel, ambos de 1519, y en el caso de los mapas posteriores, tiene presencia en los casos de Agnese (1544), el de Vespucio (1526) y en el islario general de Alonso (1539-60). 
Finalmente, se analizaron otros elementos visuales como la facilidad de lectura del texto del mapa, si las letras están en mayúsculas o minúsculas, si se observa policromía en el texto, si el texto pisa el dibujo del mapa, si se aprecia claramente la diferencia entre figura y fondo del mapa y, finalmente, si el mapa es monocromático o policromático. Respecto de los cuatro primeros, que destacan aspectos relativos al texto de los mapas, es destacable la suntuosidad del texto, que dificulta su lectura.

Un aspecto de amplia división entre los mapas, ya sean anteriores o posteriores al mapa es el uso de la policromía. Así, se observa policromía en los textos de los mapas de Juan de la Cosa (1500), Reinel (1519), Ribera (1525), Vespucio (1526) y el islario general de Alonso (1539-60).

Tabla 5. Semiótica de la cartografía. Otros datos.

\begin{tabular}{|c|c|c|c|c|}
\hline \multicolumn{2}{|l|}{ Recuento.- $N^{o}$ Mapas } & Previaje & Postviaje & Total \\
\hline \multirow{2}{*}{$\begin{array}{l}\text { ¿Es fácilmente legible el texto del } \\
\text { mapa? }\end{array}$} & Sí & 0 & 1 & 1 \\
\hline & No & 3 & 4 & 7 \\
\hline \multicolumn{2}{|l|}{ Total } & 3 & 5 & 8 \\
\hline \multirow{2}{*}{$\begin{array}{l}\text { ¿Hay policromía en el texto del } \\
\text { mapa? }\end{array}$} & Sí & 2 & 3 & 5 \\
\hline & No & 1 & 2 & 3 \\
\hline \multicolumn{2}{|l|}{ Total } & 3 & 5 & 8 \\
\hline \multirow{3}{*}{$\begin{array}{l}\text { ¿Las letras están en mayúsculas, } \\
\text { minúsculas o ambas? }\end{array}$} & Mayúsculas & 1 & 0 & 1 \\
\hline & Minúsculas & 1 & 0 & 1 \\
\hline & Ambas & 1 & 5 & 6 \\
\hline \multicolumn{2}{|l|}{ Total } & 3 & 5 & 8 \\
\hline
\end{tabular}

Fuente: elaboración propia

Respecto del uso de mayúsculas y minúsculas, destaca el uso de ambas en todos los mapas posteriores al viaje y un uso variable en los mapas anteriores al mismo. En todo caso, y para finalizar respecto del uso del texto en los mapas, destaca que todos los autores se preocuparon de situar en texto en lugares no coincidentes con líneas, facilitando notablemente la legibilidad de los mapas.

De parecida forma que, en el elemento anterior, se puede observar en todos los mapas salvo el de Juan de la Cosa (1500) con claridad la distinción entre figura y fondo. 
Finalmente, es destacable que se observa policromía en todos los mapas, dotando a los mapas de un carácter ilustrativo y estilístico además de su misión estrictamente informativa.

Tabla 6. Semiótica de la cartografía. Otros datos (II).

\begin{tabular}{|l|r|r|r|r|}
\cline { 3 - 6 } \multicolumn{2}{l|}{ Recuento .- $\boldsymbol{N}^{\boldsymbol{o}}$ Mapas } & Previaje & Postviaje & Total \\
\hline \multirow{2}{*}{$\begin{array}{l}\text { ¿Se ve clara la diferencia entre figura y fondo } \\
\text { en el mapa? }\end{array}$} & Sí & 2 & 5 & 7 \\
\cline { 2 - 6 } & No & 1 & 0 & 1 \\
\hline Total & & 3 & 5 & 8 \\
\hline \multirow{2}{*}{ El mapa está en color? } & Sí & 3 & 5 & 8 \\
\hline
\end{tabular}

Fuente: elaboración propia

\section{Discusión y conclusiones}

El objetivo esencial que persigue este trabajo pasa por considerar la diferencia en ciertos aspectos de los mapas anteriores y posteriores al viaje de la vuelta al mundo creados por la escuela de cartógrafos surgida de la Casa de Contratación de Sevilla. Con tal idea, se han seleccionado los mapas que se han considerado más representativos y directamente relacionados con el viaje de Magallanes y Elcano.

Destacamos en primer lugar la similitud que presentan los diferentes mapas en relación a los elementos formales que, en principio, debieran estar presentes en todos los mapas, al menos bajo la óptica del análisis moderno de Bertín (1983), Board y Taylor (1985) y Cleveland y McGill (1985). Similitud en primer lugar desde la ausencia, ya que tanto mapas anteriores como posteriores no contienen leyendas que expliquen la simbología de los mapas. No obstante, en este punto hay que señalar que la simbología presente en los mapas es de naturaleza descriptiva, por lo que cabría cuestionar si en efecto dicha leyenda o explicación adicional es necesaria frente a la evidencia del significado del símbolo en el mapa.

Otros elementos considerados por los autores esenciales están en general presentes, en especial escalas explícitas y brújulas o elementos similares de indicación cardinal.

Otro grupo de elementos estudiados se encontraban bajo el epígrafe de elementos esenciales referentes a contexto, donde sí se aprecian diferencias entre mapas anteriores y posteriores al viaje. En este 
particular, destacamos la ausencia de título y fecha de producción en los mapas anteriores al viaje, mientras que dichos elementos se encuentran en dos de los cuatro mapas posteriores al mismo. Además, el título dado en estos mapas es largo, descriptivo.

El último grupo de elementos formales estudiados, los elementos usados para comunicar con eficacia, destaca similar situación en los mapas anteriores y posteriores al viaje. Así, en ambos casos es frecuente el uso de un recuadro que enmarca el mapa. No obstante, tanto mapas de situación como de detalle no se usan. Finalmente, tanto elementos bibliográficos como de producción son usados de forma variable, encontrándose en uno de los mapas anteriores y en dos de los posteriores al viaje.

En consecuencia, debemos aceptar sólo parcialmente la hipótesis primera (H1), que hacía referencia a diferencias notables, de importancia en lo relativo a los elementos mencionados. Si bien es cierto que dichas diferencias se producen respecto de los elementos esenciales referentes al contexto, no se dan ni en los elementos que deberían existir en todos los mapas ni en los elementos usados selectivamente para hacer más eficiente la comunicación. En conclusión, hay diferencias entre los mapas en estos aspectos, pero considerar que sean notables o de importancia resulta al menos cuestionable.

La segunda de las hipótesis (H2) destaca la diferencia también relevante, notable, entre los elementos de semiótica cartográfica analizados. Dichos elementos se dividen en tres grupos: nominales, ordinales y de otro tipo pero que aportan valor significante al mapa.

Respecto de los elementos de tipo nominal, debe concluirse similitud entre mapas anteriores y posteriores al viaje, ya ambos grupos de mapas usan elementos simbólicos de forma generalizada, usando multitud de recursos que dotan de expresividad a los mapas.

A diferencia del anterior, en los elementos ordinales sí se han observado diferencias entre mapas, destacando un uso frecuente del tamaño de los puntos como criterio de ordenación de tamaño en los mapas posteriores al viaje, pero no en los anteriores. Cuando el elemento analizado es el grosor de la línea la situación es variable, ya 
que dicho criterio ordinal es frecuente en mapas anteriores y tiene presencia en sólo la mitad de los mapas posteriores analizados.

Sin embargo, Hay coincidencia en ambos tipos de mapas en no usar el color como fuente ordinal, ya sea en intensidad del mismo o en escala de colores diferentes.

El último grupo de elementos semióticos analizados presenta situaciones dispares. Así, mientras el color está presente en todos los mapas la diferencia entre figura y fondo es clara en la mayoría de ellos y la tipografía usada es parecida en casi todos, existen también diferencias. Así, la policromía en el texto es frecuente en mapas anteriores, pero sólo se aprecia en la mitad de los posteriores analizados. El uso de mayúsculas y minúsculas también es distinto en mapas anteriores y posteriores al viaje.

En conclusión, y en coincidencia con la hipótesis anterior, la segunda hipótesis $(\mathrm{H} 2)$ ha de ser sólo parcialmente aceptada por la misma razón. Hay diferencia entre los mapas anteriores y posteriores al viaje respecto de los elementos de semiótica cartográfica analizados, pero esta diferencia es de cuestionable entidad.

En relación a lo anterior, y considerando que un mapa es ante todo un instrumento de comunicación visual que relata los viajes realizados y comunica los hallazgos encontrados, resulta necesario realizar siquiera un leve comentario acerca de la realidad contextual que rodeaba la elaboración tanto de mapas pre-viaje como post-viaje.

En los momentos anteriores al viaje, para España era notablemente importante iniciar la navegación magallánica, en buena medida porque los portugueses, que ya habían acabado su reconquista, y por entonces ya estaban llegando a las Molucas.

En aquel momento, y así lo reflejan los mapas, el diámetro de la Tierra se creía menor, si bien de su esfericidad no se dudaba -de hecho, se consideraba una esfera perfecta-. Así, realmente no se conocía el tamaño del mundo. Pese a que Eratóstenes lo había hecho con precisión alrededor del año 230 a.C., posteriormente Ptolomeo había reducido sensiblemente su tamaño.

Además, la cartografía y la geografía eran las ciencias del momento, alimentadas por la destacada labor de la Casa de Contratación de 
Sevilla, ciudad que era líder mundial en tecnología y logística en cada nuevo viaje de exploración. Sin duda, ese fue el factor fundamental que atrajo a gran número de portugueses de gran experiencia náutica, que trajeron los conocimientos adquiridos en sus exploraciones, lo que pudo significar un importante avance en las ciencias antes señalado.

De hecho, a Magallanes se le atribuye un vasto conocimiento en navegación y cosmografía, como demuestra un escrito encontrado en el Archivo General de Indias (Sevilla), que se le atribuye, y donde aporta conocimientos geográficos que mostrarían que las Islas Molucas quedaban dentro de la demarcación castellana del Tratado de Tordesillas, y también dejarían patente que Magallanes era consciente de la magnitud del océano Pacífico.

Por ello, si bien las diferencias encontradas en los mapas sin duda son de cuestionable magnitud, no suponen óbice para destacar diferencias en otros elementos como el trazo o la consideración de la magnitud de la Tierra, que sí eran notables pues los conocimientos, aunque amplios, eran en todo caso menores en el caso de los mapas anteriores al viaje.

Así, cabe en consecuencia señalar que este trabajo posee limitaciones. $\mathrm{El}$ análisis realizado trata exclusivamente solamente un conjunto de elementos comunicativos del mapa, y deja de lado otros que podrían aportar mayores diferencias entre los mapas, como por ejemplo las relacionadas con el tipo de trazo utilizado para representar la tierra descubierta.

En cierta medida en la poesía del trazo y el mapa está el descubrimiento de la realidad, y una de las más interesantes vías de estudio futuras. Sin duda el cambio del trazo de las siluetas continentales representa el cambio de la hipótesis de lo que se esperaba descubrir a la realidad de lo descubierto, lo que supone sin duda la expresión visual más significativa de una de las mayores aventuras emprendidas por el hombre, la del viaje en torno al mundo.

\section{Referencias bibliográficas}

Azocar Fernández, P. (2017). “Tendencias cartográficas durante el periodo científico de la disciplina: Análisis y sistematización de sus representaciones". En Vega Palma, A. (ed) Del mundo al mapa y del mapa al mundo: objetos, escalas e imaginarios del territorio. 
Santiago de Chile: Universidad de Chile y Pontificia Universidad Católica de Chile

Bertin, J. (1983). Semiology of Graphics: Diagrams, Networks, Maps. Translated by W.J. Berg. Madison: University of Wisconsin Press.

Board, C. and Taylor, R.M. (1985). "Perception and maps: Human factors in map design and interpretation" Transactions of the Institute of British Geographers New Series 2: 19-36.

Bryan, J. (2009). "Where would we be without them? Knowledge, space and power in indigenous politics" Futures, 41(1), 24-32. https://doi.org/10.1016/i.futures.2008.07.005

Cleveland, W. S. and McGill, R. (1985). "Graphical perception and graphical methods for analyzing scientific data". Science 229: 828-833.

Craib, Raymond (2000). "Cartography and power in the conquest and creation of New Spain". Latin American Research Review, 35 (1), 7 36

Crampton, J. W. (2010). Mapping. A critical Introduction to Cartography and GIS. Singapore: Wiley-Blackwell. https://doi.org/10.1007/s13398-014-0173-7.2

Cuesta Domingo, M. (2016). Alonso de Santa Cruz: Estudio Crítico. Madrid: Fundación Ignacio Larramendi. https://doi.org/http://dx.doi.org/10.18558/FIL048

Gómez Martín, J. Á. (2015). "La cartografía como instrumento de poder en la época de los Reyes Católicos" Revista de Estudios Colombinos 11, 131-142.

Harley, J. B. (1990). Maps and the Columbian Encounter: An Interpretive Guide to the Travelling Exhibition. University of WisconsinMilwaukee, Golda Meir Library.

Instituto Geográfico Nacional - Servicio de Documentación. (n.d.). Mapa portulano de Juan Vespucci. Mapa del mundo conocido. Sevilla 1526. Retrieved October 2, 2018, from http://www.ign.es/web/catalogocartoteca/resources/html/031254.html

Kollicny, A. (1969). "Cartographic Information-a Fundamental Term in Modem Cartography" The Cartographic Journal, 6, 47-49.

Lois, C.M. (2000). "La elocuencia de los mapas: un enfoque semiológico para el análisis de cartografías". Documents d'analisi 
geografica, 36 93-109.

Lois, C.M. (2007). "Mare Occidentale" Terra Brasilis, 7.

Martín-Merás, L. (2000). "La Carta de Juan De La Cosa:

Interpretación e Historia". Monte Buciero, 4, 71-85.

Miranda Bonilla, J., López Lara, E., \& Canto Ruiz, J. R. (2010). Libros de viajes y cartografía. Biblioteca Universidad de Sevilla. Sevilla.

Retrieved from

http://www.expobus.us.es/cartografia/salas/sala09/s09e00i01. $\operatorname{pdf}$

Nates Cruz, B. y Raymond, S. (2006). "Cartografía semiótica para la comprensión de territorios de conflicto" Estudios Políticos, 29, 99-120.

Olmedo Granados, F. (2015). "Y la tierra se hizo agua" En J. M.

Fernández-Palacios (Ed.), Sevilla: La Primera vuelta al mundo: 1519 (pp. 62-65). Sevilla: Secretaría General de Medio Ambiente y Agua, Consejería de Medio Ambiente y Ordenación del Territorio, Junta de Andalucía.

Padrón, R. (2003). "Las Indias olvidadas" Terra Brasilis, 4.

Pigafetta, A. (1800). Primo viaggio intorno al globo terracqueo. Milano:

Giuseppe Galeazzi.

Sánchez Sorondo, G. (2006). Magallanes y Elcano: travesía al fin del mundo. Madrid: Nowtilus. Retrieved from

http://search.ebscohost.com/login.aspx?direct=true\&db=edshl c\&AN=edshlc.010291438.9\&site=eds-live

Sánchez Martínez, A. (2009). 'De la 'cartografía oficial' a la

'cartografía jurídica': la querella de las Molucas

reconsiderada, 1479-1529." Nuevo Mundo Mundos Nuevos

[En línea], Débats, mis en ligne le 08 septembre 2009,

URL:

http://journals.openedition.org/nuevomundo/56899;

DOI : $10.4000 /$ nuevomundo.56899

Sellés, M. A. (2007). "El arte de la navegación en la península ibérica". Seminario "Orotava" de Historia de la Ciencia Año XI-XII (pp. 167186). La Orotava: Fundación Canaria Orotava de Historia de la Ciencia.

Vigneras, L. A. (1962). "The Cartographer Diogo Ribeiro" Imago Mundi, 16, 76-83.

Zweig, S. (2015). Magallanes. Bookclassic. 


\title{
Juan Sebastián Elcano en la notafilia española: dos visiones, una epopeya
}

\author{
Francisco-Javier García Herrero \\ Universidad de Valladolid (UVA), España. \\ María-Cruz Alvarado \\ Universidad de Valladolid (UVA), España.
}

Cómo citar: F J García Herrero, M C Alvarado López (2019): “Juan Sebastián Elcano en la notafilia española: dos visiones, una epopeya". Revista Latina de Comunicación Social, En P Herrero-Diz/A Cárcamo/V Rodríguez Breijo/R Mancinas (Eds.) V Centenario / $1^{\text {a }}$ Vuelta al Mundo. Cuadernos Artesanos de Comunicación, cac161, pp 71-95. La Laguna (Tenerife): Latina. DOI: $10.4185 /$ cac161

\begin{abstract}
s
Introducción: La gesta culminada por Juan Sebastián Elcano junto a la tripulación de la Victoria en el año 1522 ha quedado en el imaginario colectivo hispano como uno de los mayores logros que un país puede tener como propios. Algo que quedó reflejado en piezas tan efímeras como los billetes. Metodología: En este trabajo se analiza mediante un análisis de contenido combinado con el análisis iconográfico, los dos ejemplos de la notafilia española que homenajearon al personaje y su gesta en dos momentos tan opuestos como fueron la Segunda República y el primer franquismo. Resultados y Conclusiones: Se evidencia que el uso de esta iconografía no fue casual, y que el mismo motivo, por su universalidad, fue capaz de comunicar mensajes similares de inicio de una nueva era, en momentos históricos opuestos.
\end{abstract}




\section{Keywords}

Notafilia; Juan Sebastián Elcano; Segunda República Española, Franquismo; Comunicación.

\section{Contents}

1. Marco teórico. 2. Objetivos y metodología. 3. Juan Sebastián Elcano y la primera vuelta al mundo. 4. Iconografía de las hazañas navales en la notafilia y la numismática española. 5. Análisis de los billetes con la representación de Elcano. 5.1. El billete de 500 pesetas de 1931. 5.1.1. Descripción. 5.1.2. Interpretación. 5.2. El billete de cinco pesetas de 5 de marzo de 1948. 5.2.1. Descripción. 5.2.2. Interpretación. 6. Conclusiones y discusión. 7. Bibliografía.

\section{Introducción}

$\mathrm{E}$

N ESTE TEXTO se muestran dos ejemplos muy diferentes de la notafilia española en los que quedó representada la imagen del marino español. Son dos casos de épocas históricas totalmente distintas, incluso podíamos decir que opuestas, lo que sirve como detonante de nuestra curiosidad investigadora, preguntándonos ¿qué tienen Elcano y su gesta para propiciar el acuerdo puntual en su apropiación de dos regímenes tan enfrentados como fueron la Segunda República Española y el Franquismo?

El objeto de estudio, los billetes con la representación de Juan Sebastián Elcano de la historia española, se va a abordar desde un punto de vista comunicacional si bien tendremos que contextualizar históricamente tanto al personaje y su gesta, como los momentos que dan lugar a su representación notafílica.

Dentro del contexto de las investigaciones numismáticas, suelen combinarse enfoques y metodologías procedentes de ciencias como la Historia, la Arqueología e incluso la Antropología, pero es menos frecuente la mirada desde la Teoría de la Comunicación, con excepción quizás de la incursión que se ha realizado en las aportaciones de autores como Pizarroso (1990), Martín de la Guardia (1992) o más 
recientemente Huici (2017) desde el campo de la Historia de la Propaganda.

Es por ello, generalmente, los historiadores, tanto del mundo numismático como de cualquier otra rama, cuando se han acercado (pocas veces) a la interpretación de monedas o billetes lo han hecho considerando sus representaciones como muestras propagandísticas de un determinado poder establecido con una función divulgadora de su ideología y legitimadora de su poder.

Sin embargo, en nuestro caso, la utilización por parte de emisores tan diferentes de un mismo referente en sus billetes nos puede hacer dudar de este hecho.

\section{Objetivos y metodología}

De ahí que nos planteemos como núcleo de este trabajo tratar de alcanzar algo de luz sobre dos objetivos:

- En primer lugar, conocer en qué momentos se ha utilizado en España desde la notafilia la figura y la gesta de Juan Sebastián Elcano, rescatando esas piezas de su olvido como particular homenaje.

- En segundo lugar, analizar e interpretar esas representaciones, su razón de ser, sus características formales, su iconografía y su simbolismo; en definitiva, explorar la dimensión comunicacional y artística de las piezas, delimitando en lo posible su función y contextualizando en cada caso el fenómeno.

Como metodología de análisis, además de la localización y revisión tanto de materiales históricos relativos a la figura de Elcano y el acontecimiento de la primera vuelta al mundo, como de archivos numismáticos en búsqueda de piezas alusivas en su iconografía a ambos, se ha aplicado a las piezas de notafilia seleccionadas una retícula de análisis diseñada específicamente para aplicarse a monedas y billetes. Esta retícula, probada ya en un trabajo previo con un corpus muy amplio de monedas (García Herrero, 2014) , combina elementos descriptivos e interpretativos que integran el análisis de contenido 
clásico, aplicado a la comunicación (Bardin, 1986) y el iconográfico e iconológico (Panofsky, 2005; Gombrich, 2003; Rodríguez, 2005), permitiendo el análisis descriptivo, formal y comunicacional de cada pieza en su contexto de producción, emisión y recepción. Como precedentes del uso de esta metodología en el campo destacan trabajos como los de García Herrero (2014) y Figueroa (2007) sobre piezas numismáticas, y Jiménez (2014) sobre monedas y sellos.

\section{Juan Sebastián Elcano y la primera vuelta al mundo}

La gesta de Magallanes y Elcano ha estado presente en el imaginario español desde el momento mismo en que se produjo. Antonio Pigafetta, el noble veneciano que además de geógrafo y explorador fue uno de los tripulantes que sobrevivió a esta aventura, también fue su privilegiado cronista en Relación del primer viaje alrededor del mundo (1524). Pigafetta sabe de la importancia de su presencia en tan magno hecho y de la trascendencia en todo el mundo del resultado del viaje, y afirma:

Abandoné Valladolid lo más pronto que me fue posible y me fui a Portugal para hacer relación al rey don Juan de las cosas que acababa de ver. Pasando en seguida por España fui a Francia, donde regalé algunas cosas del otro hemisferio a Madama la Regente, madre del rey muy católico Francisco I. Regresé al fin a Italia, donde me consagré para siempre al muy excelente y muy ilustre señor Felipe Villiers de l'Isle-Adam, gran maestre de Rodas, a quien di también la relación de mi viaje. (Pigafetta, 1992: 147)

Fernández Navarrete en el segundo tomo de su libro Colección de los viajes y descubrimientos que bicieron por mar los españoles, cita a varios escritores, contemporáneos al hecho en sí del viaje, y entre ellos a Juan Bautista Ramusio, "escritor coetáneo, y el más apreciado colector de los viajes de su tiempo", diciendo

... El viaje hecho por los españoles en el espacio de tres años alrededor del mundo es una de las cosas más grandes y maravillosas que se han ejecutado en nuestro tiempo, aun de las empresas que sabemos de los antiguos, porque esta excede en 
gran manera a todas las que y hasta ahora conocemos. Publicamos este viaje como uno de los mayores y más admirables de que jamás se haya tenido noticia, y de cuyo éxito y acontecimientos si oyeran ahora razonar aquellos grandes filósofos de la antigüedad se quedarían pasmados y como fuera de si [...] lo que seguramente se puede afirmar por cada uno de nosotros, es que nunca los antiguos tuvieron tanto conocimiento del mundo que el sol circunda y recorre en veinticuatro horas, como tenemos ahora por la industria de los hombres de este nuestro siglo (Fernández Navarrete, 1837: 19).

Y en la misma página, un poco más adelante, se cita al cronista contemporáneo, Gonzalo Fernández de Oviedo, el cual dice sobre Juan Sebastián Elcano y sus hombres “... Me parece a mi que son de más eterna memoria dignos que aquellos argonautas que con Jason navegaron a la isla de Coicos en demanda del vellocino de oro: cosa en la verdad que no se sabe, ni está escrita, ni vista otra su semejante, ni tan famosa en el mundo".

Como se ve, ya desde los primeros momentos, la vuelta al mundo de Fernando de Magallanes y Juan Sebastián Elcano estuvo rodeada de admiración y reconocimiento, como algo único y portentoso, solo al alcance de los elegidos. Lo que ha dado lugar a numerosas obras posteriores en las que se ensalza la hazaña (Melón, 1951; Sánchez y Hernández, 1992) entre las que destaca por su carácter divulgativo y por el relato apasionante de los acontecimientos, la Historia del Primer Viaje alrededor del mundo especialmente de Stevan Zweig (1957); y también otras que recrean la figura y la gesta universal de Elcano (Celaá y Serrano, 1988; Lucena, 2003 y Gargantilla, 2017).

Por tanto, se puede constatar que la figura de Elcano y su hazaña es algo que ha fascinado a las generaciones que lo vivieron y a las siguientes. Hoy en día, la iconografía de Juan Sebastián Elcano, junto con las epopeyas de otros marineros vascongados, como el caso de Urdaneta, es estudiada y dada a conocer en libros de texto y entidades como el Museo Naval de Madrid o el Untzi Museoa-Museo Naval de San Sebastián. Un interés acrecentado en 2018 como prólogo a la conmemoración del quinto centenario del inicio en 1519 de esta 
epopeya, para el que se han puesto en marcha a nivel del estado español diferentes iniciativas entre las que destacan una página web oficial con información divulgativa pero también científica actualizada de la misma (http://vcentenario.es/) y la creación en 2017 en el País Vasco, donde la referencialidad de Elcano es indudable, del proyecto Mundubira 500: Juan Sebastian Elkano Fundazioa, en Getaria con el objetivo de poner en valor la figura del marino guipuzcoano.

\section{Iconografía de las hazañas navales en la notafilia y la numismática españolas}

Realizada la revisión documental de la historia de la notafilia española, son dos los billetes encontrados en los que aparece representada la figura de Juan Sebastián Elcano.

Si la primera aparición del ilustre marino español se produce en 1931, durante los primeros días de la España republicana, con clara inspiración monárquico-conservadora, la segunda, de valor más pequeño (5 pesetas) más escueta en el diseño, se produce en el año 1940, prácticamente recién terminada la Guerra Civil.

De nuevo las autoridades, en este caso de la Dictadura, miran y buscan reflejo en el pasado imperial español y de nuevo la figura de Elcano y su gesta de circunvalar la tierra por primera vez, como ejemplo de esfuerzo, tenacidad y recompensa del carácter español.

Curiosamente, ambos billetes, se emitieron en sendas campañas de reorganización de sistema notafílico español, aunque en cada uno de los casos por motivos diferentes.

En el primero de ellos, abril de 1931, la emisión estaba dentro de los planes de los gobiernos monárquicos ya que la subida del precio de la vida comenzaba a obligar a los ciudadanos a utilizar cantidades muy importantes de dinero, superiores a los valores faciales de las monedas que habían sido habituales en el sistema español.

En el caso de la numismática y la utilización de las hazañas de la navegación española en las monedas, se ha encontrado un caso en los 
años 20 del siglo pasado que se considera relevante. Se daban entonces dos circunstancias históricas que marcarían las emisiones tanto en monedas como en billetes. La primera de ellas es la subida al poder del general Miguel Primo de Rivera que, entre otras cosas, realizó la primera emisión de monedas de cuproníquel de la historia de España en 1925. Una emisión que causó gran revuelo y confusión entre la población por el parecido de las piezas con las monedas de plata que hasta entonces habían circulado.

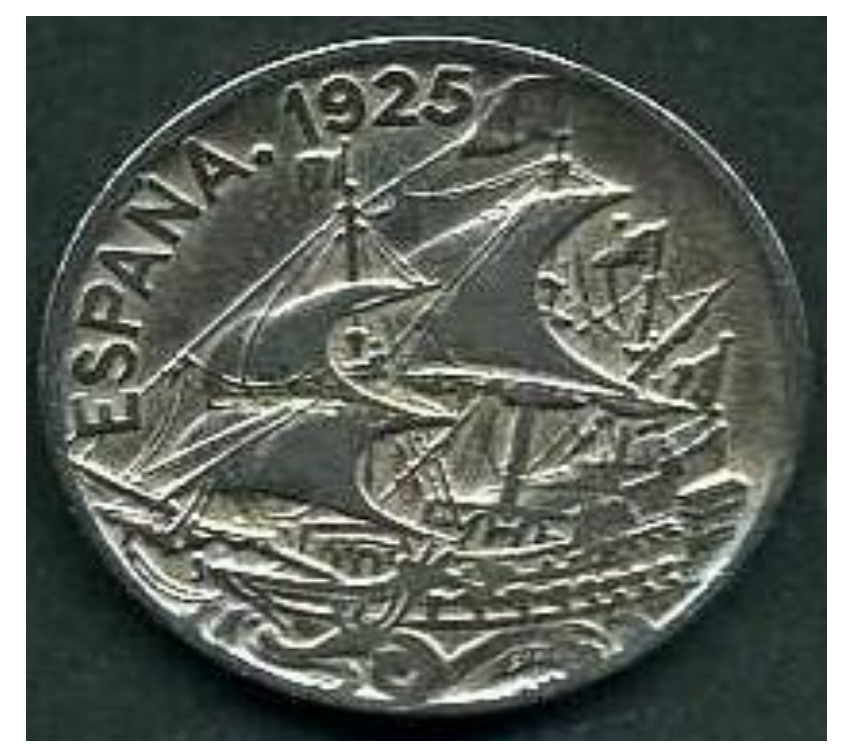

Imagen 1: Primera moneda de cuproníquel fabricada en España, en la que aparece la imagen de un barco. Fuente: Archivo Personal del autor del trabajo.

José Rodríguez Sedano, director por entonces de la Fábrica Nacional de Moneda y Timbre, comentaba en la memoria reglamentaria de 1927, lo siguiente:

"Se pensó en la oportunidad de adoptar un modelo que sirviera para rememorar una de las hazañas más gloriosas de que nuestra nación ha sido protagonista, o sea uno de aquellos galeones de la época de Cristóbal Colón, que servirá para agrandar aún más en el corazón de todos los españoles la profunda admiración que sentimos por la epopeya del navegante inmortal, orgullo de nuestra raza y envidia del universo." (Rodríguez Sedano, 1927:30). 
Como vemos, el uso de esta imagen (Imagen 1) no es aleatorio, sino claramente intencional, transmitiendo al pueblo a través de esta moneda un mensaje universal, generador de vínculos emocionales con la nación a través de una gesta universal (la de Cristóbal Colón) con la que todo ciudadano podía identificarse.

Al margen de las connotaciones de la interpretación que le diera el pueblo a la pieza, pudiera también haberse producido, el reconocimiento expreso de la intencionalidad en el uso de la iconografía alusiva a la gesta de Colón por el Estado Español. Creemos que este caso es relevante como prólogo de cara al análisis exhaustivo que a continuación se realiza de los dos billetes emitidos con posterioridad con la hazaña de Elcano.

\section{Análisis de los billetes con la representación de Elcano}

A continuación, ofrecemos el análisis de cada una de estas piezas, tanto en su contextualización numismática, como en su descripción e interpretación comunicacional, dejando la posible interpretación comparativa e histórica para la discusión posterior.

\subsection{El billete de 500 pesetas del año 1931}

Desde un punto de vista numismático, hay que decir que este billete, emitido (según la información que en él se ofrece) con fecha del 25 de abril de 1931 y que tiene a Juan Sebastián Elcano como eje iconográfico principal, formaba parte de una estrategia de normalización en cuanto al papel moneda puesto en circulación por el Estado Español, ya que los valores que se empezaban a manejar eran superiores a los faciales que históricamente, se manejaban en las monedas españolas.

Para poder valorar los precios, tenemos que tener en cuenta que en 1931 un coche de importación norteamericano valía en España de precio medio 7932,53 pesetas y uno inglés 13.086,90 (Hernández, 2002). Por tanto, un billete de 500 pesetas era un valor facial muy alto no disponible para la mayoría de las transacciones del momento, reservado, tal vez, para hacer grandes pagos como compra de tierras, bienes inmuebles o vehículos. 
Su fabricación se encargó a la casa Bradbury, Wilkinson \& Cía., de Londres, y los billetes fueron realizados con técnicas de caligrafía y litografía. Su tamaño en milímetros era de 142 x 87; un billete relativamente grande que hacía complicado su uso cotidiano al tener que ser, por fuerza, doblado para entrar en las carteras utilizadas normalmente. La tirada que se hizo de este billete fue de 2 millones de piezas y estaba numerada sin serie, con la particularidad de que la numeración presente en el anverso se realizó en color negro y la del reverso en rojo.

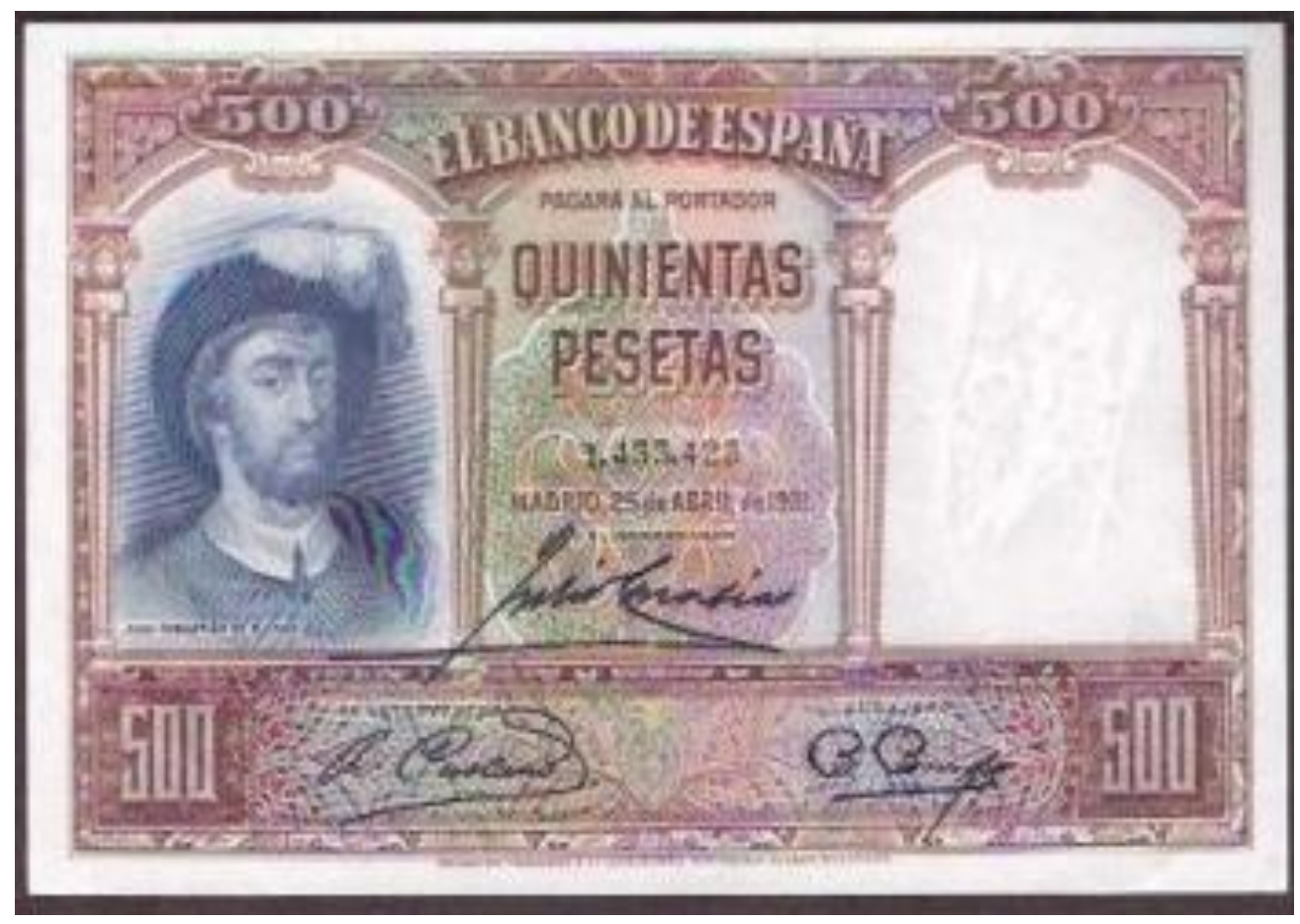

Imagen 2: El regreso anverso del billete de 500 pesetas del 25 de abril de 1931. Fuente: Archivo personal del autor del trabajo.

Cabe una particularidad en cuanto a las fechas que rodean esta emisión ya que si bien, como se ha dicho, aparece en el propio billete la fecha de 25 de abril de 1931 (Imagen 2), la aprobación del boceto de este billete de 500 pesetas se realizó el 27 de noviembre de 1931. Hay documentación del 14 de febrero de 1938, en la Gaceta de la República, anunciando la puesta en circulación de nuevas series (evidentemente se refiere a remesas, pero no a series numismáticamente hablando) de este billete de 500. Como se ve por la fecha de esta segunda puesta en circulación, se produce en plena Guerra Civil. 
Si entramos en la descripción propiamente dicha y en detalle de la pieza debemos empezar por el anverso (Imagen 2).

\subsubsection{Descripción}

El billete, en el anverso, está enmarcado por un recuadro blanco que hace de borde físico del billete y precede a la parte coloreada y trabajada. Esta se ha dividido en tres grandes zonas, siendo la situada más a la izquierda donde aparece la figura de un hombre barbado, tocado con un sombrero con pluma que mira al observador de forma fija y casi frontal, si bien se encuentra ligeramente girado a la derecha. Abotonado hasta el cuello, asoma por encima de su jubón una camisa de cuello vuelto que se pega al mismo.

Por debajo del busto, a la izquierda del lector se lee "Juan Sebastián Elcano". Las tres partes anteriormente referidas están delimitadas lateralmente por cuatro columnas tronco-piramidales invertidas, rematadas en su parte superior por caras de querubines. Estos tres espacios están rodeados de elementos decorativos que a la vez sirven de medidas de seguridad contra copias y falsificaciones.

El espacio central está reservado a lo administrativo y es donde se puede leer en distintas líneas y cuerpo de letra toda aquella información que la administración da al portador del billete. Se informa de quién es el emisor, lo que garantiza su validez, en este caso el Banco de España, que pagará al portador la cantidad de quinientas pesetas. Cabe la particularidad de que este valor se escribe aquí con letra mientras que las otras veces que aparece en esta cara del billete -cuatro en total, dos en las partes superiores de las orlas derecha e izquierda, dentro de unos elementos decorativos lobulados y en la parte inferior de la misma dentro de unos rectángulos-, se presenta en números.

En el margen inferior, se sitúa el número del propio billete, que lo hace único dentro de la emisión, justo encima de la localización y la fecha "Madrid 25 de abril de 1931". Se cierra con una columna central, que firma el Gobernador del Banco de España. 
El tercer espacio, a primera vista aparece en blanco. En él se encuentra una marca de agua que presenta una imagen del que parece ser el dios Neptuno, en concreto de su busto mirando de perfil hacia su derecha, es decir mirando en dirección al retrato de Elcano. Neptuno aparece con corona radiada, barbado y pelo por debajo de la corona, relativamente largo. Se nos presenta desnudo de hombros y el comienzo del torso. También se representa su principal elemento simbólico, el tridente, en este caso a modo de larga vara oscura rematada en un elemento tridente de forma ovalada.

A modo de faldón y ocupando todo el espacio inferior del billete, de izquierda a derecha, aparece un rectángulo en cuyo interior se pueden diferenciar tres partes presentadas de forma geométrica. En los laterales (izquierda y derecha) en unos pequeños cuadrados, más oscuros que el resto, aparece el valor en número del propio billete (500 pesetas) y junto a él, a cada lado aparecen las firmas del interventor y del cajero.

En general, en el anverso predomina el color burdeos que da personalidad a la emisión, si bien aparece otros colores en las filigranas de seguridad como son el verde y el morado.

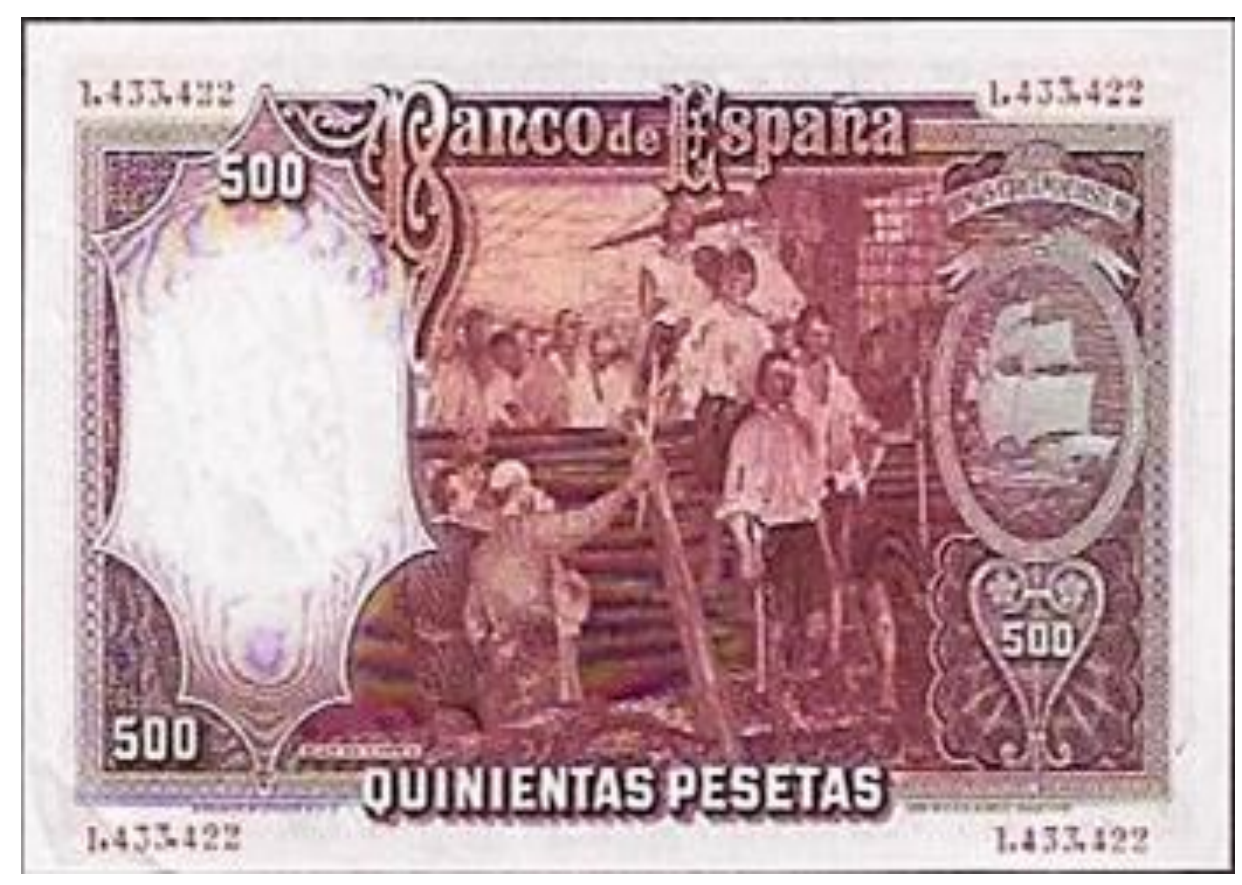

Imagen 3: Reverso de la emisión en la que se muestra la llegada de los avegantes de la nao Victoria a Sevilla. Fuente: Archivo personal del autor del trabajo. 
Por su parte, el reverso tiene por tema principal la llegada de los marineros de la nao Victoria al puerto de Sevilla (Imagen 3).

En la banda blanca de protección inferior se lee en letra muy pequeña a la izquierda "Bradbury, Wilkinson \& $C^{\circ} L^{o}$ " y "New Malden, Surrey, Inglaterra". Sobre la misma banda, en las cuatro esquinas del billete, se reproduce el número de serie, coincidente con el que aparece en el centro del anverso.

El centro del billete está ocupado por la representación de una escena en la que unos hombres descienden de una nave. Bajando por las escaleras o iniciando la bajada aparecen cinco figuras, con camisas viejas blancas y jubones oscuros. Por detrás de ellos, esperando su turno, aparecen, al menos, otros diez marineros.

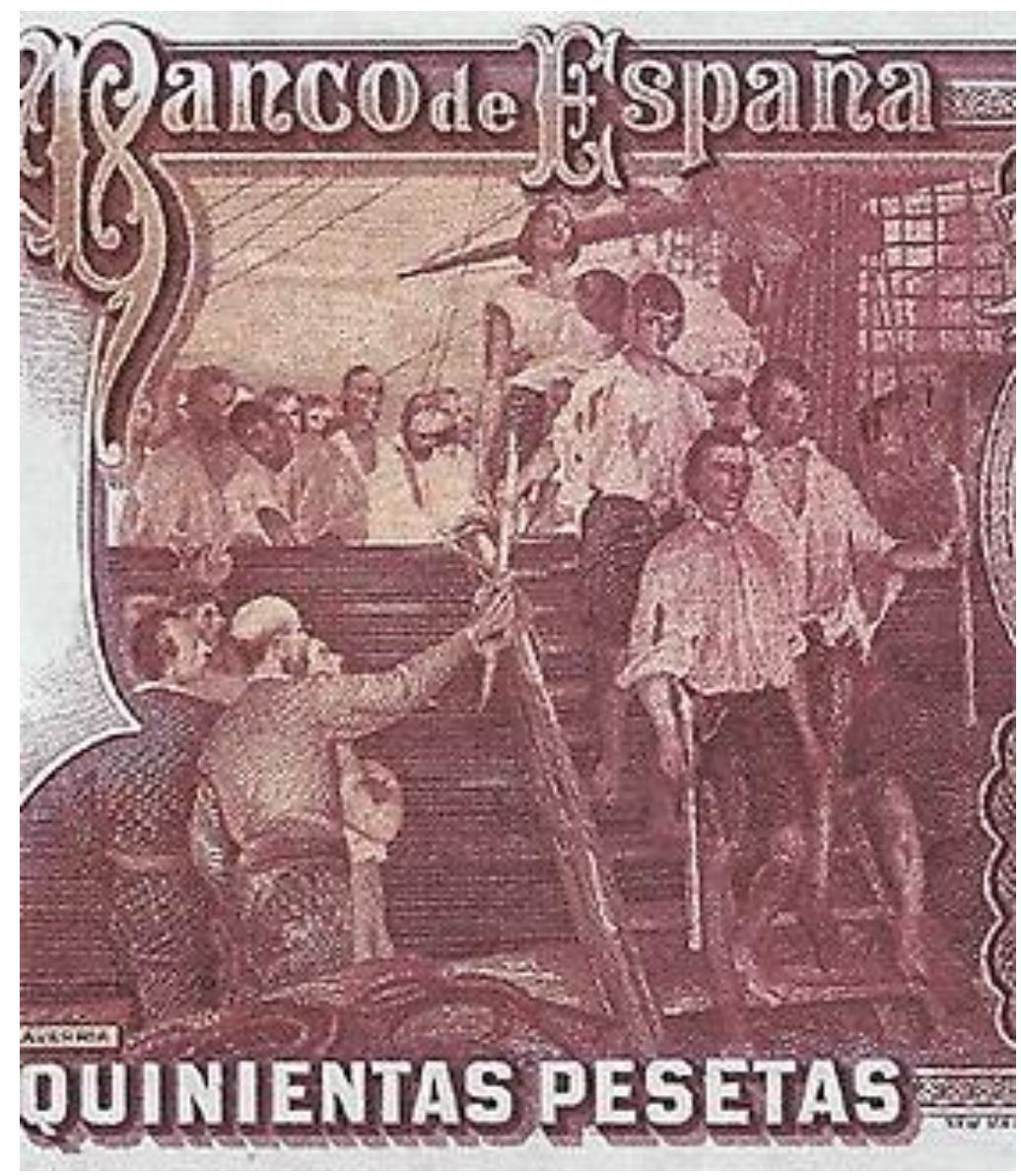

Imagen 4. Detalle del reverso del billete analizado. Fuente: Archivo personal del autor del trabajo. 
En la parte inferior izquierda de la imagen se representan, descubiertos, cinco personajes bien vestidos que van ofreciendo una vela o cirio a cada uno de los marineros que van descendiendo (Imagen 4).

Textualmente aparecen dos líneas, una superior coronando el billete y que dice "Banco de España" y una inferior, cercando en la verticalidad la pieza, y donde se lee en letra el valor, "quinientas pesetas". El valor en número aparece tres veces, una en la parte superior izquierda, sobre un elemento polilobulado en diez hacia adentro y que contiene la marca de agua con la presencia del dios Neptuno anteriormente descrito. Las otras dos veces que aparece el valor se presenta por un lado en la parte inferior izquierda, prácticamente en la misma esquina y, por otro un poco más arriba, en la parte inferior derecha, dentro de una filigrana en forma de corazón.

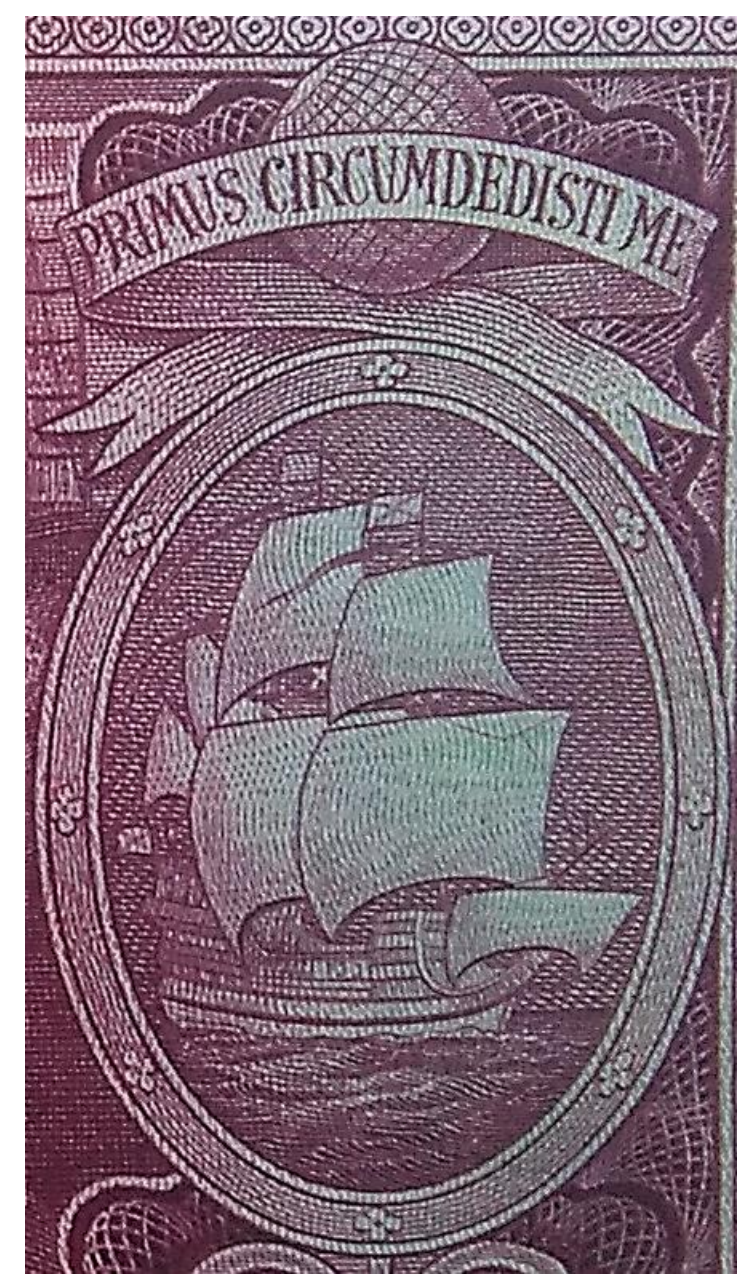

Imagen 5: Detalle del grabado en el reverso donde se puede apreciar la nao Victoria con las velas desplegadas y coronada por un mundo y una leyenda o mote. Fuente: Archivo personal del autor del trabajo. 
A la derecha de esta imagen, pero saliendo de la situación anteriormente descrita, aparece en el centro un óvalo con la imagen de la nao Victoria con las velas desplegadas al viento y con la proa a la derecha. Sobre este óvalo, a modo de coronación, aparece una cinta con el texto latino "Primus Circumdemisti Me" y, en el centro de la cinta, una esfera a modo de globo terráqueo (Imagen 5).

\subsubsection{Análisis}

Situando este billete en su contexto histórico y numismático, hay que decir que iconográficamente, la monarquía de Alfonso XIII, gestionada desde el Gobierno por el general Primo De Rivera, comenzó con su llegada al poder (1923) una serie de reformas sistemáticas y estructurales del país y su economía que, por supuesto, llegó también a las monedas y billetes circulantes y su emisión. En las emisiones de 1925, 1927 y 1928, junto con la aparición del Rey, se empezaron a introducir figuras que habían sido orgullo y ejemplo para el país, que inmerso en situaciones de gran conflictividad social, inestabilidad política y malestar militar (desastres de la campaña de África), necesitaba por todos los medios, buscar referentes que unieran a todos bajo una misma identidad. Esta iconografía se encontró en figuras como Cervantes, Quevedo, Carlos I, Felipe II, Fernando III El Santo y otros varios con alguna figura o referencia religiosa.

La República fue continuista con esta política, si bien se alejó de las referencias religiosas. Es aquí donde aparece nuestro objeto de análisis, junto al Gran Capitán en los billetes de 100 pesetas o José Zorrilla en los billetes de 1000 pesetas.

Estéticamente estamos ante uno de los billetes más bonitos y cargados de simbolismo de la notafília española donde se encajan a la perfección elementos decorativos, de seguridad y comunicacionales.

La representación de Juan Sebastián Elcano no nace como una nueva creación, sino que las imágenes elegidas son todas de reproducciones preexistentes del navegante. Eso ayudaba a su rápida identificación y a la vez al refuerzo de su significado. En el reverso, los elementos representados son propios del cuadro de 1922, El regreso de Juan 
Sebastián Elcano a Sevilla de Elías Salaverría (Imagen 6), que evoca el momento histórico anteriormente mencionado.

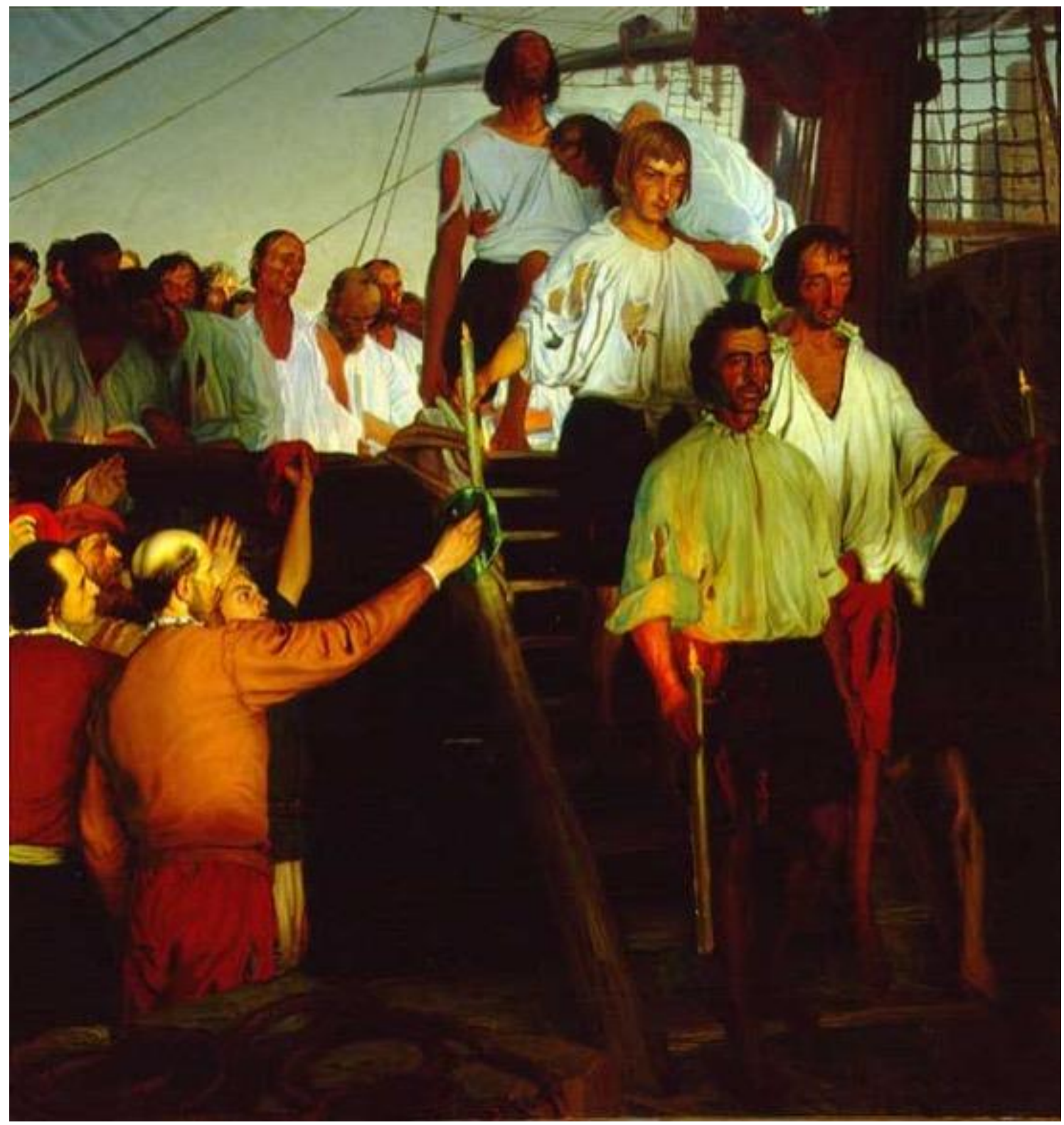

Imagen 6: Detalle del cuadro El regreso de Juan Sebastián Elcano a Sevilla, de Elías Salaverría. Fuente: Untzi Museoa, Museo Naval de Guipúzcoa

Merece la pena resaltar también la presencia en la marca de agua del dios Neptuno, representado con la misma estética y formas que el de la estatua de la fuente madrileña dedicada a la deidad (Imagen 7). 


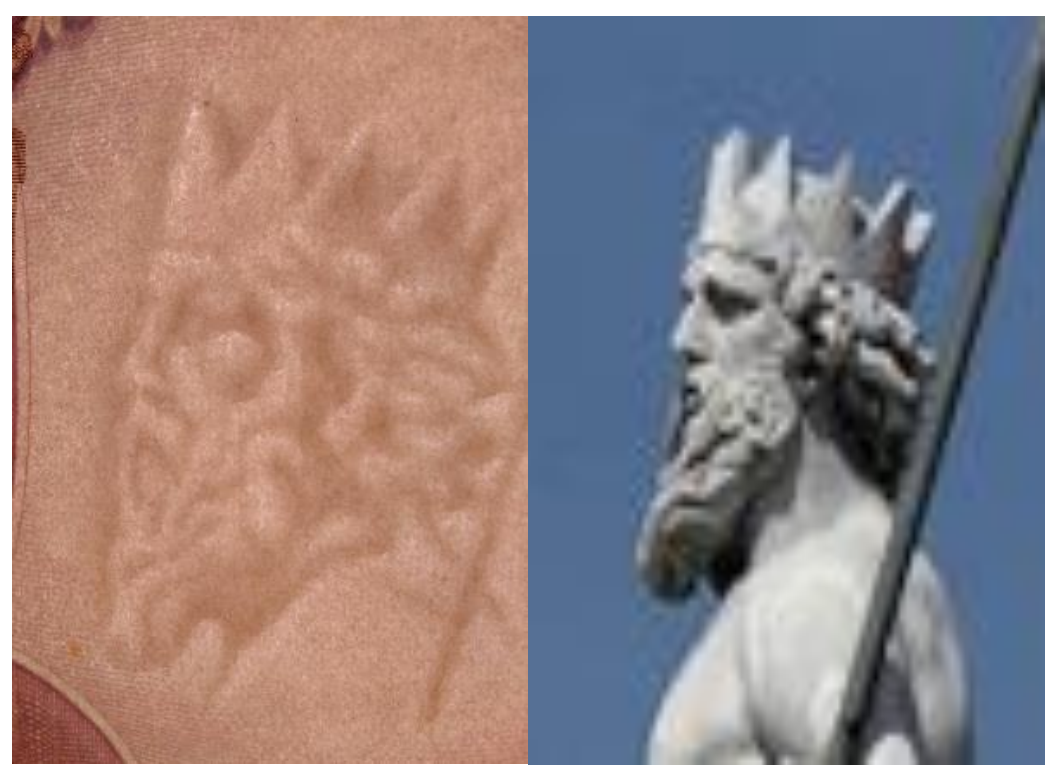

Imagen 7: Primer plano de Neptuno, según se puede ver en la marca de agua del billete y a su lado imagen del Neptuno de la fuente madrileña del mismo nombre.

Según Cirlot, Neptuno es:

"Primitivamente, deidad del cielo en su aspecto de "aguas superiores", es decir, nubes y lluvia. Luego dios de las aguas dulces y fertilizantes. Finalmente, dios del mar. En esta progresiva asimilación vemos mejor que una trayectoria cronológica e histórica una proyección espiritual que repite el mito de la "caída" integrándolo en la personalidad neptuniana. El tridente, considerado así en la posición descendente, puede asimilarse al rayo" (Cirlot, 2004: 330)

La presencia de Neptuno mirando a la cara de Elcano hace que lo podamos reconocer como su elegido, como el hombre destinado a revelar el último gran misterio de sus reinos, la esfericidad de la tierra. El navegante no le devuelve la mirada, sino que mira frontalmente al observador de manera apelativa.

El retrato de Elcano, en el reverso, es una réplica del grabado que realizó Fernández Noseret para la serie de "Retratos de Españoles ilustres", sobre un dibujo de López Eguíndanos que data entre 1791 y 1814 (Imagen 8). 


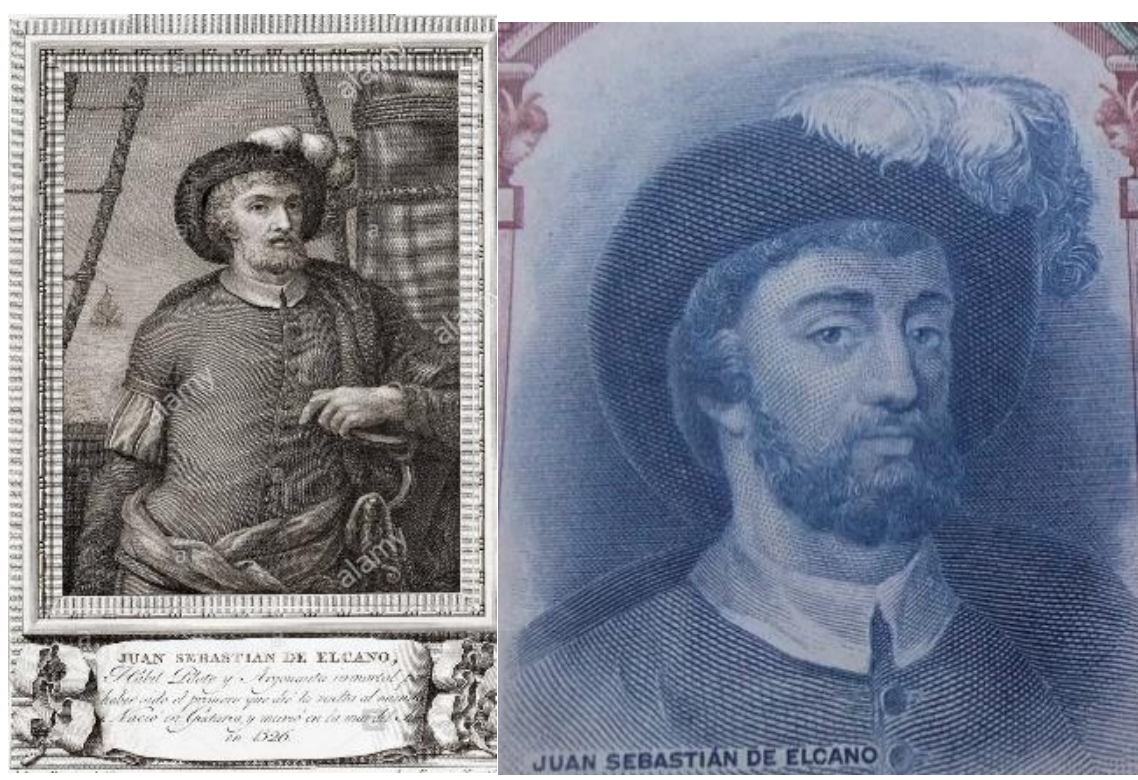

Imagen 8: Grabado de Fernández Noseret para Retratos de Españoles Ilustres y su reproducción en el billete que puso en circulación la II República.

Fuente: Untzi Museoa, Museo Naval de Guipúzcoa y archivo personal del autor del trabajo.

En este grabado tenemos un Juan Sebastián Elcano que nos mira de frente, sin dobleces, pese a tener ligeramente ladeada la cabeza. Barbado y con gesto serio, nos mira en un diálogo callado con el observador. El héroe nos aguanta la mirada, digno y conocedor de su hazaña.

Como se comentó anteriormente, la II República buscaba la identificación de la nación con sus héroes, alejados, en lo posible de la religión. Juan Sebastián Elcano era un marino, pero más allá de eso era un técnico, un científico de principios del siglo XVI, con conocimientos mecánicos y geográficos suficientes para lograr esa primera vuelta al mundo.

La carga iconográfica del reverso viene dada por la llegada al puerto en Sevilla de los supervivientes. Como se puede ver (ver imagen 5 y 6 ), no es una llegada alegre, ni aparecen grandes fastos en honor de los héroes recién llegados. Son tan solo unos hombres harapientos, con semblantes serios, resignados, famélicos, a los que otro pequeño grupo de personas les ofrecen unas velas y los miran en silencio y recogimiento. Tan solo la primera figura que baja (que podemos 
presumir que es la de Juan Sebastián Elcano) tiene un porte más digno, manteniendo la cara alta y la mirada perdida y sostenida en el horizonte, quizás como síntoma de lo alcanzado, pero también de la dureza y el sacrificio de la gesta. Amigos, compañeros y barcos se había perdido en el camino. No hay brazos en alto, ni gritos, ni vítores. Tan solo silencio y recogimiento. Reflexión.

Por su parte, la representación del globo terráqueo con la leyenda Primus circumdedisti me (El primero que me rodeaste) se corresponde con el escudo de armas que, junto con una renta de 500 ducados de oro que Carlo I de España concedió a los supervivientes de la gesta cuando les recibió en Valladolid.

El mensaje que se lanza desde las élites republicanas es claro, el viaje que ahora se inicia no será fácil. Ha costado mucho instaurar el nuevo régimen republicano y no va a ser fácil afianzarlo. Por ello, quizás como en la gesta, no hay ni vítores ni grandes alegrías y posiblemente será mucho lo que haya que sacrificar y muchos los que se puedan perder en el camino. Recordemos que tan solo cinco años después comenzó la guerra que terminó con el hundimiento del nuevo régimen

La intención de las autoridades republicanas era acercar al pueblo dentro de lo posible a esta hazaña universal sin triunfalismos y con solemnidad. Pero no debemos olvidar que era un billete de 500 pesetas, lo que en 1931 era una fortuna al alcance de pocos. Por lo que podríamos entender que el público al que se estaba dirigiendo era precisamente esa élite que, posiblemente, fuera de la que dependiera más que de todo el pueblo llano, el éxito de la implantación plena del régimen republicano.

\subsection{El billete de cinco pesetas del 5 de marzo de 1948}

La segunda emisión de billetes dedicada a Juan Sebastián Elcano se da ya dentro de la dictadura del General Francisco Franco, en los primeros años tras acabar la Guerra Civil y también terminada la II Guerra Mundial. En ese contexto se emite un billete, con un valor de 5 pesetas, dedicado de nuevo al navegante vasco (Imagen 9). 


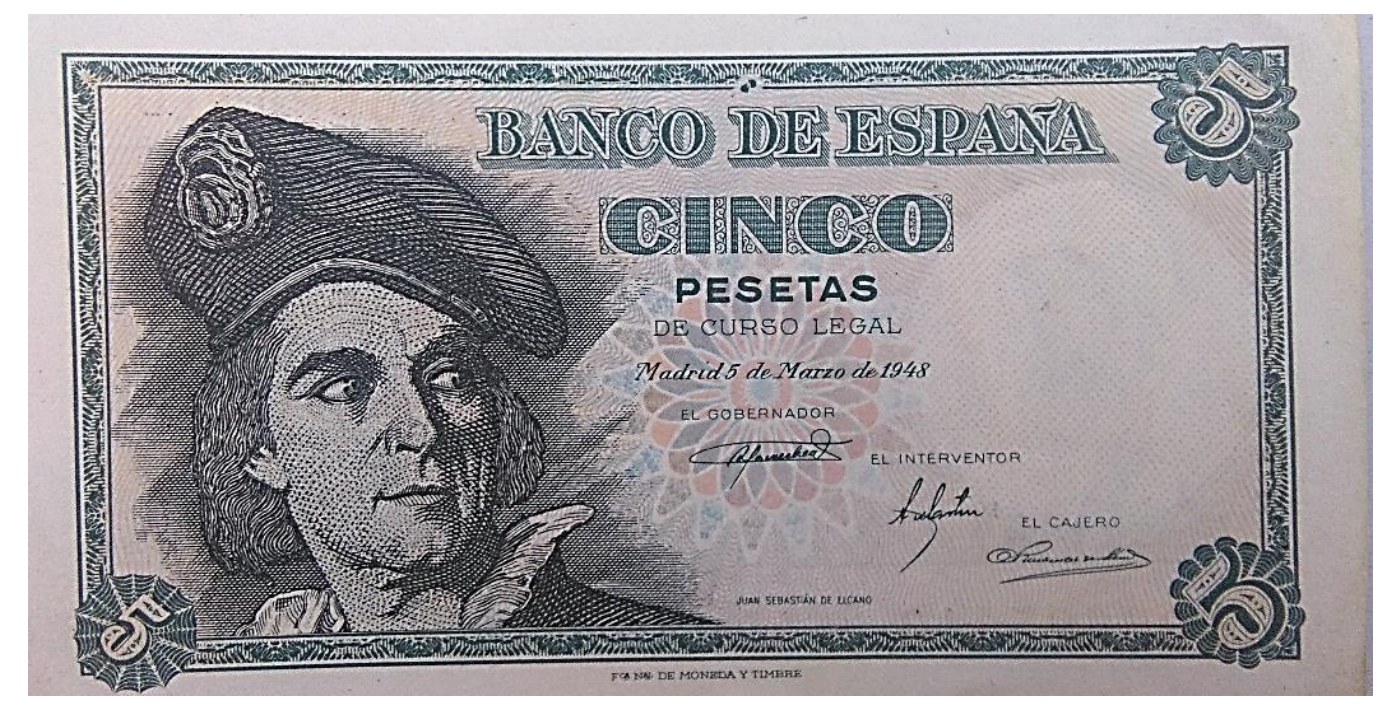

Imagen 9: Anverso del billete puesto en circulación en el año 1940, con un valor de 5 pesetas. Fuente: Archivo personal del autor del trabajo.

\subsubsection{Descripción}

En el anverso, este billete tiene el marco blanco que sirve para delimitar el mensaje impreso de las zonas de corte. Posteriormente, tras este marco blanco aparece un segundo marco en forma de orla decorativa que forma parte del grabado del billete y que tiene en tres de sus cuatro esquinas (las dos inferiores y la superior derecha) flores decorativas, las tres distintas, formadas por elementos de diseño que sirven para evitar (o dificultar) las falsificaciones y reproducciones en el centro de las esquinas aparece el valor del billete (5) en número, pero en distintos tamaños y colocados en diagonal.

Dentro ya de este segundo marco podemos leer en cinco líneas, centradas los siguientes textos: "Banco de España", "Cinco", "Pesetas", "De curso legal" y "Madrid 5 de marzo de 1948". Por debajo, y de forma escalonada, aparecen la firma del Gobernador del Banco de España, la de interventor y la del cajero.

En la parte izquierda, fuera de la información legal y administrativa, aparece el busto del navegante español, con la cabeza girada hacia la derecha, tocado con una prenda en la cabeza tipo boina embellecida con una escarapela; lleva media melena, tiene rasgos faciales sobrios y toda la cara visible e iluminada, y se le ve parte del cuello de la camisa 
o jubón. A su lado, en letra, con un tamaño inferior se lee "Juan Sebastián Elcano”.

A la derecha, salvando las filigranas del grabado que sirven de elementos de seguridad, aparare un círculo que soporta la marca de agua donde se puede apreciar el busto de otro varón que de nuevo es la imagen de Elcano.

Debajo, en la pequeña franja blanca que delimita el borde físico del billete y el marco donde comienza el grabado, se lee, de forma centrada: "Fca. Nal. de moneda y timbre". Este texto, no es algo menor, como se analizará con mayor detalle a continuación.

El reverso del billete tan solo tiene información administrativa y de seguridad, sin ningún tipo de mensaje iconográfico o textual que haga referencia a lo aquí tratado.

Aparece la numeración de la pieza en la parte superior derecha y en la inferior izquierda. Toda la parte que aparece grabada son filigranas de grabado para dificultar la reproducción. Desde el centro al lateral derecho se aprecia un rectángulo que entre líneas y distintos cuerpos dice: "Banco de", "Cinco pesetas", "España". Este recuadro está flanqueado por dos cincos de la misma altura que el rectángulo contenedor. En el lateral izquierdo también aparece el círculo que contiene la imagen que forma la marca de agua.

\subsubsection{Análisis}

La presencia iconográfica del navegante vasco y el hecho que le hizo famoso se reduce aquí a la mínima expresión. Tan solo a la presencia del busto, basado en el cuadro que Elias Salaverríaga pintó para la Diputación Foral de Guipúzcoa con motivo del cuarto centenario de la finalización de la vuelta al mundo en 1922.

Se puede observar (Imagen 10) cómo el grabado de la Fábrica Nacional de Moneda y Timbre ha dulcificado los rasgos del navegante vasco, que Salaverría presentaba con un pelo negro y un tanto descuidado, barba mal afeitada o de varios días, ojos vivarachos y agudos, facciones duras y austeras y unas cejas que llegan prácticamente a juntarse. 
El personaje presentado en el billete tiene un pelo en media melena más cuidado, aparece más aseado en su higiene facial y los rasgos son menos duros. Permanece en ambos casos la mirada ajena al espectador (poseedor del billete) y se puede ver el punto de vista no es de igual a igual, sin que esté el personaje por encima del que lo mira.

Es evidente que las autoridades nos presentan a Juan Sebastián Elcano como un superhombre, como alguien superior a nosotros hasta el punto de que evita mirarnos. Se nos presenta como ejemplo de la raza y quizás de lo que los españoles podemos llegar a hacer.
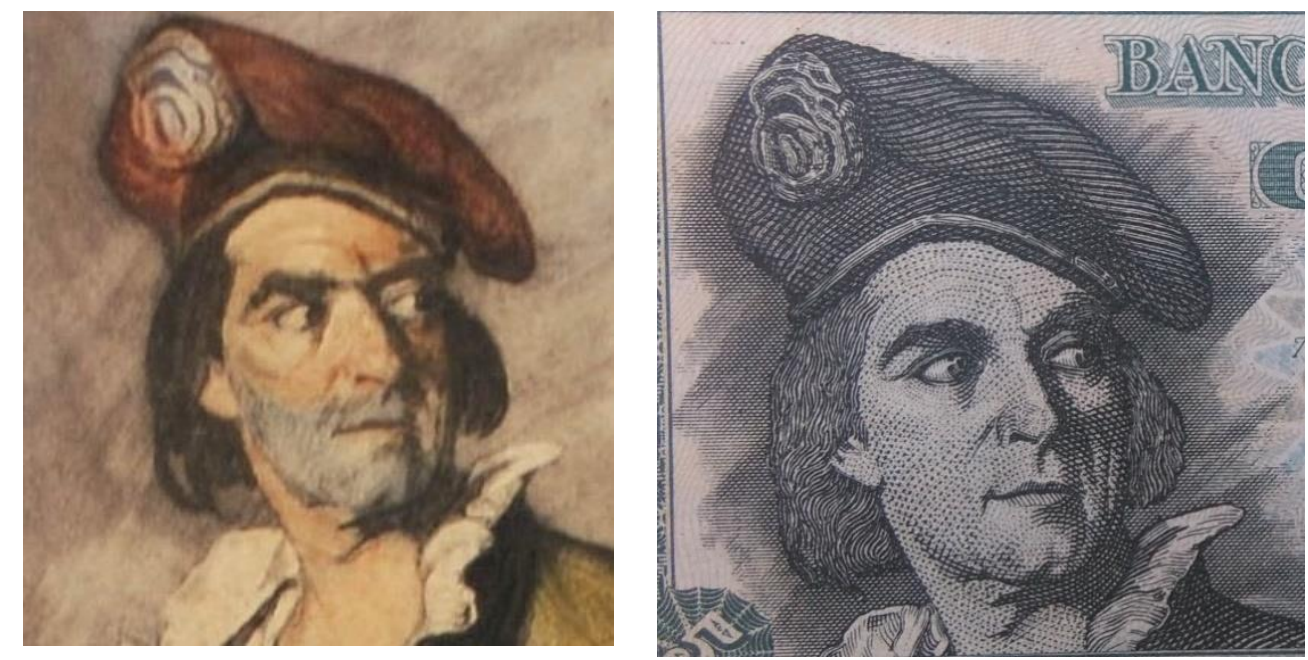

Imagen 10: Detalles y primer plano de Juan Sebastián Elcano, a la derecha de la obra de Salaverría y la izquierda la representación y copia de ella en el billete de 5 pesetas de 1940. Se puede apreciar cómo se han dulcificado los rasgos del béroe, adecentándole y borrando los efectos de la dureza del viaje. Fuente: Untzi Museoa, Museo Naval de Guipúzcoa

Como vemos, esta pieza contrasta con la anterior en casi todo. Es de valor mucho más pequeño, el tamaño es menor y la presencia iconográfica del navegante vasco y el hecho que le hizo famoso se reduce a la mínima expresión. Sin embargo, los hechos ocurridos entre 1519 y 1522 son de gran utilidad como argumento de propaganda y refuerzo del concepto de hispanidad, entendida como "unidad de destino en lo universal"; expresión utilizada por José Antonio Primo de Rivera dentro la exposición de los 27 puntos de Falange Española y 
de las JONS en 1934. Precisamente en el punto quinto de esta declaración filosófica del movimiento falangista se puede leer "España volverá a buscar su gloria y su riqueza por las rutas del mar. España ha de aspirar a ser una gran potencia marítima, para el peligro y para el comercio."

Es evidente que esta declaración entronca directamente con la aparición de la iconografía elcanista en este billete con la gesta imperial y universal de dar la primera vuelta al mundo.

\section{Conclusiones}

Realizados los análisis de ambos billetes, estableceremos algunas reflexiones de carácter comparativo entre cada caso y trataremos de elaborar unas conclusiones que permitan entender este hecho en su contexto.

La primera y común para ambas emisiones es que tanto la II República Española, como el régimen dictatorial del General Franco, vieron en la figura del navegante y su hazaña reflejo de las virtudes que ambos perseguían y espejo de ello para la población.

También encontramos como elemento común para ambos billetes el momento de emisión y es que se ponen circulación en el primer año del nuevo régimen implantado (1931 y 1940), algo que se puede interpretar metafóricamente como la asunción de la idea de la gran travesía, llena de dificultades que termina con final feliz.

Sin embargo, el diseño de las piezas y la representación del navegante vasco son diferentes en ambos regímenes (hay que tener en cuenta la diferencia de tamaños tanto en lo físico como en lo económico). No olvidemos que los nueve años que separan ambas emisiones hacen que nos encontremos ante dos Españas totalmente diferentes. Una quizá ilusionada ante lo que parecía la llegada de otros tiempos y situaciones y otra gris y oscura, justo después de una guerra civil, al comienzo de una dictadura, en tiempo de necesidades, hambre, miseria y represión. 
¿Qué hace que un estado, en este caso el español, en dos periodos bien diferenciados e incluso opuestos de su historia, a la hora de poner en marcha la emisión del papel moneda acudan a un mismo referente?

Como como ya se ha dicho, durante el reinado de Alfonso XIII la identidad española buscó referentes en la historia para reforzarse como nación, con personalidad propia, en un momento en que, tras pasar por la muerte repentina de un rey joven (Alfonso XII) y un hijo póstumo, se vive en una regencia en la que se pierden las últimas colonias ultramarinas, recuerdo de un exitoso pasado imperial. A ello, se añadió después un convulso reinado plagado de huelgas, guerras coloniales, desastres, terrorismo y asesinatos de presidentes de gobierno, entre otros hechos desestabilizadores.

En este marco, el gobierno y los órganos decisorios en la emisión de moneda y papel moneda, aprovecharon el poder propagandístico de este medio para transmitir a la población ese sentimiento de pertenencia a una nación, a unos sentimientos, a una historia y, por tanto, a un destino en lo universal; población que, por otro lado, debía utilizar estas piezas de forma obligatoria en sus transacciones diarias con lo cual, no podía escapar a su impacto.

Está claro que debemos descartar la inocencia y la falta de intencionalidad en todos los elementos iconográficos utilizados en las monedas y billetes españoles de la primera mitad del siglo XX durante la II República Española y el primer Franquismo.

La presencia de Elcano en los billetes españoles tiene la particularidad única y excepcional de aparecer dos veces sin ser un monarca. Juan Sebastián Elcano está presente en la emisión de dos billetes españoles, hecho tan sólo al alcance de figuras universales como Miguel de Cervantes, Diego Velázquez, Francisco de Goya o el premio nobel Echegaray.

El concepto de gloria patria que la gesta de Elcano encierra es recogido por todos los regímenes que se dieron en España en el siglo XX es decir monarquía, república y dictadura. 
Y es que quizá la hazaña de Juan Sebastián Elcano estaba por encima de ideologías y sirvió (y sirve) para unir a todos los españoles en un hecho histórico donde todos se reconocen y que además une, como acto primigenio a nivel mundial, a todo el planeta.

La figura de Elcano y su gesta es tan grande, tan universal, que cualquier régimen, sea del signo que sea, incluso regímenes tan dispares y enfrentados como una república democrática o una dictadura nacional sindicalista, pueden verse reflejadas y amparadas por los valores que de ella se desprenden.

\section{Bibliografía}

ML Celaá \& F Revilla (1988): Elcano. Madrid: Espa-Credit, D.L. JE Cirlot (2004). Diccionario de Simbolos. Madrid: Ediciones Siruela.

M Fernández Navarrete (1837): Colección de los viajes y descubrimientos que bicieron por mar los españoles Tomo II. Madrid: Imprenta Nacional. F Figueroa Saavedra (2007): "El grafiti en metálico. Análisis sobre el grafiti y la circulación monetaria”. En Historia y comunicación social, 12, pp. 23-44.

FJ García Herrero (2014): Dimensión comunicacional de la Numismática en España 1886-1939. Monarquía, República y Guerra; Sátira, publicidad y propaganda. (Tesis doctoral) Universidad de Valladolid. http://uvadoc.uva.es/handle/10324/7665. (10 de septiembre de 2018).

P Gargantilla (2017): "Magallanes y Elcano, la vuelta al mundo". En Clio, Revista de historia, 191, pp. 80-87.

EH Gombrich (2003): Los usos de las imágenes: estudios sobre la función social del arte y la comunicación social. Barcelona: Random House Mondadori.

JAL Hernández Marco (2002): "Los precios de los automóviles importados en la España de los años 20". En Historia Industrial.

A Huici (2017): Teoría e historia de la propaganda. Madrid: Síntesis.

L Jiménez Morales (2014): "La cara de la patria en papel y metal: la escultura en la filatelia y numismática" en Diálogos: Revista electrónica de historia, vol. 15, núm. 2.

https://doi.org/10.15517/dre.v15i2.12587. (5 de septiembre de 2018) 
M Lucena Salmoral (2003) Juan Sebastián Elcano. Barcelona: Ariel. R Martín de La Guardia (1992): Historia de la propaganda: notas para un estudio de la propaganda política y de "guerra". En Investigaciones históricas: Época moderna y contemporánea, 12, pp. 384-385.

A Melón Ruíz de Gordejuela (1951): Ensayo de heurística sobre la empresa Magallanes-Elcano, En Estudios geográficos, v. 12, num, 42, pp. 5-28.

Ministerio de Cultura y Deporte. Gobierno de España (2018): V centenario $1^{a}$ vuelta al mundo. http://vcentenario.es/ (20 de octubre de 2018).

B Olaizola (2 septiembre 2017): “Algo sabemos de su gesta”. En El Correo https://www.elcorreo.com/culturas/realidad-juansebastian-20170828185322-nt.html

(10 de septiembre de 2018).

E Panofsky (2005): Estudios sobre iconología. Madrid: Alianza Editorial. A Pigafetta (1992): Primer Viaje alrededor del Globo. Sevilla: Fundación Civiliter.

A Pizarroso Quintero, (1990): Historia de la propaganda. Madrid: Eudema Universidad.

MI Rodríguez López, (2005): Introducción general a los estudios iconográficos. Madrid: Universidad Complutense.

http://webs.ucm.es/centros/cont/descargas/documento 4795. pdf (10 de septiembre de 2018).

E Sánchez Abulí \& M Hernández Sánchez Barba (1992): Magallanesy Elcano: el océano sin fin. Barcelona: Sociedad Estatal Quinto Centenario, D.L.

Untzi Museoa/Museo Naval: “Elcano, Juan Sebastián de (Getaria, 1487-1526) Ikonografia / Iconografía”, Documento sin fecha. http://untzimuseoa.eus/images/publicaciones/Diccionario/pd fs/elkanoikonografia.pdf (15 de septiembre de 2018).

S Zweig (1957): Historia del Primer Viaje alrededor del mundo, Barcelona: Editorial Juventud. 



\title{
Teoría del framing y protoperiodismo. Estudio de los atributos asociados a la figura de Magallanes en los diarios de Pigafetta y Francisco Albo
}

\author{
David Varona Aramburu \\ Universidad Loyola Andalucía, Sevilla \\ Marta Pérez-Escolar \\ Universidad Loyola Andalucía, Sevilla \\ Marta Pérez-Escolar \\ Universidad Complutense de Madrid.
}

\begin{abstract}
Cómo citar: D Varona Aramburu, M Pérez-Escolar, G Sánchez Muñoz (2019): “Teoría del framing y protoperiodismo. Estudio de los atributos asociados a la figura de Magallanes en los diarios de Pigafetta y Francisco Albo". Revista Latina de Comunicación Social, En P Herrero-Diz/A Cárcamo/V Rodríguez Breijo/R Mancinas (Eds.) V Centenario / $1^{a}$ Vuelta al Mundo. Cuadernos Artesanos de Comunicación, cac161, pp $97-$ 118. La Laguna (Tenerife): Latina. DOI: $10.4185 /$ cac161
\end{abstract}

\begin{abstract}
s
Introducción: La presente investigación se centra en analizar las principales cualidades y atributos que los diarios de Pigafetta y de Francisco Albo utilizan para describir la figura de Magallanes durante la vuelta al mundo. Metodología: Se ha recurrido a la metodología cualitativa de análisis de framing de las noticias publicadas en los diarios de Pigafetta y de Francisco Albo. Desde una aproximación inductiva, se han identificado un total de tres tipos de encuadres: funciones, héroe/antihéroe y el viaje. Resultados: En el caso del diario de
\end{abstract}


Pigafetta, el encuadre más utilizado para describir la figura de Magallanes fue el del «héroe». En el diario de Francisco Albo, se utilizó más el «viaje». Discusión y conclusiones: El hecho de utilizar o descartar una serie de atributos en cada encuadre genera que la opinión pública se forje una opinión u otra sobre Magallanes: el diario de Pigafetta diviniza la figura de Magallanes, mientras que el diario de Francisco Albo ignora parcialmente la presencia de este navegante portugués y relega su labor a un segundo plano.

\section{Keywords}

Protoperiodismo; teoría del framing; Magallanes; atributos; Pigafetta; Francisco Albo

\section{Contents}

1. Introducción: contexto histórico. 2. Método: la teoría del framing y el protoperiodismo. 3. Los diarios, análisis a la luz del framing. 3.1 El diario de Pigaffeta. 3.2 El Derrotero de Albo. 4. Discusión y conclusiones. 5. Bibliografía.

\section{Introducción: contexto histórico}

6T A verdadera conquista empezó a partir de los viajes de Magallanes, que Lnseñó cómo era el mundo, y de Hernán Cortés, que empezó a recorrerlo" (Soler, 2015). Sin embargo, ¿qué pasaría si no nos la hubieran contado? ¿Qué visión de aquello tendríamos sin los testimonios escritos sobre el viaje de la primera Vuelta al Mundo?

Desde el primer viaje de Colón a América y hasta la hazaña magallánica que proponía el camino transoceánico pasan 27 años. Durante este periodo la idea de alcanzar las Indias pasó de ser un objetivo primordial a quedar casi relegada, puesto que, hecha patente la realidad de que se habían descubierto nuevas tierras que no estaban en los mapas conocidos, los esfuerzos y recursos, especialmente los económicos, se centran en sucesivos viajes que abren, poco a poco, el nuevo mundo para Occidente.

Son tiempos convulsos en los que la lucha por la hegemonía europea supone un coste extraordinario para las coronas. Del mismo modo, los 
conflictos internos en cada reinado engrosan las necesidades militares y de orden público, así como administrativo. En el caso de España, Carlos I deberá enfrentarse, entre otros asuntos, al desorden que provocan comuneros, afrentados por la corona y el séquito flamenco del rey, y germanías, donde la nobleza teme mermar su poder por las revueltas de los gremios locales. Mientras, en Europa, el legado Habsburgo de Carlos requería el voto de los príncipes electores y en esta carrera no estaba solo, pues el trono más importante del viejo continente también era pretendido por el rey de Francia, Francisco I (Armillas, 2007).

Estos enfrentamientos y disputas implicaban necesidades de hombres, armas, embarcaciones, traslados y movimientos de tropas, sobornos, etc. Los viajes a las recientes tierras descubiertas eran imprescindibles para obtener el patrimonio necesario que le permitiera a Carlos I alcanzar el título de Sacra Católica Cesarea Magestad y la idea de Universitas Christiana, para paliar las amenazas protestantes contra la Iglesia Católica desde el interior del continente y frenar a las tropas otomanas de los infieles turcos que acechan por el este. Entonces la idea de mundo de unos se une a la idea de lucro de otros (Soler, 2015)

Fernando de Magallanes, veterano de expediciones hacia la Especiería y que había "rodeado el cabo cuatro veces, dos por Occidente y dos por Oriente" (Zweig, 1945), partió con 5 naos y 270 hombres en ese clima de inestabilidad política y social. Sin embargo, las circunstancias le resultan propicias para que la corte española se hiciera cargo de la expedición tras la negativa obtenida de su propio rey, Manuel I de Portugal. El enfrentamiento entre el monarca lusitano y el navegante llega a que este pierda la nacionalidad, así como todos sus títulos de caballero (Zweig, 1945). No obstante, como apunta Soler (2015), era una práctica habitual el hecho de que militares y marinos pasaran al servicio de una corona que no fuera la suya. Esto, junto a las necesidades que requiere la pesada corona de Carlos, beneficia las relaciones entre el monarca español y el navegante portugués que, si bien tienen distinta naturaleza, a ambos les resultará de lo más provechoso colaborar. La llegada a las Indias por nuevas rutas inexploradas ahorraría los gastos arancelarios que exigen los viajes por el itinerario habitual, además de traer nuevas riquezas. Las especias, tan valiosas como el oro, excitaban la codicia de los comerciantes, 
gobernantes y aventureros, (Varona y Herrero-Diz, 2018). No es de extrañar, por tanto, que la corona española financiara tan cara expedición, pero con un expectante y sustancial retorno de inversión.

El 10 de agosto de 1519 la flota parte de Sevilla. Las dificultades y penurias pasan factura a la expedición que termina el viaje con 18 supervivientes entre los que no se encuentra Magallanes, pero sí dos personajes cruciales que harán de este viaje un testimonio perdurable para la Humanidad. Serán los cronistas Antonio Pigafetta, el cual recogerá los detalles del viaje en su obra Relación del primer viaje alrededor del mundo y Francisco Albo, el piloto que partió en la nao Trinidad y regresa en la Victoria habiendo anotado todos los datos de coordenadas geográficas, avatares climatológicos y las características y riquezas de las tierras descubiertas en su cuaderno de bitácora: Derrotero del Viaje de Fernando de Magallanes en demanda del Estrecho, desde el paraje del Cabo de San Agustin.

La hipótesis principal que se formula en esta investigación sostiene que la cobertura informativa de la publicación de Pigafetta y del diario de Francisco Albo sobre la figura de Magallanes y su epopeya marítima divergen tanto en el enfoque que utilizan para narrar los hechos como en el nivel de detalle que ofrecen en sus informaciones.

Se trata aquí, por tanto, de determinar cómo se presenta al público la figura de Magallanes a través de estas narraciones emparentadas con la crónica de Indias y las relaciones de raíz medieval. Son textos que en ocasiones mezclan lo real con lo inventado y que tienen intenciones claras. Igual que Margueritte Cattan (2017) reflexiona sobre la metamorfosis que experimenta el mito de Magallanes desde que es creado hasta que supera y sustituye al propio hombre, podemos aplicar esta visión al propio descubrimiento de manera que podamos distinguir la gesta mítica del hecho histórico.

Se trata, de alguna forma, de una evidencia muy primitiva de la teoría de la Agenda Setting: hasta las expresiones mediáticas más rudimentarias buscaban influir en la opinión pública al determinar los atributos y características que conceden a un asunto. Porque, si partimos de un hecho histórico basado en textos contemporáneos al propio hecho en sí, debemos tener en cuenta qué es verdad y cómo lo han adaptado -ya el propio Colón, en su primer viaje, mantuvo su idea 
de haber visto las naves del Gran Kan y rastros de civilización china-. Por su parte, Vasco de Gama y Gaspar da Gama hicieron la descripción de su viaje más para el deleite de los oídos y deseos del Rey Manuel I que en honor a la verdad (Soler, 2015).

Siguiendo esta conjetura, el objetivo principal del presente estudio se centra en analizar las cualidades y atributos que los diarios de Pigafetta y de Francisco Albo utilizan para describir la figura de Magallanes. El propósito es comprender la divergencia informativa que existe entre la noticia publicada por Francisco Albo, en 1522 -de datos precisos y minuciosos que crea una concreta situación de espacio y tiempo del viaje, pero más sintética y técnica y con escasa narrativa- y el relato de Pigafetta, en 1536- mucho más descriptivo, etnológico y épico y centrado en la figura de Magallanes: "Estaba obsesionado con él, era como un padre", según recogen Varona y Herrero-Diz (2018).

En tanto que, en este estudio, se considera que ambos diarios son manifestaciones informativas del fenómeno del protoperiodismo, se ha estimado apropiado recurrir a la metodología cualitativa de análisis de framing para examinar los encuadres que se utilizan en cada noticia y reflexionar sobre cómo esos frames pueden condicionar la percepción de los lectores (Entman, 1993).

De este modo, la justificación y factibilidad de este estudio queda avalada por su "conveniencia" (Del Río \& Velázquez, 2005), es decir, en esta investigación, se busca aportar nuevas perspectivas que pormenoricen el fenómeno del protoperiodismo en la época de Magallanes. Por ello, el presente artículo adquiere un carácter descriptivo, ya que, siguiendo la propuesta de Del Río \& Velázquez (2005), busca definir y detallar el comportamiento de un fenómeno en concreto: el establecimiento de la Agenda Setting de publicaciones pioneras del protoperiodismo.

Emilio Castelar (1988), en el epílogo de "Historia del descubrimiento de América" hace referencia a la importancia de los textos que Cristóbal Colón toma como referencia para realizar su viaje. Ya fuera por la herencia oral o escrita, el almirante basó el hecho de una tierra esférica en narraciones anteriores a Cristo, como son las letras clásicas, la literatura oriental -el texto de Iaijis, que partió de Córdoba y “engolfose por el mar de las Tinieblas" (Castelar, 1988) hasta que volvieron 
después de mucho tiempo llenos de riquezas- e incluso en la Biblia, donde entendía que en muchos de los textos sagrados de los hebreos se mostraba la intención de llevar a Dios "hacia Occidente" (Castelar, 1988). En la biografía atribuida a su propio hijo, Historia del almirante, se narra cómo Colón muestra en sus escritos anotaciones sobre los textos de Aristóteles, Séneca, Plinio, Ptolomeo, etc. (Rumeu,1971)

Del mismo modo, el descubridor dejó un fecundo legado escrito sobre sus viajes manifiesto en diarios, epístolas, apuntes, libros y un sinfín de documentación que servirán como el testimonio pionero de un nuevo género narrativo tan importante que terminará por ser auspiciado por la propia Corona bajo títulos como el de "Cronista y cosmógrafo mayor de los estados y reinos de las Indias, islas y tierra firme del mar océano" en 1571 (Domingo, 2007).

Por tanto, podemos decir que los viajes transoceánicos que hacen surgir una plétora de cronistas - "cronistas y cronistas-historiadores e historiadores generales"- configurarán una verdadera historiografía indiana (Domingo, 2007).

No obstante, para continuar, deberíamos hacer distinguida apreciación entre los narradores de las expediciones, diferenciándolos en dos grupos: aquellos que basarán el relato en fuentes, es decir, en otros que vivieron los hechos, como Pedro Mártir de Anglería y Francisco López de Gómara o Juan Ginés de Sepúlveda, y un segundo grupo que sí zarpará a las Indias para detallar, desde una perspectiva en primera persona, las vivencias, descubrimientos y situaciones que se dieron durante la expedición. Entre ellos destacan Gonzalo Fernández de Oviedo, el padre dominico Bartolomé de las Casas, el antropólogo jesuita José de Acosta y el propio Pigafetta, qué será nombrado cronista oficial del viaje de Magallanes.

\section{Método: la teoría del framing y el protoperiodismo}

Con el fin de alcanzar los objetivos propuestos en esta investigación, se ha considerado conveniente recurrir a la metodología cualitativa de análisis de framing de las noticias publicadas en los diarios de Pigafetta y de Francisco Albo sobre la figura de Magallanes y su rol en la expedición. Dadas las condiciones de la época, la información recogida en estos diarios no pudo publicarse hasta años después del 
acontecimiento. El diario de Francisco Albo salió a la luz en 1522, una vez que el propio Francisco Albo volvió de la expedición MagallanesElcano. En cambio, el diario de Pigafetta se publicó oficialmente en 1536 bajo el título Relazione del primo viaggio in torno al mondo.

Los estudios de frames o marcos de referencia de Erving Goffman (1974) han ido alcanzando un significativo protagonismo en el campo de la comunicación. "Tras un desarrollo irregular, limitado y muy diversificado, finalmente estos estudios han adquirido un espacio científico propio reconocible" (López Rabadán, 2010: 237). En la actualidad, los análisis de framing se han popularizado y consolidado, en el escenario científico, como consecuencia del progresivo y vehemente avance de investigaciones de referencia (Gandy \& Grant, 2001; D’Angelo, 2002; Tewksbury \& Scheufele, 2007; Matthes \& Kohting, 2008; Vicente \& López, 2009; Brüggemann \& D’Angelo, 2018; Busby, Flynn \& Druckman, 2018). No obstante, estos estudios de framing todavía resultan dispersos y urge consolidar una episteme compartida que otorgue mayor coherencia teórica y empírica a estos análisis mediáticos (D’Angelo, 2002; Tewksbury \& Scheufele, 2007; López Rabadán, 2010).

En cualquier caso, el propósito del análisis cualitativo que se plantea en esta investigación se centra en identificar los frames del discurso periodístico de los diarios de Pigafetta y de Francisco Albo desde una aproximación inductiva. El análisis de encuadres noticiosos mediante aproximación inductiva se centra en examinar las noticias "desde un punto de vista abierto y se intenta revelar el conjunto de posibles encuadres, sin tener prefijados de antemano un número determinado de ellos. Es decir, los encuadres afloran del análisis y no son marcados por el investigador desde un principio" (Igartua \& Humanes, 2004: 257).

Entman (1993: 52) argumenta que estos encuadres deben entenderse como la acción de seleccionar "algunos aspectos de la realidad percibida y hacerlos más prominentes en un texto comunicativo, de manera que promuevan definiciones particulares de los problemas, interpretaciones causales, evaluaciones morales y/o recomendaciones para el tratamiento del asunto descrito". De esta forma, como sostiene Takeshita (1997), el framing es similar al segundo nivel de la Agenda Setting -dimensión sustantiva y afectiva-, ya que "los medios resaltan o 
esconden atributos de las cuestiones con el subsiguiente impacto en la agenda pública y también, a la idea del gatekeeping. Esta visión del framing concibe la 'definición de la realidad' como una cuestión de selección” (Sádaba, 2001: 165).

En este sentido, tras estudiar la organización semántica (Miller \& Riechert, 2001) de las palabras asociadas con Magallanes, se han identificado un total de 3 tipos de encuadres:

Encuadre 1.- Funciones: alude a las responsabilidades que adquiere Magallanes durante el viaje, así como en detallar las consecuencias que devienen de sus acciones.

Encuadre 2.- Héroe-antihéroe: alude a los atributos que divinizan o demonizan la figura de Magallanes.

Encuadre 3.- El viaje: alude a la experiencia personal que vivieron Pigafetta y de Francisco Albo durante su travesía.

Una vez establecido este estudio de encuadres, se busca concretar, además, si existen mecanismos de propaganda en los diarios de Pigafetta y de Francisco Albo. Los mecanismos de persuasión que se buscan en esta narración se dividen en:

- Técnica de simplificación o enemigo único: la propaganda tiende a la simplicidad. Esta necesidad de precisar y resumir busca transmitir una única idea o slogan, un único símbolo e individualizar al adversario en un único enemigo.

- Técnica de exageración o desfiguración: se centra en resaltar cualquier información que le es favorable, utiliza citas fuera de su contexto y convierte cualquier hecho anecdótico desfavorable en una grave amenaza.

- Técnica de orquestación: la buena propaganda se centra en la repetición y persistencia incesante en los temas principales. Estas ideas deben presentarse incansablemente desde diferentes perspectivas -ya que la simple repetición aburriría pronto a la audiencia-, pero siempre insistiendo sobre el mismo tema central.

- Técnica de transfusión: la propaganda no surge desde la nada ni intenta imponer cualquier idea en cualquier momento: por lo 
general, la propaganda opera siempre a partir de un sustrato preexistente, ya sea una mitología nacional o un complejo de odios y prejuicios tradicionales. Se trata de difundir argumentos que puedan arraigar en actitudes primitivas.

- Técnica de la unanimidad y contagio: se centra en convencer a la masa de que esa idea es compartida por " todo el mundo" y se crea así una falsa ilusión de unanimidad. Otra técnica de contagio es reunir a diversos adversarios como un único individuo, como una única categoría individualizada.

- Maniqueísmo: presentar al enemigo como una fuerza negativa, débil e, incluso, perversa para el bienestar social, mientras que las ideas que se defienden en la propaganda son necesarias, buenas y deben predominar para fortalecer a la comunidad.

\section{Los diarios, análisis a la luz del framing}

Tras someter los diarios de ambos autores al análisis propuesto por la teoría del framing, encontramos que los principales resultados obtenidos revelan que existe una diferencia significativa de enfoques entre los diarios de Pigafetta y de Francisco Albo cuando referencian la figura de Magallanes durante el viaje por el Pacífico.

Por un lado, se ha constatado que, en el diario de Pigafetta, se utiliza un enfoque y unos atributos que ensalzan la figura de Magallanes y mitifican la experiencia positiva de su viaje. En este sentido, atendiendo a la teoría de framing, se resaltan los siguientes resultados:

\subsection{El diario de Pigaffeta}

Encuadre 1.- Funciones: En su texto, Pigafetta recurre a diversos atributos para describir las responsabilidades y de Magallanes como comandante de la expedición. La figura de Magallanes es una figura de autoridad que toma una serie de decisiones e impone determinadas normas con el propósito de garantizar la armonía social en el barco. Las expresiones más destacadas en este encuadre son: «dictó algunos reglamentos, tanto para las señales como para la disciplina», «su nave siempre debía preceder a las demás», «el jefe determinó que toda la 
tripulación se confesase, prohibiendo en absoluto que se embarcase mujer alguna en la escuadra».

Sin embargo, la figura de Magallanes también se relaciona con el rol de líder bondadoso que sabe negociar con mercaderes y que busca el bien para su tripulación: «realizamos aquí excelentes negociaciones», «aquí fue donde el comandante en jefe quiso al día siguiente desembarcar para hacer aguada con más seguridad y gozar de algún reposo después de un tan largo y penoso viaje», «el comandante les invitó, a su vez, a que pasasen a bordo de su nave, donde les hizo ver todo lo que podía sorprenderles por la novedad», «el comandante prohibió que se mostrase demasiada estimación por el oro, sin cuya orden cada marinero habría vendido todo lo que poseía para procurarse este metal, lo que habría arruinado para siempre nuestro comercio».

Encuadre 2.- Héroe-antihéroe: los atributos que utiliza Pigafetta resaltan la figura heroica de Magallanes. Las expresiones más evidentes de esta divinización son «gentilhombre portugués», «comendador de la Orden de Santiago de la Spata», «más de una vez ha surcado con gloria el Océano», «este hombre, tan hábil como valeroso, sabía que era necesario pasar por un estrecho muy oculto». Además, también lo define, de una manera indirecta, como un valiente e intrépido navegante, ya que había decidido «emprender un largo viaje por el Océano, donde los vientos soplan con furor y donde las tempestades son muy frecuentes». Ante este inhóspito panorama, Magallanes se presentó como el héroe que «había resuelto también abrirse un camino que ningún navegante había conocido hasta entonces».

De igual forma, como todo héroe, Magallanes también encontró enemigos durante su periplo; según Pigafetta, estos adversarios eran los comandantes españoles de las otras cuatro naves -que se encontraban bajo la autoridad de Magallanes-, ya que ellos eran españoles y Magallanes, portugués. Durante la travesía, los enemigos se rebelaron: «habíamos apenas fondeado en este puerto cuando los capitanes de las otras cuatro naves formaron un complot para matar al comandante en jefe». Sin embargo, cuando se descubrió el complot, se decidió ajusticiar a los amotinados con la muerte, pero Magallanes se mostró como un héroe piadoso y compasivo «que no osaba quitarle la vida» al cuarto insurrecto, así que «lo arrojó de la escuadra y lo abandonó en la tierra de los patagones». 
Ahora bien, cabe destacar que, en este contexto concreto, el atributo de héroe no solo está vinculado con encuadres sobre la personalidad de Magallanes, sino que también está asociado con la ideología religiosa: el héroe no solo es un valiente ídolo, sino que debe actuar también como un cristiano devoto, un creyente incansable que intenta difundir y hacer llegar el cristianismo a aquellas poblaciones que permanecen en el ostracismo y viven en pecado porque adulan a falsas deidades: "plantamos una cruz en la cumbre de una montaña vecina, que llamamos Montecristo, y tomamos posesión de esta tierra en nombre del rey de España», «antes de abandonar este sitio, dispuso el comandante que todos se confesasen y comulgasen como buenos cristianos», «el comandante bajaba a tierra todos los días para oír misa, a la cual concurrían también muchos de los nuevos cristianos, a quienes se hacía una especie de catecismo y se les explicaban algunas de las verdades de nuestra religión», «habiendo oído esto el comandante y animado de santo celo, dijo que si tenían verdadera fe en Jesucristo, quemasen todos sus ídolos e hiciesen bautizar al enfermo», «el capitán especialmente tributó gracias a Dios».

En última instancia, al igual que ocurre en el argumento de las novelas épicas, la figura de Magallanes, como héroe del viaje, se enaltece con su muerte: «un isleño logró al fin dar con el extremo de su lanza en la frente del capitán, quien, furioso, le atravesó con la suya, dejándosela en el cuerpo», "así fue cómo pereció nuestro guía, nuestra lumbrera y nuestro sostén. Cuando cayó y se vio rendido por los enemigos, se volvió varias veces hacia nosotros para ver si habíamos podido salvarnos», «fue así como debimos la salvación a nuestro comandante», «la gloria de Magallanes sobrevivirá a su muerte», «estaba adornado de todas las virtudes, mostrando siempre una constancia inquebrantable en medio de las más terribles adversidades», «a bordo se condenaba a privaciones más grandes que cualquiera de los de la tripulación», «versado como ninguno en el conocimiento de las cartas náuticas, poseía a la perfección el arte de la navegación, como lo probó dando la vuelta al mundo, que nadie antes que él había osado tentar».

El fallecimiento del héroe siempre supone una desgracia que ocurre durante un acto denodado del héroe durante una contienda; desde una perspectiva literaria, esta muerte representa también un punto de inflexión en el relato. Pigafetta continúa con la narración del viaje -- 
donde describe también el regreso de los supervivientes a Sevilla--, pero establece un significativo punto y aparte en el contenido porque, aunque el viaje prosigue para el resto de la tripulación, el héroe ya no les acompaña y eso aviva el sentimiento de fracaso: «siguiendo nuestra derrota, arribamos a una isla que se llama Butuán».

Encuadre 3.- El viaje: los atributos relacionados con el viaje resaltan la cautivadora experiencia de Pigafetta como observador del navío. Estos enfoques aduladores se presentan, sobre todo, al principio de la publicación de Pigafetta con expresiones como «las cosas maravillosas que he visto», «he sido feliz», «navegando por el Océano se observan cosas admirables», «atrevido proyecto», «todos lloramos de alegría».

Aunque, posteriormente, Pigafetta fue introduciendo algunos atributos y enfoques menos gentiles en su discurso para enfatizar el riesgo que suponía haberse embarcado en un viaje tan pionero: «para no correr riesgo alguno, debe navegarse en este paraje con alta marea y ayuda de pilotos», «aquí es donde habitan los caníbales, es decir, los que comen carne humana [...] Aquí fue donde Juan de Solís, que andaba como nosotros descubriendo nuevas tierras, fue comido con sesenta hombres de su tripulación por los caníbales, en quienes se había confiado demasiado», "en medio de estas islas experimentamos una tormenta terrible», «este estrecho está limitado por montañas muy elevadas y cubiertas de nieve, y es también muy profundo», «navegamos durante el espacio de tres meses y veinte días, sin probar ni un alimento fresco», «el agua que nos veíamos obligados a beber estaba igualmente podrida y hedionda», «nuestra mayor desgracia era vernos atacados de una especie de enfermedad que hacía hincharse las encías hasta el extremo de sobrepasar los dientes en ambas mandíbulas, haciendo que los enfermos no pudiesen tomar ningún alimento», «el lunes santo, 25 de marzo, me encontré en el mayor peligro».

No obstante, esta visión apocalíptica se aprecia de una forma sutil en el relato, ya que Pigafetta pretendía resaltar las bondades del viaje, de los nuevos descubrimientos que presenciaron y de las nuevas experiencias que vivieron en cada isla en la que desembocaban: «Nos contaron de esta isla un fenómeno singular, que en ella jamás llueve», «durante los días serenos y de calma, nadaban cerca de nuestra nave grandes peces llamados tiburones», «hemos visto aves de diferentes especies: algunas parecía que no tenían cola; otras no hacen nidos, 
porque carecen de patas», «he visto también pescados que vuelan», «los isleños se familiarizaron bastante con nosotros».

\subsection{E1 Derrotero de Albo}

Por otro lado, el análisis del llamado Derrotero de Francisco Albo es el otro texto que se conserva de un superviviente de la expedición de Magallanes. Como visión del viaje, presenta notables diferencias con la relación de Pigafetta. Albo era un piloto que inició el viaje en la Trinidad, la nao capitana que mandaba Magallanes, y lo completó, lógicamente, a bordo de la Victoria de Elcano. Su texto no es una narración del viaje al estilo de la que elabora el cronista italiano, sino que tiene más de cuaderno de bitácora, de diario de navegación. Sin embargo, entre los registros de la posición del barco y las diferentes vicisitudes del viaje, Albo consigna hechos que tienen que ver con el comportamiento de los expedicionarios, sus actividades y actitudes y, por supuesto, con los hechos de Magallanes.

De alguna forma, Albo también hace su propia crónica. Deslizadas entre los comentarios técnicos, va dejando noticia -o protonoticia- de lo que sucedió y atestiguó. Aplicando las técnicas el framing, podemos también analizar el encuadre de las funciones que Albo atribuye a Fernando de Magallanes. Sin embargo, de nuevo a diferencia de Pigafetta, los casos son pocos y hay que saber entenderlos en el contexto de un piloto que comenta lo que hace su capitán y no se atreve muchas veces a criticar sus actos o a consignar hechos polémicos.

Encuadre 1.- Funciones. Atendiendo a las funciones de Magallanes, hay varias referencias a su inclinación por el comercio con las gentes de las tierras que visita la expedición. Por ejemplo, al tocar Brasil, señala que «en la dicha bahía hay buena gente y mucha, y van desnudos, y contratan con anzuelos, espejos y cascabeles por cosas de comen». Es de las pocas veces que hace referencia a estas técnicas de mercadeo, con lo que subraya su importancia para la expedición y, por ende, para su capitán general.

También incide Albo en describir las funciones de Magallanes como conquistador. Por ejemplo, el 16 de marzo de 1521, tras encontrar una isla llamada Mazava, consigna que «Allí pusimos una cruz encima de un monte». Remarca así el carácter de Magallanes como agente difusor 
del cristianismo, algo que encontramos en más puntos: al llegar a Subu, anota que «el Rey y la Reina de allí, con mucha gente, se hicieron cristianos con buena voluntad», otro triunfo para la cristiandad que atribuir a Magallanes y su empresa.

Algunas fechas después vuelve a marcar el carácter doblemente conquistador y mercantil de la expedición de Magallanes: «hasta un pueblo Laocao, y allí hicimos paces, y eran moros, y fuimos a otro pueblo que es de cafres, y allí mercamos mucho arroz y así nos avituallamos muy bien». Es muy interesante cómo subraya Albo que "allí hicimos paces", dando a Magallanes ese carácter de descubridor y hombre de paz que lleva el imperio español y la fe cristiana a nuevos territorios. Lo repetirá más veces: «entre Mare y Tedori [Tidore], en la cual surgimos, y allí fuimos muy bien recibidos e hicimos muy buenas paces. Hicimos casa en tierra para contratar con ellos, y así estuvimos muchos días, hasta que cargamos».

Encuadre 2.- Héroe-antihéroe. Hay ejemplos interesantes sobre la percepción que Albo tiene de Magallanes como líder y héroe. Encontramos uno en enero de 1520, cuando relata lo sucedido en la exploración de lo que hoy se conoce como Río de la Plata y por algún tiempo fue el Río de Solís. Magallanes estaba convencido de que era el paso al Mar del Sur, pero se da de bruces con la realidad de que, lejos de ser un paso, aquella extensión de agua era, efectivamente, un río. Albo explica que, mientras uno de los barcos exploraba el Río de la Plata, «en este tiempo íbamos otras dos naos a la parte del Sur, a ver si había pasaje para pasar [al Mar del Sur], y ellos fueron en espacio de dos días, y allí fue el capitán general y hallaron tierra al Sursudoeste, lejos de nosotros 20 leguas, y estuvieron [tardaron] en venir 4 días».

Con sutileza, Albo habla de las mentiras de Magallanes como explorador: envía una nao a recorrer lo que aseguraba que era el paso, pero al mismo tiempo envía otras hacia el sur. Es decir, Albo sugiere que Magallanes no se fía de sus propios conocimientos, los mismos que le habían valido para convencer a la Corte de Carlos V para que financiase la expedición y que en ese momento se demuestran erróneos. Albo, con sus neutras anotaciones técnicas, acusa claramente a Magallanes de haber mentido. 
Poco después tiene lugar el motín de Puerto San Julián, donde buena parte de los capitanes se subleva contra Magallanes, que logra sofocar la rebelión, ajusticia a algunos de sus cabecillas y, según algunas fuentes, intenta hacer un escarmiento aún más cruel. Sorprendentemente, Albo no registra nada en su 'Derrotero'. Cabe preguntarse por qué creyó que esos sucesos no eran dignos de ser contados. Es posible que tratara de defender a Magallanes, que era su capitán general. Es posible que al estar él mismo enrolado en la nao del portugués, se mantuviera fiel y eso lo hiciera sospechoso a los ojos de otros comandantes españoles. Quizá nunca se sepa: lo cierto es que Albo dedica espacio y tiempo en su texto a explicar cómo era la Bahía de San Julián y las gentes que allí encontraron, pero no dice nada del motín ni de su resolución.

Sí se explaya Albo al narrar en octubre de 1520 el descubrimiento de lo que llamaron Estrecho de Todos los Santos, hoy de Magallanes, que a la postre daría renombre para siempre al líder de la expedición. Incluso en la prosa técnica y muy aséptica de Francisco Albo palpita cierta emoción al señalar cómo «desembocando de este estrecho, vuelve la costa al Norte, y a la mano izquierda vimos un cabo con una isla y le pusimos nombre, Cabo Hermoso y Cabo Deseado». Es el momento cumbre de la vida de Magallanes y la constatación de que, a pesar del error del Río de la Plata, tenía razón: había un paso hacia el Mar del Sur.

Pero de nuevo encontramos silencio sobre la muerte de Magallanes en la isla de Mactán. Una vez más se escapan los motivos de Albo para obviar un hecho de semejante trascendencia, pero quizá tenga que ver con la protección de la figura del héroe. Magallanes comete errores muy graves que le cuestan la vida y es posible que Albo no quiera subrayar ese proceder poco airoso del capitán general.

Encuadre 3. El viaje. Si para los otros encuadres tenemos que leer casi entre líneas a Francisco Albo, en este que dedicamos a analizar su visión del viaje sucede lo contrario: abundan los ejemplos. Como piloto experimentado que es, Albo consigna sobre todo mensajes destinados a otros navegantes que surquen las aguas que explora. Muchos son de advertencia y nos permiten conocer las dificultades y riesgos que afrontaban las naves de Magallanes. Queda patente cuando dice, por ejemplo, que costeando Patagonia iban «en derecho de los bajos, donde la Victoria dio muchas culadas», o, frente a Brasil: «En dichos Brasil y 
San Tomé hay muchos ríos y puertos, y viniendo por costa unas 6 leguas, hay muchos bajíos». Parecidos comentarios hacen al surcar lo que sería el Estrecho de Magallanes: «el cual hay muchos bajíos» y «guardaos de unas bajas antes tres leguas de la boca»; y también cuando exploran las Filipinas y señala que «en este camino y de luengo de Poluan hay muchos bajos».

A lo largo de todo el relato se van dejando caer noticias sobre las penalidades que afrontan los marinos. Estas referencias menudean sobre todo en las páginas correspondientes a 1522, cuando ya la expedición estaba muy agotada. En mayo señala que «hicimos vela y fuimos de luengo de costa por hallar algún puerto para surgir y tomar refresco para la gente, que estaban los más dolientes, el cual no hallamos». Más tarde, cuando escapan de Cabo Verde, apunta: «nos fuimos con 22 hombres, dolientes y sanos», lo que ya muestra el estado lamentable en que está la tripulación. En ese momento, también da cuenta de los peligros que afrontaron al tratar de librarse de la persecución de los portugueses: «y vino una barca y dijo que nos rindiésemos, que nos querían enviar con la nao que venía de las Indias, y que meterían de su gente en nuestra nao».

Otras veces, en cambio, anota que el camino es fácil: «en 4 leguas a la mar hallamos fondo de 25 brazas, limpio», «la Isla de la Gada, que es deshabitada, y allí nos fornecimos [proveímos] de agua y leña, y es muy limpia de bajos». Como vemos en esa cita, también da cuenta de los lugares donde se puede hacer aguada y aprovisionar las naves. Lo indica en la desembocadura del río Santa Cruz: «allí pescamos muchos peces e hicimos agua y leña»; en la isla de Mare: «y allí tomamos leña para quemar» o isla de Palawan «por haber mantenimientos de arroz, porque hay mucho en aquella isla, y cargan muchos navíos para otras partes».

También hace referencias a las riquezas que encuentran en los lugares que van encontrando. Por supuesto, señala dónde están las valiosas especias que han ido buscando: «Las islas de los Malucos son estas: Ternate, Tidore, Mare, Notil, Maquian, Bachian y Gilolo. Estas son todas las que tienen clavo, y algunas, nueces moscadas» o «Burnei [Borneo] es una isla grande $y$ hay en ella canela, mirabolanis [mirobálanos] y canfora». Pero también habla de otras riquezas, como el oro en la exploración de Filipinas: «de allí nos mostraron 3 islas a la 
parte del Oessudoeste, y dicen que hay mucho oro» y «la cual se llama Baybay [Leyte], y dicen que hay en ella mucho oro».

Junto a sus noticias, va dejando Albo otras igualmente relevantes: presencia y dirección de las corrientes, nombres de los lugares muchos de ellos, nombrados por primera vez para Occidente-, y detalles sobre asuntos como las embarcaciones que usan en los lugares que recorren: «tenían las velas de estera, hechas en triángulo, y andaban por ambas partes».

\section{Discusión y conclusiones}

Nuestra investigación se proponía analizar los encuadres y atributos que los diarios de Pigafetta y de Francisco Albo utilizan para describir la figura de Magallanes y, de esa forma, comprender la divergencia informativa que existe entre la noticia publicada por Francisco Albo y el texto de Pigafetta.

En este sentido, encontramos que el hecho de utilizar o descartar una serie de atributos en cada encuadre genera que la opinión pública se forje una idea u otra sobre Magallanes: dependiendo del diario que lea el individuo, se creará en su mente una imagen positiva o negativa de Magallanes.

En el diario de Pigafetta, el encuadre más utilizado fue el del «héroe», lo que coincide con lo señalado por autores como Cattán (2018: 550), quien sostiene que los personajes históricos que son "heroizados" suelen convertirse también en protagonistas de su propio mito (Raglan, 1936; Campbell, 1949), como así ocurre en manuscritos como las de Barros Arana (1830), donde también se idealiza la figura de Magallanes. En nuestro análisis se evidencia cómo Pigafetta crea esa imagen heroica recurriendo a dos mecanismos de persuasión: la 'técnica de simplificación o enemigo único' y la 'técnica de exageración o desfiguración'.

Por un lado, al emplear la 'técnica de simplificación o enemigo único', Pigafetta utiliza ciertos atributos relacionados con las condiciones adversas a las que se tuvo que enfrentar Magallanes -el mal tiempo, los motines, los comandantes españoles como principales adversarios, etc.- como estrategia para poder transmitir la única idea de que, a pesar de todos los infortunios, Magallanes fue el héroe del viaje y un 
comandante jefe encomiable. Así, en nuestro análisis, y a la luz de la teoría del framing, hemos visto cómo se utilizan una serie de expresiones y atributos -como, por ejemplo, «gentilhombre portugués», «comendador de la Orden de Santiago de la Spata», «más de una vez ha surcado con gloria el Océano» o «este hombre, tan hábil como valeroso, sabía que era necesario pasar por un estrecho muy oculto»para ensalzar el comportamiento de Magallanes y presentarlo como el artífice de los logros de la expedición, a pesar de los avatares y dificultades que tuvo que afrontar.

Por otro lado, los resultados muestran que Pigafetta también aplica la 'técnica de exageración o desfiguración', ya que, en la narración del diario, se busca intencionadamente resaltar cualquier rasgo, característica o actitud como un dato positivo y, a su vez, convierte los datos negativos en minúsculos contratiempos que sirven para evidenciar el ímpetu de superación y el carácter heroico de Magallanes; por ejemplo, cuando se descubrió que algunos miembros de la tripulación habían gestado un complot contra su capitán, se decidió ajusticiar a los amotinados con la muerte, pero Magallanes se mostró como un héroe piadoso y compasivo «que no osaba quitarle la vida» al cuarto insurrecto, así que «lo arrojó de la escuadra y lo abandonó en la tierra de los patagones».

En el caso de Francisco Albo, si bien la naturaleza del texto es diferente, los resultados apuntan que el encuadre más utilizado fue el del «viajé» con atributos como, por ejemplo, «en dichos Brasil y San Tomé hay muchos ríos y puertos, y viniendo por costa unas 6 leguas, hay muchos bajíos» o «hicimos vela y fuimos de luengo de costa por hallar algún puerto para surgir y tomar refresco para la gente, que estaban los más dolientes, el cual no hallamos». En el registro de este piloto, la importancia la tiene la propia expedición, los lugares que encuentran y las rutas o derroteros por los que los alcanzan. Eso supone acallar deliberadamente a Magallanes, que pasa a un papel realmente secundario en el diario de Albo. De hecho, la divergencia en la forma de contar lo sucedido es tan grande que no podemos por menos que estar de acuerdo Flores (2013: 5) cuando compara los textos de Pigafetta y Albo y señala que "da la impresión de que nos encontramos con dos expediciones diferentes". Si bien se aprecia una evidente implicación emocional de Pigafetta, durante el relato de su 
viaje, con expresiones como «las cosas maravillosas que he visto», «he sido feliz», "navegando por el Océano se observan cosas admirables», «atrevido proyecto» o «todos lloramos de alegría»; Albo se muestra más aséptico e indiferente, como así se evidencia en los encuadres que utiliza para narrar el viaje: «en dichos Brasil y San Tomé hay muchos ríos y puertos, y viniendo por costa unas 6 leguas, hay muchos bajíos» $\mathrm{o} \ll y$ vino una barca y dijo que nos rindiésemos, que nos querían enviar con la nao que venía de las Indias, y que meterían de su gente en nuestra nao».

Es posible que Albo no quisiera dejar por escrito nada que le comprometiese ante Magallanes porque, como queda claro en el interrogatorio que se le hace a la vuelta del viaje, conocía con detalle lo que había pasado en los momentos más complejos de la expedición, como el motín de Puerto San Julián y la muerte de propio Magallanes. La técnica de la ‘simplificación’ parece, en este caso, dedicada al capitán general, cuyas acciones son unas veces criticadas, otras ignoradas y en pocos casos destacadas. De forma deliberada, Albo no quiso dar apenas importancia a lo que hizo el responsable máximo de la expedición durante el viaje. Esta perspectiva coincide con la planteada por Cattan (2018: 551), que señala cómo algunos de los cronistas que cuentan el viaje están en contra de Magallanes.

En todo caso, y a modo de conclusión, cabe señalar que los textos de Pigafetta y Albo permiten explorar la noción de noticia en un tiempo en el que los descubrimientos no dejaban de asombrar a Europa. Lejos todavía del periodismo que empieza a configurarse en el siglo XVIII, estos hombres y los cronistas de Indias informan a su manera, pero informan porque, y aquí coincidimos con Bravo (2015: 102), tienen una clara finalidad informativa $y$ cabe, por tanto, hablar de protoperiodismo. Desarrollan esa actividad informativa, además, utilizando técnicas narrativas y recursos informativos que más tarde serán utilizados también por los periodistas de épocas más cercanas. Coincidimos así con Puerta (2011: 58) y con Ruiz (2015: 621) en señalar que en esas primitivas crónicas están los gérmenes del desarrollo de este género periodístico que es la noticia. Unos gérmenes bien visibles que prosperaron en el caldo de cultivo de una sociedad ya moderna y necesitada de saber más sobre su verdadera naturaleza y sobre los contornos de su propio mundo -aunque siendo conscientes de que la 
percepción de ese mundo varía según los encuadres que los periodistas utilizan, siguiendo la teoría del framing, para retratar la realidad-.

\section{Bibliografía}

JA Armillas Vicente (2007): "Descubrimiento y contacto con otros mundos", en VVAA, Historia Moderna Universal (Coord., A Floristán Imízcoz). Barcelona: Ariel.

E Bravo García (2015): "La construcción de estereotipos en las crónicas de Indias". Politeja: Journal of the Faculty of International and Political Studies of the Jagiellonian University, 38, pp.97-114.

D Barros Arana (1830). Vida i viajes de Hernando de Magallanes. Santiago de Chile: Imprenta Nacional

M Brüggemann \& P D'Angelo (2018): “Defragmenting News Framing Research: Reconciling Generic and Issue-Specific Frames", en VVAA, Doing News Framing Analysis II (Editor P D'Angelo). Nueva York: Routledge

E Busby, DJ Flynn \& JN Druckman (2018): “Studying Framing Effects on Political Preferences. Existing Research and Lingering Questions", en VV AA, Doing News Framing Analysis II (Editor P

D'Angelo). Nueva York: Routledge

J Campbell (1949): The Hero with a Thousand Faces. Princeton: Princeton University Press

E Castellar (1988): Historia del descubrimiento de América. Sevilla: Edisur S.C.A.

M Cattan (2018): "Fernando de Magallanes: la creación del mito del héroe". Hipogrifo, 6(1), pp. 535-553.

P D’Angelo (2002): "News framing as a multiparadigmatic research program: a response to Entman", Journal of Communication, 4(52), pp.870-888.

O Del-Río \& T Velázquez (2005): "Planificación de la investigación en Comunicación: fases del proceso", en VVAA, Investigar en Comunicación. Guía práctica de métodos y técnicas de investigación social en Comunicación (Coord., M R Berganza Conde \& J A Ruiz San Román). Madrid: McGraw Hill. 
M Cuesta Domingo (2007): "Los cronistas oficiales de Indias. De López de Velasco a Céspedes del Castillo". Revista Complutense de Historia de América, 33, pp.115-150.

RM Entman (1993): "Framing: Toward Clarification of a Fractured Paradigm". Journal of Communication, 43(4), pp. 51-58.

OH Gandy \& AE Grant (2001): Framing Public Life. Mahwah. Nueva Jersey: Lawrence Erlbaum

E Goffman (1974): Frame analysis. Los marcos de la experiencia. Madrid: CIS.

JJ Igartua \& ML Humanes (2004). Teoría e investigación en comunicación social. Madrid: Editorial Síntesis.

MA Flores (2013): "Un mito del Estrecho de Magallanes", en VVAA, El mar en la bistoria y en la cultura (Eds. A Morgado \& J Rodríguez). Cádiz: Universidad de Cádiz.

P López Rabadán (2010): "Nuevas vías para el estudio del framing periodístico. La noción de estrategia de encuadre". Estudios sobre el Mensaje Periodístico, 16, pp. 235-258

J Matthes \& M Kohting (2008): "The content analysis of media frames: toward improving reliability and validity", Journal of Communication, 2(58), pp.258-279.

MM Miller \& BP Riechert (2001): "The spiral of opportunity and frame resonance. Mapping the issue cycle in news and public discourse", en VVAA, Do the media govern? Politicians, voter and reporters in America (Eds. SD Reese, OH Gandy \& AE Grant). California: Sage

A Puerta (2011): "El periodismo narrativo o una manera de dejar huella de una sociedad en una época". Anagramas: Rumbosy Sentidos de La Comunicación, 9(18), pp.47-60.

FRS Raglan (1936): The Hero. A Study in Tradition, Myth, and Drama. Westport: Greenwood Press

A Rumeu de Armas (1971): "Cristóbal Colón, cronista de las expediciones atlánticas". Anuario de Estudios Atlánticos 1(17), pp.533-560.

J Ruiz Astiz (2015): "Negocio editorial y protoperiodismo en Navarra: estudio de la relación de sucesos impresa". Príncipe de Viana, 76(262), pp.619-634. 
T Sádaba (2001): “Origen, aplicación y límites de la "teoría del encuadre" (framing) en comunicación". Communication \& Society, $14(2)$.

I Soler (2015): El sueño del Rey. Viajes y mesianismo en el Renacimiento peninsular. Acantilado: Barcelona.

T Takeshita (1997): "Exploring the media's roles in defining reality: from issue-agenda setting to atrribute-agenda setting", en VVAA, Communication and Democracy. Exploring The Intellectual frontiers in Agenda-Setting Theory (Eds. M Maxwell, DL Shaw. \& D Weaver). Nueva Jersey: Lawrence Erlbaum Associates.

D Tewksbury \& DA Scheufele (2007): "Special Issue on Framing, Agenda Setting, \& Priming: Agendas for Theory and Research", Journal of Communication, 1(57), pp.9-173.

D Varona \& P Herrero-Diz (2018): "Verdad y propaganda en el legado escrito de la primera vuelta al mundo". Revista de Occidente, 440, pp.7-16.

M Vicente \& P López (2009): “Resultados de la investigación sobre framing: sólido avance internacional y arranque de la especialidad en España", Zer. Revista de Estudios de Comunicación, 26(14), pp.13-34.

S Zweig (1945): Magallanes. Editorial Juventud: Barcelona.

Paper relacionado:

AI Ardèvol Abreu (2015): Framing o teoría del encuadre en comunicación. Orígenes, desarrollo y panorama actual en España. Revista Latina de Comunicación Social. 70. Pp. 424-450. 


\section{Del "Primer viaje alrededor del Globo" (s. XVI) a "Le Tour du Monde" (s.XIX-XX)}

Los relatos de viajes y la conformación de los medios de comunicación modernos en torno las categorías de información y espectáculo

\section{Eduardo Gallegos Krause}

Universidad de La Frontera, Temuco, Chile.

Jaime Otazo Hermosilla

Universidad de La Frontera, Temuco, Chile

“... a fin de poder hacer a los demás la relación de mi viaje, tanto para entretenerlos como para serles útil...” Antonio de

Pigafetta

"Le Tour du Monde tiene por objetivo dar a conocer los viajes (...) que ofrezcan el mayor interés a la imaginación, la curiosidad o al estudio."

Edouard Charton

Cómo citar: E Gallegos Krause, J Otazo Hermosilla (2019): Los relatos de viajes y la conformación de los medios de comunicación modernos en torno las categorías de información y espectáculo". Revista Latina de Comunicación Social, En P Herrero-Diz/A Cárcamo/V Rodríguez Breijo/R Mancinas (Eds.) V Centenario / $1^{a}$ Vuelta al Mundo. Cuadernos Artesanos de Comunicación, cac161, pp 119-144. La Laguna (Tenerife): Latina. DOI: 10.4185/cac161 


\section{Abstracts}

Introducción. El presente trabajo da cuenta de algunas continuidades presentes en el relato de Antonio de Pigafetta donde registra la primera vuelta al mundo (1519-1522) y los textos publicados en la revista francesa de viajes "Le Tour du Monde" (1860-1914). La pertinencia en la comparación de estos textos reside en que ambos se desarrollan en un contexto colonial donde aparecen como formas prematuras de medios de comunicación, teniendo ambos, un componente central que involucra el contacto con la alteridad indígena no europea. Metodología y resultados. Mediante una metodología semiótica de análisis se demuestra cómo las nociones de información y espectáculo, se vinculan con la forma en que se significa a la alteridad en estos textos. Discusión y Conclusiones. Se discute entonces acerca de la pertinencia de hablar de "periodismo de viajes" como un género subestimado por no ser información pura y dura; antes de ser una forma moderna de periodismo, el periodismo de viajes es un antecedente del periodismo tradicional.

\section{Keywords}

relato de viajes, información, entretención, alteridad, medios de comunicación, industria cultural.

1. Antecedentes teórico-contextuales: colonialismo, alteridad, literatura de viajes y periodismo

1.1 La continuidad colonial entre el siglo XV-XVI y el siglo XIX-XX: (des)encuentro con la alteridad

— L SIGLO XIX se caracterizó por la puesta en marcha de un como una continuidad de los procesos de expansión del s. XV donde las potencias europeas buscaban la articulación económica y cultural del globo con fines imperialistas. Esto da lugar a un colonialismo global, cuyas consecuencias discursivas y materiales se dejan sentir hasta hoy a lo largo y ancho del globo (Wallerstein, 2007; Mignolo, 2007; Said, 1990 y 2005; Dussel, 1994). 
Respecto a la particularidad del siglo XIX en estos procesos, desde 1852 los estados monárquicos europeos tradicionales comenzaron a declinar y a dar paso a sistemas políticos y económicos de corte cada vez más liberal (Bouvier, 1999). Además, la segunda revolución industrial, que se sitúa habitualmente entre 1870 y 1914 en el espacio europeo, cambió completamente el orden socio-económico y político del mundo. Toda la automatización de procesos que siguió a la producción industrial trajo como consecuencia una política colonial de anexión de nuevos territorios para la obtención de materias primas y el posicionamiento de manufacturas. En el caso de América Latina, las élites burguesas en auge, que se consolidan después de las guerras de independencia con la formación de los estados-nacionales, reprodujeron las dinámicas coloniales (colonialismo interno) sometiendo a las poblaciones indígenas a la exclusión basada en la dicotomía civilización/barbarie ya impuesta por los europeos (Flores, 2000; Rabasa, 2009; Navarro, 2005; Salgado, 2016; Pinto, 2003 y 2008)

En este contexto de expansión colonial se editan revistas de viaje y una serie de relatos de viajeros, ya sea contratados por las nacientes repúblicas que afianzan sus independencias, sea por iniciativas de países coloniales o por el puro gusto de la aventura; como sea, el globo se encuentra en un proceso de (re)descubrimiento, expansión y reapropiación, donde el viaje y los viajeros/exploradores, se constituyen en un elemento central de lo que será la nueva articulación de territorios y finalmente una nueva concepción geopolítica del globo, lo que llevará a un proceso que en el caso particular de la América del sur se ha llamado desde Europa un "redescubrimiento de América" (Huerta, 2002).

Los relatos de viaje representan entonces uno de los medios de difusión y de propaganda de la ideología expansionista/colonialista y de la inherente función civilizadora de las naciones europeas en lugares lejanos a las metrópolis. Así, el relato de viajes es parte de la "cultura de viajes" (Venayre, 2006), inserta esta a su vez en la "cultura colonial" (Blanchard, et.al. 2008) que inunda el pensamiento del s. XIX e impulsa los sueños, anhelos y miedos de la sociedad europea. Los relatos de viajes asociados a espacios desconocidos y exóticos es lo que representan las nuevas naciones de América para los europeos (Salgado, 2016). Así, Staszak (2006) ha hecho notar la dimensión de 
exotismo en que se construye la alteridad en los relatos de viajes que aparece como atracción por la diferencia y manifestación de la superioridad europea-occidental.

En este marco la revista Le Tour du Monde aparece como la más relevante empresa editorial dedicada a los viajes; en efecto, y si bien en la época existía una gran cantidad de revistas sobre literatura de viajes (Huerta, 2002), Le Tour du Monde tiene sin duda una preponderancia sobre las deáas. Esta relevancia viene dada por la permanencia en el tiempo que tuvo la revista (1860-1914), por estar asociada a Hachette, -una de las editoriales más prestigiosas del campo editorial francés-, y por ser dirigida por Edouard Charton, un importante hombre de la época relacionado a la educación y la política en Francia. Le Tour du Monde, no fue la primera aventura editorial de Charton, quien antes del éxito de esta revista había fundado ya el Magasin pittoresque y L'illustration, imbuido por las ideas del san simonismo y con un profundo interés por la educación (Grijalba, 2003). Consideramos que los tres textos que conforman el corpus del presente trabajo (Cordemoy, 1896; De la Vaulx, 1900 y Nordenskjoeld, 1902) son una fiel muestra de todos los demás relatos divulgados por Le Tour du Monde. Estos tres textos fueron elegidos, principalmente, por haberse abocado a la descripción de los territorios australes de Chile y Argentina, que son los mismos por los que también se despliega la expedición magallánica y el relato de Pigafetta.

Por su parte, el relato producido por el cronista italiano al servicio de Magallanes, se constituye en la fuente más reconocida y difundida de la primera vuelta al mundo aún habiendo otras como las de Francisco Albo, Gines de Mafra, Herrera, y aún las propias cartas de Elcano. El ejercicio de Pigafetta logra entonces una suerte de discurso cerrado o consensuado, donde otras voces de disenso tienen poco que decir en atención a que el cronista italiano logró construir una verdad poco cuestionada (Varona \& Herrero-Diz, 2018). Esta es la razón por la que para este análisis en torno a la primera circunnavegación del globo se ha elegido la obra de Pigafetta como la más importante y relevante para analizar.

Tanto la expresión colonial del siglo XV como la del siglo XIX manifiesta entonces un componente de (des)encuentro entre mundos; el mundo europeo y el criollo-indígena no europeo, lo que se traduce 
en relaciones con la alteridad, o el otro, pero que al mismo tiempo conforma parte de la propia dimensión identitaria: "Y no hay identidad sin la relación dialógica con el Otro. El Otro no está afuera, sino también dentro del uno mismo, de la identidad." (Hall. 2010: 344).

Resulta esclarecedor para entender esta relación entre la identidad/alteridad en el caso del relato de Pigafetta el hecho de que la península ibérica a finales del siglo XV e inicios del XVI se había concretado el proceso de expulsión de los moros, cuestión que algunos historiadores han considerado clave para entender el espíritu de descubrimiento-conquista de rutas y territorios que caracteriza al siglo XV y XVI. Cardaillac (2015) se refiere a esto señalando que el recuerdo del islam hispánico conforma una suerte de imaginario que está presente en los colonizadores de América, continuidad que es referida por las propias fuentes coloniales trabajadas por el citado autor: "De modo que los indígenas son nuevos infieles que hay que dominar y evangelizar" (p. 439). A esto se sumó el interés que se despertaba en Europa las tierras desconocidas de altamar (Martinic, 2017) y la historiografía moderna ha notado la vinculación entre la proyección que se hace a los indígenas en América con lo que acaecía en España con la expulsión de las comunidades árabes; a ojos de Todorov (2003) no es para nada casual que la victoria española sobre los árabes, el exilio de los judíos, el descubrimiento de América y la primera gramática del español ocurran en el mismo año.

La problemática de la identidad en las lógicas coloniales que aquí someramente se han descrito se relacionan con la otorgación de significaciones existenciales que se expresan dicotómicamente en la relación yo/otro, se trata de una negación del otro como un no-Yo (Dittus, 2011); la demarcación de un territorio simbólico-significativo donde se distingue entre un nosotros y los otros da cuenta de la conformación de amigos y enemigos (Baczko, 2005).

En su acepción más básica, la identidad incluye asociaciones con, por una parte, los rasgos que caracterizan a los miembros de una colectividad frente a los otros que no pertenecen a la misma y, por otra, a la conciencia que un individuo tiene de ser él mismo y, entonces, distinto a los demás. Entre lo mismo y lo otro se abre, así, el territorio material y simbólico de la identidad. (Solórzano-Thompson \& Rivera- Garza, 2009, p.138) 


\subsection{Hacia una definición extensiva de las industrias culturales: literatura de viajes, periodismo y medios de comunicación}

Unido a lo hasta aquí expuesto en términos de la configuración de significaciones coloniales, Spurr (2013) señala que en el marco del discurso imperial-colonial se entremezclan componentes del periodismo, los relatos de viaje y otros elementos asociados a la administración burocrática imperialista. Del mismo modo, Pratt (2011) da cuenta de cómo en la mirada imperial se entreteje el discurso de viajeros, científicos, aventureros, políticos, entre otros. Cuestión similar a la que proponen Blanchard (et. al. 2008) quienes señalan que el proceso de "inmersión colonial" (bain coloniale) acaecido en Francia, considera una serie de dispositivos culturales tales como la literatura, canción popular, el cabaret, relatos de viajes, zoológicos humanos, etc. que dieron forma a un tipo de relación con las alteridades -los otrosque Francia fue encontrando a lo largo de su avanzada colonial y civilizatoria.

Más que cualquier otro viajero, el explorador es quién pone como tema central la circulación de información, y quién más solicita la atención de la prensa en el s.XIX. Porque él recorre espacio lejanos definidos por estar ajenos a la mirada de un mundo europeo en expansión [...] (Surun, 2007, p.57)

De modo similar, variados son los autores que han relacionado los relatos de viaje con los medios de comunicación modernos y con el periodismo. Así, para el caso de las crónicas o relaciones de sucesos propios del siglo XV al XIX, sobretodo en España, del Valle (2004) señala que representan una forma de memoria donde se representa a los indígenas mapuches. Más aún, del Valle propone el sugerente concepto de "paleo-periodismo" para las narraciones de las relaciones de sucesos. Perspectiva similar es la que desarrollan Bernal y Espejo (2003) al dar cuenta de una serie de condiciones en términos de expresión, contenido y estructura editorial que permiten hablar de las relaciones de sucesos del s. XVII como textos pre-periodísticos.

Por otra parte, desde el ámbito de la literatura en general autores como Chillon (2002) han señalado la vinculación inherente entre el relato de viajes como antecedente de la crónica periodística, que tiene que ver no tan solo con la vinculación entre literatura y periodismo sino con la 
reivindicación del lenguaje como poseedor de una naturaleza audiovisual donde se construyen conceptos a partir de imágenes mentales. También en términos de vinculación entre periodismo y literatura, Albuquerque (2006) señala que, a la luz de la pragmática, el relato de viajes corresponde a un género híbrido entre el periodismo y la literatura.

La vinculación que aquí entonces se propone entre periodismo, medios de comunicación y literatura de viajes se enmarca dentro de un enfoque crítico-narrativista que incorpora a todos estos elementos dentro del concepto de industria cultural, y que ha posibilita a autores como del Valle (2018) proponer análisis en torno a las continuidades en la producción de lo que él denomina "enemigo íntimo" que permite excluir a grupos étnicos como los mapuches, que es el caso que estudio del Valle. En este sentido se señala que ya durante los siglos XIX y XX funcionaron formas de pensar y ver a la alteridad como enemiga donde confluyen los relatos de la prensa, literatura, crónicas, memorias y discursos políticos, económicos y judiciales: “(...) forman parte de una estructura de tipo industria cultural que ha actuado de modo sistemático e histórico (...) (del Valle, 2018, p.51)".

De modo similar, resulta coherente pensar como formas prematuras de medios de comunicación a los antiguos relatos de viaje del siglo XIX y a las aún más antiguas relaciones de sucesos del siglo XV-XVI y siglos posteriores. Esta coherencia viene dada por la definición que teóricos como Thompson (1998) han hecho de la comunicación mediática o mediatizada: "(...) la producción institucionalizada y difusión generalizada de bienes simbólicos a través de la fijación y transmisión de información o contenido simbólico.” (Thompson, 1998, p.47).

Así, se considera para los fines de este trabajo que tanto las relaciones de los viajes netamente coloniales como la de Pigafetta y tantos otros, junto con las revistas de viaje que surgen con cuatro siglos de distancia, como la francesa Le Tour du Monde, son formas prototípicas de medios de comunicación que conforman una industria cultural en el marco de una situación colonial en un caso (siglo XV-XVI) y de un (pos)colonialismo en el otro caso (siglo XIX-XX). 


\section{Marco metodológico}

\subsection{Modelo de análisis semio-discursivo}

El modelo semio-discursivo que aquí se propone retoma elementos de la semiótica narrativa desarrollada en Francia desde mediados del siglo pasado con los trabajos de Greimas (1973, 1980), Bremond (1964, 1966), Todorov (1971), Barthes (1966), y otros autores que desarrollaron su labor investigativa sobretodo en Francia en lo que hoy se ha venido a denominar "Escuela Semiótica de París" donde confluyen corrientes, epistemes y métodos diversos aunque con una preocupación transversal por los conjuntos significantes, la narratividad y la discursividad (Fontanille, 2009).

\section{Figura 1. Modelo de análisis semio-discursivo}

\begin{tabular}{|c|c|c|}
\hline $\begin{array}{l}\text { NIVEL DE } \\
\text { ANALISIS }\end{array}$ & COMPONENTES & DEFINICION \\
\hline \multirow[t]{2}{*}{ Figurativo } & Figuras & $\begin{array}{l}\text { Calificaciones y sustituciones entre } \\
\text { conceptos }\end{array}$ \\
\hline & Isotopías & $\begin{array}{l}\text { Unidad significacional de universos } \\
\text { semióticos }\end{array}$ \\
\hline \multirow[t]{4}{*}{ Narrativo } & Programas narrativos & \multirow{4}{*}{$\begin{array}{l}\text { Los programas narrativos se } \\
\text { entienden como la búsqueda de } \\
\text { objetos de valor en disputa } \\
\text { entendiéndolos como motor de } \\
\text { significación (Greimas, 1973) con los } \\
\text { que los actantes entran en relación } \\
\text { (Courtes, 1980). Estos objetos } \\
\text { generan un hacer lo que da lugar a } \\
\text { programas narrativos (GDE, 1979) } \\
\text { modalizados por un hacer de tipo } \\
\text { sancionatorio o competente (Idem.) en } \\
\text { el que entran en relación ayudantes y } \\
\text { oponentes (ECE, 1980; Courtes, } \\
\text { 1980, etc.). }\end{array}$} \\
\hline & $\begin{array}{l}\text { Objetos de valor en } \\
\text { disputa }\end{array}$ & \\
\hline & $\begin{array}{l}\text { Modalización (poder, } \\
\text { querer, deber, saber) }\end{array}$ & \\
\hline & $\begin{array}{l}\text { Ayudantes y } \\
\text { oponentes }\end{array}$ & \\
\hline Axiológico & $\begin{array}{l}\text { Estructura y valores } \\
\text { elementales de la } \\
\text { significación }\end{array}$ & $\begin{array}{l}\text { Unidades dicotómicas que entran en } \\
\text { relaciones lógicas de contrariedad y } \\
\text { contradicción incluyendo la } \\
\text { posibilidad de elementos intermedios } \\
\text { mediante metatérminos }\end{array}$ \\
\hline
\end{tabular}


Si bien el desarrollo de mediados del siglo pasado en torno a la semiótica puso énfasis en los elementos estructurales y en la inmanencia del texto, hoy es posible visualizar propuestas donde la semiótica del discurso o el análisis semio-discursivo aparecen más bien como un método que puede ser útil para visualizar las narrativas y significaciones propias de determinada cultura, entendidas estas como conjuntos significantes (Fontanille, 2004; Abril, 1999).

El modelo de análisis utilizado consta de tres niveles de análisis: nivel figurativo, nivel narrativo/actancial y nivel axiológico. Estos niveles se describen en la figura 1 y son tomados por Fontanille (2004) para dar cuenta de una semiótica de los textos y los discursos como un método de análisis cualitativo para las ciencias sociales.

\section{Resultados: entre información/veracidad y espectáculo/exotismo \\ 3.1. La dimensión informativa y de veracidad}

Pigafetta comienza señalando en las primeras páginas de su relato lo que motiva su embarco en la expedición magallánica y aquello que lo moviliza a salir de la comodidad que le ofrecía estar al servicio del Obispo Monseñor Chieregato:

Como por los libros que había leído y por las conversaciones que había sostenido con los sabios que frecuentaban la casa de este prelado, sabía que navegando el Océano se observan cosas admirables, determiné de cerciorarme por mis propios ojos de la verdad de todo lo que se contaba, a fin de poder hacer a los demás la relación de mi viaje, tanto para entretenerlos como para serles útil y crearme, a la vez, un nombre que llegase a la posteridad. (Pigafetta, 2012, p.8)

Aparece entonces una modalización de tipo veredictoria; un querer saber que orienta la narratividad del relato, más allá de que el objeto de la misión era llegar a las islas Molucas por una vía alternativa a aquella de la que disponían los portugueses. Pigafetta busca erigirse como el adalid de la verdad que puede testimoniar la veracidad de las historias de ultramar que escuchaba en su posición privilegiada de cortesano eclesiástico; "cerciorarse de la verdad" aparece como el deseo y el valor en disputa que da sentido a su viaje. Apenas iniciado el recorrido se 
aprecia el tenor del relato que articula Pigafetta en torno a desmantelar cualquier suerte de fábula que aparezca como puro mito y que no tenga un sustento de realidad que permita la información que en sus términos debe ser útil. La búsqueda de la verdad aparece entonces como una isotopía ineludible en el relato:

Nos contaron de esta isla un fenómeno singular, que en ella jamás llueve, y que no hay fuente ni río, pero que crece un árbol grande cuyas hojas destilan continuamente gotas de un agua excelente, que se recoge en una cavidad al pie del árbol, donde los isleños van a coger el agua, y los animales, tanto domésticos como salvajes, a abrevarse. Una neblina espesa, que sin duda suministra el agua a las hojas, envuelve constantemente a este árbol." (Pigafetta, 2012, p. 13)

El relato del primer viaje alrededor del globo se posiciona entonces como un texto que busca (re)fundar el conocimiento y sustentarlo en la novedad de la información recogida, descartando así los mitos añejos: "Aquí experimentamos vientos contrarios o calmas chichas acompañadas de lluvias, (...) habiendo durado este tiempo lluvioso sesenta días, a pesar de la opinión de los antiguos." (Pigafetta, 2012, p.13)

Sin embargo, se aprecia dentro de este ambicioso programa narrativo la prominencia de figuras religiosas entendidas como parte del conjunto significacional de la época y que aparecen como una isotopía a lo largo del relato. $\mathrm{Al}$ respecto, en ningún caso se podría considerar el texto de Pigafetta como un intento "científico" cuando aún faltan al menos tres siglos para la conformación de las ciencias modernas: "En medio de estas islas experimentamos una tormenta terrible, durante la cual los fuegos de San Telmo, de San Nicolás y de Santa Clara se vieron varias veces en la punta de los mástiles; notándose cómo, cuándo desaparecían, disminuía al instante el furor de la tempestad." (Pigafetta, 2012, p.20)

El texto como la mayoría de las relaciones de sucesos y crónicas de viajes relativas al "nuevo mundo" del siglo XV-XVI se encuentran a medio camino entre una concepción medieval del mundo centrada en Dios y la comunidad, y una concepción moderna del mundo centrada en el valor de las mercancías y el esfuerzo individual, cuestión a la que 
se ha referido Todorov (2007), al caracterizar los diarios de viaje de Cristóbal Colón.

"Durante las horas de borrasca, vimos a menudo el Cuerpo Santo, es decir, San Telmo. En una noche muy oscura, se nos apareció como una bella antorcha en la punta del palo mayor, donde se detuvo durante dos horas, lo que nos servía de gran consuelo en medio de la tempestad. En el momento en que desapareció, despidió una tan grande claridad que quedamos deslumbrados, por decirlo así. Nos creíamos perdidos, pero el viendo cesó en ese mismo momento." (Pigafetta, 2012, p. 14)

Después de relatar este milagro, que aquí se podría considerar como parte de una espectacularización, pero que para Pigafetta era probablemente una información de carácter sobrenatural, el cronista retoma enseguida su tono naturalista describiendo al detalle aves de diferentes especies, y la geografía que rodea al viaje, haciendo gala de detalles etnográficos que le permiten hacer relación de indígenas del Brasil a los que dedica fácilmente cuatro o cinco páginas de descripción informativa que atiborra el texto: "Muchas otras cosas podría decir de sus costumbres, que omito por no hacerme demasiado prolijo." (Pigafetta, 2012, p. 18)

Cuando el cronista no tiene respuesta para las causas de aquello que consigna, se contenta con el hecho de que haber sido testigo del hecho, que, aunque sin explicación, aparece para él como una verdad digna de ser contada: "Se nos aseguró que diariamente un pájaro negro, del tamaño de un cuervo, venía durante la noche a posarse sobre las casas (...) No se nos quiso jamás decir la causa de este fenómeno del que todos fuimos testigos." (Pigafetta, 2012, p.74)

Dentro de esta modalización veredictoria Pigafetta se apoya no tan solo en su calidad de testigo ocular sino en el testimonio de otros sujetos, apareciendo como una suerte de proto-reportero que se vale de sus fuentes para la construcción de la noticia. Si el acceso a los acontecimientos queda para él vedado, echa mano a ayudantes que aparecen como fuentes información real y verídica, y que por tanto, resultan para Pigafetta pertinentes: "No he presenciado nada de todo lo que acabo de contar y escribo estos detalles simplemente por la 
relación de un moro que me aseguró haber visto todo eso." (Pigafetta, 2012, p. 142)

Se dice que el rey de Burné posee dos perlas tan grandes como huevos de gallina y tan perfectamente redondas, que, colocándolas sobre una mesa bien lisa, no se están jamás quietas. Cuando le llevamos nuestros presentes, le manifesté por señas que deseaba mucho verlas, y aunque prometió mostrárnoslas, no lo merecimos, pero algunos de los jefes me dijeron que el hecho era exacto. (Pigafetta, 2012, p. 96)

Sin embargo, la primacía de la propia experiencia aparece como la validación preponderante del relato del italiano. Esta experiencia le permite dar cuenta, informar y ser útil, con información certera y de primera mano, lo que al mismo tiempo va dando forma al ideal de Pigafetta de crearse "(...) un nombre que llegase a la posteridad." (Pigafetta, 2012, p.8):

"En seguida corrimos doscientas leguas al oeste; después de lo cual cambiamos de nuevo de dirección, corriendo a cuarta de sudoeste, hasta que nos hallamos por el grado $13^{\circ}$ de latitud septentrional. Esperábamos llegar por esta ruta al cabo de Gaticara, que los cosmógrafos han colocado a esta latitud; pero se han equivocado, porque esta cabo se halla $12^{\mathrm{a}}$ más al norte. Sin embargo, es preciso disculparles el error, ya que no han visitado, como nosotros, estos parajes. "(Pigafetta, 2012, p.38)

La misma característica que se ha propuesto en torno al "Primer viaje alrededor del globo" como un ejercicio de (re)fundación del conocimiento sustentado en la novedad de un viaje nunca antes realizado y por lo tanto la novedad de la información recogida, aparece en la revista Le Tour du Monde del siglo XIX. Al respecto el editor de la revista, Edouard Charton señala en el prefacio al primer número de la serie:

Nuestro campo es vasto; podemos decir que es ilimitado. No solamente la tierra no está enteramente conocida, y cada día nos revela descubrimientos importantes [...] si no que aún la mayor cantidad de regiones que podríamos creer mejor exploradas, lo han sido sólo imperfectamente. (Charton, 1860, p.VII) 
Así, Edouard Charton, reivindicará la idea de educación que hay detrás de la revista, lo que tenga que ver quizás con su faceta política y su vinculación con el san simonismo, y por extensión, con el positivismo. En 1862 crea la revista científica Cosmos y en 1864 la Biblioteca popular de Versailles. Participa además en el departamento de educación popular, encontrándose con anterioridad a la creación de Le Tour du Monde siempre ligado al mundo de la educación. (Sirven, 1993, p.265; Grijalba, 2003, p.74).

La dimensión figurativa del análisis muestra la presencia de figuras que dan cuenta de una relevancia científica para la época en cuestión: "Este Kupulué, muy curioso desde el punto de vista etnográfico $\mathrm{C}_{2}$ merece una pequeña descripción.” (De la Vaulx, 1900: 234). La isotopía relacionada con la preponderancia (pseudo)científica de la época se reitera como una forma de cualificación de los viajeros de finales del siglo XIX y comienzos del XX:

“(...) como ya le he dicho que mis locuras tienen especialmente un objetivo antropológico, él me señala que hace apenas dos meses vio enterrar un Tehuelche que los indígenas consideraban como un gigante. Él me promete indicarme mañana el lugar exacto de la sepultura." (De la Vaulx, 1900: 240)

Las figuras relacionadas al cientificismo que inunda la época y que conforma un ideal comunicativo en términos de formas y contenidos (Mattelart, 1995) y la construcción de un paradigma racial con bases científicas (Reynaud, 2006). Este afán cientificista que inunda la época del s.XIX-XX y que se constituye por tanto en un referente histórico para analizar estos relatos, nos permite entender esta dimension factual y veredictoria que se vincula con el afán de informar y presentar pruebas feacientes en torno a la verdad de lo que se describe en los relatos.

Así, el viaje del sueco Otto Nordenskjoeld (Nordenskjoeld, 1902) comienza presentándose como de naturaleza científica ligado a una expedición en la tierra del fuego cuestión que viene a justificar la supuesta misión científica, educadora y divulgativa de Le Tour du Monde. En este sentido, otros números de la revista incluyen relatos de otros connotados hombres de ciencia de la época. Destaca un relato firmado por Charles Darwin y otro de Gustave LeBone. 
Más allá de la importancia en la reivindicación científica y la educación que le atribuyen algunos a Le Tour du Monde, una cosa es segura: la revista se mueve entre los límites de la descripción científica y los relatos de aventura. Benize-Daoulas (2002) habla en este sentido de una "polifonía textual", donde se plasman las etapas del viaje, bajo una narratividad que sigue la lógica del itinerario (inicio-final), y donde al mismo tiempo se plasman las experiencias, reflexiones y recuerdos del viajero; es lo que respectivamente Benize-Daoulas llama el "eje sintagmático" y el "eje vertical de fragmentación", y que orientan en conjunto el relato. (Benize-Daoulas, 2002, p. 187-188). Así, en ocasiones hay textos con una orientación más bien descriptiva y que van a renegar de la novela y de la literatura (Antoine, 2006), mientras otros que estarán orientados hacia la escritura de espectáculo (Weber, 2006; Martin, 2007).

\subsection{La dimensión espectacular y exotista}

La posición hasta aquí planteada da cuenta de que más que una distinción absoluta entre el motivo informativo y el de entretención, los relatos de viajes analizados mezclan ambas dimensiones donde estás se funden y con-funden para articular la descripción de tierras lejanas y de la alteridad que se encuentra en ellas. La territorialidad misma en este sentido aparece como una figura de alteridad; de lo otro, desconocido y, por lo tanto, exótico: ¡En todas partes espectáculos singulares, curiosos, solemnes, emocionantes!" (Charton, 1860, p. VIII)

Se mezcla así la dimensión informativa y divulgativa junto con la de entretención y espectáculo:

Le Tour du Monde no está, además, destinada a ninguna clase especial de lectores. Esto no respondería a la intención de sus fundadores, si no fuera tan variada y tan universal como el objeto que persigue; el espectáculo verdadero y animado de la naturaleza y de la vida humana sobre toda la superficie de la tierra. (Charton, 1860, p. V)

Se propone aquí que es en esta dimensión espectacular en donde se configura la significación de lo exótico que no es otra cosa sino el posicionamiento de una lógica colonial por la cual el otro, la alteridad, 
queda relegada a un plano anecdotario, curioso y donde se posiciona la diferencia radical. En esta configuración de la alteridad el otro y su territorio puede aparecer de manera idealizada, como representante de una humanidad prístina y no contaminada: "En este mundo desierto donde el cazador no había aparecido nunca, los guanacos en grupos numerosos, llegaban a la vista del viajero sin desconfianza y le seguían los pasos. ¡Una impresión de Paraíso terrestre!” (Nordenskjoeld, 1902, p. 24). En paralelo a esta idealización opera una negativización donde el otro aparece como lo extraño, incomprendido e incomprensible: "Apenas en tierra, heme aquí en las calles, en la búsqueda de impresiones sin duda extrañas que no puede dejar de inspirar una ciudad tan alejada de Europa y de las grandes rutas del globo" (Cordemoy, 1896, p. 582)

Aunque siempre estos componentes exotistas se mezclan con la pretensión enciclopedista de la información. Así, en el relato publicado en Le Tour du Monde y relativo al periplo del sueco Nordenskjoeld comienza presentándose la naturaleza de la expedición científica que él dirige, pero al mismo tiempo, no dejará de lado los elementos de aventura y de entretención que definen la polifonía textual de la revista a la cual se ha hecho referencia. Así, las descripciones detalladas de los accidentes geográficos, de la flora, y del clima se hace presente con fuerza en porciones extensas del relato (Nordenskjoeld, 1902, p.16, 22, p.e.) para luego dar paso a cuasi-naufragios, tormentas terribles, y otro tipo de avatares (Ibid, p.24, 28, 48). De esta forma, el traductor señalará en alguna ocasión: "Después de este paréntesis geológico, volvamos al relato del viaje.” (Ibid, p.49), manteniendo así el equilibrio entre educación y entretención. Aunque en ocasiones las divisiones educación/entretención se anulan y la fusión es notable, tal como lo demuestra una porción del texto de De la Vaulx:

"Esta vez, la búsqueda de cráneos ha estado coronada de éxito. En un valle, en medio de arbustos de mata blanca, los exploradores encontrarán tres cadáveres de indios. Sin perder un instante, los exploradores comienzan a trabajar y transforman esa pequeña esquina alegre en un lúgubre anfiteatro de anatomía, comenzando a cortar los cuerpos con sus chuchillos. ¡Una verdadera escena de antropofagia en nombre de la ciencia! Si ustedes quieren experimentar las sensaciones del asesino, 
transfórmense en coleccionistas de cráneos." (De la Vaulx, 1902, p.17)

Se aprecia aquí un aspecto donde la información se vincula directamente con lo espectacular y la entretención ahora en un tono morboso y un tanto burdo. Se trata de un nivel de información similar al rumor o al chisme, donde precisamente se está en la zona fronteriza del conocimiento informativo y de la entretención especulativa.

En este sentido el texto de Pigafetta entrega claros ejemplos de esta información morbosa que tiende más al entretenimiento. Así, Pigafetta discurre en torno a las formas en que los indígenas curan sus dolencias físicas: "Por muy salvajes que sean no dejan estos indios de poseer cierta ciencia médica..." (Pigafetta, 2012, p.26), siguiendo a esto una profusa descripción de sangre, vómitos, incisiones y otras cuestiones morbosas. Del mismo modo describe una oportunidad en la que una indígena colocó un clavo en su vagina señalando que él y el comandante fueron en esta oportunidad "testigos de una aventura singular" (Pigafetta, 2012, p. 19). Esta última anécdota picaresca ligada a la sexualidad se repetirá en ocasiones a propósito de la desnudez de los indígenas (Pigafetta, 2012, p. 16; 17; 22; 39 y ss.) y en otras en relación a cuestiones con un detalle de morbo más acabado, como cuando describe conductas homosexuales de un rey antes de ir a la guerra (Pigafetta, 2012, p. 125-126) o como cuando señala que la preferencia sexual de las indígenas se inclina más hacia los europeos que a los indígenas:

Consignaré otra observación acerca de sus extrañas costumbres. He dicho ya que estos indígenas andan completamente desnudos, sin más que una tira de palmera que les cubre sus órganos genitales. Todos los hombres, tanto jóvenes como viejos, llevan el prepucio cerrado con un pequeño cilindro de oro o de estaño, del grueso de una pluma de ganso, que lo atraviesa de alto abajo, dejando al medio una abertura para el paso de la orina, y guarnecido en los dos extremos de cabezas parecidas a las de nuestros clavos grandes, los cuales también, a veces, se ven erizados con puntas en forma de estrellas. Me aseguraron que no se quitaban jamás esta especie de adorno, aun durante el coito; que eran sus mujeres las que querían eso, siendo ellas las que preparaban de este modo desde la infancia a sus hijos: pero lo 
que hay de cierto es que, a pesar de tan extraño aparato, todas las mujeres nos preferían a sus maridos... (Pigafetta, 2012, p.74-75)

Aparece así la dimensión del "ego fálico colonizador" noción que desarrolla Dussel (1994) a propósito de la actitud de los colonizadores españoles del s. XV y XVI frente a las mujeres indígenas. Según Dussel la relación que se establece entre conquistadores (españoles) y conquistados (indígenas) es una relación de violencia y dominación donde el otro debe ser doblegado. A partir de ahí comienza un proceso ya no de conquista, sino que de "colonización del mundo de la vida", donde "La violencia erótica vino simplemente a mostrar la "colonización" del mundo de la vida indígena” (Dussel, 1994, p.50).

Consideramos aquí el relato de Pigafetta como parte de la avanzada colonizadora principalmente por tres razones: la primera se refiere al hecho de que estos relatos conforman parte de un imaginario colonial que es imposible no vincular con elementos colonizadores. Al respecto, Martinic (2017) ha señalado a Magallanes y su viaje como un elemento fundacional para el descubrimiento de Chile, y en ese sentido, no es menor que común y acertadamente se hable en términos historiográficos de la vinculación inherente entre descubrimiento y conquista. En segundo lugar, operan en el relato de Pigafetta motivos expansionistas y civilizatorios que no es posible vincular sino con un afán de conquista. Se trata en este sentido de avanzar las fronteras de lo civilizado-europeo y reducir lo bárbaro-indígena, en una avanzada que no tiene fin pues no se trata de una frontera física, sino que asociada las significaciones de los europeos (Otazo \& Gallegos, 2011).

El relato de viajes del siglo XIX-XX recoge también este "ego fálico colonizador" en ocasiones a través de breves inserciones, como cuando al ver a las mujeres untarse un barro en la cara les consulta el motivo de este acto y se le señala que es para proteger la cara del viento: "Esta explicación me deja atónito. ¡Hasta dónde puede llegar la coquetería!”. (De la Vaulx, 1900, p.226-227). Esta dimensión figurativa de la sexualidad asociada a la mujer da cuenta del exotismo como forma de entretención y, por cierto, de poder y control. Aparece una modalización de querer en los viajeros, un deseo profundo de poseer que se expresa en la posesión de los cuerpos de la alteridad de la mujer indígena. Staszack (2008) al referirse a la puesta en escena de los cuerpos de la alteridad en el marco de un análisis geográfico cultural señala: "La alteridad del 
indigena se adjuntará a la de la mujerpara estructurar una doble heterosexualidad que articulará el género y la "raza" para avivar mejor el deseo del hombre blanco." (p. 139).

"Todas las mujeres portan alrededor del cuello y de los brazos collares hechos de pequeños huesos de pájaro o de conchas [...] Inútil es señalar que en la Tierra del Fuego como en todas partes, los objetos de adorno ejercen el más grande atractivo para las hijas de Eva [...]" (Nordenskjoeld, 1902, p.34)

Otras significaciones de este ego fálico, y por lo tanto, de la naturaleza pícara y de entretención que tienen estos textos se expresa en formas más extensas y con un componente un tanto más agresivo:

Yo agradezco con un gesto y el mate comienza a circular. Losha, una de las hijas del cacique [Saihuéqué] prepara la yerba. Es una bella criatura Losha; tiene los labios un poco gruesos, pero sus ojos son tan dulces, tan lánguidos. Tiene gestos tan encantadores, tan suaves. Un encanto emana de su persona, se siente que es una mujer, una verdadera mujer, y que usa todos los artificios de seducción de los que puede ser capaz una India. (De la Vaulx, 1900, p.222)

Pigafetta, ya se ha señalado, toma también elementos de esta caracterización centrada en la sexualidad para entretener a su audiencia, dando cuenta de las consecuencias de lo que aquí se denomina "ego fálico" como expresión de colonialidad: "En todas las islas del archipiélago que habíamos visitado, reina la enfermedad del Santo Job [venérea], y aquí mucho más que en ninguna parte, donde la llaman for franchi, esto es, enfermedad portuguesa". (Pigafetta, 2012, p.137)

Pero la dimensión erótica-sexual no es la única figura de entretención y exotismo que desarrolla el italiano en la relación de su viaje. Ya se ha establecido el hecho de que la dimensión veredictoria aparece con una centralidad en el relato. Sin embargo, y sobretodo hacia el final de la relación del viaje, Pigafetta sistemáticamente va posicionando descripciones que responden más bien a la dimensión entretención/exotismo que a la de información/veredicción:

De camino, nuestro viejo piloto moluqués nos contó que en estos parajes hay una isla llamada Amcheto, cuyos habitantes, tanto 
hombres como mujeres, no pasan de un codo de alto y que tienen las orejas tan largas como todo el cuerpo, de manera que cuando se acuestan una les sirve de colchón y la otra de frazada. (...) De buena gana habríamos ido a esta isla, si los bajos y las corrientes no nos lo hubiesen impedido. (Pigafetta, 2012, p.135)

Cierto es que se aprecia aún la naturaleza investigativa y veredictoria sobretodo al final de la cita, pero igualmente resulta notable como el mismo sujeto que al inicio del relato fue capaz de cuestionar el mito de una tierra en la que nunca llueve sea tan magnánimo con lo que resulta a todas luces una fábula añosa.

Nos contaron también que en una isla llamada Ocoloro, más acá de Java, no hay sino mujeres, que son fecundadas por el viento. Si les nace un hijo, le matan en el acto, y si es hija, la crían; y si algún hombre se atreve a visitar la isla, le matan. (Pigafetta, 2012, p.138)

Interesante resulta el hecho de que, al parecer, Pigafetta tiene total claridad de que lo que está relatando son más bien cuentos divertidos para entretener a su público, cuestión que por lo demás declara en el principio de su obra. Esta conciencia de que lo relatado responde a una forma de entretención se delata al señalar en esta etapa final de su relato: "Nos refirieron todavía otras historietas." (Pigafetta, 2012, p. 139), contando posteriormente la historia de un árbol gigante en China donde se juntaban aves capaces de levantar a un elefante, y otras "cosas curiosas" (Pigafetta, 2012, p. 145).

Se señaló más arriba respecto a la modalización veredictoria que Pigafetta actúa como una especie de proto-reportero puesto que no tan solo se apoya en su calidad de testigo, sino que en el caso de aquellas cosas que él no ha podido presenciar se vale de otras fuentes. Esta misma situación es posible apreciar ahora ya no como parte de un relato enfocado en la información de la verdad, sino como una forma de entretención a través de "historietas" que llegan a sus oídos por terceras personas; puede haber aquí una suerte de justificación a modo de evadir la responsabilidad acerca de la verdad o no de estas historias a todas luces poco creíbles, en el sentido de que estos relatos fabulosos no tendrían la misma dimensión de verdad/veracidad de aquello que el propio Pigafetta ha visto y contado. 


\section{Consideraciones finales}

En términos axiológicos y de acuerdo a lo expuesto en los resultados precedentes se considera que la dicotomía fundamental que articula tanto al relato de Pigafetta como a los relatos de viaje de Le Tour du Monde, son las categorías de Verdad y Mentira (figura 2) que se articulan en conjunto con las de información y entretención, donde la verdad (no mentira) estaría vinculada ineludiblemente a una dimensión informativa y a la inversa la mentira (no verdad) se vincularía con la entretención. La designación de "historietas..." por parte de Pigafetta a las historias que evidencian cuestiones míticas pero que entretienen es decidora al respecto.

\section{Figura 2. Valores elementales de la significación}

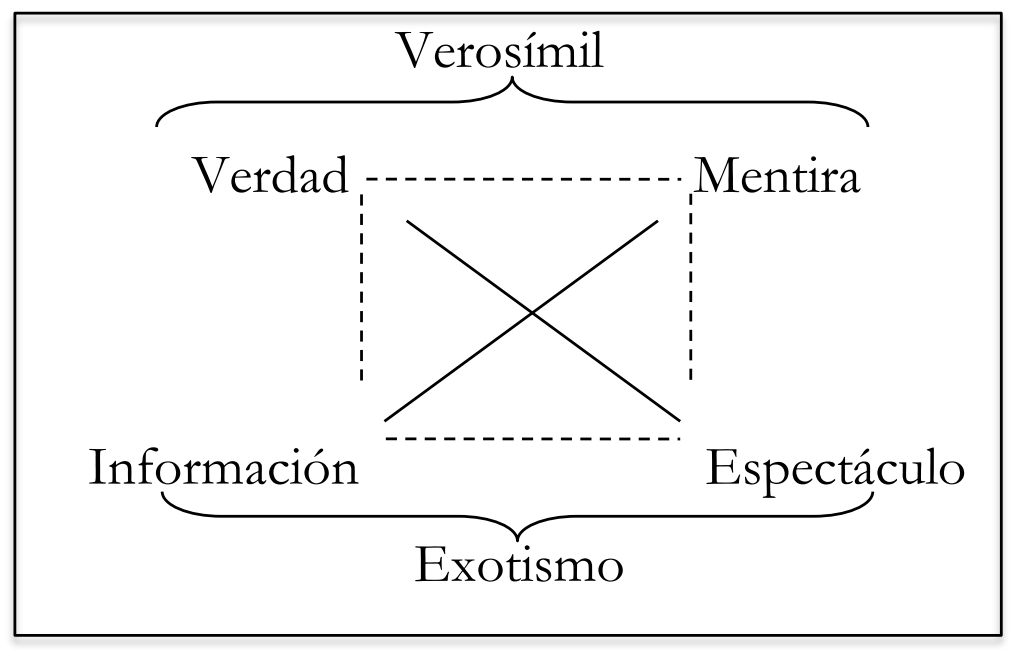

Sin embargo, y de acuerdo a lo expresado en tanto la distinción información/espectáculo constituye una polifonía textual, es posible articular estos conceptos aparentemente dicotómicos que dan cuenta finalmente de la complejidad de los textos analizados; la información y el espectáculo se confunden en el exotismo con el que se simboliza tanto a la tierra desconocido y sus habitantes como expresión de una alteridad distinta a lo europeo, y del mismo modo la verdad con la mentira no aparecen como categorías absolutas sino como una frontera difusa entre lo verosímil.

En términos teóricos, y si a la luz de los antecedentes expuestos se ha hablado de pre-periodismo o paleo-periodismo para las relaciones de sucesos (Bernal y Espejo, 2003; Del Valle, 2004), resulta razonable 
entonces pensar en una categoría para los relatos de viajes ya no del siglo XV-XVI sino para aquellos publicados en revistas de viajes propias del siglo XIX; en este sentido se propone hablar de protoperiodismo para aquellos relatos sobre lugares lejanos publicados en las revistas de viajes que se editan a propósito del periodo colonial propio del siglo XIX e inicios del XX.

Las investigaciones tradicionales en relación al periodismo han posicionado en parte la idea de la existencia de límites diferenciados en torno la dimensión informativa y la de entretenimiento de los medios (Fursich, 2002) en este sentido el "periodismo de viajes" contemporáneo ha sido menospreciado por no ser información pura y dura (Cocking, 2009).

Pues bien, a la luz de lo expuesto es posible tener una postura razonablemente contraria a estas ideas; el periodismo de viajes lejos de ser una forma moderna de periodismo se posiciona como un antecedente del periodismo tradicional donde se mezcla el entretenimiento y la información. Repensar entonces los medios de comunicación modernos considerando sus formas prototípicas permitiría tener un mayor horizonte comprensivo no tanto solo en términos pretéritos, sino que para explicar o entender situaciones actuales (fake-news, por ejemplo) en un contexto de post-verdades donde los límites entre la verdad/mentira y la información/espectáculo (re)aparecen del todo difusos.

\section{Referencias bibliográficas}

Abril, G. (1999). Análisis semiótico del discurso. En: Delgado, J. y Gutierres, J. (Eds.) "Métodos y técnicas cualitativas de investigación en ciencias sociales". Ed. Síntesis. Madrid. pp. 427-463

Albuquerque, L. (2006). Periodismo y Literatura: el "Relato de viajes" como género híbrido a la luz de la pragmática. En: Hernández, J. "Retórica, literatura y periodismo: actas del V Seminario Emilio Castelar. Servicio de Publicaciones de la Universidad de Cádiz. Cádiz. 
Antoine, P. (2006). Ceci n'est pas un livre. Le récit du voyage er le refus de la littérature. En: "Sociétés et Représentations". No 21, Le siècle du voyage. Abril, 2006. Francia. pp. 45-58.

Baczko, B. (2005). Los imaginarios sociales: memorias y esperanzas colectivas. Buenos Aires: Nueva Visión.

Bancel (Editores), "Culture Coloniale en France. De la Révolution française à nos jours”, Ediciones CNRS, Paris, 761 pp.

Barthes, R. (1966) Introduction à l'analyse structurale des récits. En: "Communications", No 8, Recherches sémiologiques : l'analyse structurale du récit. pp. 1-27.

Benize-Daoulas, R. (2002). Voyage en Paulie-Laurencie, essai sur une construction narrative polyphonique. En: "Bulletin Institut français d'études andines". No 31, vol. 2. Francia. pp. 183-218

Bernal, M. y Espejo, C. (2003) Tres relaciones de sucesos del siglo XVII. Propuesta de recuperación de textos preperiodísticos. Recuperado de la siguiente dirección electrónica: https://idus.us.es/xmlui/bitstream/handle/11441/13894/file_ 1.pdf;sequence $=1$ [11-06-2018]

Blanchard, P; Lemaire, S ; y Bancel, N. (2008). La formation d'une culture coloniale en France, du temps des colonies à celui des "gerres de mémoire". pp. 11-64. En: Blanchard Pascal, Sandrine Lemaire y Nicolas

Bremond, C. (1964) Le message narratif. En: "Communications", no4, Recherches sémiologiques, pp. 4- 32.

Bremond, C. (1966) La logique des posibles narratifs. En: "Communications", No8, pp. 60-76

Cardaillac, L. (2015). Lo morisco peninsular y su proyección en la conquista de América. En: Rios, M. (ed.) "El mundo de los conquistadores”. Sílex Ediciones. México. pp. 437-454

Charton, E. (1860). Préface. En : "Le Tour du Monde, nouveau journal des voyages". Seconde semestre, premier anné, Francia, pp. I-VIII. [Trad. Prop.]

Chillón, A. (2002). Literatura y periodismo: una tradición de relaciones promiscuas. Universidad Autónoma de Barcelona. Barcelona.

Cocking, B. (2009). Travel Journalism. Europe imagining the Middle East. En: "Journalism Studies", Vol. 10, No1, pp. 54-68 
Cordemoy, J. (1896). Au Chili (1er. partie). En: "Le Tour du Monde, nouveau journal des voyages". Deuxième année, pp. 577-624. [Trad. Prop.]

Courtes, J. (1980) "Introducción a la semiótica narrativa y discursiva. Metodología y aplicación”. Ed. Librería Hachete S.A, Buenos Aires

De la Vaulx, H. (1900). En : Voyage en Patagonie. En : "Le Tour du Monde, nouveau journal des voyages". Nouvelle série, $\sigma^{\mathrm{e}}$ année, Francia, pp. 193-264. [Trad. Prop.]

Del Valle, C. (2004) Los indígenas de Chile en las Relaciones de Sucesos españolas: representación y memoria desde la interculturalidad. Revista ZER, vol. 9, Núm. 16

Del Valle, C. (2018). La producción del enemigo íntimo en la industria cultural chilena: Crítica a la certeza moral, la razón neoliberal y la sujeción criminal. En: Caldevilla, D. (Coord.) "Perfiles actuales en la información y en los informadores". Ed. Tecnos. Madrid. pp. 51-68

Dittus, R. (2011) El imaginario social del otro interiorizado. Taxonomía de la alteridad como espejo del yo contemporáneo. En: Coca, J; Valero, J; Randazzo, F; Pintos, J. (coord.) "Nuevas posibilidades de los imaginarios sociales". Ed. CEASGA. La Coruña. pp. 67-98

Dussel, E. (1994). “1492. El encubrimiento del otro. Hacia el origen del mito de la modernidad”. Ed. Plural. La Paz. 186 pp

ECE, (Equipe Cahiers Evangile). (1980) "Iniciación en el análisis estructural". 2a edición. Editorial Verbo Divino. Navarra

Flores, J. (2000). Europeos en la Araucanía. Los colonos del Budi a principios del siglo XX. En: "Revista Iberoamericana". No 8. año 2000. pp. 313-329

Fontanille, J. (2004) Sémiotique des textes et des discours. En : Mucchielli, A. "Dictionnaire des méthodes qualitatives en sciences humaines". $2^{a}$ edición. Ed. Armand Colin. Paris. pp. 251-253

Fontanille, J. (2009) Sémiotique de l'École de Paris. En : "Vocabulaire des études sémiotiques et sémiologiques", Presses Universitaires de France-Comté, Paris. pp. 43-48. 
Fursich, E. (2002) How Can Global Journalism Represent the 'Other'? A critical assessment of the cultural studies concept for media practice. En: “Journalism” 3(1), pp. 5788.

GDE, (Groupe d'Entrevernes). (1979) "Analyse sémiotique des textes.” 6a Edición. Presses Universitaires de Lyon, Lyon.Genette, G. (1998) "Nuevo discurso del relato”. Ed. Cátedra. Madrid.

Giroud, J.C. \& Panier, L. (1988) "Semiótica". Editorial Verbo Divino. Navarra.

Greimas, A.J. (1973) Un problème de sémiotique narrative: les objets de valeur. En: "Langages", 8e année, n³1, pp. 13-35

Greimas, A.J. (1980) Las adquisiciones y los proyectos. En: Courtes, J. "Introducción a la semiótica narrativa y discursiva.

Metodología y aplicación”. Ed. Librería Hachete S.A, Buenos Aires, pp. 5-25

Grijalba, C. (2003). Viajar contar, soñar... con Le Tour du Monde. pp. 71-84. En: Iñarrea Ignacio y Salinero María Jesús (coordinadores). "El texto como encrucijada: estudios franceses y francófonos". Ediciones Universidad de la Rioja. España.

Hall. S. (2010a) Etnicidad: identidad y diferencia. En: Restrepo, E; Walsh, C. y Vich, V. (eds.) "Sin garantías: Trayectorias y problemáticas en estudios culturales". Envión editores. Colombia. pp. 339-348

Huerta, M. (2002). Le voyage aux Amériques et les revues savantes françaises au XIXe siécle. En: Bertrand michel et Vidal Laurent (dir.) A la redéconverte des Amériques. Les voyageurs européens au siècle des indépendances. Tolousse: PUM (Presses Universitaires du Mirail). pp. 73-93.

Martin, M. (2007). Le voyage du grand reporter, de la fin du XIXe siècle aux années 1930. En: "Les temps des Médias". No 8. 2007. pp. 118-129.

Martinic, M. (2017). "Hallazgo y navegación del estrecho de Magallanes". Punta Arenas. Editorial La Prensa Austral

Mattelart, A. (1995). “La invenciñn de la comunicaciñn”. Cap. 3-5. pp. 82-169. Siglo XXI editores. Madrid. 386 p.

Mignolo, W. (2007). "La idea de América Latina: la herida colonialy la opción decolonial." Ed. Gedisa. Barcelona. 241 pp. 
Navarro, P. (2005). La conquista de la memoria. La historiografía sobre la frontera sur argentina durante el siglo XIX. En: "Revista Universum", No20, vol.I, pp. 88-111.

Nordenskjoeld, O. (1902). La terre du feu. En : "Le Tour du Monde, nouveau journal des voyages". Nouvelle série, 8 e année, Francia, pp. 13-60. [Trad. Prop.]

Otazo, J. \& Gallegos, E. (2011). La Frontera infranqueable : La aracanía en los relatos de viaje de los dos ingenieros francófonos en el Chile de fines del siglo XIX (Gustave Verniory y Camille Jacob de Cordemoy). En: "Revista S", vol. 5, pp. 127-144

Pigafetta, A. (2012). "Primer viaje alrededor del Globo". Ed. Fundación Civiliter. Sevilla.

Pinto, J. (2003). "De la inclusión a la exclusión: la formación del estado, la nación y el pueblo mapuche". 2a edición. Dibam eds. Santiago. 248 $\mathrm{p}$.

Pinto, J. (2008). Proyectos de la elite chilena del siglo XIX (I). En: "Revista Alpha", No 26, Julio 2008, pp. 167-189

Pratt, Mary Louise. Ojos imperiales: literatura de viajes y transculturación. Buenos Aires: Fondo de Cultura Económica, 2011

Rabasa, J. (2009). Poscolonialismo. En: Szurmuk, M. \& Mckee, R. (coord.) "Diccionario de Estudios Culturales Latinoamericanos". Siglo XXI editores. México. pp. 217-221.

Reynaud, C. (2006). "La république raciale. 1860-1930". Primera Parte: La construction scientifique du paradigme racial au sein de la société d'anthropologie de Paris. pp. 9-147. Presses Universitaires de France (PUF). París. 338 p.

Said, E. (1990). “Orientalismo”. Ed. Libertarias. Madrid.

Said, E. (2005). Cultura, identidad e historia. En: Schröder, G. \& Breuninger, H. (comps.) "Teoría de la cultura. Un mapa de la cuestión”. Fondo de Cultura Económica. Bs. As. pp. 37-54

Salgado, I. (2016). Contexto histórico de la Araucanía a mediados del siglo XIX. En: Salgado, I. (Comp.) "Travesías por la Araucanía. Relatos de viajeros de mediados del siglo XIX”. Eds.

Universidad Católica de Temuco. Chile.

Sirven, H. (1993). "L'image de l'Océanie a travers la revue Le Tour du Monde (1860-1914). Figures de l'exotisme”. Thèse d'esthétique, 
Doctorat Nouveau Régime. Sous la direction de Gilbert

Lascault, Université de Paris I, Panthéon Sorbonne, 908 pp.

Solórzano-Thompson, N. \& Rivera-Garza, C. (2009) Identidad. En:

Szurmuk, M. \& Mckee, R. (coord.) "Diccionario de Estudios

Culturales Latinoamericanos". Siglo XXI editores. México. pp.

138-144

Spurr, David. La retórica del Imperio. El discurso colonial en periodismo, escritura de viajes y administración imperial. Santiago: Ediciones Universidad Alberto Hurtado, 2013

Staszak, J. (2008). Danse exotique, danse érotique. Perspectives géographiques sur la mise en scène du corps de l'Autre (XVIIIeXIXe siècles). En: “Annales de Géographie”. No 660-661. Où en est la géographie culturelle? Año 117. Marzo-Junio, 2008. Francia. pp. 129-158

Surun, I. (2007). Les figures de l'explorateur dans la presse du XIXe siècle. En: "Les temps des Médias". No 8. 2007. Francia. pp. $57-74$

Thompson, J. (1998). "Los media y la modernidad”. Barcelona. Editorial Paidós

Todorov, T. (1971) “Literatura y significación”. Ed. Planeta. Barcelona

Todorov, T. (2003). "La conquista de América: el problema del otro". 2a edición. Siglo XXI editores. Buenos Aires

Varona, D. \& Herrero-Diz, P. (2018). Verdad y propaganda en el legado escrito de la primera vuelta al mundo. En: "Revista de Occidente". $\mathrm{N}^{\circ}$ 440, enero. pp. 5-16

Venayre, S. (2006). Pour une histoire culturelle du voyage au XIX siècle. En: "Sociétés et Représentations". No 21, Le siècle du voyage. Avril, 2006. Francia. pp. 5-21. [Trad. Prop.]

Wallerstein, I. (2007). 'Universalismo Europeo: el discurso del poder”. Siglo XXI, México

Weber, A. (2006). Le genre romanesque du récit de voyage scientifique au XIX siècle. En: "Sociétés et Représentations". No 21, Le siècle du voyage. Abril, 2006. Francia. pp. 59-77 


\title{
Dos travesías, dos formas de relatar la vuelta al mundo: Antonio Pigafetta, Richard Hakluyt y The World Encompassed
}

\author{
Irene Rodríguez Cachón \\ Universidad Loyola Andalucía, ULA \\ Beatriz Valverde \\ Universidad Loyola Andalucía, ULA
}

Cómo citar: I Rodríguez Cachón, B Valverde (2019): “Dos travesías, dos formas de relatar la vuelta al mundo: Antonio Pigafetta, Richard Hakluyt y The World Encompassed". Revista Latina de Comunicación Social, En P Herrero-Diz/A Cárcamo/V Rodríguez Breijo/R Mancinas (Eds.) V Centenario / $1^{\text {a }}$ Vuelta al Mundo. Cuadernos Artesanos de Comunicación, cac161, pp 145-173. La Laguna (Tenerife): Latina. DOI: 10.4185/cac161

\begin{abstract}
Abstracs
Introducción. El propósito de este trabajo es analizar los mecanismos argumentativos y apelativos de los tres textos principales que narran las primeras cicunnavegaciones al mundo. Por un lado, la española de Magallanes-Elcano (1519-1521), descrita por Antonio Pigafetta en la Relación del primer viaje alrededor del mundo y, por otro, la inglesa de Francis Drake (1577-1580), descrita en "The Famous Voyage of Sir Francis Drake" y The World Encompassed by Sir Francis Drake. Metodología y resultados. El análisis comparativo de los textos anteriores revela que en pleno siglo de los descubrimientos ambos países buscaron similares formas discursivas a la hora de dar cuenta a la Corona y comunicar al mundo los nuevos lugares descubiertos.
\end{abstract}




\section{Keywords}

Antonio Pigafetta, Richard Hakluyt, The World Encompassed, relato de viaje, circunnavegación.

\section{Contents}

1. Justificación preliminar 2. El relato del viaje español 1.1. Sobre la Relación del primer viaje alrededor del mundo (1536) de Antonio Pigafetta 3. El relato del viaje inglés 3.1. "Sir Francis Drake's Famous Voyage Round the World": la primera crónica sobre la travesía de Francis Drake 3.2. The World Encompassed, o la exaltación de Sir Francis Drake como héroe nacional 4. Consideraciones finales y coda 5. Bibliografía

\section{Justificación preliminar}

L PROGRAMA de televisión británico Cunk on Britain ${ }^{1}$, de cinco
episodios de duración y emitido en el segundo canal de la cadena pública BBC, busca contar la historia de Gran Bretaña sarcásticamente desde el Big Bang hasta el Brexit. Concebido y entendido como un mockumentary (o una docu-comedy), grabado en un ambiente pseudoartificial de documental histórico real, está escrito por el conocido satírico y escritor inglés Charlie Brooker ${ }^{2}$ y protagonizado por la escritora y actriz británica de comedia Diane Morgan, que bajo su alter ego de Philomena Cunk rastrea desde un punto de vista hilarante tanto al almirante Nelson o la historia de los Tudor, como la llegada de la patata a Gran Bretaña o la adicción crónica a las bodas de Enrique VIII, entre una gran variedad de temas históricos, sociales y culturales.

\footnotetext{
${ }^{1}$ Todos los episodios de este programa de televisión pueden verse en abierto a través de la página web de la BBC2 (Cunk on Britain, https://bbc.in/2VcmcYQ [consultado el 02/02/2019]).

${ }^{2}$ Entre otros, Charlie Brooker es conocido por ser el creador de la conocida antológica serie de televisión británica Black Mirror, emitida en sus dos primeras temporadas por el Channel 4 británico y sus dos siguientes a través de la plataforma de video bajo demanda Netflix.
} 
Sin embargo, parece que el episodio 2, estrenado el 10 de abril de $2018^{3}$, creó cierta controversia entre parte de su audiencia, especialmente la de nacionalidad española, y pocos días después El Confidencial digital titulaba lo siguiente: "Centenares de españoles, indignados con un falso documental de la BBC que le arrebata un hito a Juan Sebastián Elcano". El motivo, alega el periódico, es que este capítulo "genera confusión y enfado al asegurar que el pirata Drake fue el primero en 'circuncidar' [y no 'circunnavegar'] la tierra, y no el marino de Guetaria". Este hecho ocurre en el momento en el que Philomena Cunk se sube a bordo de una réplica del Golden Hinde, varado actualmente en el St Mary Overie Dock en Londres, barco con el que Francis Drake circunnavegó el globo entre 1577 y 1580, es decir, cincuenta y ocho años después de la primera vuelta al mundo liderada por Magallanes-Elcano. Aunque la clara, pero sutil, broma consiste en un simple juego lingüístico entre ambos términos, 'circuncidar' por 'circunnavegar', no todos los espectadores lo entendieron así y rápidamente comenzaron a aparecer en diferentes redes sociales comentarios críticos contra la cadena ${ }^{5}$ y el desacierto, según ellos, de este tipo de humor que genera confusión entre la audiencia en el acercamiento y conocimiento de cualquier hecho histórico.

${ }^{3}$ El capítulo 2 completo, y el clip concreto titulado "Life on board Sir Francis Drake's ship", puede verse completo en la página web de la BBC2 (Cunk on Britain, Episode 2, https://bbc.in/2XgNpv3 [consultado el 02/02/2019]).

${ }^{4} \mathrm{El}$ artículo completo puede verse en El Confidencial digital, 20 de abril de 2018, https://bit.ly/2XgY219 [consultado el 02/02/2019].

${ }^{5}$ Algunos comentarios que se pueden ver en el perfil público de Facebook del programa son los siguientes: "Dear BBC. The first travel around the world is the one made by Fernando de Magallanes and Juan Sebastián Elcano, Spanish. I invite you to study a little bit more about Spanish history, you will be amazed". "You are liars, the first person to sail around the world was the Spanish sailor Juán Sebastián Elcano, Drake was simply a thief and a low-pitched pirate, as well as a coward. "Drake was a pirate at the service of the queen of England. He was not the first to circumnavigate the globe, was Juan Sebastian Elcano from Spain, Drake was the first English man to do it, is a big difference". "I'm sorry Philomena, you've shown us the second ship to go around the world. The first was Nao Victoria (1519-1522), on the Magallanes-Elcano expedition" (@CunkOnBritain, [Actualización de Facebook] https://bit.ly/2GFfN5c, consultado el 02/02/2019). 
Este bastante anecdótico, pero ciertamente provocativo a su vez, hecho televisivo nos hace volver de nuevo la mirada a la intensa y extensa relación histórica de rivalidad en cuanto a la exploración del mundo que han mantenido a lo largo de la historia España y el Reino Unido. Así, chocan continuamente sentimientos como la admiración y la afectividad mutua, contra otros contradictorios como el temor, el orgullo o la subestimación y deslegitimación de uno con el otro y viceversa. En este sentido, siempre juega un papel clave quién, cuándo y cómo se cuentan estas expediciones, dimensión que en pleno siglo XVI tomaba en muchas ocasiones forma de diario, libro, crónica o relato de viajes.

Así, y en lo que respecta a la expedición liderada por MagallanesElcano -financiada por capital privado español ${ }^{6}-$, y que culminará con la primera vuelta al mundo, fue el cronista italiano Antonio Pigafetta (c. 1480-c. 1534) el encargado de tomar las notas preceptivas sobre todo lo que acontecía en el viaje. Pigafetta concretó a posteriori a mano estos apuntes bajo el formato de un libro o crónica del viaje, texto que se publicará primero en francés, con fecha incierta entre 1526 y 1536 y, posteriormente en 1536 en italiano. El texto que actualmente conocemos bajo el título de Relación del primer viaje alrededor del mundo no es más que una relaboración de todas estas primitivas versiones.

Por otro lado, y en lo que respecta a la expedición inglesa de circunnavegar el globo - patrocinada por inversores privados y alentada por la Corona británica-, realizada más de medio siglo después de la española y liderada por Francis Drake, fue el historiador Richard Hakuyt (c. 1552-1616) quien se ocupó en primera instancia de construir la narración del viaje a partir de las supuestas anotaciones hechas por el marinero Francis Pretty, recogidas a su vez en un texto publicado en 1589, "Sir Francis Drake's Famous Voyage Round the World", y dentro del libro The Principall Navigations, Voiages, and Discoveries of the English Nation. Posteriormente, en 1628, un sobrino

\footnotetext{
${ }^{6}$ Hay que tener en cuenta que de acuerdo con "la práctica habitual de la corona de Castilla, el viaje se financió con capital privado - principalmente banqueros de Sevilla-, y fue necesario prometer a los inversores una importante participación en los beneficios: la quinta parta de las ganancias que se obtuvieran por cualquier transacción comercial, en un plazo de diez años, y el gobierno de las islas conquistadas" (Fernández-Armesto, 2012: 290).
} 
homónimo de Drake ampliará, retocará y reconfigurará el texto, publicándolo con el título The World Encompassed by Sir Francis Drake.

A partir de estos textos publicados a la culminación de ambos viajes el de Pigafetta con unos quince años de margen después del mismo, el de Hakluyt nueve años después de la travesía y The World Encompassed casi treinta años después-, las siguientes líneas buscarán analizar y descubrir cómo estos cronistas y/o relatores configuraron cada uno su discurso sobre la vuelta al mundo (bajo, obviamente sus propios intereses), cómo comunican tanto a la Corona como a sus compatriotas lo que van viendo y cómo sus crónicas e informaciones participan en el testimonio y transmisión de los hechos que van ocurriendo a lo largo de esta magna travesía alrededor del mundo.

\section{E1 relato del viaje español}

El relato español que conocemos sobre el primer viaje alrededor del mundo, capitaneado por Magallanes-Elcano, y relaborado posteriormente por Antonio Pigafetta no se configura como "una estructura rígida textual al estilo de una narración geográfica ${ }^{7}$, sino que la Instrucción Real entendía que como nadie sabía adónde se iba, se solicitaba detallar todo cuanto el cronista viera; alejándolo así de un mero informe" (Vera, 2013: 116). En este sentido, aunque el texto pigafettiano tiene algunas marcadas características de informe oficial (formato de testimonio en un proceso, vocativos directos hacia el rey, comparaciones con elementos conocidos, obtención de mercedes, etc.), al mismo tiempo contiene muchos y marcados tópicos propios del relato o libro de viajes ${ }^{8}$. Además, el texto contiene también

\footnotetext{
${ }^{7}$ La relación geográfica es un tipo de informe oficial con preguntas tipo que busca conocer lo visto y oído por el cronista. Lo característico de este tipo de texto es representar lo más detalladamente el nuevo espacio descubierto, intentando dejar de lado cualquier apreciación subjetiva.

${ }^{8}$ En este trabajo se utilizarán los términos relato, crónica o libro de viajes de manera indistinta para referirnos a la totalidad de textos, informativos, cronísticos o literarios, que aspiraron a contar un viaje, travesía o expedición cualquiera por el mundo. Aunque no es el objetivo de este trabajo, es importante tener en cuenta también la variedad de formatos y heterogeneidad temática que estos términos abarcaron a su vez: crónicas de indias, cartas de relación, textos de conquista, historias naturales o morales, historias iniciáticas, diarios de abordo, peregrinaciones, naufragios, etc.
} 
ingredientes de escritura etnográfica muy matizada, a su vez, por las narraciones antiguas clásicas de expediciones marítimas griegas y romanas llevadas a cabo por el mar Mediterráneo.

Una idea muy extendida en pleno siglo de los descubrimientos fue el planteamiento que al trasladar al papel todo lo nuevo que acontecía o se veía de un viaje, expedición o travesía había que conectarlo de alguna manera con lo ya conocido. Es lo que Colón entendió como "observar las nuevas tierras con viejos ojos" (Tuninetti, 2011), pero sin que ello supusiera cambiar la experiencia personal previa, las convicciones o los pensamientos propios del que escribe el texto. Sin embargo, este hecho ha acarreado la desafortunada creencia de que muchos de estos relatos de viajes, travesías o expediciones buscaron únicamente "europeizar lo diferente, donde lo indígena es atrapado por una belleza clásica propia de la tradición y cultura europea" (Sanfuentes, 2009: 194). Aun así, la escritura de Pigafetta, aunque colaboracionista con la empresa marítima imperial que lo lleva abordo, no se percibirá completamente como la de un "navegante-colonizador que somete al colonizado" (Vera, 2013: 117), lo que le permite libertad discursiva y cierta visión desapasionada.

Así, el relato del viaje español alrededor del mundo se configura a partir de unas características y condiciones personales casuales de un autor que, sin ser español, y con únicamente una función administrativa, quiere mostrarse como protagonista o testigo principal ocular. Esta posición, en muchas ocasiones también exagerada -con especial énfasis a partir del episodio de los patagones-, no coincide demasiado con su cometido dentro de la expedición, que no era más que la de ser un mero escribano administrativo. Otra perspectiva muy diferente será la que se muestre en el relato inglés, tal y como se verá más adelante en detalle en el apartado correspondiente.

\subsection{Sobre la Relación del primer viaje alrededor del mundo (1536) de Antonio Pigafetta}

Se conocen pocos detalles biográficos de Antonio Pigaffeta, natural de Vicenza (Italia) -"gentilhombre vicentino", como él se describe en la portada de su libro sobre la primera vuelta al mundo- (Pigafetta, 2012: 185), de familia bien posicionada, llegó a ser Caballero de la Orden de San Juan. Recibe una exquisita educación, propia de un ambiente 
plenamente renacentista, destacando en geografía, astronomía y cartografía. No se sabe mucho más de él hasta que en 1518 se instala en Barcelona y desde allí viaje a Sevilla para enrolarse como voluntario en la expedición que Fernando de Magallanes preparaba en la ciudad con la idea de encontrar un paso por el oeste hacia las islas Molucas. Probablemente de complexión fuerte y con muy buena salud, fue uno de los 18 únicos tripulantes, de 265 que zarparon desde España, que sobrevivieron a la ingente travesía, liderada a su fin por Juan Sebastián Elcano.

El libro que hoy conocemos como Relación del primer viaje alrededor del mundo (en el original italiano Relazioni in torno al primo viaggio di circumnavigazione) de Antonio Pigafetta no es en sí misma una obra original e inmediata de su autor sobre el transcurso del viaje, sino que es una reelaboración narrativa posterior, ampliada en los siguientes años, a partir de las notas tomadas en la travesía. A su vuelta, Pigafetta presenta un duplicado del manuscrito a Carlos I en Valladolid en el año 1524 pero esta copia, actualmente perdida, es la que se utilizó como fuente para dar la noticia de la vuelta al mundo al papa Adriano VI, texto que igualmente se pierde en el saqueo de Roma del año 1527. A lo largo de los siguientes años, Pigafetta hará lo mismo en otras cortes europeas, tales como Portugal o Francia, al presentar también otras copias, reproducciones o versiones de su texto.

Entre esta variedad de reproducciones y relaboraciones se conservan actualmente cuatro manuscritos con diferentes textos derivados de esas notas del diario de abordo original de Pigafetta (Cachey, 2007, XLVI): un manuscrito en italiano, custodiado en la Biblioteca Ambrosiana de Milán (sign. L.103 sup.), y tres en francés, conservados dos en la Bibliothèque Nationale de París (sign. MS 5650 y sign. MS fr.24224) y uno en la Beinecke Rare Book and Manuscript Library de la Universidad de Yale (sign. MS 351). Muy probablemente el más antiguo sea el italiano, datado entre 1524-1525, es decir, solo tres años después de su vuelta a España, siendo las copias francesas algo más tardías. Hay que destacar que todas las primeras versiones españolas impresas que conocemos provienen del texto ambrosino y, por tanto, el más alineado en su sentido primigenio al sensus del texto original.

En cuanto a los impresos que se conservan de la época se sabe que la edición princeps del texto se publica en francés (Le voyage et navigation faict 
par les Espaignolzes isles de Mollucques, des isles quilz. ont trouvé audict voyage, des roys d'icelles, de leur gouvernement et manière de vivre, avez plusieurs autres choses) entre 1526 y 1536 y es básicamente un nuevo resumen simplificado del texto ambrosino encargado por la reina regente María Luisa de Saboya, madre de Francisco I de Francia (Arriba, 2004, 57). A partir de este texto francés, en 1536 se publica otra edición italiana dentro de una compilación de textos sobre viajes (Il viaggo fatto dagli Spagnoli atorno al mondo) y en 1550, de nuevo, otra versión italiana dentro de la colección de viajes del geógrafo italiano Ramusio, Navigazioni e viaggi, en la que se incluyen testimonios directos de algunos exploradores de la época. La obra, finalmente, se conocerá en inglés a través de las Decades of the New World (1555) de Richard Eden.

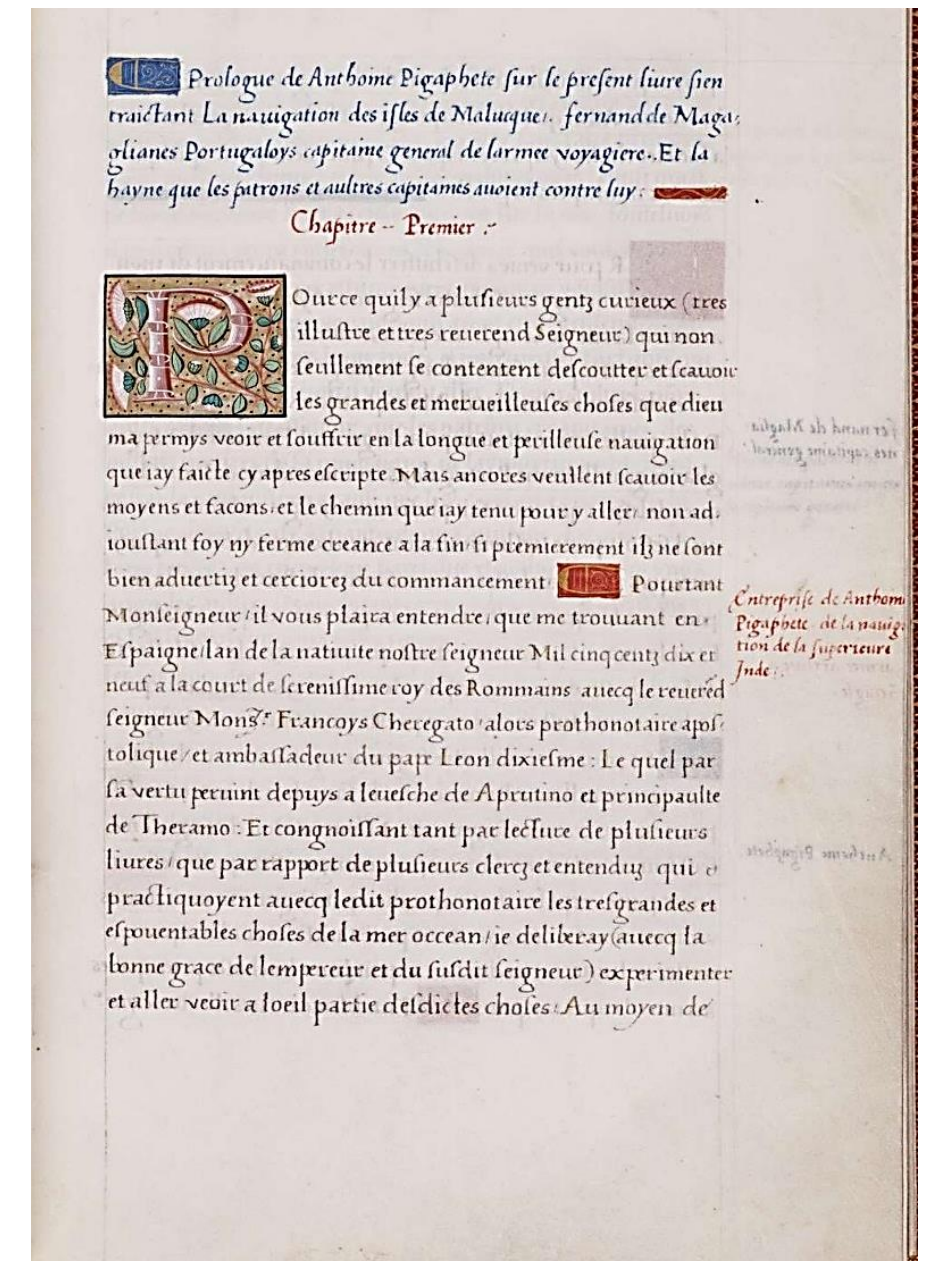

Imagen 1: Manuscrito en francés a partir de las notas tomadas por Antonio Pigafetta sobre el viaje alrededor del mundo de Magallanes-Elcano (c. 1525). Beinecke Rare Book and Manuscript Library, Universidad de Yale (EEUU) (sign. MS 351, fol. $3^{\mathrm{r}}$ ) [C CC BY-SA 4.0] 
Teniendo en cuenta esta amplia relación de textos, es importante avisar que cualquier aproximación moderna al texto de Pigafetta, y a lo que se cuenta en él, tiene que tener en cuenta esta abultada nómina de reelaboraciones y aportaciones posteriores que, de una u otra manera consciente o inconscientemente, dejaron huella en el mismo. Por tanto, el texto que conocemos actualmente como Relación del primer viaje alrededor del mundo es un texto varias veces reducido, ampliado, enmendado y también traducido, lo que implica, a su vez, aceptar todas las variaciones que asume cualquier traducción ya que las formas de significar pueden variar sustancialmente entre lenguas.

En la misma línea, también es importante reconocer, por un lado, el conocimiento propio del mundo que aportan estas modificaciones y añadidos posteriores, su visión del hecho o situación que se cuenta y, por otro lado, muy especialmente, su capacidad para discernir entre lo verídico, lo verosímil y lo ficticio a lo largo del relato. Aquí, como cualquier texto de su tiempo, los límites entre lo fantástico, influido para la extensa tradición libresca medieval de viajes, y lo real, descrito a la manera de una crónica de viajes, son todavía en el siglo XVI demasiado difusos.

El hecho de contar un viaje remite tanto a la experiencia de lo que supone el viaje como también al relato sobre cómo se cuenta, ya sea desde su expresión retórica, -transmisora de información-, como de utilidad pragmática. Contar un viaje abarcaría un "amplio rango de prácticas, más o menos voluntarias, de dejar la casa para ir a otro lugar [...] con un propósito de una ganancia -material, espiritual o científica, e involucra la obtención de un conocimiento o la vivencia de una experiencia (excitante, edificante, placentera, expansiva o de extrañamiento)" (Clifford, 1997, 66). Sin embargo, pese a la larga tradición desde ya la Antigüedad, y consolidada en su actualización medieval sobre cómo contar un viaje (desde los Caterbury Tales de Chaucer a los Livres des merveilles du monde de Marco Polo, por nombrar dos ejemplos reconocidos), el descubrimiento de América y posteriormente la hazaña de la primera vuelta al mundo de MagallanesElcano hicieron que ese relato, instalado muchas veces en la mirabilia, se desprendiera de ese carácter metafórico y excesivamente imaginario. Así, se interesa por una retórica y un discurso más real de tipo 
cronístico - en lo que se refiere al relato y la representación del tiempo y del espacio- con mayores rasgos informativos y explicativos.

Además, y tal y como señala Añón (2014, 16-17), en este cambio descriptivo del relato del viaje en el inicio de la Edad Moderna "suelen sumarse al menos tres dimensiones más como constitutivas del relato de viaje: la construcción de un itinerario, la organización de una cronología que organiza el relato del desplazamiento y la presencia constante (constitutiva) de la digresión"; sin olvidar tampoco todo el aspecto contextual del propio relato, que involucra tanto al lector como al autor, y que en pleno siglo XVI se encuentra también en constante ampliación y evolución (Chartier, 2002).

Pigafetta construye su relato de forma continua desde el punto de vista cronológico, pero sin un orden interno prefijado acerca de los temas y sucesos que van ocurriendo; tan pronto describe la ceremonia y etiqueta de la boda de una hija de un rey ([15 de diciembre de 1521] Casamiento de la hija del rey de Tadore con el hermano del rey de Bachian (Pigafetta, 2012: 299)), como inmediatamente después, sin aviso alguno, pasa a relatar que "este mismo día pusimos en los navíos velas nuevas, sobre las que pintamos la cruz de Santiago de Galicia: Este es el signo de nuestra buena ventura" (Pigafetta, 2012: 300). Vuelve a cambiar en seguida de nuevo el tema del relato y narra la alianza establecida con el rey de Bachian, seguidamente lo altera con la descripción del ave del paraíso para volver inmediatamente despues a describir la sodomización de un rey antes de una batalla (Pigafetta, 2012: 301). Termina el relato de este día cambiando de nuevo rápidamente el tema al describir una fuga de agua de la nao Trinidad, la cual es abandonada en las Molucas definitivamente el 19 de diciembre de 1521. De esta manera, y sirva lo anterior como ejemplo, el orden discursivo lo generan los propios acontecimientos del viaje pero, aun así, el autor no es ni mucho menos ajeno a lo que va ocurriendo y se incluye en muchas ocasiones como un personaje protagonista más de su hilo discursivo y no solo como el cronista o relator del mismo:

[25 marzo 1521] El lunes santo, 25 de marzo, día de Nuetra Señora, corrí un grandísimo peligro (Pigafetta, 2012: 231). 
[29 marzo 1521] Cuando pisamos tierra, el rey elevó las manos al cielo y se volvió hacia nosotros dos, que hicimos otro tanto, así como todos los que nos seguían. Me cogió después el rey de la mano, y uno delos principales hizo lo mismo con mi camarada. [...]. Nos sirvieron de inmediato un plato de cane de cerdo, con un gran cántaro de vino (Pigafetta, 2012: 233-234).

[9 abril 1521] Pigafetta lleva los regalos al rey. Después que se fueron los isleños, el capitán me envió a tierra con otro para llevar los regalos destinados al rey (Pigafetta, 2012: 245).

Esto significa que la experiencia como viajero de Pigafetta es "la fuente de autoridad etnográfica, lo que le permite constituirse como el garante de la verdad" (Urdapilleta Muñoz, 2015: 174), tal y como había ocurrido ya en otros textos similares como, por ejemplo, el Diario de navegación (1492-1493) de Cristóbal Colón o la Segunda carta de relación (1520-1522) de Hernán Cortés.

A lo largo del relato, también llama la atención observar a un Pigafetta que se asombra poco ante todo lo nuevo que ve y percibe, y que intenta no escandalizarse tampoco ante las inauditas costumbres que observa: tribus antropófagas, seres gigantescos, adornos extraordinarios, mujeres bellísimas o ceremonias fúnebres escabrosas como las siguientes descripciones:

[13 diciembre 1520] Los hombres y las mujeres son bien constituidos, y conformados como nosotros. Algunas veces comen carne humana, pero solamente la de sus enemigos, lo que no ejecutan por deseo ni por gusto, sino por una costumbre (Pigafetta, 2012: 199).

[22 abril 1521] Las demás mujeres están sentadas alrededor de la pieza con un aire triste, y una de ellas con un cuchillo corta poco a poco los cabellos del muerto. Otra que ha sido la esposa principal (porque, aunque un hombre pueda tener tantas mujeres como le plazca, una sola es la principal) se tiende sobre él de tal manera que tiene su boca, sus manos y sus pies, sobre la boca, las manos y los pies del muerto. En tanto que la primera corta los cabellos, ésta llora, cantando cuando se detiene la primera (Pigafetta, 2012: 254).

Aunque Pigafetta es consciente de la magna diversidad que va encontrando en el transcurso del viaje, a la vez sorprende cómo en 
muchas ocasiones no muestra juicio de valor alguno ante tantísima novedad: animales extraños en ese momento como pingüinos, focas o leones marinos, hombres grandes que viven desnudos, excentricidades de todo tipo, ceremonias fastuosas, alimentos exóticos y un sinfín de situaciones y elementos nuevos y asombrosos para un europeo del momento. Con un estilo, en muchas ocasiones muy similar al de un informador moderno, busca comprender, usar la lógica con respecto a lo nuevo e intenta, la mayoría de las veces, limitarse a describir rigurosamente la otredad (Luzzana, 1992: 292). Sin embargo, en alguna pequeña ocasión sí que se permite aportar comentarios valorativos en la percepción de lo que ve, estimación positiva o negativa que es construida a partir de cómo la expedición es recibida, acogida o percibida por los pueblos y lugares que se atraviesan. Si el recibimiento es cordial o afectuoso, entonces la descripción del lugar será bella y agradable, como ocurre, por ejemplo, en la descripción de la isla de Saluán, en las Islas Marianas:

[18 marzo 1521] El capitán, viéndoles tan pacíficos, hizo que les diese de comer y les ofreció al mismo tiempo algunos bonetes rojos, espejitos, cascabeles, bocacíes, algunas joyas de marfil y otras bagatelas semejantes. Los isleños, encantados con la cortesía del capitán, le dieron pescado, un vaso lleno de vino de palmera, que ellos llaman uraca, bananas de más de un palmo de largo, otras más pequeñas y más sabrosas y un cocotero (Pigafetta, 2012: 228).

Sin embargo, si el recibimiento o la impresión no es todo lo amable que pudiera esperarse, entonces la descripción y comentario del lugar o sobre sus gentes pasa a ser muy diferente, son salvajes, feos, viven en un lugar inhóspito y sin valor, como ocurre por ejemplo en la descripción de una isla dentro del archipiélago de las Molucas a la que intentan acercarse, pero en la que no son del todo bien recibidos:

[10 enero 1522] Los indígenas de esta isla son salvajes, más parecidos a bestias que a hombres, son antropófagos, y van desnudos, con un trocito de corteza de árbol tapándoles las partes sexuales; pero cuando van a combatir se cubren el pecho, la espalda y los costados con pieles de búfalo [...]. Llevan los cabellos recogidos sobre la cabeza por medio de una peineta de caña con largos dientes [...] moda de que nos reímos mucho. En una palabra, 
son los hombres más feos que encontramos durante todo nuestro viaje (Pigafetta, 2012: 313).

Así, aunque esta primera travesía española alrededor del mundo no fuera concebida en su origen como un viaje naturalista y mucho menos poético o bucólico, los procedimientos discursivos que Pigafetta selecciona y utiliza en su texto se acercan mucho al modelo de imparcialidad y objetividad indispensables en el relato cronístico moderno y contemporáneo. En cambio, y como se analizará en el siguiente apartado, el relato inglés de su vuelta al mundo será totalmente distinto.

\section{El relato del viaje inglés}

Al iniciar el análisis comparativo entre la forma de comunicar al mundo las travesías de las dos primeras circunnavegaciones al globo -la española y la inglesa-, uno de los primeros datos que llama la atención es la fecha de publicación de los dos textos. Como se ha dicho anteriormente, el libro de Pigafetta se publica por primera vez en francés entre 1526 y 1536, lo que supone un margen de casi quince años desde de que se completara la travesía. Las circunstancias que rodean la comunicación que se hace al mundo del mismo viaje que Francis Drake emprendió entre 1577 y 1580 no son muy diferentes. Se da la paradoja de que un acontecimiento de tal magnitud -la primera vez que un inglés consigue dar la vuelta al mundo- y que tan fuerte impacto tuvo en la imaginación popular de la época (Nievergelt, 2009: 54) solo aparece recogido tardíamente en dos principales relaciones sobre el viaje. La primera de ellas consiste en una breve narración atribuida a Francis Pretty, uno de los hombres de armas que completó la travesía junto a Drake, titulada “Sir Francis Drake's Famous Voyage Round the World”. El relato fue relaborado posteriormente por el escritor, traductor e historiador inglés Richard Hakluyt para ser incluido en su libro The Principall Navigations, Voiages, and Discoveries of the English Nation: Made by Sea or Over Land to the Most Remote and Farthest Distant Quarters of the Earth at Any Time within the Compasse of These 1500 Years, publicado en Londres en 1589.

Hay que esperar hasta 1628 para tener una segunda narración más amplia del viaje de Francis Drake, basada principalmente en las notas 
del capellán que acompañó a la expedición inglesa, Francis Fletcher. El relato en cuestión fue revisado y publicado bajo la supervisión del sobrino homónimo del navegante inglés bajo el título The World Encompassed by Sir Francis Drake. Además de estos dos textos, existen otras narraciones completas y parciales sobre la travesía que han permitido a la crítica posterior contrastar el relato ofrecido primero por Hakluyt y el que se presenta posteriormente en The World Encompassed. Entre estos textos sueltos, destaca el manuscrito con unas notas de Francis Fletcher -cuyo texto incompleto, conservado en el Museo Británico, arroja una luz distinta a los hechos narrados en The World Encompassed, como veremos líneas más abajo- y el relato de John Cook, uno de los marineros de la nao Elizabeth, comandada por John Winter, y que acompaña al Golden Hinde. Sin embargo, tal y como afirma Quinn (1984: 34), el texto de Hakluyt, y completado posteriormente en The World Encompassed, ha sido la fuente de autoridad primaria en lo que se refiere a la narración pública de la circunnavegación de Drake.

Tal y como señala Nievergelt (2009: 53-54), las referencias de la travesía de Drake en el terreno textual de la época no son muy numerosas. Nicholas Breton, en $A$ Discourse in commendation of the valiant as vertuous minded Gentleman, Maister Frauncis Drake, with a reioysing of his happy aduentures (Londres, 1581), incluye poco más que alabanzas a la figura del navegante inglés en términos vagos y generales. Ocurre lo mismo en la obra de Henry Robarts, A most friendly farewell giuen by a welwiller to the right worshipful Sir Frauncis Drake Knight (Londres, 1585). En este caso, el texto de Robarts se concentra en los viajes de Drake al Caribe y da poca información sobre la circunnavegación. Existe, además, de William Gager, un poema corto en latín moderno, "In laudem fortissimi viri domini Francisci Draconis" (escrito entre 1586 y 1588), y un texto -ya algo tardío, de 1596- que en tono épico tiene como protagonista al propio Drake, Commendatory Lamentation on the Death of Drake de Charles Fitzgeffrey.

De entre estos textos, se considera que la obra de mayor relevancia en cuanto al ensalzamiento de la figura de Francia Drake es The Voyage of the Wandering Knight, una traducción de una obra francesa publicada en 1581 por un comerciante, del cual solo conocemos su nombre, William Goodyear (Nievergelt, 2008: 55). Esta obra, dedicada "to the Right worshipfull Sir Frauncis Drake, Knight”, sirve para presentar al 
marinero inglés a través de una alegoría, como si fuera un desconocido que consigue llegar a ser nombrado caballero tras probar su innata nobleza de espíritu. En ella, el rol de Drake "resonates with echoes of a wider quest for a new social identity and self-definition on the part of the merchant-adventurers he represents" (Nievergelt, 2008: 59). Así, $\mathrm{y}$ teniendo en cuenta todos estos textos, se puede afirmar que la mayoría de las escasas noticias fiables de la circunnavegación de Drake solo han permanecido a través de referencias relaboradas y secundarias (García Redondo y Varela, 2013: 443).

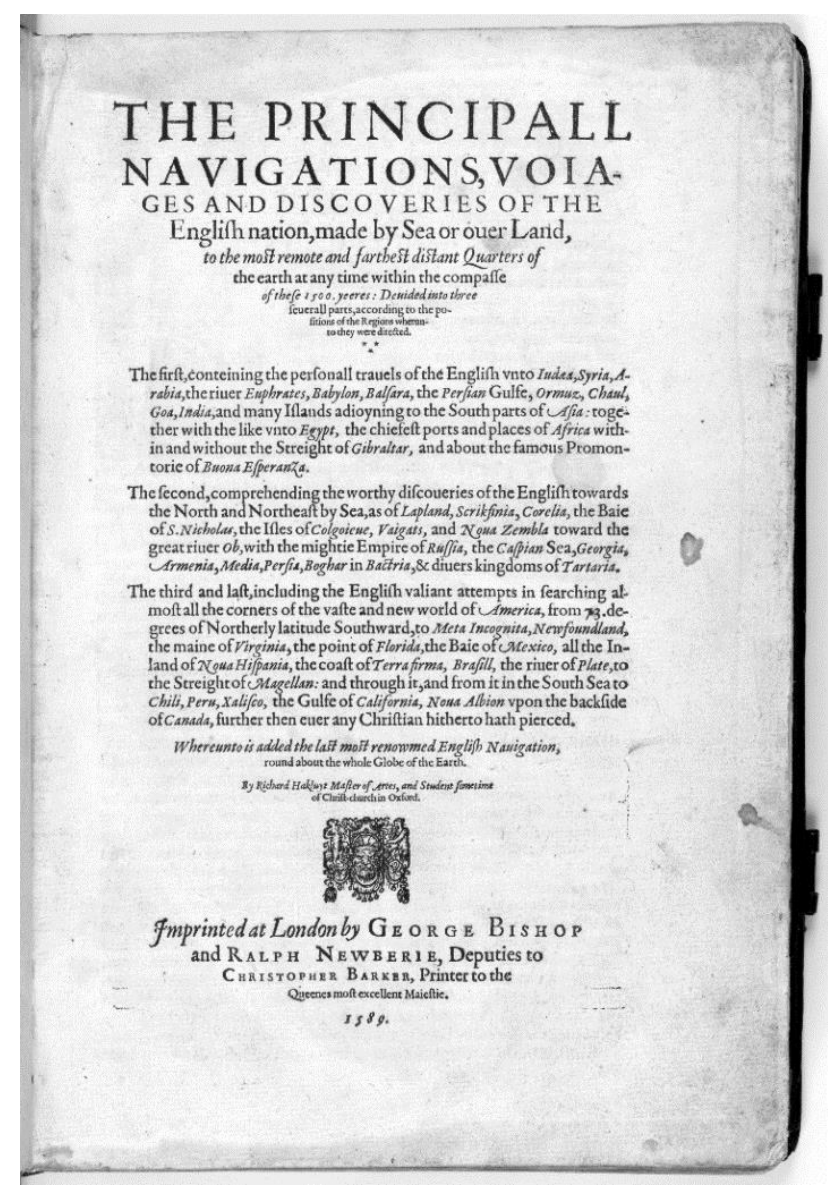

Imagen 2: Impreso de The Principall Navigations, Voiages, and Discoveries of the English Nation de Richard Hakluyt (1589) [C CC BY-SA 4.0].

El exitoso regreso a Plymouth de Drake y parte de sus hombres en el Golden Hinde, así como los detalles del relato de su travesía, siempre han estado envueltos en el secreto, llenos de rumores e incluso falsos informes. En palabras de Fuller (2008: 40), "Drake's honor was public and national; it was granted with one hand, while the documents of his 
voyage, with their specific information, were collected and retained with the other".

Varios son los motivos que pueden ayudar a explicar esta falta de comunicación a la opinión pública del éxito obtenido, si lo comparamos, por ejemplo, con el texto anterior de Pigafetta: por un lado, las tensiones políticas y diplomáticas entre España e Inglaterra con ataques a barcos españoles llevados a cabo por la expedición de Drake -es revelador en este sentido que Hakluyt indique al comienzo del relato que el viaje de Drake tenía como supuesto destino Alejandría, por ejemplo-. En relación con esto, la reputación controvertida del navegante inglés no le convertía tampoco el candidato más indicado para convertirse en héroe nacional, tal y como sí fue, por ejemplo, Juan Sebastián Elcano. Una posible tercera causa en lo que respecta a este secretismo, y que apuntan tanto Kelsey (1998: 211-215) como Bawlf (2003), es que quizás esto formara parte de una estrategia de la corona británica para mantener la confidencialidad de la ruta de la travesía de Drake, emulando así la política de sigilo cartográfica española y que tantos éxitos dio a la Corona española.

En este sentido, la Inglaterra de la reina Elizabeth I a partir de su coronación en 1558 se caracterizaba por la intriga, la intensa violencia, la guerra y una acusada debilidad económica, especialmente llamativa si se compara con el resto de monarquías del continente. Durante su reinado, expediciones a tierras lejanas fueron por primera vez equipadas, principalmente con recursos privados, pero con el permiso, o al menos el consentimiento tácito del su gobierno (Vaux, 1854: II). La reina eligió y alentó a sus mejores capitanes, entre otros John Hawkins, Francis Drake o Thomas Cavendish - quien repetiría años después la hazaña de Drake entre 1586 y 1588-, los cuales se convirtieron en temibles enemigos de las todopoderosas monarquías europeas de la época, aunque siempre envueltos en actividades de muy dudosa legitimidad en contra de los intereses de las coronas extranjeras (Dudley, 2013: 58).

\section{1. "Sir Francis Drake's Famous Voyage Round the World": la primera crónica sobre la travesía de Francis Drake}

La publicación del relato "Sir Francis Drake's Famous Voyage Round the World", supuestamente a partir de unas notas de Francis Pretty, 
inserto en The Principall Navigations, Voiages, and Discoveries of the English Nation de Richard Hakluyt, no está exenta de complicaciones y cierto misterio. En su pionero ensayo sobre este asunto, Kerr (1940: 283-284) intentó arrojar cierta luz sobre el tema porque, a pesar de que el propio Richard Hakluyt, al final de su "Address to the Favourable Reader", indica que ha estado a punto de no incluir estas notas -dando como única explicación que hay otro relato de más calado ya en marcha-, el lector encuentra el texto de Pretty en cuarenta de las cuarenta y siete copias que conservamos del libro de Hakluyt. "The Famous Voyage" es básicamente un relato de unas catorce mil palabras que Hakluyt incluye entre las páginas 643 y 644 de su libro, después de ser impreso pero previo a su salida al mercado (Quinn, 1984: 34).

No hay evidencias claras acerca del texto original que sirve de base a "The Famous Voyage" (Quinn, 1984: 35). Se trata de un relato cronístico escrito por una sola mano en el que se mezclan varias voces: la tercera persona del singular - cuando el narrador habla de Drake- y la primera del plural -en el resto del discurso-. En este sentido, Hakluyt, clérigo acostumbrado a explicar en sermones conceptos teológicos o morales de forma accesible, tenía la suficiente habilidad para convertir datos sueltos recogidos en bruto en una narración coherente que permitiera dar a conocer el viaje de Drake. Su discurso sobre la primera circunnavegación inglesa del mundo sigue de forma clara algunos de los puntos básicos de su pensamiento como infatigable defensor de la aventura colonizadora inglesa.

Entre los variados argumentos que utiliza Hakluyt en este texto para convencer sobre las bondades de las empresas ultramarinas, llama la atención la explicación que aporta en relación con el imperio español y la limitación papal establecida desde 1493 por Alejandro VI en la bula Inter Caetera?, y confirmada posteriormente en 1506 por Julio II con la bula Ea quae pro bono pacis -que ratificaba finalmente el Tratado de Tordesillas (1494)-, en cuanto a la posibilidad de la colonización inglesa del hemisferio septentrional:

\footnotetext{
${ }^{9}$ Esta bula papal, escrita a instancias de los Reyes Católicos, definía el meridiano a partir del cual todo lo hallado y por hallar al oeste del mismo pertenecería a la Corona castellana.
} 
... this voyadge will be a greate bridle to the Indies of the Kinge of Spain [...] the lymites of the Kinge of Spaines domynions in the West Indies be nothinge so large as ys generally ymagined and surmised, neither those partes which he holdthe be of any such forces as ys falsly geven out by the popishe [Roman Catholic] clergye and others his fautors, to terrifie the princes of the relligion and to abuse and blynde them (Hakluyt et al., 1877: 3- 4).

Así, la intervención inglesa se vería justificada también desde un punto de vista moral, ya que:

... the Spaniards have executed moste outrageous and more then Turkishe cruelties in all the West Indies, whereby they are everywhere there become moste odious unto them whoe woulde joyne with us or any other moste willingly to shake of their moste intollerable yoke [...] (Hakluyt et al., 1877: 4).

Por tanto, la conclusión de la argumentación anterior de Hakluyt se consolida porque:

... the Queene of Englands title to all the West Indies, or at the leaste to as moche as is from Florida to the circle articke, is more lawfull and righte then the Spaniardes, or any other Christian Princes (Hakluyt et al., 1877: 5).

Si se examina la crónica de "The Famous Voyage" a la luz de los argumentos esgrimidos por Hakluyt a favor de la colonización inglesa de tierras del nuevo mundo, se percibe una similar inspiración. Por un lado, el relato alienta a otros navegantes, marineros (y patrocinadores) a seguir los pasos de Drake (Fuller, 2007: 38) en el nombre de Dios y en el nombre de su reina y de su patria. En su narración del viaje, no son pocas las ocasiones en las que se relatan los diversos peligros a los que se tuvieron que enfrentar los hombres de Drake: vientos en contra, violentas tormentas, falta de puertos seguros donde abastecerse, peligrosas rocas o habitantes de tierras poco amistosas. Sin embargo, y a pesar de las pérdidas materiales y humanas, el discurso apuesta porque la voluntad de Dios siempre se muestra a favor de que los valientes marineros ingleses prosigan su travesía. La confianza en la misericordia y la protección de Dios los salva, por ejemplo, de lo que parecía una muerte segura en su navegación por las Islas Molucas. También la Corona, en el nombre de Dios, debe enviar a estas tierras 
misioneros que evangelicen y 'civilicen' a las numerosas tribus que van apareciendo a lo largo del viaje, desconocedoras de la verdadera religión, como, por ejemplo, los salvajes nativos que realizan sacrificios humanos y que encuentran a su paso por tierras de Norteamérica. El texto de Pigafetta también hace lo mismo, aunque decididamente de una forma mucho más velada.

En este aspecto, uno de los episodios más llamativos en la narración de Hakluyt es el más que cuestionable descubrimiento de lo que Drake llama Nova Albion, en la costa del actual norte de California (Kelsey, 2012: 86):

At our departure hence our General set up a monument of our being there, as also of her Majesty's right and title to the same; namely a plate, nailed upon a fair great post, whereupon was engraved her Majesty's name, the day and year of our arrival there, with the free giuing up of the province and people into her Majesty's hand, together with her Highness' picture and arms, in a piece of six pence of current English money, under the plate, whereunder was also written the name of our General (Hakluyt, Beazley, Raymond \& Payne, 1907: 219).

Al igual que Pigafetta -que pasa de puntillas, por ejemplo, en asuntos importantes como la sublevación de la nao Concepción o, incluso, obvia completamente a Juan Sebastián Elcano a lo largo de todo su relato-, Hakluyt persigue un tipo de discurso que le permita celebrar la travesía como una hazaña nacional, aunque eso suponga también ocultar o maquillar, por ejemplo, los episodios de enfrentamiento entre algunos miembros de la expedición -como el juicio y la posterior ejecución de Thomas Doughty-. De esta manera, "Drake's concern for the voyage, the queen's expectations, and the honor of his country overcame his "private affection" for Doughty, and so "it was concluded" (a notable passive) that he be punished appropriately" (Fuller, 2007: 49).

A través del personaje de Drake, la voz narradora deja clara su opinión sobre la posibilidad de medrar en la sociedad a través de los actos propios. No podemos olvidar que Drake representa a esa clase de comerciante, incipiente nueva burguesía, que busca un nuevo y superior estatus social dentro de la sociedad isabelina (Nievergelt, 2008: 
59). Así, dejando de lado todas las consideraciones controvertidas y adversas que han marcado y representado siempre la figura de Drake, es manifiesto reconocerle como un hombre de origen humilde pero hecho a sí mismo, que parte de Inglaterra como un aventurero/comerciante/corsario y que a su regreso es nombrado Sir por la mismísima reina de Inglaterra. Alcanza tal honor, hecho sin precedentes para alguien sin pedigrí ni estatus alguno, tras probar, como dicen las crónicas de su tiempo, su innato espíritu de nobleza (Nievergelt, 2009: 53). En el relato de Hakluyt son numerosas las ocasiones en las que se narran los resultados económicamente favorables de sus actividades, tanto comerciales como de piratería con ataques incluidos a barcos españoles y portugueses durante la travesía.

Un segundo y no menos primordial objetivo de la construcción narrativa de Hakluyt es que el texto pudiera servir para extender una campaña de propaganda antiespañola. Las referencias en el relato a los españoles (y en menor medida a los portugueses) son numerosas, especialmente cuando se narran los saqueos a barcos y posiciones españoles en el Pacífico. A través de estas, la imagen que se da de los españoles se resume en un cúmulo de cualidades negativas, entre las que se encuentran la pereza (en el episodio en el que se roban trece barras de plata a un español que estaba dormido (Hakluy et al., 1907: 219)) o la cobardía (en varios episodios se cuenta cómo los españoles no pueden enfrentarse a los hombres de Drake o simplemente salen huyendo antes de que estos lleguen). Además, se trata a los españoles, y asimismo a los portugueses, de crueles en su trato hacia los nativos de las nuevas tierras conquistadas, como, por ejemplo, los habitantes de la isla de Mocha, en la actual Chile:

Where we found people, whom the cruel and extreme dealings of the Spaniards have forced, for their own safety and liberty, to flee from the main, and to fortify themselves in this island (Hakluy et al., 1907: 208).

Así, se puede decir que la narración de Hakluyt de la primera circunnavegación inglesa del globo se construye como un ejercicio de manipulación cronística con el objetivo último de celebrar las glorias nacionales. El propósito final de Hakluyt siempre fue que Inglaterra se uniera a la conquista de territorios inexplorados en las nuevas tierras encontradas, así como también el de revigorizar el comercio marítimo 
como solución a los problemas de superpoblación y desempleo que padecía el país.

\subsection{The World Encompassed, o la exaltación de Sir Francis Drake como héroe nacional}

Tal y como señala Parry:

The Famous Voyage Round the World proved to be the turning point of Drake's career. By means of this voyage he graduated, one might say, from slightly disreputable though successful slaver and pirate to famous privateer-explorer. He was to become a widely $[\ldots]$ respected admiral and ultimately a folk hero and a national legend (1984: 3).

Sin embargo, en la narración de Hakluyt se arrojan pocos datos particulares sobre la personalidad o la manera de actuar de Francis Drake. En general, al igual que el texto de Pigafetta, el relato se concentra más en el viaje que en el hombre que lo dirige; los detalles biográficos aparecen únicamente cuando son relevantes para las acciones que se narran. En este sentido, Hakluyt sigue el objetivo declarado en el título de su propia obra, la de narrar las "navigations, voiages and discoveries" (Quinn, 1984: 43-44).

Así, en lo que respecta a lo narrado en The World Encompassed (1628), se persiguen objetivos similares a los de Hakluyt. De nuevo, en este segundo relato aparecen continuas referencias en cuanto a la voluntad de Dios con respecto al éxito del viaje, a pesar de los reveses, así como a la importante necesidad de evangelizar a los nativos con los que se van encontrando (Drake, Vaz, Cliffe, Silva, Pretty, Cooke, Vaux \& Fletcher, 1854: 53; 124; 129). Asimismo, se enfatiza de nuevo que la travesía es para mayor gloria del país (Drake et al., 1854: 7) y se argumenta el derecho de Inglaterra a asentar colonias en las nuevas tierras (Drake et al., 1854: 108-109), en contra de lo que se había establecido ya entre españoles y portugueses en el mencionado ya Tratado de Tordesillas $(1494)^{10}$.

${ }^{10}$ El Tratado de Tordesillas (1494) supuso la división de las áreas de navegación en el Atlántico por parte de España y Portugal. El trazado de esta línea -O antimeridiano de Tordesillas- se situó a 370 leguas al oeste de las islas de Cabo Verde pero solo se tuvo en cuenta que el planeta tenía un océano, y no dos. 


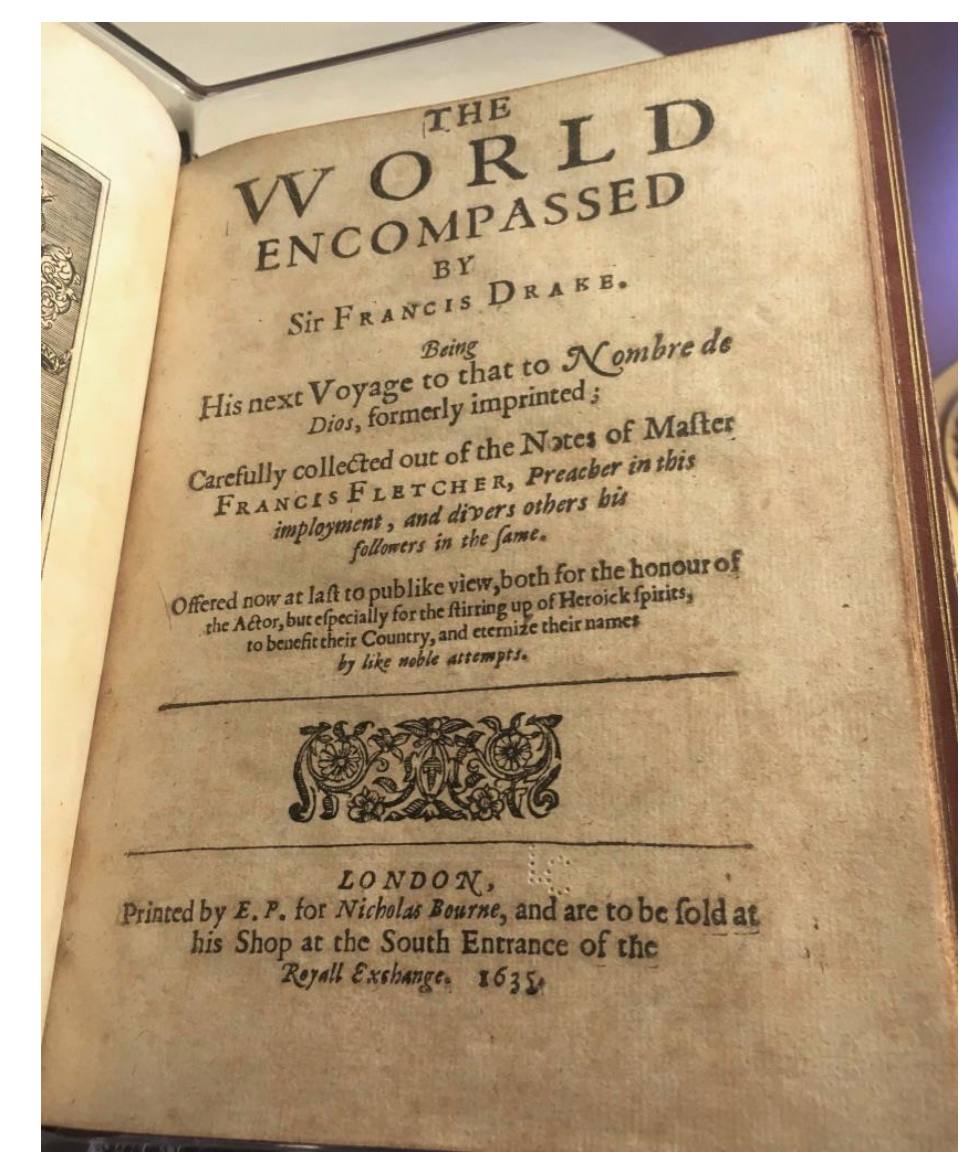

Imagen 3: The World Encompassed, edición de 1635. Library of Congress, Washington D.C. (EEUU) [C CC BY-SA 4.0].

De nuevo, la propaganda antiespañola es frecuente también en este relato (Drake et al., 1854: 61; 97; 99; 102), en términos muy similares a los ofrecidos por Hakluyt. Sin embargo, lo que diferencia en mayor medida a los dos textos es el objetivo de elevar la figura de Francis Drake a héroe nacional, hecho que se ve completamente cumplido en este segundo relato ya desde el propio título, The World Encompassed by Sir Francis Drake. Offered now at last to Public view, both for the honor of the Actor, but especially for the stirring up of heroic Spirits, to benefit their Country, and eternalize their Names by like noble attempts. El título y subtítulo de la obra, sumamente iluminador con respecto a los objetivos que persigue comunicar, pretende alentar a los espíritus heroicos ingleses a seguir los pasos de Drake en beneficio de su país, pero también a glorificar la figura del protagonista principal del relato (entiéndase Francis Drake) para que su nombre pase a la historia como un auténtico héroe nacional. Otro pequeño detalle importante a tener en cuenta en este subtítulo es el uso de la expresión at last, la cual da cierta muestra de las dificultades en la publicación del mismo y que, a su vez, conectan con las mismas razones ya explicadas anteriormente con respecto a la 
inclusión a última hora de "The Famous Voyage" en la obra de Hakluyt.

The World Encompassed es un relato en primera persona, claro y directo, del viaje en su totalidad. El texto es mucho más amplio que el anterior de Hakluyt, casi tres veces más largo (Quinn, 1984: 41). Ya en su cubierta se deja constancia de que es una obra "collected out of the Notes of Master Francis Fletcher Preacher in this employment, and compared with divers others Notes that went in the same Voyage". Tal y como afirma Quinn (1984: 37; 39), no hay duda de que el diario del capellán Fletcher se usó de manera extensa para construir esta narración del viaje, "but Fletcher purified of any adverse comments on Drake". De hecho, al comparar el texto del diario de Fletcher (fechado en 1577) con The World Encompassed se pueden ver diferentes puntos de vista en cuanto a la figura de Drake. El texto muestra cómo en este último se omitieron o modificaron conscientemente pasajes que podían perjudicar la construcción ideal de la figura de Drake como héroe (Vaux, 1854: XXI). Así, se percibe cómo las menciones a Drake se hacen siempre en términos laudatorios: "rare and thrice worthy Captain" (Drake et al., 1854: 5) y su valentía es palpable en pasajes como el siguiente:

Our General [...] was neuer wont to relye onely on other mens care, how trusty or skilfull soeuer they might seeme to be; but always contemning danger, and refusing no toyle, he was wont himselfe to be one, whosoeuer was a second, at every turne, where courage, skill, or industry, was to be imployed; neither would hee at this time intrust the discouery of these dangers to anothers paines, but rather to his owne experience in searching out and sounding of them (Drake et al., 1854: 43).

Ante los reveses que va encontrando en el viaje, como por ejemplo la pérdida del navío Swan, siempre está de buen ánimo y confía en su pronta recuperación (Drake et al., 1854: 42). Hace un alarde de su inteligencia cuando decide ir a tierra a hacer fuego para que el humo sirva de guía al barco perdido (Drake et al., 1854: 44); de su liderazgo con sus hombres, "as his use was at all times in all other things belonging to the relieuing of your wants, and the maintenance of our goood estate" (Drake et al., 1854: 58); y de su capacidad como capitán, "if our generall had not been both expert in such affaires, able to judge, 
and giue present direction in the danger thereof, and had not valiantly thrust himselfe into the dance against these monsters, there had not one of our men, that there were landed, escaped with life" (Drake et al., 1854: 59).

Por otro lado, se muestran también sus excelsas virtudes como ser humano cuando, por ejemplo, prefiere intentar salvar la vida de uno de sus hombres a vengarse de los nativos -en este caso los patagonesque lo han herido (Drake et al., 1854: 60). Pero, el punto álgido de la caracterización de su figura se encuentra en el episodio del juicio y posterior condena a muerte de Thomas Doughty (Drake et al., 1854: 62-70), mismo hecho que ya se relataba en "The Famous Voyage". La narración, en este caso mucho más extensa que en el caso del texto de Hakluyt, no se caracteriza por su neutralidad, sino todo lo contrario. Se aprovecha este episodio para dar cuenta de todas las bondades de Drake, quien en todo momento se muestra afable en su trato con Doughty, antes, durante y después de su condena, algo llamativo tratándose de una ejecución por traición. La manipulación narrativa de este episodio es evidente, especialmente si se compara con los extractos del cuaderno de viaje de Fletcher o la propia narración de John Cook, donde la imagen que se da de Drake se aleja mucho de esta visión tan cándida (Vaux, 1854: XXXVII).

Así, en la configuración de la figura de Drake como héroe nacional no basta con ensalzar únicamente su persona, sino que el otro pilar fundamental es la narración de la travesía en sí misma, en la que ya el primer párrafo es muy esclarecedor:

Ever since Almighty God commanded Adam to subdue the earth, there have not wanted in ages some heroicall spirits which, in obedience to that high mandate, either from manifest reason alluring them, or by secret instinct inforcing them thereunto, have expended their wealth, imployed their times, and aduentured their persons, to finde out the true circuit thereof (Drake et al., 1854: 5).

Aunque este comienzo lleva a la conclusión de que el propósito del viaje de Drake no es otro sino conseguir dar la vuelta al mundo, actualmente no existen pruebas documentales que prueben fehacientemente tal propósito. Existe documentación de la época que acredita que Drake buscaba en un primer momento solo la exploración 
de la Patagonia y de la costa chilena (Quinn, 1984: 42; Bicheno, 2012: 132; Kelsey, 1998: 77-78); al igual que Magallanes, que únicamente buscaba llegar a las Molucas por el oeste $-\mathrm{y}$ evitar así las rutas portuguesas por el este- y retornar a España haciendo el mismo camino.

En líneas generales, el tono épico y grandilocuente de The World Encompassed continuará a lo largo de todo el relato, e incluso se compararán las hazañas de Drake con las de los mismísimos Argonautas en busca de vellocino de oro (Drake et al., 1854: 6) y los peligros que tienen que sortear se asemejarán también a episodios bíblicos: "no traveller hath felt, neither hath there ever beene such a tempest (that any records make mention of), so violent and of such continuance since Noabs flood" (Drake et al., 1854: 87). En este sentido, tal y como García Redondo y Varela (2013: 458) afirman, hay que tener en cuenta que "la mayoría de los relatos sobre Francis Drake que hoy conocemos fueron conscientemente editados y preparados antes de ser publicados. En este proceso, los testimonios de primera mano se enriquecieron con detalles de otras crónicas, los matices oscuros se suavizaron cual poema épico y las evidencias patrióticas se desarrollaron con exagerada reincidencia”.

Por último, la exaltación de la hazaña de Drake al dar la vuelta al mundo no quedaría completa sin una referencia comparativa a la de Magallanes-Elcano. No se puede discutir que la primera circunnavegación del globo fue realizada por la expedición española; sin embargo, el relator de The World Encompassed explicita que Drake fue el primer navegante que lideró una vuelta al mundo y no deja pasar la ocasión de añadir que la expedición inglesa fue mucho más meritoria:

And therefore that valiant enterprise, accompanied with happy successe, which that right rare and thrice worthy Captaine, Francis Drake, atcheiued, in first turning up a furrow about the whole world, doth not onely ouermatch the ancient Argonautes, but also outreacheth in many respects, that noble Mariner Magellanus, and by farre surpasseth his crowned victory. But hereof let posterity judge (Drake et al., 1854: 6).

Al igual que el relato de Hakluyt fue editado y preparado con el objetivo de que la aventura de Drake apoyara sus argumentos sobre el rol que 
Inglaterra debía tener en el espacio global, la crónica de la circunnavegación de The World Encompassed modifica el relato que se comunica a la opinión pública con el fin de hacer de Drake la figura nacional a seguir.

\section{Consideraciones finales y coda}

A la luz de lo expuesto en las anteriores líneas, se puede afirmar que aunque estos tres relatos se configuran con intereses y objetivos muy particulares y distintos, sí que presentan similares argumentos persuasivos y análogos recursos apelativos a la hora de dar cuenta tanto a la Corona, como al resto del mundo, noticia de sus respectivos viajes.

Si desde un punto de vista aristotélico, el ethos, el pathos y el logos son los medios de prueba que tiene todo orador/escritor, se puede avalar que tanto Pigafetta, como Hakluyt y el autor de The World Encompassed modelan y construyen sus discursos teniendo en cuenta los temas, prejuicios, intereses y aspiraciones de su tiempo. Así, los argumentos que exponen los tres textos relativos al ethos, es decir aquellos que atañen al emisor del discurso, apelan a la honestidad y autoridad del que escribe: Pigafetta metiéndose en el propio texto como un personaje más, Hakluyt aportando testimonio directo de un marinero embarcado en la travesía y The World Encompassed tomando como base el diario del capellán de a bordo, los tres miembros de pleno derecho de la expedición. En lo que respecta al pathos, ligado a todo lo afectivo que muestra el receptor del discurso, los tres relatos ensalzan el significado e importancia que tuvo para sus respectivos países estos colosales viajes al tener muy en cuenta que lo que verdaderamente cambia el comportamiento del público no son los hechos en sí mismos, sino la emoción que conlleva su retransmisión y la influencia que ejercen posteriormente. Finalmente, el logos, que conlleva todos los razonamientos lógicos de un discurso, se consigue en los tres textos gracias a las evidencias sólidas y ejemplos concretos de situaciones o aventuras vividas a lo largo de la travesía: desde tribus que prefieren cosas útiles, como un vaso o un plato, y lo intercambian rápidamente con los españoles por grandes pepitas de oro, como se cuenta en el texto español, hasta el descubrimiento de nuevas frutas y árboles que son descritos en los relatos ingleses. 
Al fin y al cabo, tanto españoles como ingleses compartían similares intereses políticos y comerciales, pero también recursos discursivos y retóricos equivalentes a la hora de comunicar al mundo las hazañas nacionales logradas.

\section{Bibliografia}

V Añón (2014): “Narrativas de viaje y espacialidad en crónicas de la conquista de América. Apuntes comparativos para una discusión". Anales de Literatura Hispanoamericana, 43, 13-31, http://dx.doi.org/10.5209/rev ALHI.2014.v43.47164.

ML Arriba (2004): "Los sonidos de la enunciación en la primera vuelta al mundo". Revista de Crítica Literaria Latinoamericana, XXX(60), 57-67, https://bit.ly/2GFc47O.

BBC2 (2018): Cunk of Britain, https://bbc.in/2VcmcYQ.

S Bawlf (2003): The Secret Voyage of Sir Francis Drake, 1577-80. New York: Walker \& Co.

H Bicheno (2012): Elizabeth's sea dogs: how the English became the scourge of the sea. London: Conway.

T Cachey (2007): "Bio-bibliograpgical note". Antonio Pigafetta. The first voyage around the world 1519-1521. An account of Magellan's expedition. Toronto: University of Toronto Press.

P Castro Hernández (2018): “El viaje renacentista y la visión estética del otro: Una aproximación a la belleza y fealdad de la otredad en El primer viaje alrededor del mundo de Antonio Pigafetta (s. XVI)". Revista de Historia, 25(1), 161-182, http://revistahistoria.udec.cl/wpcontent/uploads/2018/07/7Pablo-Castro-Hernandez-El-viajRev2018Vol1.pdf.

R Chartier (2002): El mundo como representación. Barcelona: Gedisa. JR Clifford (1997). Travel and translation at the late twentieth century. Cambridge, Massachusetts: Harvard University Press.

F Drake, L Vaz, E Cliffe, N Silva, F Pretty, J Cooke, W S Vaux, F Fletcher (1854): The world encompassed by Sir Francis Drake: being his next voyage to that to Nombre de Dios. London: Printed for the Hakluyt Society. 
W Dudley (2013): “Elizabeth's Sea Dogs: Hawkins, Drake and their fellow English privateers served their queen, repelled the Spanish and made their fortunes in the age of sail". Military History, 30(4).

El Confidencial digital, 20 de abril de 2018, https://bit.ly/2XgY219.

F Fernández-Armesto (2012): Los conquistadores del horizonte. Una historia global de la exploración. Barcelona: Ariel.

M Fuller (2007): "Writing the Long-Distance Voyage: Hakluyt's Circumnavigators". Huntington Library Quarterly: Studies in English and American History and Literature, 70(1), 37-60, https://doi.org/10.1525/hlq.2007.70.1.37.

J García Redondo, C Varela (2013). "Ecos literarios y memoria cartográfica del Famous Voyage de Francis Drake". Anuario de Estudios Americanos, 70(2), 441-478, https://doi.org/10.3989/aeamer.2013.2.03.

R Hakluyt, R Beazley, C Raymond, EJ Payne (1907): Voyages of Hawkins, Frobisher and Drake: select narratives from the 'Principal navigations' of Hakluyt. Oxford: Clarendon Press.

R Hakluyt, L Woods, C Deane (1877): A discourse on western planting: written in the year 1584. Cambridge: Maine Historical Society.

H Kelsey (1998): Sir Francis Drake: the Queen's pirate. New Haven: Yale University Press.

W Kerr (1940). “The Treatment of Drake's Circumnavigation in Hakluyt's 'Voyages', 1589'. The Papers of the Bibliographical Society of America, 34, https://bit.ly/2VcuLmg.

I Luzanna (1992): Navegantes italianos. Madrid: Mapfre.

M Nievergelt (2009): “Francis Drake: Merchant, Knight and Pilgrim". Renaissance Studies: Journal of the Society for Renaissance Studies, 23(1), 53-70, https://doi.org/10.1111/j.1477-4658.2008.00543.x.

JH Parry (1984): "Drake and the World Encompassed". Sir Francis Drake and the Famous Voyage, 1577-1580. Essays commemorating the quadricentennial of Drake's circumnavigation of the Earth. Berkeley: University of California Press.

A Pigafetta (2012): Primer Viaje en torno del globo. Madrid: Ediciones Polifemo.

DB Quinn (1984): "Early Accounts of the Famous Voyage". Sir Francis Drake and the Famous Voyage, 1577-1580. Essays commemorating the quadricentennial of Drake's circumnavigation of the Earth. Berkeley: University of California Press. 
O Sanfuentes (2009): Desvelando el Nuevo Mundo. Imágenes de un proceso. Santiago de Chile: Universidad Católica.

AT Tuninetti (2001): Nuevas tierras con viejos ojos. Buenos Aires: Corregidor.

M Urdapilleta Muñoz (2015): “La etnografía retórica en las relaciones de viaje a Indias hasta la primera mitad del siglo XVI". Viajesy ciudades miticas. Pamplona: Servicio de Publicaciones de la Universidad de Navarra, 171-183.

WS Vaux (1854): "Introduction". The world encompassed by Sir Francis Drake: being his next voyage to that to Nombre de Dios. London: Printed for the Hakluyt Society.

M Vera (2013): "Proceso de singularización en la escritura colonial de Antonio Pigafetta: fluctuaciones entre el 'yo', el 'nosotros' y el 'ellos"'. Telar: Revista del Instituto Interdisciplinario de Estudios Latinoamericanos, 9 (11-12), 114-133, https://bit.ly/2GEbFIW. 



\title{
La falsa primera vuelta al mundo. El caso de la supuesta circunnavegación china de 1421 desde el paradigma de la posverdad
}

Who controls the past, controls the future. George Orwell

\author{
José Antonio Muñiz-Velázquez \\ Universidad Loyola Andalucía, Sevilla, España \\ Javier Lozano Delmar \\ Universidad Loyola Andalucía, Sevilla, España
}

Cómo citar: J A Muñiz-Velázquez y J Lozano Delmar (2019): “La falsa primera vuelta al mundo. El caso de la supuesta circunnavegación china de 1421 desde el paradigma de la posverdad". Revista Latina de Comunicación Social, En P Herrero-Diz/A Cárcamo/V Rodríguez Breijo/R Mancinas (Eds.) V Centenario / $1^{\text {a }}$ Vuelta al Mundo. Cuadernos Artesanos de Comunicación, cac161, pp 175-203. La Laguna (Tenerife): Latina. DOI: $10.4185 / \operatorname{cac} 161$

\begin{abstract}
s
Introducción. Hace 500 años, Magallanes emprendía un viaje que acabaría siendo, en manos de Juan Sebastián Elcano, la primera vuelta al mundo. Pero, por sorprendente que parezca, no todo el mundo acepta esta verdad histórica. Tal es el caso del libro 1421: the Year China Discovered the World, publicado con notable éxito en 2002, y con sucesivas ediciones y traducciones. Su autor, Gavin Menzies, construye un relato en torno al hecho alternativo de que no fue Elcano, sino una expedición china la que un siglo antes de la expedición española
\end{abstract}


completara la primera circunnavegación del globo. Metodología. Se propone el caso de estudio del libro de Menzies. Para ello, la pregunta de estudio de partida es: ¿cómo y por qué el relato de una falsa primera vuelta al mundo es construida y diseminada? ¿Cómo un caso de fake history es contrarrestado? Para responder a dichas preguntas, analizamos múltiples fuentes de evidencia, tales como los discursos y documentación tanto online como offline en torno al caso. Asimismo, se construye un modelo de análisis desde el paradigma contemporáneo de las noticias falsas y la posverdad. Resultados. El estudio subraya que el impacto del libro arranca justo con el inicio de la llamada era de la posverdad, y que su incremento coincide con el momento propicio de la posverdad en el mundo digital. Una vez analizadas las evidencias, se verifica cómo unos "hechos alternativos" históricos como estos son creados, trasmitidos y mantenidos en el tiempo, y cómo intereses comerciales y propagandísticos pueden estar detrás de algo así.

\section{Keywords}

fake news, pseudohistoria, posverdad, circunnavegación, Gavin Manzies.

\section{Contents}

1. Introducción: de Magallanes-Elcano a la flota china. 2. Gavin Menzies y su versión del primer viaje alrededor del mundo. 3. 3. Pseudohistoria y Posverdad. 4. Objetivos y metodología. 5. Resultados. 6. Conclusiones. 7. Referencias.

\section{Introducción: de Magallanes-Elcano a la flota China}

$\mathrm{E}$ NTRE 2019 y 2022 se cumple el quinto centenario de la que fue la primera vuelta al mundo de la historia de la humanidad. Emprendida por Fernando de Magallanes en 1519 y completada tres años más tarde a manos de Juan Sebastián Elcano, esa primera circunnavegación a la Tierra supuso lo que es para muchos, al menos hasta la llegada a la Luna, el mayor capítulo en la historia de la exploración humana (Joyner, 1992, p. 3). Gracias a aquellos hombres, la humanidad tendrá por primera vez una base real para concebir con mayor precisión continentes y océanos, así como el planeta mismo que nos acoge. Huelga señalar las implicaciones geográficas, políticas, filosóficas, científicas, e incluso teológicas y metafísicas que ello tendrá. 
Porque lo cierto es que, aunque existía ya una concepción esférica del mundo más o menos compartida por muchos (Bueno, 1989), aún nadie lo había comprobado empíricamente.

Hay que hacer notar que esa primera vuelta al mundo nunca fue premeditada, o al menos no hay pruebas de que fuera así (Brotton, 2012, p. 240). Aquellos hombres al mando de Magallanes salieron al océano en busca, entre otras muchas cosas (Muñiz-Velázquez y López Casquete de Prado, 2018), de riquezas. Las islas que sí constituían la meta de la expedición magallánica eran las de las especias, las Molucas, en la actual Indonesia. Magallanes, caballero errante marino en palabras de Fernández-Armento (2006), venía trabajando en la hipótesis de una ruta hacia Asia bordeando América. Al ser su propuesta rechazada vehementemente por el monarca luso Manuel I (Rodríguez González, 2018, p. 39), buscará el patrocinio del monarca vecino, Carlos V, quien acogerá de buen grado la propuesta y facilitará la expedición con el apoyo financiero de sus propios banqueros (Brotton, 2012, p. 244; Fernández-Armesto, 2006, p. 290). Es precisamente por eso por lo que Kelsey (2016), entre otros, no duda en el calificativo de española para la expedición, contrapuesta principalmente a Portugal. País de cuyas flotas, por cierto, la expedición estuvo huyendo y jugando "al gato y al ratón" buena parte de la travesía para no ser interceptada (Brotton, 2012 , p. 246). No es de extrañar, por tanto, que el entendimiento entre los dos países ibéricos en relación a la hazaña ha tenido a lo largo de la historia sus altibajos (García Calero, 2019). Pero no es de tal contienda de lo que se pretende hablar en el presente trabajo, sino de otra batalla historiográfica, y también comunicativa, que surgió a principios del siglo XXI en torno a otra supuesta primera vuelta al mundo.

Muchas son las circunvalaciones terráqueas que se han dado después de la lograda por Magallanes y Elcano, como nos recuerda Chaplin (2012, 2013) dejando claro que ninguna antes de 1522. Sin embargo, por inverosímil que parezca, no todo el mundo está de acuerdo con esta verdad histórica. Tal es el caso del autor británico Gavin Menzies y su libro 1421: the Year China Discovered the World, publicado con notable éxito en 2002, y con sucesivas ediciones y traducciones. Dicho autor construye un relato que gira en torno al supuesto hecho de que fue una expedición china, comandada por almirantes subalternos del célebre marino Zheng He, la que nada menos que un siglo antes de la 
expedición española, además de llegar a América antes que Colón, completara la primera circunnavegación del globo.

Ciertamente, parece que Zheng He (1371-1433) fue un marino notable (Boorstin, 1985; Fernández-Armesto, 2006; Joyner, 1992; Paine, 2013), que estuvo al frente de buena parte del poder chino en el cénit de su dominio oceánico durante la dinastía Ming. Es Joyner (1992, p. 13) quien reconoce a China como uno de los pueblos "early seafarers" del planeta, una de las primeras "gentes de mar" de la historia. Pero más allá de ello, las evidencias científicas de que alguna expedición china de entonces llegara a dar la vuelta al mundo, o si quiera arribar a América y Europa, son nulas para la práctica totalidad de la comunidad científica (Davenport, 2003; Fritze, 2002, 2009b; Steele, 2005; Thompson, 2008). No así para el mencionado Gavin Menzies, marino británico nacido en China, que sin ser historiador cuestionará la "versión oficial" en torno al papel de China en el mundo durante el Renacimiento. Centraremos la atención en uno de los logros de entonces más sobresalientes: la primera vez que el ser humano experimenta la esfericidad de la Tierra.

\section{Gavin Menzies y su versión de la primera vuelta al mundo}

Dicen Beretta \& Conforti (2014) que la historia siempre ha sido terreno fértil para las falsificaciones. Un hecho como la primera vuelta al mundo, tan contrastado histórica y científicamente como aparentemente inocuo desde el punto de vista político o ideológico, tampoco se escapará de ello. Ninguno de todos los grandes viajes y descubrimientos europeos "ha sido peor interpretado que la primera circunnavegación del globo", dirá Brotton (2012, p. 240), lo cual no es óbice para que subraye al mismo tiempo que tal viaje eclipsa al resto de hazañas de su época y de muchas otras. Más allá de las rencillas hispano-lusas ya mencionadas, o de la controversia en torno a la verdadera trascendencia del mismo a corto y medio plazo (Kamen, 2014, p. 83; Fernández-Armesto, 2006, p. 292), lo cierto es que la constatación fehaciente en base a evidencias científicas de que fueron aquellos hombres los que completaron "la primera circunnavegación de la que se tiene constancia" (Brotton, 2012, p. 246) jamás se ha puesto en cuestión. Hasta la llegada de Gavin Menzies.

Menzies comienza su relato con la génesis de su libro, describiéndola como una cruzada (sic), la cual comienza, según siempre el autor, tras 
una especie de epifanía vivida en la James Ford Bell Library, de la Universidad de Minnesota, al encontrarse con un mapa en el que vería claramente una "pista oculta" (Menzies, 2002, p. 20). Tal mapa era el de Zuane Pizzigano, de 1424, donde Menzies interpretará que se distinguen ciertas islas norteamericanas. Al ser un mapa precolombino, lo conectará con China y sus travesías de inicios del siglo XV. A este mapa, como piedra clave argumental del libro, se sumarán otros con los que Menzies se irá encontrando (Rojas Sandoval, 2004).

Como se afirma en la misma sinopsis del libro, a lo largo de quince años el autor habría realizado "un trabajo de investigación" que le ha posibilitado la reconstrucción de aquellas supuestas navegaciones chinas del siglo XV, dando como resultado un libro "tan audaz como riguroso, tan monumental como apasionante, que ha merecido el respeto de la comunidad científica" (Menzies, 2002). Termina dicha sinopsis con la promesa de que su lectura nos obligará "a cambiar nuestra visión de la época de los grandes descubrimientos europeos".

Grosso modo, Menzies narra cómo la supuesta flota china más grande de todos los tiempos se repartiría por los océanos hasta llegar a África, América, Europa, Australia, para dar finalmente la vuelta al mundo. Así, sus distintos almirantes habrían visitado las costas americanas setenta años antes que Colón, descubierto Australia 350 años antes que Cook y circunnavegado el globo un siglo antes que Elcano. Sin embargo, nada de ello ha dejado huella en esos lugares supuestamente contactados, ni cambiaría tampoco el devenir histórico de China. La causa de ello, defenderá Menzies, sería que, tras el regreso de todas esas expediciones, cambió el emperador, se le dio la espalda al mar, y voluntaria y accidentalmente se destruyó todo rastro documental del expansionismo marítimo anterior. Tan épicos viajes serían, por tanto, condenados al olvido hasta que Menzies encontró suficientes pruebas para resucitarlos (Menzies, 2002, p. 452).

Como ya se ha dicho, es cierto que Zheng He pudo marcar la cúspide de la navegación de entonces (Prazniak, 2010), y que China en aquel tiempo ya era una superpotencia mundial, siendo el "primer Estado moderno" en muchos sentidos (Fernández-Armesto, 2010, p. 228). No en balde, 
Un observador del mundo en el siglo XV hubiera pronosticado sin duda que China precedería a los demás pueblos en la hazaña de completar la vuelta al planeta, en la apertura de rutas transoceánicas y en establecimiento de un imperio marítimo. [Pero lo cierto es que] en realidad, nada de eso llegó a producirse, y quedó libre el camino para que fueran los exploradores europeos, de perfil mucho menos prometedor, quienes descubrieron las rutas alrededor del mundo (FernándezArmesto, 2006, p. 179).

En cualquier caso, en 1433 las expediciones se cancelaron abruptamente, y China, efectivamente, se volvió hacia sí misma por varias razones: un motivo de costes-beneficios de las expediciones, nuevos intereses, amenazas y prioridades de una nueva oligarquía, etc. (Fernández-Armesto, 2010, p. 242; Joyner, 1992, p. 14; Paine, 2013, p. 420; Sen (2016, p. 612). Así, "otras potencias de menor envergadura, incluidas las europeas, consiguieron aprovechar las oportunidades a las que el poderío chino había renunciado en el mar" (FernándezArmesto, 2010, p. 247). Menzies (2002) no puede negar tal evidencia, pero lo dirá de otro modo. Será toda una declaración de intenciones su insistencia en que, tras la retirada china, portugueses y españoles "disfrutarían de una gloria que por derecho les correspondía a otros", para continuar diciendo que, con su libro, "ahora ha llegado el momento, por fin, de que restauremos el equilibrio de la historia y otorguemos los méritos a quienes realmente lo merecen" (Menzies, 2002 , p. 466). Aunque seguidamente diga que "afirmar la primacía china en la exploración del Nuevo Mundo y de Australia no equivale a denigrar los logros ni la memoria de Dias, Colón, Magallanes y Cook" (Menzies, 2002, p. 466), sus propias páginas ponen de manifiesto que no es así.

En paralelo a ello, afirmará Menzies (2002, p. 465) que "en lugar de los educados chinos, a los que se había dado instrucciones de 'tratar con bondad a las gentes distantes', serían los crueles y casi bárbaros cristianos los colonizadores". En cambio, Fernández-Armesto (2010, p. 242) lo dejará claro, cuando apunta que las relaciones de poder y dominio que iban también buscando los chinos hasta donde llegaron eran tan agresivas o más que las europeas. Zheng He, el supuesto "'ambassador of friendship', fue un exponente claro de proto- 
colonialismo, dirá Sen (2005), sin diferenciarse tanto en intenciones y modales de aquellos otros viajeros europeos. También para Wade (2005) eran exactamente actos de invasión en pro de una política expansionista.

Parece, por tanto, que ni unos eran tan pacíficos y desinteresados, ni otros tan beligerantes y dañinos. Pero, como vemos, esta polarización a favor de los chinos será algo en lo que Menzies ahondará, construyendo así una versión del pasado que encajará, en lo épico y también en lo moral, con los intereses y la importancia económica de la China del presente. Esta necesita "que el mundo tenga una opinión mucho mayor de sus roles en la configuración de la historia mundial", dirán Melleuish, Sheiko \& Brown (2009, p. 1492), por lo que no es de extrañar que, a pesar de las evidencias científicas en contra, el propio Partido Comunista Chino respaldara el libro de Menzies (Goodman, 2006, p. 212), y que su promoción fuera apoyada desde el inicio por el gobierno chino (Steele, 2005, p. 278). Cuenta Richardson (2008, p. 34) cómo el presidente de China llegó a defender la tesis del libro relativa a que China había descubierto Australia en el siglo XV, ante el propio Parlamento Australiano un 24 de octubre de 2003. Hecho que por otro lado usaría luego Menzies como aval.

Como vemos, lo político, lo propagandístico, lo económico y lo comercial se mezclan estrechamente en la pugna historiográfica, y "el creciente papel de China, económico, estratégico y hasta cultural, no ha sido ajeno a una reescritura de su pasado, que ha llegado a suscitar alguna exageración sinocéntrica" (Taboada, 2007, p. 761). Durante 2005, en Singapur, se organizó una exposición sobre Zheng He. El objetivo era celebrar el sexto centenario de su primer gran viaje, y reivindicar así la importancia de las grandes exploraciones chinas frente a los navegantes europeos del Renacimiento (Folch, 2008). La organización, el Singapore Tourism Board, junto a otros muchos agentes, participó activamente en la publicidad del libro de Menzies (Prazniak, 2010). El argumento de que China descubrió América antes de Colón y circunnavegó el mundo antes de Magallanes, amén de lograr tales gestas menos belicosamente que los europeos, era lo bastante apetitoso como para no aprovecharlo. Así, el libro de Menzies tuvo amplio eco en los fastos, ante lo cual las protestas fueron numerosas desde el ámbito científico y académico, también desde la propia China. 
A tales protestas la organización respondió que ni respaldaba ni rechazaba las afirmaciones de Menzies, y que se debía permitir que el público decidiera por sí mismo su veracidad.

El campo de batalla estaba ya definido, por tanto. Nos encontramos con una neutralidad que, desde los estudios sobre la posverdad, la pseudociencia y la pseudohistoria será a todas luces falaz, como advierte Mcintyre (2018). Falaz porque no se sitúa a media distancia entre dos voces autorizadas y con pleno criterio científico que opinan distinto, sino entre una voz que sí lo está, y otra que en absoluto. De ello, la posverdad sacará buen partido, como veremos.

\section{Pseudohistoria y Posverdad}

La obra de Menzies ejemplifica de manera canónica cómo incluso una verdad histórica sin sombra de duda puede verse acechada por ataques de desinformación y cuestionada por una verdad alternativa, pseudohistórica. Como afirman Melleuish, Sheiko \& Brown (2009, p. 1485), los pseudohistoriadores, o escritores de Weird History, como también la llaman los autores, consideran que lo que están haciendo es escribir una historia que "corrige" los supuestos errores de los historiadores profesionales, quienes dominan el ámbito, pero están atrapados por las limitaciones metodológicas, académicas, etc.

Este será precisamente uno de los factores de éxito de los relatos pseudohistóricos, la subversión de un supuesto orden establecido. Son escritores normalmente "outsiders", por lo que sustentarán su legitimidad no sobre la confrontación con los pares, sino sobre la admiración del público que lo acoge. Otro factor de éxito que señalan Melleuish, Sheiko \& Brown (2009, p. 1492) gira en torno al zeitgeist de la época. Es decir, los relatos pseudohistóricos exitosos suelen girar en torno a preocupaciones más o menos extendidas del presente, tales como identidades nacionales, catástrofes naturales, relaciones de poder, etc. Así, Menzies y su equipo muestran una gran maestría en su modo de proceder, lo cual es plenamente analizable desde los modelos de desinformación y posverdad contemporáneas.

De manera general, posverdad viene definiéndose como la "subordinación de la verdad a intereses políticos" (McIntyre, 2018, p. 180), a lo que habría que añadir también económicos o sociales. Implica asimismo la subordinación de los hechos objetivos a las emociones y a 
las creencias. Todo lo cual constituye un fenómeno, por otro lado, nada nuevo (O'Connor y Weatherall, 2019; Tattersall \& Nevraumont, 2018; Tucher, 1994), especialmente si pensamos en escenarios bélicos (Iglesias Rodríguez, 1997; Schulze Schneider, 2001). Pero lo cierto es que la tecnología ha marcado un punto de inflexión en la construcción y difusión de mentiras (Jacomella, 2017). Hoy, desde el paradigma líquido tan profusamente descrito por Bauman (2000), también el pasado es objeto de un revisionismo lubricado por el postmodernismo, "padrino de la posverdad" en palabras de McIntyre (2018, p. 16). Aunque puede que el concepto de posverdad se esté convirtiendo en un lugar común y del que se pueda estar abusando (Carrera, 2018), lo cierto es que estamos ante un fenómeno que en lo cuantitativo y cualitativo no tiene precedentes en la historia de la humanidad.

Así, la principal amenaza hoy se cierne sobre la confianza en la certeza científica, y por tanto en el pensamiento racional en sí (McIntyre, 2018, p. 16). No en balde, la era contemporánea de la posverdad a gran escala se inaugura con el negacionismo científico, dirá McIntyre (2018): tabaquismo, cambio climático, vacunas, etc., debates falaces donde se busca prender la duda ante la evidencia científica, nunca verdad objetiva al $100 \%$ a causa precisamente del método científico y sus principios popperianos. Es ahí donde los mercaderes de la duda (Oreskes \& Conway, 2010) promueven el escepticismo bajo una equidistancia tramposa, pues "el punto medio entre la verdad y el error es, aún, el error” (McIntyre, 2018, p. 102). Así, las compuertas para la sospecha, al mismo tiempo que para la credulidad máxima, quedan abiertas. Los media, por cierto, tendrían aquí que entonar el mea culpa, pues por cuestiones de audiencia fomentan a menudo la controversia por encima de la verdad.

Por multitud de razones, podemos ver cómo el caso de Gavin Menzies y su libro se ajusta a la perfección al patrón contemporáneo de posverdad. Siguiendo el análisis que hace, entre otros, McIntyre (2018), podríamos fijar una serie de elementos que constituyen una posverdad pseudohistórica de éxito, todos ellos perfectamente visibles en el caso del marino británico: 
1. Extravagancia: la posverdad plantea cuestiones sobre algún asunto extravagante, singular, que invite al sensacionalismo. Así, las hipótesis de los pseudohistoriadores "suelen contener afirmaciones espectaculares" (Fritze, 2009b, p. 22).

2. Emoción: la posverdad es ante todo un fenómeno emocional (D’Ancona, 2017), siendo las emociones más importantes que los hechos. En nuestro caso, la idea de que barcos chinos circunnavegaron el globo por primera vez es siempre "an exciting story" (Goodman, 2006, p. 212).

3. Evidencias: no las hay en términos científicos, así que se relativiza su importancia. Más allá de la convicción, y de la emoción, no se podrán mostrar pruebas sin sesgos, ni contar con el método científico para avalarlas.

4. Establishment. será necesario inocular la sospecha de que los expertos, historiadores en nuestro caso, son parciales y esconden intereses. En palabras de D'Ancona (2017, p. 18) anatemizarles como "cártel malintencionado". Así, la caída de la autoridad científica y del respeto al conocimiento están servidos, y el "relativismo malsano" (D’Ancona, 2017, p. 63) campará a sus anchas.

5. Nicho de mercado: llegar a inocular la controversia al menos en una parte mínima del público. Con los nuevos canales horizontales de difusión, redes sociales, etc., esa masa crítica mínima puede autoalimentarse, mantenerse e incluso crecer exponencialmente en poco tiempo.

6. Predisposición: se hace conveniente el ensamblaje con ideas preconcebidas relacionadas con la posverdad en cuestión, y el acomodo a la propia ideología del público objetivo. Así, el sesgo confirmatorio y otros de índole claramente irracional (Sutherland, 1992), trabajarán a favor.

7. El medio es el mensaje: por coger el ya clásico paradigma de McLuhan, el peso de lo escrito es inexorable. La propia aparición en sí en cualquier medio o rincón digital es un aval de legitimidad suficiente para buena parte de la ciudadanía. Paradigmático es, en el caso de Menzies, cuando la Public Broadcasting System (PBS) de Estados Unidos produce un documental sobre su libro. Menzies obviará las numerosas críticas que aparecen en él, y 
propagará el mero hecho de que la PBS le dedica un documental, tomándolo como prueba para legitimarse (Fritze, 2009b).

8. Terceros: es importante en la difusión de una posverdad implicar a terceros. Esto es, instituciones, organismos o celebridades. Que sean expertos o no en el tema es lo de menos; el que algún famoso se haga eco de las tesis pseudohistóricas será clave (Rubin, Chen \& Conroy (2015). En Menzies esto es una constante.

\section{Objetivos y metodología}

El objetivo principal de este trabajo es estudiar la difusión del relato de la primera vuelta al mundo de Gavin Menzies y cómo penetra como relato alternativo a la vuelta al mundo de Magallanes-Elcano. De este primer objetivo se desprende un segundo objetivo igualmente importante: construir un estudio de caso que pueda ayudar a comprender la construcción de una posverdad histórica de tal forma que pueda contribuir a futuras investigaciones sobre casos semejantes.

Teniendo esto en cuenta, seguiremos una metodología de estudio de caso. Según Yin (2014, p. 29), este nos ayuda a entender un fenómeno complejo, especialmente de orden social. Es decir, la metodología del estudio de caso nos permite, enfocándonos en un ejemplo determinado, mantener una perspectiva holística. El mencionado autor nos dice que hay tres componentes claves que guían el diseño de la investigación hacia la recolección de datos. En primer lugar, la cuestión de estudio. En segundo lugar, sus proposiciones, las cuales deben añadirse a la cuestión de estudio para avanzar hacia la dirección correcta diciéndonos dónde buscar evidencias. Y, en tercer lugar, la unidad de análisis bien definida. Aquí, por tanto, su formulación es la siguiente:

Cuestión de estudio: ¿Cómo y por qué se difunde y legitima el relato de la primera vuelta al mundo de Gavin Menzies?

Proposiciones: El relato se construye partiendo de la dispersión de información y la construcción de posverdad.

Unidad de análisis (el caso): el libro de Gavin Menzies 1421: The Year China Discovered America. 
Así, de cara a la recolección de datos, se ha decidido recurrir a un análisis de contenido de dos de las seis fuentes de evidencias propuestas por Yin (2014, p. 106): documentación y observación directa. Para ello, de un lado, se ha llevado a cabo un estudio del debate científico y académico que ha generado el libro de Menzies con la intención de evaluar el enfoque crítico en torno a la obra, presentando los argumentos científicos que contrastan y desmontan la posverdad del discurso de Menzies. Para esto, se ha decidido buscar en las bases de datos de la Web of Science, Scopus, Google Books y Google Scholar las palabras clave "Gavin Menzies", "Chinese Circumnavigation" y "Zheng He", de cara a entender la complejidad y el alcance del fenómeno y la respuesta científica al discurso de Menzies. De otro lado, se ha analizado la presencia, impacto y huella online que ha dejado el libro en internet. Para ello se ha recurrido al análisis de Google, como fuente de información principal de cualquier usuario digital, Wikipedia, como referencia de enciclopedia online universal, y varias bases de datos bibliotecarias y de medios de comunicación. Por último, como parte del estudio del impacto del libro, se ha querido utilizar la observación directa con un análisis de la valoración del libro y las opiniones de los lectores en las principales plataformas de venta de libros, al menos en España, como son Amazon o La Casa del Libro, así como Barnes \& Noble en EE.UU.

Con la triangulación de los resultados de estos datos se pretende explicar la conexión de la proposición con la cuestión de estudio. Como explica Tellis (1997: 2):

Case studies are multi-perspectival analyses. This means that the researcher considers not just the voice and perspective of the actors, but also of the relevant groups of actors and the interaction between them. This one aspect is a salient point in the characteristic that case studies possess.

Por último, conviene señalar que para el análisis de contenido de estos datos no se ha recurrido a ninguna codificación preestablecida previamente, sino que se ha optado por una aproximación abierta. Así, se espera que de los resultados del análisis emerjan una serie de conclusiones que los vinculen con la proposición planteada al inicio. 


\section{Resultados}

\subsection{Las voces del "establishment" científico ante Menzies}

Conviene comenzar este apartado precisando que alguna voz considerada experta sí ha sido receptiva hasta cierto punto a las tesis de Menzies, tales como las de Vargas Martínez (2004) o Dussel (2004), si bien no exentas de críticas. Lysa \& Jianli (2009, p. 297) dirán, por su parte, que las teorías de Menzies son presentadas de una manera entretenida e intelectualmente desafiantes, y que será el lector quien habrá de decidir por sí mismo la veracidad de lo narrado, algo llamativo, por otro lado. Steele (2005, p. 276) dirá que el libro puede divertir, pero manteniendo siempre un saludable escepticismo, pues se basa en hechos históricos para luego usarlos y mezclarlos a su antojo, dando como resultado un libro que no es más que un delicioso divertimento. Dejando aparte otros dos libros que respaldaban las tesis de Menzies (Andro, 2005 y Chiasson, 2006), también acusados de ficción por los académicos (Fritze, 2009b, 126), hasta aquí grosso modo llegarían los elogios a Menzies. Así, el rechazo generalizado de los historiadores que casi unánimemente tacharán su trabajo de pseudohistórico y pseudocientífico, llevará a Menzies a vilipendiarlos, siguiendo un doble juego con ellos.

Entre los numerosos académicos mencionados por Menzies en los agradecimientos de su libro, detalle que trata de convertir en fuente de legitimidad y credibilidad, se encuentran Kirsten y Paul Seaver. La primera, que sí es miembro de la Royal Geographic Society, en su exhaustivo trabajo en torno a la veracidad de otro de los mapas que usa Menzies en su argumentación, el mapa de Vinland (Menzies, 2002, p. 355 y 362), no deja lugar a dudas: es falso (Seaver, 2004). Tal mapa no proviene del siglo XV sino del XX. Igual de falso es otro mapa que presenta Menzies en 2006 como nueva prueba de su tesis de la circunnavegación china, un mapa del siglo XVIII que es una supuesta copia de otro perteneciente a Zheng He, de cuya falsedad Wade (2007) no dejará tampoco dudas. Kirsten Seaver, por cierto, se considerará manipulada por Menzies, pues a pesar de pedirle a este que no la incluya en los mencionados agradecimientos del libro, lo sigue haciendo (Fritze, 2009b).

Desde el punto de vista metodológico, el libro es juzgado de fallido, y es por ello que Fritze (2002), entre otros, lo acusa sin más de ser un 
artefacto de pseudociencia y pseudohistoria. Cabe hacer notar que el prefijo pseudo- no significa otra cosa que falso, y de una manera contundente y sin paliativos. Esto es, pseudohistoria es falsa historia, aunque vaya mezclada con retazos de verdad. Así, Menzies toma algunas verdades contrastadas de la historia para, combinándolas y al mismo tiempo soslayando otras, construir unos hechos alternativos de relativa plausibilidad (Taboada, 2007). Aunque no cuente con pruebas fehacientes, y muchos de los datos que muestre "son aglutinados con ligereza y poco rigor" (Rojas Sandoval, 2004, p. 22), salpicará su libro continuamente con expresiones argumentales científicamente temerarias y poco honestas, tales como "no cabe duda que", hay "pruebas de", "firmes evidencias", o "la explicación más plausible" (Taboada, 2007, p. 76). En ese sentido, Menzies usa la confusión entre lo posible y lo probable. Que algo sea posible, o que no sea imposible, no quiere decir que sea probable, es decir, que haya grandes oportunidades de que ocurra o haya ocurrido.

Para Elman (2007), quien llama al trabajo de Menzies ciencia-ficción bien orquestada, son tantas y tan variadas sus mentiras, que desmentir una a una supondría un esfuerzo ingente (Taboada, 2007, p. 762). Coincide en ello Goodman (2006, p. 212), quien dirá que el libro tiene todos los elementos para "una buena conspiración contemporánea", algo que es siempre un buen motor para la ficción, y la pseudohistoria (Gottschall, 2012). Contundente es asimismo Rivers (2006), quien afirma que estamos ante un ejercicio de licencia literaria que no es historia revisionista, sino ficción, a secas, ni siquiera ciencia ficción. En todo ello coinciden las numerosas críticas sobre el libro que resume JuddStallard (2008), ante las cuales Menzies ha optado siempre por algún artefacto argumental nuevo que le permitiera esquivarlas.

El ya mencionado Fritze (2009b) le dedica a Menzies un capítulo entero de su libro Conocimiento Inventado. En él relata con profusión de detalles su mezcla de verdades históricas con falacias. Partiendo de la figura de Zheng He, comienza el británico con las especulaciones de cómo almirantes suyos llegan hasta la costa sudamericana y atraviesan el estrecho de Magallanes, y cómo a partir de ahí la expedición se habría dividido en dos: Hong Bao se dirige al Sur, y Zhou Man al Norte, alcanzando así todas las grandes regiones del mundo. Una vez Menzies y Bonomi, su agente, tuvieron una primera versión del libro preparada, 
emprenderían la campaña de comunicación para vendérselo, en primer lugar, a alguna editorial de prestigio, contratando para ello a Midas Public Relations (Fritze, 2009b, p. 122). La editorial que finalmente se quedó con los derechos fue Bantam Press, del grupo Transworld, una gran editorial de prestigio, lo cual incrementaría la credibilidad de Menzies (Fritze, 2009b, p. 122). Para aquel evento de presentación alquilaron un local en la Royal Geographic Society de Londres, con lo que lograron, además de asociar el nombre de una institución de prestigio, crear cierta polémica, siempre generadora de notoriedad. Con igual modus operandi intentaron más tarde una publicity similar en la Universidad de Stanford, en la Annual Meeting de la American Historical Association de 2004, en Washington DC, e incluso en la Biblioteca del Congreso de Estados Unidos (Goodman, 2006, p. 212).

Para Fritze (2009b) el libro es una especie de híbrido entre relato histórico, documental sobre viajes e historia de detectives y aventuras, pero nada más. A pesar del aparente abrumador conjunto de pruebas, estaríamos solo ante especulaciones o meras "opiniones" de Menzies, en contra del "criterio" de los verdaderos historiadores, quienes las ven no solo "improbables, sino también absurdas y completamente desvinculadas de cualquier prueba convincente o verosímil" (Fritze, 2009b, p. 121). No pocos especialistas han declarado a Menzies "incompetente, deshonesto o ambas cosas", incluso en temas técnicos marinos (Rivers, 2004). Sin mencionar a nadie, Fernández-Armesto (2010, p. 244) llega a decir que "se han formulado afirmaciones absurdas acerca de los viajes de Zheng He", para afirmar seguidamente, y con toda rotundidad que "los buques de su flota no traspasaron los límites del océano Índico ni, menos aún, descubrieron América o la Antártida". Mucho menos, se entiende, que ni He ni ninguno de sus subalternos dieran la vuelta al mundo.

Richardson (2008, p. 37) clasificará el trabajo de Menzies como "invented history". El libro, dirá, nunca debiera verse en los programas de historia de ninguna universidad. En todo caso, como advertencia de lo fácil que es "ser estafado por autores y editores sin escrúpulos". Asimismo, diseccionando algunos mapas que usa Menzies para sus tesis (Richardson, 2004; Robinson, 2010) dirá que no son "evidencias cartográficas", sino "imaginografía", pues Menzies "traduce" 
libremente muchos de los topónimos de una manera desinformada e inespecífica.

Como dice Goodman (2006), Menzies podría haberse limitado a escribir una entretenida novela. Incluso haber optado por el género contrafactual, tan de moda actualmente, construyendo una historia alternativa bajo la premisa “¿qué hubiera pasado si...?”. Historia contrafactual la define Evans (2014, p. 13) como aquellas "versiones alternativas del pasado en las que una alteración en la serie de sucesos conduce a un resultado distinto del que realmente ocurrió". Aun con sus sombras, además de entretener, el modelo contrafactual puede tener su utilidad científica. Aunque como afirma Evans (2014), todos los contrafactualistas en el fondo tienen la tendencia a expresar deseos y "saldar cuentas pendientes" (Evans, 2014). Es aquí donde sí que parece coincidir Menzies. Para Taboada (2007) y Rojas Sandoval (2004) no cabe duda de que lo que pretende el británico es sustituir a los héroes europeos por los chinos, saldar las supuestas deudas que tiene la historia con China.

Sus páginas rezuman también, de alguna manera, la trampa en la que suelen caer los contrafactualistas, la de "imaginar que las cosas hubieran sido mejores si hubieran sido diferentes" (Evans, 2014, p 150). Al igual que las hipótesis contrafactuales son irónicas porque siempre, en última instancia, arrojan más luz sobre el presente que sobre el pasado (Evans, 2014), también se podría decir lo mismo de Menzies. Pero dicho esto, se acabaron las coincidencias, porque lo cierto es que el autor ha optado en todo momento por defender historiográficamente su trabajo.

La circunnavegación que plantea Menzies jamás tuvo lugar, concluirá Finlay (2004, p. 242), mostrándose contundente en acusar el razonamiento del libro de inexorablemente circular, sustentado en evidencias falsas, sacadas de una investigación irrisoria. Sin paliativos, Fernández-Armesto (2010) calificará el libro como "la tontería de un niño de dos años". Pero a pesar de esta denostación y la del resto de expertos de forma casi inmediata a su publicación, nos encontramos ante un libro que fue un superventas, un "paradigma del éxito de la literatura pseudocientífica” (Fritze, 2009b, p. 121), que gracias al marketing vendió ya en su primer lustro de vida más del millón de ejemplares. 
Así, ante la confrontación con la academia, dirá Menzies: "el público está a mi lado, y ellos son los que cuentan" (en Fritze, 2009b, p. 126). Se apela, por tanto, a la autoridad del público, frente a la que pueda ostentar la academia y la ciencia. No obstante, cuando consigue que universidades prestigiosas, tales como Harvard, Oxford, Lisboa, o Melbourne lo inviten a hablar de su libro, lo valore y lo tome como aval, pues según Menzies, esto "no sucedería si los profesores de esas universidades no pensasen que estoy en lo cierto" (en Fritze, 2009b, p. 125). Es óbice decir que no siempre una universidad está de acuerdo con sus invitados, atendiendo a la pluralidad que debe regir en ella. Pero también supone un toque de atención en relación a la verdadera naturaleza de la neutralidad científica universitaria.

En cualquier caso, Menzies (2002, p. 19) señala que su libro no va destinado a la academia, sino al "público en general", algo que ya nos pone en la pista de que esa "investigación" tan audaz como "rigurosa" que se defiende en la sinopsis no está siguiendo los protocolos canónicos de la ciencia. Es decir, en toda disciplina científica, ante un supuesto hallazgo, lo primero que se ha de hacer es compartirlo con la comunidad científica experta para su confrontación exhaustiva y rigurosa. Una vez superados los filtros que corroboran al menos el rigor metodológico, se comparten los resultados con la opinión pública, pero no antes.

\subsection{La huella de 1421}

\subsubsection{Catalogación, materias y CDU}

En relación a la legitimación y difusión de la pseudohistoria, Henige (2008) pone el dedo en la llaga: la catalogación bibliográfica. La forma en que las bibliotecas clasifican todos los materiales relativos al pasado, esto es, historia, ficción, creencias, contrafactuales, etc., tiene inexorablemente un impacto sobre la credibilidad y legitimidad sobre lo clasificado. Así, las bibliotecas, uno de los principales agentes responsables de clasificar los libros en el mundo, fallan en distinguir entre los hechos probables, la ficción palpable, y la historia científicamente contrastada, dejando a los usuarios de alguna manera indefensos. $\mathrm{O}$, dicho de otro modo, la catalogación mediante materias y CDU a veces no las prepara para obras controvertidas como esta. 
A día de hoy, las principales bibliotecas nacionales y algunas de las más relevantes internacionalmente siguen clasificando la obra de Menzies en las categorías "Discoveries in geography-Chinese", "Voyages around the world", "China--History--Ming dynasty, 1368-1644" y "America--Discovery and exploration-China". Es decir, la obra aparece catalogada, en la mayoría de las ocasiones, en materias dedicadas a la historia en general y, en particular, a la historia de China o a los "Descubrimientos chinos" y a la "Historia del mundo". En lo que respecta a la clasificación CDU se opta, en algunas ocasiones, por el 355.49 "Historia naval. Campañas navales. Batallas navales" y 94. "Historia general". Otras incluyen el libro en el 910: "Generalidades. La geografía como ciencia. Exploraciones. Viajes".Si recurrimos a Amazon, como el referente de comercio electrónico de libros, observamos que la obra se cataloga, de nuevo, tanto en la tienda estadounidense como en la española, bajo la materia de "Historia". Más concretamente, en España, se ubica dentro de Historia/Edad Media, mientras que en Amazon.com puede encontrarse en History/Asia/China, History/World/Expeditions and discoveries y History/Militar/Naval.

Por el contrario, el análisis y la catalogación más precisa la hace quizás Wikipedia. En primer lugar, la obra no tiene en ella una página dedicada, ni en su versión en inglés ni en español. En la versión española existe no obstante la entrada "Hipótesis de 1421", catalogada bajo la materia "Contactos transoceánicos precolombinos" y "Pseudohistoria". La página de Gavin Menzies en la versión en inglés lo recoge también dentro de la materia "Pseudohistorians", aunque igualmente aparece en la categoría de "Pre-Columbian trans-oceanic contact". En cualquiera de los casos, no aparece en ningún momento ninguna referencia al autor o sus libros bajo las materias o categorías de "Circunnavegación", "Exploración del Océano Pacífico" o "Era de los Descubrimientos" como sí es el caso de la entrada dedicada a la "Expedición de Magallanes-Elcano". En la versión en español, la entrada del autor ni siquiera existe.

\subsubsection{Presencia e impacto en Internet}

En términos cuantitativos, la huella del libro en internet no es excesivamente extensa. Siguiendo con Wikipedia, la supuesta vuelta al mundo china no aparece referenciada de ninguna forma en la entrada 
sobre "Circunnavegación", ni en la edición en inglés ni en la española. En el anexo "Circunnavegaciones del mundo" (en inglés "List of Circunnavegations") tampoco tiene ninguna presencia ni la obra ni Zheng He ni los almirantes Yang Qing, Zhou Man, Hong Bao o Zhou Wen. Además, en la entrada en inglés sobre Gavin Menzies, en la sección de "Discusión" ("Talk"), se rechaza mayoritariamente la posibilidad de que se dediquen entradas a sus obras por el carácter de pseudohistoria. En la edición en español, en la misma sección, se establece que toda referencia a la obra de Menzies debe estar recogida en la entrada que mencionamos anteriormente: "Hipótesis de 1421".

Si se busca en Google "Primera vuelta al mundo" el buscador no muestra ninguna información que vincule esto con China. Lo mismo ocurre si se busca "Vuelta al mundo china" o "Primera vuelta al mundo China". Los resultados solo comienzan a visualizar la historia de Menzies si añadimos como palabra clave "Zheng". En estos casos, aparecen varios sitios webs que sí recogen la supuesta vuelta al mundo de la flota china. En YouTube los resultados son similares. Al incluir "Zheng" a las combinaciones anteriores podemos ver la aparición de tres vídeos: "La Armada china misteriosos viajes del almirante Zheng He en el siglo XV" (1928 visualizaciones), del canal Historia; otro con el mismo título y 237.092 visualizaciones; y un tercero, "¿China Descubrió América? Los viajes de Zheng He”, que cuenta con 20.533 visualizaciones.

\subsubsection{La presencia en medios de comunicación españoles}

La práctica totalidad de la prensa española, en un momento u otro, recoge la existencia del libro de Menzies. Así, para realizar el análisis de ello, se ha procedido a realizar una búsqueda en la base de datos MyNews, que recoge 1444 fuentes de medios periodísticos españoles desde 1996 y más de 250 millones de artículos. Se realizaron dos búsquedas. En una primera, se usaron como palabra clave "vuelta + mundo + china + zheng" desde el 1 de enero de 2004 hasta el 22 de marzo de 2019 en todos los medios. En líneas generales, se observa poca penetración en medios de comunicación. De todos los resultados, y una vez filtrados por la temática, se obtuvieron ocho noticias relevantes en diarios como La Vanguardia, Diario de Navarra, El Heraldo de Aragón, Abc, Eldiario.es o La Verdad. Todas las noticias se centraban en la hipótesis de que Zheng He descubrió América antes que Colón. 
Además, los artículos se escribieron, en la mayoría de casos, como respuesta a varios eventos y acontecimientos claves en China, como el ya mencionado sexto centenario de los viajes de Zheng He, o la nueva ruta de la seda de China y las declaraciones del presidente turco Erdogan sobre la navegación musulmana.

En lo que respecta al género informativo, pueden encontrarse desde noticias a artículos de opinión. La mayoría de textos precisan el carácter de "conjeturas", "hipótesis" o "especulaciones" cuando se habla del supuesto descubrimiento de América por parte de Zheng He, señalando que estamos ante "otro intento de estirar la historia para favorecer la expansión cultural y económica de un país" (La Verdad, $18 / 11 / 2014)$. En cambio, otros titulares otorgan un rol importante a Zheng He, "La odisea del Colón chino" (ABC, 14/08/2005), y dan cabida a las teorías y conjeturas de forma más abierta. Relevante es señalar un artículo de la agencia EuropaPress (11/10/2016) que da explícitamente por válida la tesis de la vuelta al mundo china.

En una siguiente búsqueda, se usaron las palabras clave "China + Menzies + Zheng", con el objetivo de ver la cobertura informativa de Menzies y su libro. Se obtuvieron un total de 49 resultados en los diarios españoles. En términos generales, la cobertura informativa estaba centrada, de nuevo, en la presentación del mapamundi, la ruta de la seda, y el centenario de los viajes de Zheng He. Algunos medios hablan de "interesante libro de Gavin Menzies" (El Mundo, 27/01/2005, La Verdad, 16/01/2006). En esta búsqueda aparece un nuevo tema, cual es la exposición sobre los viajes de Zheng He en el Museo Marítimo de Barcelona.

En cualquier caso, la mayoría de los medios trata la obra de Menzies como mera conjetura. Así, por ejemplo, La Vanguardia (17/01/2006) en un artículo en la sección de Cultura sentencia que la historia se hace con pruebas y documentos sobre los hechos, "y, de momento, no hay evidencias de su llegada a América [de Zheng He], aunque la tesis del británico haya alegrado muchos corazones en China”. Asimismo, con respecto a la exposición en Barcelona, El Periódico (14/11/2008) entrevista a una sinóloga de la Universidad Pompeu Fabra para desmentir el debate: “África sí, América no" reza el titular del artículo. Dejando de lado este caso, el resto de medios no suelen incorporar investigadores o historiadores a sus columnas como entrevistados. 
Además de todo ello, el propio Menzies tiene una entrevista en $A b c$ (5/04/2009) con el titular «Leonardo da Vinci fue un artista genial, pero no inventó nada», para hablar de su segundo libro y la vinculación de Zheng He con el Renacimiento europeo.

Tanto en la primera como en la segunda búsqueda, los almirantes de He tienen también poca presencia en la prensa, excluyendo un artículo publicado en el XL Semanal y titulado "¿Descubrieron América los chinos en 1421?”, que cita a los almirantes Yang Qing, Zhou Man, Hong Bao y Zhou Wen.

\subsubsection{Observación Directa. Valoración de los usuarios}

Además de las fuentes anteriores, se ha querido recurrir a los principales sitios donde se encuentra disponible la obra, y observar directamente la opinión de los usuarios y lectores. Así, en Amazon.com, el libro tiene 525 reseñas y una nota media global de 4,1 estrellas sobre 5. Es decir, la mayoría de lectores y usuarios valoran muy positivamente la obra, destacando, entre muchos otros aspectos, su buena prosa, "el trabajo detectivesco de los mapas", "bien argumentado". Recordemos lo que dijimos antes respecto al nicho de mercado, siempre propicio a todo tipo de relatos. El libro únicamente cuenta con un $19 \%$ de comentarios con 1 estrella y $6 \%$ con dos estrellas, coincidiendo todos ellos en los términos "pseudohistoria", "implausible" o "poco científico".

En Amazon.es cuenta con 10 reseñas y una nota media excelente: 4,5 sobre 5. La única valoración crítica, con 3 estrellas indica: "Un libro entretenido, pero con muy poco rigor histórico. Las conclusiones del autor son excesivamente voluntaristas y a pesar de tratar de hechos históricos comprobados es un libro de ciencia ficción". En La Casa del Libro, la obra aparece con una valoración media de 8 sobre 10 y solo una nota negativa. Por último, en Barnes \& Noble, una de las cadenas de librerías con mayor cuota de mercado en EE.UU., aparece con una puntuación de 3,7 sobre 5 por parte de los 77 usuarios que han dejado su valoración.

\section{Conclusiones}

Como vemos, la vuelta al mundo de Magallanes-Elcano tampoco se salva de la posverdad. La primera circunnavegación al globo, subraya Paine (2013, p. 376), es uno de los triunfos no solo de aquella era, sino 
de cualquier era. Con esta y con el resto de aquellas expediciones europeas, el ser humano se hace consciente de que vive en un solo mundo, a partir de lo cual será capaz de reconocer "a todos los pueblos como integrantes de una única comunidad moral de envergadura planetaria" (Fernández-Armesto, 2010, p. 12). De la mano de ambos países ibéricos se inicia, por tanto, la globalización (González Sánchez, 2007) en la que seguimos inmersos. Asimismo, la gesta pone de manifiesto la importancia de dejar trazo escrito de todo cuanto acontece, como apuntan Varona-Aramburu y Herrero-Diz (2018), pues la historia constituye ese relato verídico del pasado del hombre, fundamentado en pruebas recabadas bajo el método científico. Todo lo demás será fake history o junk history, asíllamada precisamente por los barcos chinos (Thompson, 2008).

A continuación, y basándonos en los resultados expuestos, se pretende ofrecer una respuesta a cómo y por qué se difunde y legitima el relato de la primera vuelta al mundo de Gavin Menzies a partir de la dispersión de información y la construcción de posverdad. Así, en primer lugar, se observa que, en términos generales, la crítica hacia la obra es casi unánime desde la academia y la ciencia, quedando calificada como pseudohistoria o pseudociencia. Aunque a priori se podría pensar que estamos ante un caso hasta cierto punto inofensivo, y que se trata de un fenómeno con una trascendencia limitada, al menos de momento, conviene reparar en los riesgos que, como todo revisionismo histórico acientífico, puede entrañar. Como apunta Fritze (2009b, p. 16), "la pseudohistoria se presta fácilmente a ser una herramienta del racismo, el fanatismo religioso y el extremismo nacionalista". O como sentencia Baggini (2018, p. 77), "hechos falsos pueden conducirnos a sostener una ética defectuosa", de ahí que el revisionismo pseudocientífico, por tanto, amén de ser un gran negocio, puede suponer en cualquier momento una chispa para otros problemas. Máxime hoy, cuando parece haber un desprecio creciente hacia la experiencia, el conocimiento y la verdad (Kakutami, 2018; D'Ancona, 2017).

La obra de Menzies, como hemos visto, goza de una muy positiva catalogación en las bibliotecas más reconocidas, siendo ubicada en secciones vinculadas con la Historia y con poca revisión o mención a este concepto de fake history o junk history. De este modo, el rechazo 
historiográfico no parece trasladarse al ámbito de la documentación, el cual sigue recogiendo la obra de una forma nada crítica. Solo la enciclopedia online Wikipedia parece romper esta ingenua objetividad en la catalogación y saca provecho de su germen de proyecto de inteligencia colectiva que se autocorrige y se autocritica. La obra de Menzies, de este modo, no deja ningún rastro en esta referencia online y, de hacerlo, se cataloga siempre bajo la etiqueta de "pseudohistoria", rechazando toda construcción de verdad histórica que no siga un método científico ampliamente reconocido. Google también parece filtrar bastante bien la pseudohistoria de la historia, no ofreciendo resultados sobre la vuelta al mundo china y prevaleciendo los resultados que conducen hacia la vuelta al mundo de Magallanes y Elcano. Por el contrario, los medios de comunicación impresos, así como Amazon, contribuyen a dar espacio al relato de Menzies. En el caso de la plataforma de compra online, el tema se agrava con las valoraciones de los usuarios que valoran muy positivamente la obra, contribuyendo a su posición dentro de los rankings y las materias relacionadas con la Historia y con China.

Sin duda, al igual que ocurre con otros casos de posverdad, con este trabajo se corre el riesgo de favorecer al propio Menzies, pues más de un lector lo conocerá ahora, al leer estas páginas. Esa es la paradoja de la lucha contra la fake history y las fakes news. Como afirma Lakoff (2010), la verificación de las falsedades es a veces contraproducente. De Keersmaecker \& Roets (2017) dirán que incluso en circunstancias óptimas, la influencia inicial de información errónea no se puede deshacer simplemente señalando que tal información es incorrecta. Así, una posible solución es la llamada "verdad sandwich" (Lakoff, 2010), esto es, enmarcar la discusión en la verdad, explicar luego la posverdad, para terminar de nuevo con la verdad. Pues, como apunta Ball (2017), incluso el más obvio sinsentido se puede inventar en minutos, requiriendo mucho más tiempo y esfuerzo probar su falsedad. Los investigadores deben estar preparados para vivir y convivir inexorablemente con ello.

El conspiracionismo, ligado a menudo a la pseudohistoria, es algo que cuando arraiga, lo hace férreamente (Gottschall, 2012), y los argumentos racionales y empíricos en contra pueden no ser suficientes (Melleuish, Sheiko \& Brown, 2009). Entre los relatos que más fascinan 
al ser humano destacan aquellos que cuentan un buen conflicto, una lucha ardua entre protagonistas y antagonistas. Así, el punto de partida del relato pseudohistórico en general es el de autor y/o protagonista proscrito, que se enfrenta a la conspiración del establishement, y en el caso de Menzies, en paralelo a la supuesta proscripción de los chinos de la historiografía. Es el arquetipo quijotesco que se repite una y otra vez. Quizás por ello estamos ante una industria que mueve tanto dinero (Fritze 2009b).

Por todo ello, conviene recordar de nuevo la necesidad de enseñar y divulgar la historia de una manera rigurosa, ejercitando a la vez el pensamiento crítico y los valores éticos (Corones, 2009; Lazer et al., 2018). Pero hacerlo también de forma atractiva y seductora. Al menos tanto como lo hace la pseudociencia, los relatos disruptivos y las teorías conspiratorias, siempre tan sugerente para una buena porción del público, hoy creciente gracias al ecosistema digital. Así, si la posverdad es un fenómeno emocional, el contraataque ha de ser también "emocionalmente inteligente, además de rigurosamente racional" (D’Ancona, 2017, p. 150).

Como señala González Sánchez (2007 p. 74), el Renacimiento representó "el triunfo de la simbiosis de la experiencia y el razonamiento". Quinientos años después, el diagnóstico de FernándezArmesto (1997) es claro. La verdad y el sentido común surgidos de esa simbiosis se encuentra en medio de una guerra cultural entre dos extremismos: el fundamentalismo y el nihilismo. Pero la búsqueda de la verdad ha de continuar, dejando a ambos extremismos en los márgenes de la historia. Sin embargo, el cosmos digital ha diluido los márgenes y las fronteras entre el centro y la periferia, entre lo oficial y lo marginal, la opinión y los hechos, el experto y el lego (D'Ancona, 2017; Kakutami, 2018).

Termina el propio Menzies (2002 p. 467) diciendo que su historia es algo "que apenas está empezando". Ya hemos visto hasta dónde ha llegado en sus primeros años de vida. Veamos, ahora que estamos ante el quinto centenario de la verdadera primera vuelta al mundo, si queda circunscrita a una mera y triste anécdota historiográfica, cuyo único valor pedagógico debiera ser el de ejemplo de cómo no (re)escribir la historia (Finlay, 2004). O de cómo no debemos renunciar a la búsqueda rigurosa de la verdad. Abrazando por primera vez el mundo en su 
completa redondez, Magallanes y Elcano expandieron al máximo nuestros horizontes, entre los cuales esa búsqueda de la verdad jamás debiera esfumarse. Prescindir de ello sería renunciar a la esencia de nuestra especie.

\section{References}

Andro, A. (2005). The 1421 Heresy. An Investigation into the Ming Chinese Maritime Survey of the World. Autoedition.

Baggini, J. (2018). A Short History of Truth: Consolations for a Post-Truth World. London: Quercus.

Ball, J. (2017). Post-Truth. How Bullshit Conquered the World. London: Biteback Publishing.

Bauman, Z. (2000). Liquid Modernity. Cambridge: Polity Press.

Beretta, M. \& Conforti, M. (2014). Fakes!? Hoaxes, counterfeits, and deception in early modern science. Sagamore Beach, MA: Science History Publications.

Boorstin, D.J. (1985). The discovers. A History of Man's Search to Know His World and Himself. New York, NY: Random House.

Brotton, J. (2012). A History of the world in twelve maps. London: Penguin Press.

Bueno, G. (1989). La teoría en la esfera y el descubrimiento de América. El Basilisco: Revista de materialismo filosófico, 1, 3-32.

Carrera, P. (2018). Estratagemas de la posverdad. Revista Latina de Comunicación Social, 73, 1469 a 1482. DOI: 10.4185/RLCS-20181317

Chaplin, J. E. (2012). Round about the Earth: Circumnavigation from Magellan to Orbit. New York: Simon \& Schuster.

Chaplin, J. E. (2013). Planetary Power? The United States and the History of around-the-World Travel. Journal of American Studies, 47.

Chiasson, P. (2006). The Island of the Seven Cities. New York: Saint Martin's Griffin.

Corones, A. (2009). When Fakery Meets Fantasy. Metascience, 18, 443446 https://doi.org/10.1007/s11016-009-9302-x

D’Ancona, M. (2017). Post Truth. The New War on Truth and How to Fight. London: Random House. 
Davenport, T. R. H. (2003) Junketing for China in 1421: The First World Tours?, South African Historical Journal, 49:1, 233-253, DOI: $\underline{10.1080 / 02582470308671457}$

De Keersmaecker, J., \& Roets, A. (2017). "Fake news": Incorrect, but hard to correct. The role of cognitive ability on the impact of false information on social impressions. Intelligence, 65, 107-110. https://doi.org/https://doi.org/10.1016/j.intell.2017.10.005

Dussel, E. (2004). China (1421-1800): razones para cuestionar el eurocentrismo. Archipiélago, 44, 6-13.

Elman, B. (2007). China and the world History of Science. Education about Asia, 12(1), 40-44.

Evans, R. J. (2014). Contrafactuales, ¿Y si todo bubiera sido diferente? Madrid: Turner.

Fernández-Armesto, F. (1997). Truth. A History and a Guide for the Perplexed. New York: St. Martin's Press.

Fernández-Armesto, F. (2006). Pathfinders: A Global History of Exploration. New York: W.W. Norton \& Company.

Fernández-Armesto, F. (2010). 1492: El nacimiento de la modernidad. Madrid: Debate.

Finlay, R. (2004). How not to (re)write world history: Gavin Menzies and the chibese discovery of America. Journal of World History, $15,229-242$.

Fritze, R. H. (2002). New worlds: the great voyages of discovery, 1400-1600. Westport, CT: Praeger.

Fritze, R. H. (2009). On the Perils and Pleasures of Confronting Pseudohistory. Historically Speaking 10(5), 2-5.

Fritze, R. H. (2009b). Invented Knowledge: False History, Fake Science and Pseudo-religions. London: Reaktion Books.

Folch, D. (2008). Els grans viatges de Zheng He. Barcelona: Angle Editorial.

García Calero, J. (5 de febrero de 2019). Las mentiras de Portugal para apropiarse de la gesta de Magallanes y Elcano. A $b c$ Recuperado de https://www.abc.es/cultura/abci-primeravuelta-mundo-mentiras-portugal-para-apropiarse-gestamagallanes-y-elcano-201902050221 noticia.html

González Sánchez, C. A. (2007). Homo viator, homo scribens. Cultura gráfica, información y gobierno en la expansión atlántica (siglos XVXVII). Madrid: Marcial Pons. 
Goodman, D. S. G. (2006) Mao and The Da Vinci Code: conspiracy, narrative and history, Literature \& Aesthetics, 16:1, 196-222.

Gottschall, J. (2012). The storytelling animal. How stories make us human. New York: Mariner Books.

Henige, D. (2008). The Alchemy of Turning Fiction into Truth. Journal of Scholarly Publishing 39(4), 354-372. https://doi.org/10.3138/jsp.39.4.354

Iglesias Rodríguez, G. (1997). La propaganda en las guerras del siglo XX. Madrid: Arco Libros.

Jacomella, G. (2017). Il falso e il vero. Fake News: che cosa sono, chi ci guadagna, come evitarle. Milan: Feltrinelli.

Joyner, T. (1992). Magellan. Camden, ME: McGrawHill.

JuddStallard, A. (2008) Better Than the Da Vinci Code: The

Theological Edifice that is Gavin Menzies' 1421, History Australia, 5, 3, 77.1-77.12, DOI: 10.2104/ha080077

Kakutami, M. (2018). The Death of Truth. Notes on Falsehood in the Age of Trump. New York: Tim Duggan Books.

Kamen, H. (2014). Brevísima Historia de España. Barcelona: Austral.

Kelsey, H. (2016). The First Circumnavigators. Unsung Heroes of the Age of Discovery. New Haven: Yale University Press.

Lakoff, G. (2010) Why it Matters How We Frame the Environment. Environmental Communication, 4:1, 70-81, DOI:

10.1080/17524030903529749

Lazer, D. M. J., Baum, M. A., Benkler, Y., Berinsky, A. J., Greenhill, K. M., Menczer, F., ... Zittrain, J. L. (2018). The science of fake news. Science, 359 (6380), 1094-1096.

https://doi.org/10.1126/science.aao2998

Lysa, G., \& Jianli, H. (2009). Portable Histories in Mobile City

Singapore: The (Lack)Lustre of Admiral Zheng He. South East Asia Research, 17(2), 287-309.

https://doi.org/10.5367/000000009788745822

Melleuish, G., Sheiko, K., \& Brown, S. (2009). Pseudo History/Weird History: Nationalism and the Internet. History Compass 7, 6, 1484-1495, 10.1111/j.1478-0542.2009.00649.x

McIntyre, L. (2018). Post-truth. Cambridge: MIT Press.

Muñiz-Velázquez, J. A. \& López Casquete de Prado, M. (2018).

Navigare felicitas est. De la felicidad de la travesía en la primera vuelta al mundo. Revista de Occidente, 440, 29-40. 
O'Connor, C. \& Weatherall, J. O. (2019). The Misinformation Age. New Have: Yale University Press.

Oreskes, N. and Conway, E.M. (2010). Merchants of Doubt: How a Handful of Scientists Obscured the Truth on Issues from Tobacco Smoke to Global Warming. New York: Bloomsbury Press.

Paine, L. (2013). The Sea \& Civilization. A Maritime History of the World. New York: Vintage Books.

Prazniak, R. (2010). Menzies and the New Chinoiserie: Is Sinocentrism the Answer to Eurocentrism in Studies of Modernity? The Medieval History Journal, 13(1), 115-130. https://doi.org/10.1177/097194580901300105

Richardson, W. A. R. (2004). Gavin Menzies' cartographic fiction: the case of the chinese "discovery" of Australia. Globe (0311-3930), (56), 1-11.

Richardson, W. A. R. (2008). Yet More "Imaginography": Gavin Menzies and Peter Trickett. The Skeptic, 28 (3), 34-37.

Rivers, C. P. J. (2004). '1421' V oyages: Fact and Fantasy. Ipoh: Perak Academy.

Rivers, C. P. J. (2006). Footprints in the sea: nautical and physical impossibilities of Menzies 1421 voyages. Globe (0311-3930), (58), 1-50.

Robinson, K. R. (2010) Gavin Menzies, 1421, and the Ryūkoku Kangnido World Map. Ming Studies, 2010:61, 56-70, DOI: 10.1179/014703710X12772211565945

Rodríguez González, A. R. (2018). La primera vuelta al mundo. 15191522. Madrid: Edaf.

Rojas Sandoval, C. (2004). Los olvidos y secretos de la historia. Archipiélago, 11, 44, 2-12-22.

Rubin, V. L., Chen, Y., \& Conroy, N. J. (2015). Deception detection for news: Three types of fakes. Proceedings of the Association for Information Science and Technology, 52(1), 1-4. https://doi.org/10.1002/pra2.2015.145052010083

Schulze Schneider, I. (2001). El poder de la propaganda en las guerras del siglo XIX. Madrid: Arco Libros.

Sen, T. (2005). Did Zheng He Set Out to Colonize Southeast Asia? In L. Suryadinata (Ed.), Admiral Zheng He and Southeast Asia (pp. 42-57). ISEAS-Yusof Ishak Institute. 
Seaver, K. (2004). Maps, Myths, and Men: The Story of the Vinland Map. Palo Alto, CA: Stanford University Press.

Sen, T. (2016). The impact of Zheng He's expeditions on Indian Ocean interactions. Bulletin of the School of Oriental and African Studies, 79(3), 609-636. doi:10.1017/S0041977X16001038

Stake, Robert E. (1995). The Art of Case Study Research. University of Illinois at Urbana-Champaign, USA: Sage Publications.

Steele, T. (2005). 1421: The Year China Discovered America by Gavin Menzies. The Sixteenth Century Journal, 36(1), 276-278.

Sutherland, S. (1992). Irrationality: The enemy within. London: Constable $\&$ Co.

Taboada, H. G. (2007). Reseña de "1421: el año en que China descubrió el mundo" de Gavin Menzies. Estudios de Asia y África, XLII, 3, 760-769.

Tattersall, I., \& Nevraumont, P. (2018). Hoax. A History of Deception. 5,000 years of fakes, forgeries and fallacies. New York City, NY: Black Dog \& Leventhal Publishers.

Tellis, W. M. (1997). Application of a Case Study Methodology. The Qualitative Report, 3(3), 1-19. Retrieved from https://nsuworks.nova.edu/tqr/vol3/iss3/1

Thompson, D. (2008) Counterknowledge: how we surrendered to conspiracy theories, quack medicine, bogus science and fake bistory. London: Atlantic Books.

Tucher, A. (1994). Froth and Scum: Truth, Beauty, Goodness, and the Ax Murder in America's First Mass Medium. Chapel Hill: The University of North Carolina Press.

Vargas Martínez, G. (2004). 1421: el año en que los chinos descubrieron América. Archipiélago, 44, 14-20.

Varona-Aramburu, D. \& Herrero-Diz, P. (2018). Verdad y propaganda en el legado escrito de la primera vuelta al mundo. Revista de Occidente, 440, 5-16.

Yin, Robert K. (2014). Case Study Research: Design and Methods. Beverly Hills, CA: Sage Publications.

Wade, G. (2005). The Zheng He Voyages: A Reassessment. Journal of the Malaysian Branch of the Royal Asiatic Society (Vol. 78). https://doi.org/10.2307/41493537

Wade, G. (2007). The "Liu/Menzies" world map: A critique. ePerimetron, 2(4), 273-280. 



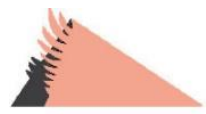

\section{Los autores}

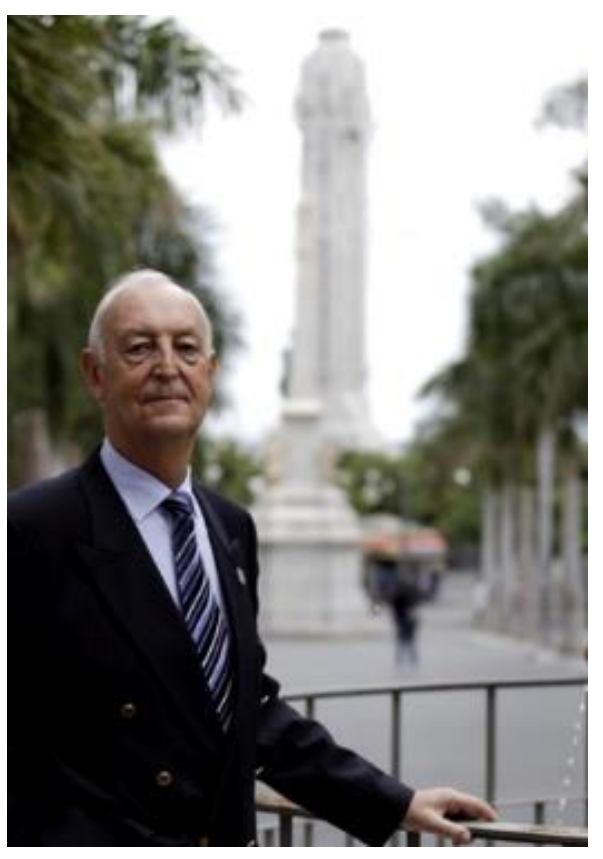

\section{José Manuel Ledesma Alonso}

Técnico en la Organización de Servicios Escolares, en la Inspección de Educación de Santa Cruz de Tenerife. Fundador y Director de la Radio-Enseñanza en Canarias. Radio Popular de Tenerife. Fundador y Profesor del Colegio Miguel Pintor de Santa Cruz de Tenerife.

Director del Centro del Profesorado de La Laguna.

Asesor de Educación Ambiental de la Consejería de Educación Cultura y Deportes.

Creador y Coordinador de los Programas de Educación Ambiental "Conoce Nuestro Puerto" y "El mar y la Escuela".

Miembro de la Tertulia Amigos del 25 de Julio, de la Real Sociedad de Amigos del País de Tenerife, de la Asociación de Marinos Mercantes de Canarias, y de los Hidalgos de Nivaria.

Premios: Consejería de Educación y Puertos de Tenerife.

Cronista Oficial de la Ciudad de Santa Cruz de Tenerife.

\section{Autor de los libros:}

El Puerto de Santa Cruz de Tenerife, un recurso pedagógico para los Centros Educativos de Canarias.

Colección Didáctica "Conoce Nuestro Puerto": Libro para el Profesorado. Fichas de Trabajo para los alumnos. Video Educativo.

Mirando al Mar. El entorno histórico de los Puertos de Tenerife, La Palma, La Gomera. El Hierro y Los Cristianos. 
Al Compás de La Farola: Poesías, Coplas, Canciones, Adivinanzas, Dichos y Refranes del Puerto, los Barcos y la Gente de la Mar.

El Transporte Terrestre, Marítimo y Aéreo en Santa Cruz de Tenerife Los Presidentes del Centenario de la Junta de Obras del Puerto.

Relatos del Teide. Viajeros Ilustres, Siglos XVIII y XIX.

Relatos del Puerto y la Ciudad de Santa Cruz de Tenerife. Viajeros Ilustres, Siglos XVIII y XIX,

Valle de Las Mercedes. Recuerdos para su Historia.

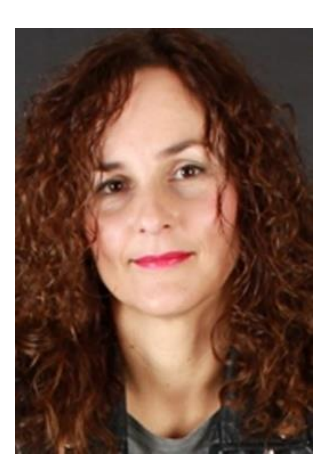

\section{Ángeles Martínez-García}

angelesmartinez@,us.es

Profesora de la Facultad de Comunicación de la Universidad de Sevilla. Ha sido miembro del Área de Comunicación de la Fundación Audiovisual de Andalucía (RTVA) y asesora del Gabinete de la Presidencia del Consejo Audiovisual de Andalucía, además de trabajar como profesora en distintas universidades españolas.

Es miembro del grupo de investigación HUM-1013: Equipo de Investigación de la Imagen y la Cultura Visual en el Ámbito de la Comunicación (EIKON).

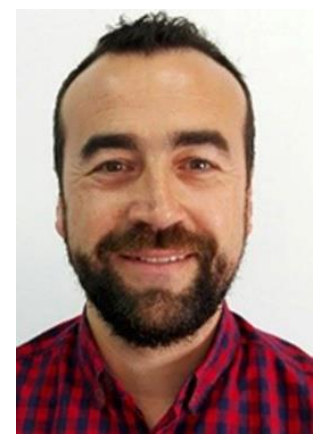

\section{Antonio Gómez-Aguilar agomez16@us.es}

Profesor de la Facultad de Comunicación de la Universidad de Sevilla. Ha sido miembro del Área de Comunicación de la Fundación Audiovisual de Andalucía (RTVA), profesor de Formación Profesional de Imagen y Sonido y profesor en el Centro Universitario EUSA.

Es miembro del grupo de investigación HUM-1013: Equipo de Investigación de la Imagen y la Cultura Visual en el Ámbito de la Comunicación (EIKON).

Sus líneas de investigación son las tecnologías de la comunicación y la realización audiovisual. 


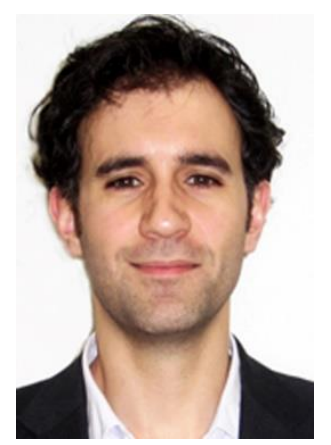

\section{Enrique Martínez Jiménez}

emartinez@uloyola.es

Arquitecto por la Universidad de Granada (2006) y Doctor por la Universidad de Córdoba (2015). Es profesor de los Grados en Educación Primaria y en Educación Infantil en la Universidad Loyola Andalucía. Ha realizado estancias de investigación docentes en las universidades de Algarve (Portugal) y La Sapienza (Italia).

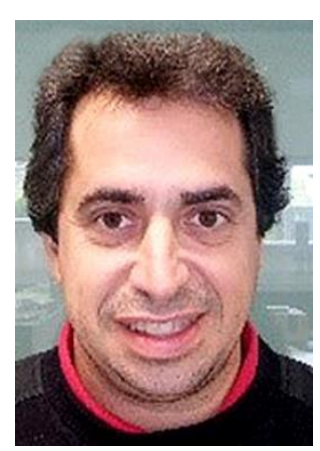

\section{Alejandro Tapia Frade} ajtapia@uloyola.es

Licenciado y Doctor en Ciencias de la Información (1999, 2005) por la Universidad Complutense de Madrid. Acreditado a la figura de Profesor Contratado Doctor por ANECA. También tiene concedido un sexenio de investigación por CNEAI.

Actualmente es profesor en el Grado de Comunicación en la Universidad Loyola Andalucía. También ha realizado intercambios docentes en las universidades de Leiría, Guarda y Algarve (Portugal), Konstanz (Alemania) y HAN (Holanda).

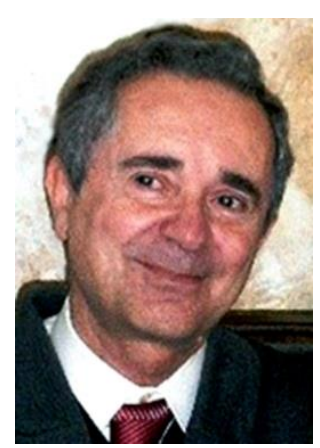

\section{Francisco Montes Tubío}

ir1motuf@uco.es

Doctor Ingeniero agrónomo por la Universidad de Córdoba. Profesor del Departamento de Ingeniería Gráfica y Geomática de la Universidad de Córdoba.

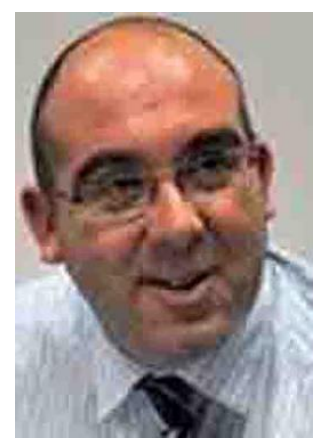

\section{Francisco-Javier García Herrero}

fjgherrero@yahoo.es

Doctor en Publicidad y RR.PP., desde 2015, imparte docencia en el Grado en Publicidad y RR.PP. 
Las líneas preferentes de investigación se centran en la Historia de la Comunicación y específicamente la de la Publicidad a través de las piezas numismáticas y en la Comunicación Publicitaria de los anunciantes.

Realiza una labor investigadora y divulgativa del papel histórico de la Casa de la Moneda de Segovia, realizando asesoría para la preparación de exposiciones en la misma por su carácter de experto en el tema.

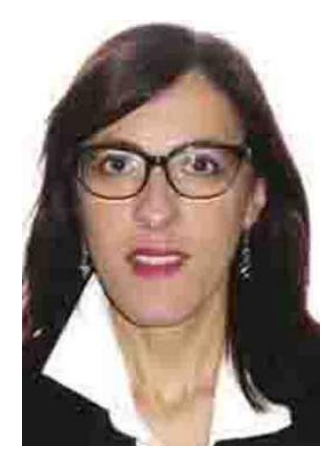

\section{María-Cruz Alvarado López} mariacruz.alvarado@uva.es

Profesora en el Grado en Publicidad y RR.PP., donde imparte la asignatura de Teoría e Historia de la Publicidad. En la misma Facultad es profesora en el Máster en Comunicación con Fines Sociales: Estrategias y Campañas, donde coordina la materia Comunicación y cambio social: modelos teóricos y experiencias prácticas.

Los ámbitos de investigación son, la publicidad con fines sociales, la historia de la publicidad, la controversia sobre prostitución a través de la publicidad y las competencias mediáticas de los profesionales de la comunicación.

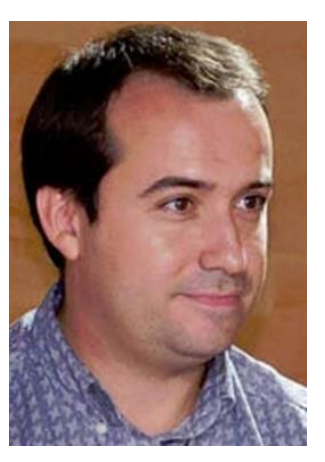

\section{David Varona Aramburu}

dvarona@uloyola.es

Doctor en Periodismo por la Universidad Complutense de Madrid con una tesis sobre el uso de las redes sociales por parte de los periodistas españoles. Licenciado en Periodismo por la Universidad Complutense, es también Máster en Relaciones Internacionales por dicha universidad, además de Experto en Comunicación Científica por la Universidad Rey Juan Carlos de Madrid.

Actualmente es profesor de Diseño y Producción de Contenidos Digitales y de Periodismo Digital en la Universidad Loyola Andalucía. Ha sido docente de la Universidad Francisco de Vitoria, donde impartió Ciberperiodismo y Nuevos Productos Digitales y 
Comunicación 2.0 para Dircom. Profesor de redes sociales en los másteres de Realización, Radio y Reportaje Transmedia del Instituto de RTVE y las universidades Complutense y Carlos III de Madrid. Profesor de redes sociales (presencial y on line) del Instituto de RTVE. Ha sido también profesor de Community Management en el Máster de Márketing Digital de la escuela de Negocios Esden.

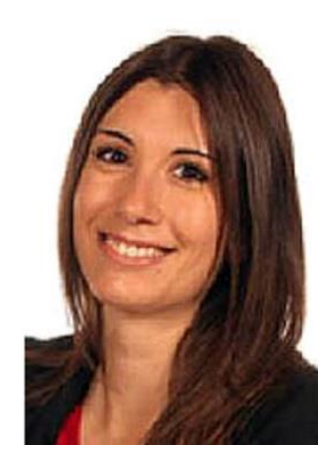

\section{Marta Pérez-Escolar}

martaperez@uloyola.es

Es profesora ayudante doctor en el departamento de Comunicación de la Universidad Loyola Andalucía (España), desde 2018, en asignaturas como 'Opinión pública' e 'Issues management'. Obtuvo la mención de doctor internacional en Ciencias Sociales y de la Comunicación por la Universidad Católica de Murcia (2017) y, actualmente, también está imparte docencia en programas de posgrado como el MBA Sports Management del departamento de Administración de Empresas de la Universidad Católica de Murcia con el módulo 'Bibliographic Searching'

Está vinculada al grupo de investigación 'Quokka. Estudios en Comunicación y Educación positivas' de la Universidad Loyola Andalucía. Sus principales líneas de investigación se centran en el estudio del ciberactivismo, participación política, civic engagement, ciberdemocracia, inteligencia colectiva, movimientos sociales $y$ protestas en red.

En relación con la producción científica, cabe mencionar capítulos de libro publicados en editoriales de prestigio como IGI Global (n 116 en SPI extranjera con ICEE 0.944) o Tecnos ( $\mathrm{n}^{\circ} 6$ en SPI nacional con ICEE 34.996); un libro con autoría compartida que nace de un proyecto de investigación (convocatoria competitiva) sobre economía de la participación, así como artículos en revistas de impacto como 'El profesional de la información' (JCR) u 'Opción' (Q2 en el índice SCOPUS). También ha realizado varias estancias de investigación de larga duración en universidades como la Universidad de Helsinki (Finlandia), FLACSO Buenos Aires (Argentina) y en la Universidade Lusófona de Lisboa (Portugal). 


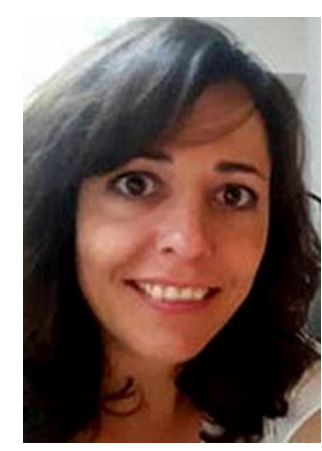

\section{Gema Sánchez Muñoz}

Gsanchez01@,ucm.es

Ha sido profesora asociada en la Universidad Loyola Andalucía, donde ha impartido la asignatura de Media Planning. Es licenciada por la Universidad Complutense en Ciencias de la información (1999) y Máster en Dirección de Márkting Digital y Social Media por la UNED (2014).

Comenzó su andadura incorporándose a $\mathrm{CNN}+$ como programadora en 1999. Posteriormente, fue productora del departamento de Autopromoción de Cuatro y desde el 2010 ha enfocado su carrera al entorno digital desde los departamentos de Gestión de proyectos, Nuevos negocios y Estrategia digital de Yomvi.

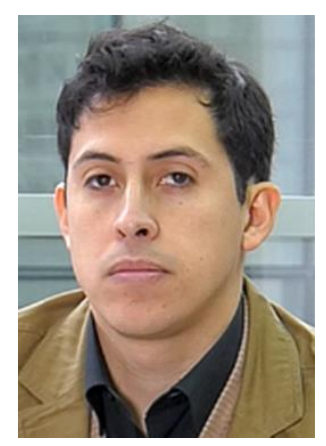

\section{Eduardo Gallegos Krause}

eduardo.gallegos@ufrontera.cl

Licenciado en Comunicación Social y Magíster en Ciencias de la Comunicación por la Universidad de La Frontera, Temuco, Chile. Realizó un año de estudios equivalente a Master 1 en l'Institute d'Etudes Politiques de Rennes, Francia, donde comenzó su interés por los relatos de viajes decimonónicos y la representación de la alteridad indígena de las Amércias que aparecían en estos textos. Actualmente cursa el Doctorado en Comunicación dictado en conjunto por la Universidad de la Frontera y la Universidad Austral, ambas de Chile. Al mismo tiempo se desempeña como profesor en el Departamento de Lenguas, Literatura y Comunicación y en el Magíster en Ciencias de la Comunicación, donde además es coordinador académico, todo en el marco de la Facultad de Educación, Ciencias Sociales y Humanidades de la Universidad de La Frontera.

Sus áreas de investigación se concentran en las representaciones semiodiscursivas de la identidad y la alteridad en diversos objetos culturales tales como: relatos de viajes, publicidad, prensa contra-hegemónica, entre otras. Ha publicado los resultados de sus reflexiones en una decena de revistas y capítulos de libros 


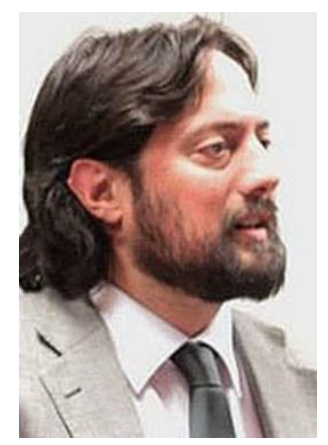

Jaime Otazo Hermosilla

jaime.otazo@ufrontera.cl

Doctor en Ciencias de la Información y de la Comunicación por la Université de la Sorbonne Nouvelle (Paris III), Magíster en Ciencias de la Comunicación y Periodista por la Universidad de La Frontera.

Ha participado como investigador asociado en proyectos con financiamiento estatal e institucional en torno al discurso público y representaciones en el contexto del denominado conflicto mapuche, (FONDECYT 1000234, DIUFRO-EP 2023 y FONDECYT 1030274, DIUFRO-INI 2100) y sobre la historia y cartografía de la semiótica en Chile. Actualmente participa como co-investigador en estudios sobre las Transformaciones de la Cultura Jurídica en la Macro-región Sur (FONDECYT 1170505) y sobre la construcción de imaginarios del Estado y la Democracia en Memorias emblemáticas chilenas (FONDECYT 1161253).

Su línea actual de investigación se centra en el rol de la prensa en el contexto de movimientos socio-culturales. Ha presentado ponencias y dictado conferencias en seminarios y congresos tanto nacionales como internacionales. Ha publicado artículos en revistas especializadas en torno al tema de la relación entre prensa y conflicto mapuche. En el ámbito académico se ha desempeñado como profesor de Semiótica y Análisis del discurso en la Universidad de La Frontera y otras universidades de la región, teniendo dedicación exclusiva en la Universidad de La Frontera desde el año 2003.

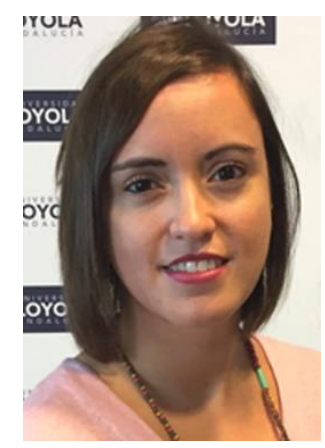

\section{Irene Rodríguez Cachón}

irodriguez@uloyola.es

Irene Rodríguez Cachón, Doctora en Filología Hispánica (2013) por la Universidad de Valladolid. Ha sido investigadora predoctoral FPI (2009-2013) en la Universidad de Valladolid e investigadora visitante en la University of Oxford (Reino Unido) y en La Sapienza-Università di Roma (Italia), así como profesora e investigadora contratada postdoctoral (2013-2015) en el Romanisches 
Seminar de la Westfälische Wilhelms-Universität Münster (Alemania). Actualmente es Profesora Ayudante Doctor de Lengua y Literatura en la Universidad Loyola Andalucía (España).

Tiene varias publicaciones a nivel nacional e internacional sobre literatura española del siglo XVI, con especial atención en la narrativa breve, las traducciones sobre poética, las misceláneas y los tratados poéticos renacentistas. Entre otros, es miembro del grupo de investigación "7PDigital" de la Universidad de Valladolid (FFI201675014-P, Programa Estatal de Fomento de la Investigación Científica Técnica de Excelencia, Ministerio de Ciencia, Innovación y Universidades), donde trabaja en una edición crítica digital de las ediciones históricas de las "Siete Partidas" del rey Alfonso X el Sabio.

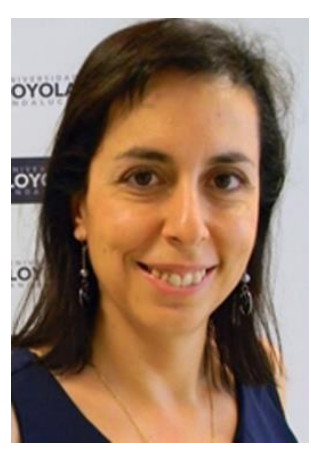

\section{Beatriz Valverde}

bvalverde@,uloyola.es

Beatriz Valverde es doctora en Filología inglesa (especialidad literatura) por la Universidad de Jaén. Además de eso, tiene un Máster en la Enseñanza del Español como Lengua Extranjera por Loyola University Chicago (EEUU). En ambos campos de investigación ha publicado artículos en diferentes revistas nacionales e internacionales. Sus principales líneas de investigación son: TIC aplicadas a TEFL; CLIL; Literatura y estudios culturales en inglés y español; Humanismo crítico en la enseñanza de las humanidades

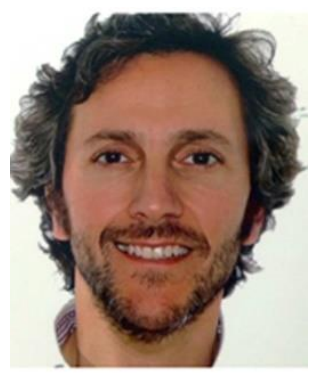

José Antonio Muñiz-Velázquez

jamuniz@,uloyola.es

Profesor, investigador y director del Departmento de Communicación y Educación de la Universidad Loyola Andalucía. Doctor en Comunicación por la Universidad de Sevilla. Licenciado en Publicidad y Relaciones Públicas por la Universidad de Sevilla y Licenciado en Psicología por la U.N.E.D. Máster Europeo en Marketing Relacional, Directo e Interactivo por ICEMD-ESIC Business School.

Estudios de Publicidad Gráfica en el Istituto Europeo di Design (Milán), de Comunicación Social de la Energía y de Comunicación y 
Gestión Política en la Universidad Complutense de Madrid. Programme for Leadership Development en ESADE-Loyola.

Ha sido profesor e investigador en la Universidad Pontificia de Salamanca (2004-2008), en la Universidad de Sevilla (2009-2011), y vicedecano en la Universidad San Jorge de Zaragoza (2011-2013), además de director en dicha universidad del Felicicom Lab.

Ha sido profesor invitado en la Università di Bologna, la IULM di Milano, la Universitá di Macerata, de la Phnom Penh University (Camboya), la Università di Siena, y en Loyola Chicago University.

Enseña en diferentes postgrados en varias universidades españolas, y su labor investigadora gira en torno a la persuasión y la comunicación positiva, esto es, la relación entre la comunicación (principalmente la publicitaria) y su relación con la felicidad y el bienestar.

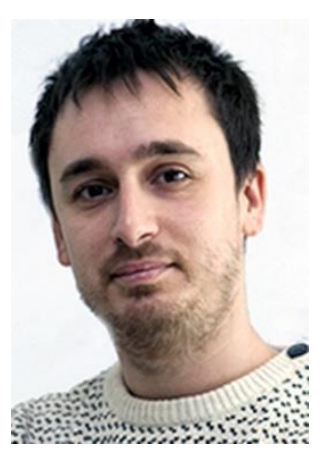

\section{Javier Lozano Delmar \\ jamuniz@uloyola.es}

Javier Lozano Delmar es doctor en Comunicación por la Universidad de Sevilla. Profesor asociado en la Universidad de Andalucía Loyola, en sus campus de Sevilla y Córdoba, donde imparte cursos de tecnología de la comunicación, narrativa audiovisual y estética y creatividad. Su actividad de investigación se enmarca principalmente en el campo de la comunicación digital y su trabajo se dedica principalmente al estudio de las tecnologías digitales en publicidad, audiencias activas y fandom, narración transmedia y el uso de nuevas estrategias promocionales para contenido ficticio en cine y televisión.

Sus últimos trabajos incluyen varios estudios centrados en la comunicación positiva y su participación en el grupo Communication Researchers League, que ha publicado varios trabajos colectivos que analizan el impacto de las series de televisión actuales. También es uno de los coordinadores del libro titulado Reyes, espadas cuervos y dragones. Estudio del fenómeno televisivo Juego de Tronos ("Reyes, espadas, cuervos y dragones. Estudio del fenómeno televisivo Juego de tronos") publicado por Forge en 2013. 